\title{
WestVirginiaUniversity
}

THE RESEARCH REPOSITORY @ WVU

Graduate Theses, Dissertations, and Problem Reports

2002

\section{Analysis and robust decentralized control of power systems using FACTS devices}

Karl E. Schoder

West Virginia University

Follow this and additional works at: https://researchrepository.wvu.edu/etd

\section{Recommended Citation}

Schoder, Karl E., "Analysis and robust decentralized control of power systems using FACTS devices" (2002). Graduate Theses, Dissertations, and Problem Reports. 1697.

https://researchrepository.wvu.edu/etd/1697

This Dissertation is protected by copyright and/or related rights. It has been brought to you by the The Research Repository @ WVU with permission from the rights-holder(s). You are free to use this Dissertation in any way that is permitted by the copyright and related rights legislation that applies to your use. For other uses you must obtain permission from the rights-holder(s) directly, unless additional rights are indicated by a Creative Commons license in the record and/ or on the work itself. This Dissertation has been accepted for inclusion in WVU Graduate Theses, Dissertations, and Problem Reports collection by an authorized administrator of The Research Repository @ WVU.

For more information, please contact researchrepository@mail.wvu.edu. 


\title{
Analysis and Robust Decentralized Control of Power Systems Using FACTS Devices
}

\author{
by \\ Karl E. Schoder \\ Dissertation submitted to the \\ College of Engineering and Mineral Resources \\ at West Virginia University \\ in partial fulfillment of the requirements \\ for the degree of \\ Doctor of Philosophy \\ in \\ Electrical Engineering \\ Professor Ian Christie, Ph.D. \\ Professor Asadollah Davari, Ph.D. \\ Professor Ronald L. Klein, Ph.D. \\ Professor Powsiri Klinkhachorn, Ph.D. \\ Professor Ali Feliachi, Ph.D., Chair \\ Lane Department of Computer Science and Electrical Engineering \\ Morgantown, West Virginia \\ 2002
}

Keywords: Power Analysis Toolbox, PAT, FACTS, transient stability, fuzzy control, robust decentralized control design

Copyright 2002 Karl E. Schoder 


\author{
Abstract \\ Analysis and Robust Decentralized Control of \\ Power Systems Using FACTS Devices \\ by \\ Karl E. Schoder \\ Doctor of Philosophy in Electrical Engineering \\ West Virginia University \\ Professor Ali Feliachi, Ph.D., Chair
}

Today's changing electric power systems create a growing need for flexible, reliable, fast responding, and accurate answers to questions of analysis, simulation, and design in the fields of electric power generation, transmission, distribution, and consumption. The Flexible Alternating Current Transmission Systems (FACTS) technology program utilizes power electronics components to replace conventional mechanical elements yielding increased flexibility in controlling the electric power system. Benefits include decreased response times and improved overall dynamic system behavior. FACTS devices allow the design of new control strategies, e.g., independent control of active and reactive power flows, which were not realizable a decade ago. However, FACTS components also create uncertainties. Besides the choice of the FACTS devices available, decisions concerning the location, rating, and operating scheme must be made. All of them require reliable numerical tools with appropriate stability, accuracy, and validity of results. This dissertation develops methods to model and control electric power systems including FACTS devices on the transmission level as well as the application of the software tools created to simulate, analyze, and improve the transient stability of electric power systems.

The Power Analysis Toolbox (PAT) developed is embedded in the MATLAB/Simulink environment. The toolbox provides numerous models for the different components of a power system and utilizes an advanced data structure that not only increases data organization and transparency but also simplifies the efforts necessary to incorporate new elements. The functions provided facilitate the computation of steady-state solutions and perform steady-state voltage stability analysis, nonlinear dynamic studies, as well as linearization around a chosen operating point.

Applying intelligent control design in the form of a fuzzy power system damping scheme applied to the Unified Power Flow Controller (UPFC) is proposed. Supplementary damping signals are generated based on local active power flow measurements guaranteeing feasibility. The effectiveness of this controller for longitudinal power systems under dynamic conditions is shown using a Two Area - Four Machine system. When large disturbances are applied, simulation results show that this design can enhance power system operation and damping characteristics. Investigations of meshed power systems such as the New England - New York power system are performed to gain further insight into adverse controller effects. 


\section{Acknowledgments}

I would like to begin with a heartfelt thank you to Sandra for her love and encouragement toward my work and for making the decision to come to Morgantown in the first place. I thank my family for their support and inspiration that they have provided throughout my entire life and educational experience.

This dissertation came into existence during my years as research assistant for Dr. Ali Feliachi, Electric Power Systems Chair Professor, in the Lane Department of Computer Science and Electrical Engineering, West Virginia University. I would like to thank him for his encouragement, support, and help. His advise and guidance throughout the work was an invaluable resource.

I would also like to acknowledge the contributions of my advisory committee, Professor Ian Christie, Professor Asadollah Davari, Professor Ronald L. Klein, and Professor Powsiri Klinkhachorn.

I want to thank a special group of people, my friends and colleagues at the Power Systems Computing Lab with whom I have enjoyed working in a highly motivated atmosphere, namely: AE, Amer, Azra, Kourosh, Lingling and Miao. Through them I had the privilege to learn in a truly multinational environment and their involvement and support helped shape this dissertation.

Finally, I would like to thank my friend Warren for the time he spent on perusing this dissertation and helping me make it better readable.

Funding for this work was provided in part by the National Science Foundation (NSF) under grant ECS-9870041, and a US DOE/EPSCoR WV State Implementation Award. 


\section{Contents}

Acknowledgments $\quad$ iii

List of Figures vi vi vis

List of Tables $\quad$ viii

Notation and Acronyms ix

$\begin{array}{lll}1 & \text { Introduction } & 1\end{array}$

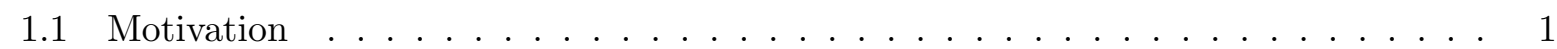

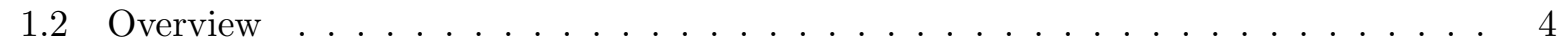

1.3 Power system dynamics $\ldots \ldots \ldots \ldots \ldots \ldots \ldots$

\begin{tabular}{|lll}
2 & Literature survey and related work & 8
\end{tabular}

$2.1 \quad$ Modeling and simulation environments for power systems . . . . . . . . . . . 8

2.1 .1 Introduction to power system analysis $\ldots \ldots \ldots \ldots$. . . . . . . . . . 9

$2.1 .2 \quad$ Related work on simulation and analysis software . . . . . . . . . . . . . . 9

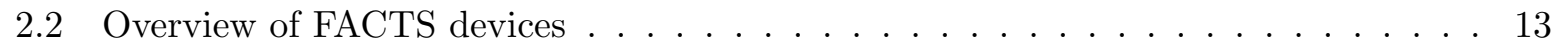

2.3 Damping control design $\ldots \ldots \ldots \ldots \ldots \ldots \ldots \ldots \ldots \ldots$

2.4 Rule-based control - Fuzzy logic technology . . . . . . . . . . . . . . . . . . . 16

2.5 Contribution of the dissertation $\ldots \ldots \ldots \ldots \ldots \ldots \ldots$

\begin{tabular}{|lll}
\hline 3 & Power Analysis Toolbox & 18
\end{tabular}

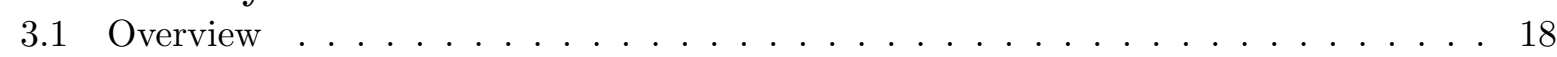

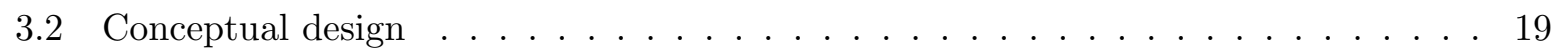

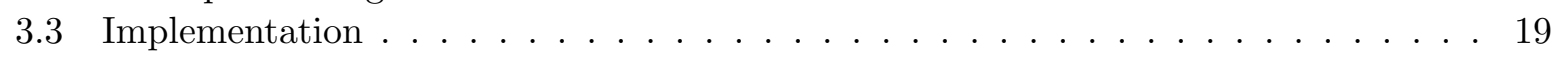

3.3 .1 Power system data structure $\ldots \ldots \ldots \ldots$. . . . . . . . . . . . . . . 21

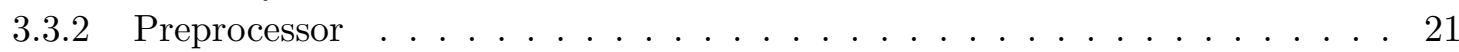

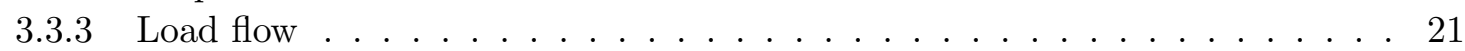

3.3 .4 Transient analysis - Simulink block library . . . . . . . . . . . . . . . . . . 23

3.3.5 Linear system representation and modal analysis . . . . . . . . . . . . . . . 25

3.3 .6 Example . . . . . . . . . . . . . . . . . . . 26

3.4 Modeling of FACTS devices $\ldots \ldots \ldots \ldots \ldots \ldots$

3.4 .1 Unified Power Flow Controller (UPFC) . . . . . . . . . . . . . . . . 31

$3.4 .2 \quad$ GTO Back-To-Back HVDC link (BTBL) . . . . . . . . . . . . . . . . . 40 
$3.4 .3 \quad$ Static Synchronous Compensator (STATCOM) . . . . . . . . . . . . . . . . 47

$3.4 .4 \quad$ Static Synchronous Series Compensator (SSSC) . . . . . . . . . . . . . . . . 50

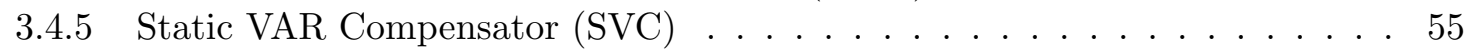

$3.4 .6 \quad$ Thyristor Controlled Series Capacitor (TCSC) . . . . . . . . . . . . . . . . 58

\begin{tabular}{|lll}
4 & Transient stability enhancement using FACTS devices & 63
\end{tabular}

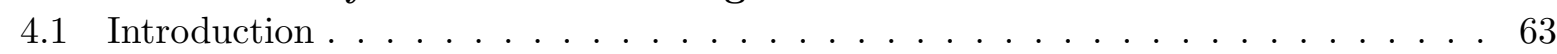

4.2 UPFC as an actuator . . . . . . . . . . . . . . . . . . . . . . . . . 64

$4.3 \quad$ Fundamentals of fuzzy systems - Takagi-Sugeno-Kang fuzzy logic . . . . . . . . . 65

4.4 Control Scheme $\ldots \ldots \ldots \ldots$. . . . . . . . . . . . . . . . . . . . . . . . . . . 67

4.4 .1 Damping using excitation systems . . . . . . . . . . . . . . 67

4.4 .2 Damping through devices within the transmission system . . . . . . . . 68

4.5 Input signal conditioning $\ldots \ldots \ldots \ldots \ldots \ldots \ldots$

4.6 Fuzzy damping control $\ldots \ldots \ldots \ldots \ldots \ldots \ldots$

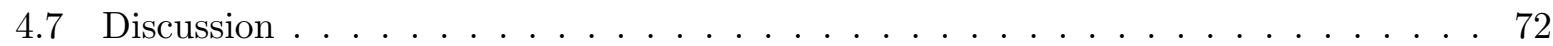

$\begin{array}{lll}5 & \text { Power system case studies } & \mathbf{7 4}\end{array}$

$5.1 \quad$ Stability of the Two Area - Four Machine power system . . . . . . . . . . . . . . . 74

5.1 .1 Load flow and voltage stability . . . . . . . . . . . . . . . . . . . 75

5.1 .2 Damping - dynamic stability . . . . . . . . . . . . . . . . 79

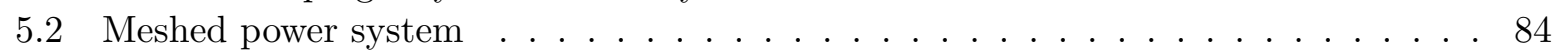

5.2 .1 Investigating the influence of the UPFCs using local signals . . . . . . . . . 84

$5.2 .2 \quad$ Investigating the influence of the UPFCs using wide-area measurements . . 86

5.3 New England - New York power system . . . . . . . . . . . . . . . . . . . 91

5.3 .1 Load flow analysis and UPFC siting . . . . . . . . . . . . . . . . . 91

5.3 .2 Contingency 1 - Far case . . . . . . . . . . . . . . . . . . 92

5.3 .3 Contingency 2 - Near case . . . . . . . . . . . . . . . . . . . . . . . 95

5.3 .4 Contingency 3 - Region of influence $\ldots \ldots \ldots$. . . . . . . . 96

6 Summary and conclusions 102

6.1 Work based on this dissertation $\ldots \ldots \ldots \ldots \ldots$. . . . . . . . . . . . . . . . . . . . . . . . . . . . .

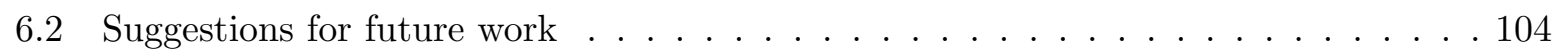

\section{APPENDICES}

\begin{tabular}{ll}
\hline A Publications & 106
\end{tabular}

\begin{tabular}{ll}
\hline B Three machine-Nine bus system data & 109
\end{tabular}

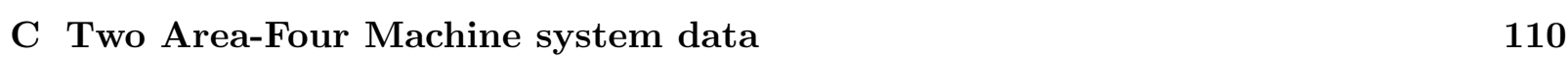

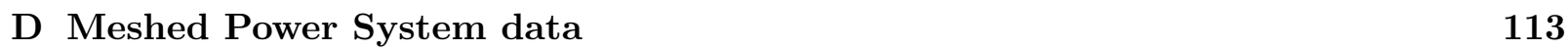

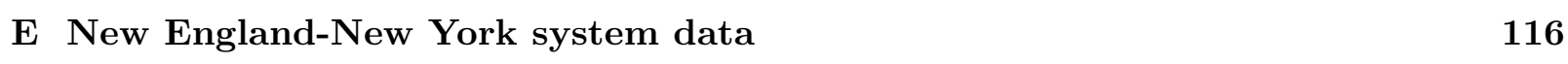

$\begin{array}{ll}\text { References } & 122\end{array}$ 


\section{List of Figures}

1.1 Time horizon and control tasks after fault occurrence in a power system . . . . . . 7

2.1 Identified environment and components . . . . . . . . . . . . . . . . . . . . . . 12

3.1 PAT's conceptual design . . . . . . . . . . . . . . . . . . . . . . . . . 20

3.2 PAT's functionality . . . . . . . . . . . . . . . . . . . . . . . . . . . . . . . . . . . 20

3.3 Power system data structure . . . . . . . . . . . . . . . . . . . . . . . . . 22

3.4 PAT's transient modeling concept. . . . . . . . . . . . . . . . . . . . . . . . . 23

3.5 PAT's Simulink block library . . . . . . . . . . . . . . . . . . . . . . . . . . . . . 24

3.6 Three machine nine bus example . . . . . . . . . . . . . . . . . . . . . . . . . . . . 27

3.7 Analyzing power systems with PAT. . . . . . . . . . . . . . . . . . . . . . . . . . . 27

3.8 Three machine nine bus example: State response . . . . . . . . . . . . . . . . . . . 28

3.9 Three machine nine bus example: Bus voltages . . . . . . . . . . . . . . . . . . . . 28

3.10 Three machine nine bus example: Compass plot of speed participation . . . . . . . 30

3.11 UPFC fundamental frequency model . . . . . . . . . . . . . . . . . . . . . 32

3.12 UPFC load flow model: (a) Schematic (b) Load flow representation . . . . . . . . . 33

3.13 UPFC load flow algorithm . . . . . . . . . . . . . . . . . . . . . 34

3.14 UPFC interface model . . . . . . . . . . . . . . . . . . . . . . . . . . . . . . . 36

3.15 Algorithm for interfacing VSC-based FACTS devices with the power network . . . 38

3.16 UPFC series control . . . . . . . . . . . . . . . . . . . . . . 39

3.17 UPFC shunt control . . . . . . . . . . . . . . . . . . . . . . . . . 40

3.18 BTBL fundamental frequency model . . . . . . . . . . . . . . . . . . . . . . . . 4 41

3.19 BTBL load flow model: (a) Schematic (b) Load flow representation. . . . . . . . . . 43

3.20 BTBL control scheme . . . . . . . . . . . . . . . . . . 46

3.21 STATCOM dynamic model . . . . . . . . . . . . . . . . . . . . . . . . . 47

3.22 STATCOM control scheme . . . . . . . . . . . . . . . . . . . . . . . 50

3.23 SSSC dynamic model. . . . . . . . . . . . . . . . . . . . . . . . . . . . . . . . . . 51

3.24 Load flow algorithm for line power flow control of SSSC and TCSC . . . . . . . . . 53

3.25 SSSC control scheme . . . . . . . . . . . . . . . . . . . . . 55

3.26 Modeling the SVC . . . . . . . . . . . . . . . . . . . . . . . 56

3.27 SVC characteristics . . . . . . . . . . . . . . . . . . . . . . . 57

3.28 SVC control scheme . . . . . . . . . . . . . . . . . . . . . . . . . 58

3.29 TCSC dynamic model . . . . . . . . . . . . . . . . . . . . . . . . . . . . 59 
3.30 TCSC characteristics: solid - sinusoidal voltage, dashed - sinusoidal current . . . . 60

3.31 TCSC equivalent model $\ldots \ldots \ldots \ldots \ldots \ldots$

3.32 TCSC control scheme $\ldots \ldots \ldots \ldots$. . . . . . . . . . . . . 62

4.1 Lead-lag controller structure . . . . . . . . . . . . . . . . . . . . . . . . 64

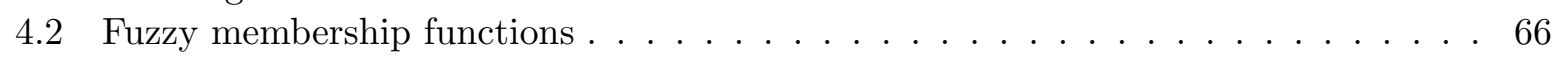

4.3 Takagi-Sugeno-Kang fuzzy system $\ldots \ldots \ldots \ldots \ldots \ldots$

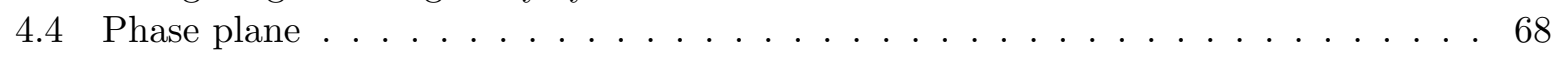

4.5 Obtaining input signals for fuzzy damping controllers . . . . . . . . . . . . . . . . 69

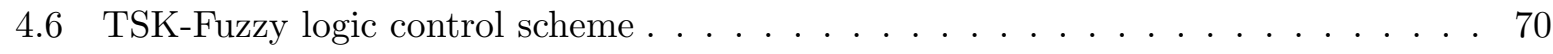

4.7 TSK-Fuzzy logic control scheme: Phase plane . . . . . . . . . . . . . . . . 70

4.8 Fuzzy membership functions for the phase plane $\ldots \ldots \ldots \ldots$. . . . . . . . 71

5.1 Two area - Four machine power system . . . . . . . . . . . . . . . 74

5.2 Simulink model of the Two area - Four machine system including UPFC . . . . . 75

5.3 Two area system: Voltage stability $\ldots \ldots \ldots \ldots \ldots \ldots \ldots$

5.4 Two area system: UPFC load flow characteristics . . . . . . . . . . . . . . 77

5.5 Two area system: Maximum UPFC converter interactions $\ldots \ldots \ldots$. . . . . . . 78

5.6 Two area system: Converter interactions $\ldots \ldots \ldots \ldots \ldots \ldots$

5.7 Two area system: Active and reactive line flows $\ldots \ldots \ldots$. . . . . . . . . 79

5.8 Two area system: Line flows as controlled by series VSC control scheme . . . . . . 80

5.9 Relative machine angles $\delta_{1-3}$ for case (a) $\ldots \ldots \ldots \ldots \ldots$. . . . . . . . 82

5.10 Damping signals of CM- and TSK-fuzzy schemes for case (a) . . . . . . . . . . . 83

5.11 Two area system: Consequence surfaces of fuzzy schemes $\ldots \ldots$. . . . . . . . 83

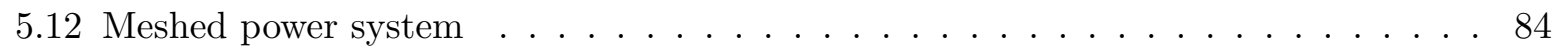

5.13 MPS: Active power injected by generators 1-4 . . . . . . . . . . . . . . . 87

5.14 MPS: Controlled components of UPFC 2 . . . . . . . . . . . . . . . . . . 88

5.15 Voting damping controller $\ldots \ldots \ldots \ldots \ldots$. . . . . . . . . . . . . 89

5.16 MPS: Damping signals inferred by voting process $\ldots \ldots \ldots \ldots$. . . . . . . . 90

5.17 New England - New York system . . . . . . . . . . . . . . . . . . . . . . 91

5.18 NE-NY contingency 1: Influence on machine $9 \ldots \ldots$. . . . . . . . . . . . 93

5.19 NE-NY contingency 1: Fuzzy damping control influence on machine 9 . . . . . . . 93

5.20 NE-NY contingency 1: Machine speed response for different types of loads . . . . . 94

5.21 NE-NY contingency 1: Active line power flows at UPFC sites $\ldots \ldots$. . . . . . . 95

5.22 NE-NY contingency 2: Speed responses $\ldots \ldots \ldots \ldots$. . . . . . . . . . . 97

5.23 NE-NY contingency 3: Speed responses . . . . . . . . . . . . . . . . . . . . 100

5.24 NE-NY contingency 3: Speed responses $\ldots \ldots \ldots$. . . . . . . . . . . . . . 101 


\section{List of Tables}

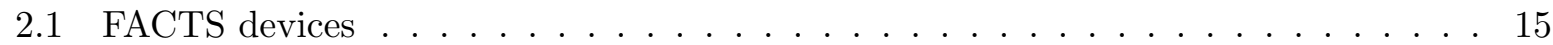

3.1 Three machine nine bus example: Modal analysis . . . . . . . . . . . . . . . . . . 29

3.2 System matrix of the WSCC example . . . . . . . . . . . . . . . . . . . . . . 29

3.3 Modal group analysis of the WSCC example . . . . . . . . . . . . . . . . . 30

5.1 Two area system: Injected series voltages $\ldots \ldots \ldots \ldots \ldots$. . . . . . . . 76

5.2 Two area system: Operating conditions (values in MW and MVA) . . . . . . . . 81

5.3 Two area system: Interarea mode for different system configurations . . . . . . . . 81

5.4 MPS: UPFCs' influence on active line flows (in \%) $\ldots \ldots \ldots$. . . . . . . . . . . 85

5.5 MPS: UPFCs' influence on generators $\ldots \ldots \ldots$. . . . . . . . . . . . . . 90 


\title{
Notation and Acronyms
}

\section{Notation}

Lower case symbols denote instantaneous values (e.g., $v, i$ );

Upper case symbols denote root-mean-square or peak values (e.g., $V, I$ );

A bar on top of a symbol denotes a phasor or complex number (e.g., $\bar{V}, \bar{I}$ );

Subscripts "P" and "Q" refer to the components mainly controlling the active and reactive power flow (e.g., $V_{P}, V_{Q}$ );

The imaginary part of a complex number is denoted by " $j$ " (e.g., $\left.\bar{I}=I_{R e}+j I_{I m}\right)$;

The conjugate transpose of a complex number is denoted by "** (e.g., $\bar{I}^{*}$ ).

\section{Acronyms}

\author{
BTBL Back-to-Back Link \\ AC Alternating Current \\ AEP American Electric Power \\ CIGRE Conseil International des Grands Réseaux Électriques \\ CM Center-of-Gravity Method \\ DAE Differential-Algebraic Equation \\ DC Direct Current \\ EMTP Electromagnetic Transient Program \\ EPRI Electric Power Research Institute \\ FACTS Flexible Alternating Current Transmission Systems \\ GA Genetic Algorithm \\ GTO Gate Turn-Off thyristor \\ HVDC High-Voltage Direct Current
}


continued from previous page

\begin{tabular}{|c|c|}
\hline $\mathrm{LF}$ & Load Flow \\
\hline MDL-file & Simulink Model-file \\
\hline MIMO & Multi-Input-Multi-Output \\
\hline mksA & Meter-Kilogram-Second-Ampere \\
\hline MPS & Meshed Power System \\
\hline NR & Newton-Raphson \\
\hline ODE & Ordinary Differential Equation \\
\hline PAT & Power Analysis Toolbox \\
\hline PI (PD) - controller & Proportional-Integral (Proportional-Derivative) - controller \\
\hline PSAPAC & Power System Analysis Package \\
\hline PSB & Power System Blockset (a Simulink Toolbox) \\
\hline PSS & Power System Stabilizer \\
\hline $\mathrm{PSS} / \mathrm{E}$ & Power System Simulator for Engineering \\
\hline PST & Power System Toolbox \\
\hline PWM & Pulse Width Modulation \\
\hline S-function & Simulink System-function \\
\hline SMES & Superconducting Magnetic Energy Storage \\
\hline SSSC & Static Synchronous Series Compensator \\
\hline STATCOM & STATic synchronous COMpensator \\
\hline SVC & Static VAR Compensator \\
\hline SVS & Synchronous Voltage Source \\
\hline TCSC & Thyristor-controlled Series Compensator \\
\hline TEF & Transient Energy Function \\
\hline TSK & Takagi-Sugeno-Kang (often referred to as Takagi-Sugeno scheme) \\
\hline UPFC & Unified Power Flow Controller \\
\hline VAR & Volt-Ampere-Reactive \\
\hline VSC & Voltage-Source Converters \\
\hline WECC & Western Electricity Coordinating Council \\
\hline WSCC & Western Systems Coordinating Council (now WECC) \\
\hline ZIP-load & (constant) Impedance-Current-Power load \\
\hline
\end{tabular}




\section{Chapter 1}

\section{Introduction}

\subsection{Motivation}

The restructuring process of the electricity that is now taking place will affect all business aspects of the power industry as it exists today from generation to transmission, distribution, and consumption. Transmission circuits, in particular, will be stretched to their thermal limits exceeding their existing stability limits due to the fact that building of new transmission lines is difficult, if not impossible, from environmental and/or political aspects. With deregulation comes the need for tighter control strategies to maintain the level of reliability that consumers not only have taken for granted but expect even in the event of considerable structural changes, such as a loss of a large generating unit or a transmission line, and loading conditions, due to the continuously varying power consumption.

High-voltage direct current (HVDC) links have been in use for decades in order to allow safe power transfer combined with improved dynamic performance. Schemes for long distance power transfer as well as back-to-back schemes have been applied using thyristor technology and current-source converters. New developments in the field of power electronic devices led the Electric Power Research Institut $\mathrm{S}^{1}$ (EPRI) to introduce a new technology program known as Flexible Alternating Current Transmission Systems (FACTS) in the late 1980s [21]. FACTS devices are based on high-voltage and high-speed power electronics devices. They increase the controllability of power flows and voltages enhancing the utilization and stability of existing

\footnotetext{
${ }^{1}$ Electric Power Research Institute (EPRI), Company Vision/Mission: "EPRI is a nonprofit organization committed to providing science and technology-based solutions of indispensable value to our global energy customers. To carry out our mission, we manage a far-reaching program of scientific research, technology development, and product implementation.", Palo Alto, California, http:\\www.epri.com.
} 
systems. FACTS devices have not only become common words in the power industry, but they have started replacing many mechanical control devices as well. They are certainly playing an increasing role in the operation and control of today's power systems [28], [33].

The two main control modes to enhance power system operation are scheduling and stabilization. Other important functions are monitoring, protection, and diagnostics. Scheduling involves a rather slow adjustment of voltages and power flows to maintain a chosen state of the system. Stabilization involves rapid response following contingencies allowing higher power transfers while maintaining a desired level of security as well as continuous stabilizing actions during normal operation to prevent spontaneous growth of oscillations [21].

The range of FACTS devices includes thyristor-based applications, e.g., Static VAR Compensator (SVC) and Thyristor-Controlled Series Capacitor (TCSC), the conventional High-Voltage Direct Current (HVDC) transmission systems, and Gate Turn-Off (GTO) based applications, e.g., Static Synchronous Compensator (STATCOM), Static Synchronous Series Compensator (SSSC), Static Phase Angle Regulator (SPAR), and Unified Power Flow Controller (UPFC). The advantages of these solid-state semiconductor devices over mechanically-switched compensators include:

- Improved operating and performance characteristics;

- Reduced equipment size and installation labor;

- Fewer concerns about equipment wear.

The relatively new GTO-based converter technology comes with the additional advantages of:

- No commutation failure when system voltage is decreased or distorted;

- Almost no harmonics allows filter-less converters;

- Reactive power can be generated or absorbed locally by the converter;

- Real and reactive power can be independently controlled;

- Reduced response time due to increased switching frequency.

SVC and TCSC devices vary their actual effective impedance to influence the power system in a desired way. The solid-state synchronous voltage source (SVS) as introduced by L. Gyugyi [27] is the operational basis for devices such as the STATCOM, SSSC, and UPFC. The SVS behaves 
like an ideal synchronous machine, i.e., generates fundamental frequency three-phase balanced sinusoidal voltages of controllable magnitude and phase angle. It can internally generate both inductive and capacitive reactive power. If coupled with an appropriate energy storage, e.g., capacitor, battery, etc., the SVS is able to exchange real power with the AC system. The SVS can be implemented by the use of voltage-source converters (VSCs). Shunt compensation capabilities of the STATCOM and the series control characteristics of the SSSC to independently control real and reactive power have found applications in power system stability studies. As one of the most complex FACTS devices the UPFC combines these advantages in a single device. The benefits are a more flexible, reliable, and economical operation and loading of power systems. The UPFC is the first device to simultaneously and independently control the parameters influencing power flows. Until recently all four parameters that affect real and reactive power flows on the line, i.e., line impedance, voltage magnitudes at the terminals of the line, and power angle, were controlled separately using either mechanical or other FACTS devices. However, the UPFC allows switching from one control scheme to another in real-time.

A large number of control designs for FACTS devices have been presented in the literature. These include numerous designs for linearized models using a specific operating condition, making them prone to system changes as well as more advanced control schemes such as robust control, self-tuning control, sliding mode control, and fuzzy logic control. These new techniques lead to better, and in some cases guaranteed, dynamic performance than conventional fixed parameter controllers. These control schemes have been based on both local measurements as well as measurements at different locations in the system resulting in decentralized and centralized approaches.

Fuzzy logic and rule-based techniques were originally introduced as a means of both capturing human expertise and dealing with uncertainty by Zadeh [100] in 1973. Since then, these concepts have been applied with great success to processes and systems which are normally operated and designed by experienced individuals who often achieve excellent results despite receiving imprecise information [9]. Fuzzy control design is attractive because it does not require a mathematical model of the system under study. It can cover a wider range of operating conditions and yet it is simple enough to be implemented in real-world applications. These advantages make it an ideal candidate for the design of controls for FACTS devices and will be explored in detail later.

An indispensable part of applying FACTS devices is the availability of a good simulation tool for a detailed system study. Many operating conditions can only be investigated by means 
of simulation. Therefore, confidence in the power system model and its controls is crucial [21]. Control strategies have to be designed and tested for robustness in applying such simulation tools. Advances in simulation environments and their capabilities allow detailed studies of the highly nonlinear dynamics of power systems. The MATLAB/Simulink ${ }^{2}$ simulation software gives the engineer the possibility of advanced vectorized computations as well as a block-oriented simulation environment. Therefore, the conditions for performing steady-state analysis, including not only load flow calculations and voltage-stability analysis but also fast dynamic stability analysis are given. MATLAB's capability can be expanded through script-files to perform computations in a routine manner, and Simulink allows the extension of its libraries through self-created blocks. Also, the steadily growing number of add-on products in the form of toolboxes creates an ideal environment for electric power system modeling, analysis, and design.

The progress made and ideas mentioned in the areas above motivated this dissertation: To combine building a suitable simulation environment for power systems and modern control techniques. This environment should include FACTS devices in load flow computations, be applicable to perform dynamic stability analysis, and allow the application of advanced control design techniques to improve power system performance.

\subsection{Overview}

This dissertation consists of the following chapters:

- Chapter 1: Introduction

The introduction continues with an overview of power system dynamics (section 1.3).

- Chapter 2, Literature survey and related work

This chapter presents a survey concerning related work on modeling and simulation environments (section 2.1), FACTS devices (section 2.2), damping control (section 2.3), and fuzzy control (section 2.4). It is concluded by the objectives and contribution of this dissertation (section 2.5].

- Chapter 3: Power Analysis Toolbox

The Power Analysis Toolbox (PAT) is presented in the third chapter. An overview (section 3.1), the conceptual design (section 3.2), the implementation (section 3.3), and included

\footnotetext{
${ }^{2}$ MATLAB and Simulink are products of The Mathworks, Inc., http: \\www.mathworks.com.
} 
FACTS devices (section 3.4 are given in detail. A small example to introduce the use of PAT as a tool is provided in section 3.3.6.

- Chapter 4. Transient stability enhancement using FACTS devices

The proposed fuzzy damping scheme and its application to the UPFC is discussed in this chapter. An introduction to the topic is given in section 4.1. This is followed by the UPFC as an actuator (section 4.2), fundamentals of fuzzy control (section 4.3), damping schemes for excitation systems and FACTS devices (section 4.4), signal conditioning (section 4.5), and the resulting fuzzy damping control (section 4.6). A discussion of the fuzzy damping schemes and comparison with another damping control design is given in section 4.7 .

- Chapter 5: Power system case studies

In this chapter case studies using the Two area - Four machine power system (section 5.1), a meshed power system example (section 5.2), and the New York - New England system (section 5.3 are presented to validate the suggested fuzzy damping scheme and to examine effects in highly interconnected power systems.

- Chapter 6: Summary and conclusions

This chapter summarizes the benefits of the developed PAT and the enhancements achieved by designing damping controls using the proposed fuzzy scheme, lists research work already done or in progress that is based on parts of this dissertation (section 6.1), and gives suggestions for future work (section 6.2).

A list of publications as a result of this research is given in appendix $\mathrm{A}$.

\subsection{Power system dynamics}

Stability or instability of power systems can be classified due to the nature of the resulting problem: loss of synchronism and voltage collapse [46]. These two categories are also known as angle and voltage instability. Concentrating on angle stability, a further distinction can be made: Small-signal (or small-disturbance) stability and the transient stability problem. Small-signal disturbances occur continually because of small variations in load demands and power generation. These changes are considered to be small enough to base the analysis on the linearized power system. Oscillations of concern due to small disturbances are: 
- Local modes or machine-system modes - swinging of machines at a power station (or small part of the power system) against the rest of the system. An oscillation is also classified as a local mode if it is strongly controllable in only one area and also strongly observable in the same area 98 .

- Interarea modes - different parts of the system swinging against each other. Such a mode might be strongly observable and weakly controllable in one area, but strongly controllable and weakly observable in another area, or strongly controllable in different areas [98].

- Control modes - generator oscillations due to power system controllers.

- Torsional modes - mechanical oscillations of turbine-generator shaft systems caused by interactions with other control systems.

The main concern of this research is the transient stability of electric power systems. As defined in [46] the term transient stability refers to

“... the ability of the power system to maintain synchronism when subject to a severe transient disturbance such as a fault on transmission facilities, loss of generation, or loss of a large load. The system response to such disturbances involves large excursions of generator rotor angles, power flows, bus voltages, and other system variables."

If the resulting angular separation between the synchronous machines remains within certain bounds, the system maintains synchronism. Otherwise the system is said to lose synchronism and is classified as transiently unstable. The power system stability itself is highly influenced by its nonlinearity. A period limited to 5 to 15 seconds following the disturbance is usually enough to classify the system as stable or unstable. A tentative overview of the different control tasks and their time horizon following a major disturbance is shown in Fig. 1.1. The control of the actual operating point is active before and after a disturbance has occurred. For the first seconds the goal is to guarantee first swing and transient stability. The stability of power systems may need further adjustments to avoid voltage instability before returning to the control scheme for the postdisturbance operating point, which itself may require generation rescheduling. Numerous factors influence the transient stability of an electric power system, e.g., generator loading, generator inertia, generator output during the fault, fault-clearing time, postfault transmission system impedance, etc. Transient stability can be improved through system (re-)configuration, e.g., lower line reactances, or devices, e.g., power system stabilizer as additional control devices applied 


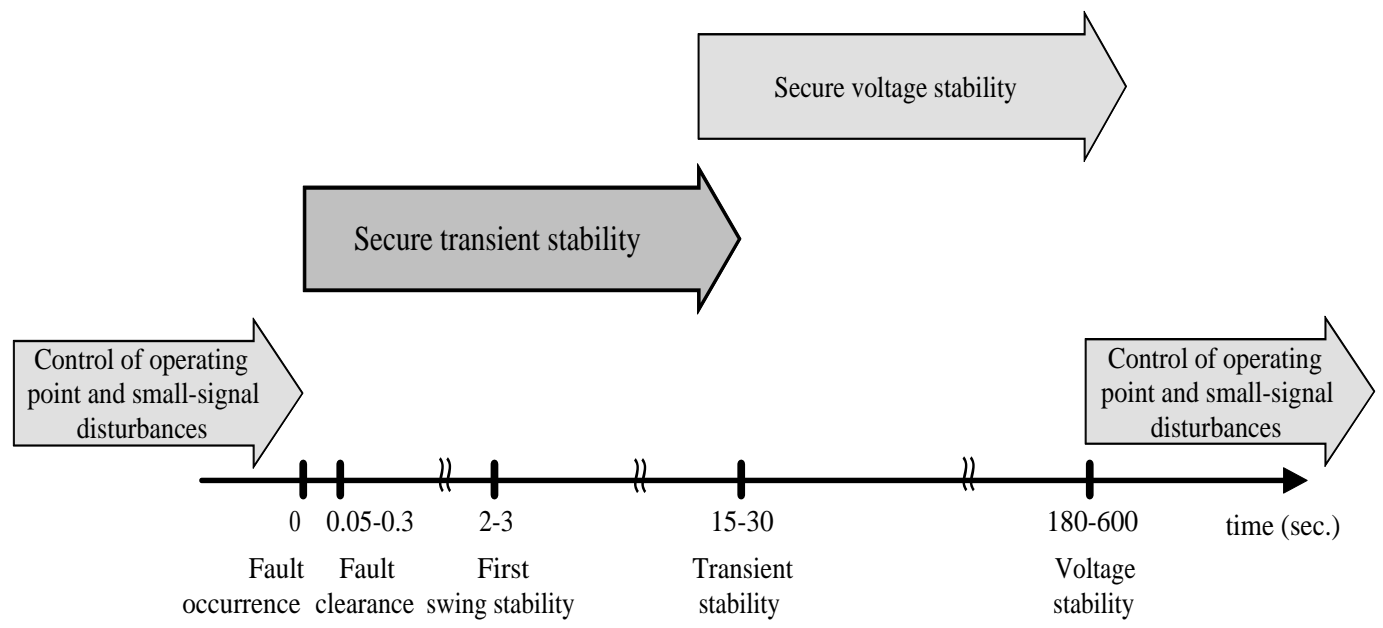

Figure 1.1: Time horizon and control tasks after fault occurrence in a power system

to generator excitation systems, and devices installed throughout the transmission grid, e.g., STATCOM, TCSC, and UPFC.

This research will focus on applying FACTS devices and design controls to improve transient stability of electric power systems. The design of such controls is known as damping control design. A survey of simulation environments to analyze and design power system controls and schemes applied follows in the next section. 


\section{Chapter 2}

\section{Literature survey and related work}

Software tools for an improved power system modeling, simulation, analysis, and control design cycle have been of interest to both electric utilities and universities for decades. Many different approaches have been investigated and implemented. This chapter introduces common elements of all tools and gives a survey of concepts and tools found in section 2.1. The main purpose of power system analysis packages is to allow the design of controls. This is especially important for the new FACTS devices as they are the most powerful control elements of today's electric power systems. Their possible impact on system stability requires insight into their characteristics and operating schemes. Section 2.2 gives an overview of FACTS devices and controls found in the literature. This is followed by related work on damping control and an introduction to rule-based or fuzzy control in sections 2.3 and 2.4 .

\subsection{Modeling and simulation environments for power systems}

Modeling at the transmission level is based on balanced three-phase systems allowing a simplified single-phase approach. Nevertheless, numerous difficulties due to increasingly complex interconnections between different power generation and consumption areas, as well as the introduction of high-power and high-voltage power electronics, exist. This section discusses issues arising in the field of power system simulation and analysis and introduces fundamental elements of simulation environments in section 2.1.1, followed by an overview of commercial software products and reported approaches at universities in section 2.1.2. 


\subsubsection{Introduction to power system analysis}

The analysis of electric power systems on the transmission level involves many different aspects. Key elements are briefly introduced next.

System representation: The power system seen at the transmission level allows the simplified representation by an equivalent single-phase system at the fundamental system frequency. This assumption means that the costumers' load demands are equally split among the three phases and all electrical quantities are balanced throughout the system with only minor deviations from the nominal frequency. Harmonics are not of concern at this modeling level.

Load flow: The first step in any power system study is the computation of the load flow solution. The load flow solution gives a full description of the system at a specific point in time. Taking into account the costumers' load demands, the operational transmission system, and the generators and their controls, the bus voltages and resulting power flows are computed. The result is used during the initialization phase of dynamic studies to specify the power system at the start time. Repeated load flow computations based on different loading conditions can be used to examine the steady-state voltage stability.

Steady-state voltage stability: Load flow solutions due to different loading conditions can be used to identify buses in the power system which are likely to violate recommended voltage limits (usually $\pm 5 \%$ of the nominal value). The identified buses serve as indicators for required additional voltage stabilizing elements, e.g., SVC, STATCOM, and their ratings.

Transient stability analysis: Based on the load flow solution describing a specific operating condition and a given disturbance scenario transient studies are performed. The differentialalgebraic power system equations are continuously solved over a specified period of time. The system stability is judged on the ability of the power system to maintain synchronism.

All of the above mentioned elements have been realized utilizing different approaches with very different capabilities. An overview of related work, development environments, fundamental concepts, and limitations is presented next.

\subsubsection{Related work on simulation and analysis software}

Several products, e.g., Eurostag [22, PSAPAC [70], and PSS/E [71], have been developed using FORTRAN. Though this has the advantages of widely available and well-tested numerical routines, e.g., eigenvalue computations, and the possibility to handle large-scale systems, it comes with the drawback of high development time. Functionality and components which cannot be 
added using a graphical user interface require a difficult and error prone low level coding process. Also, libraries for control design and artificial intelligence technologies are not available. In order to overcome some or all of these limitations different approaches have been taken.

The object-oriented software design has been suggested to cope with the problem of implementation of new devices. In [24] and [56] $\mathrm{C}++$ was utilized to increase modeling flexibility. Each model object represents a physical subsystem and can be further used by inheritance and aggregation to develop a power system class structure. While greatly improving modeling and model reuse this approach suffers from an increase in required simulation time and the necessity of low level coding. Just as in the previous case user interface and graphical representation of results have to be provided by the user.

A power system modeling toolbox based on the object-oriented simulation environment Dymola [17] is ObjectStab [63] 68]. Dymola supports the unified object-oriented modeling language for physical systems Modelica [59]. The support of noncausal modeling and symbolic preprocessing allows minimize the size of the differential-algebraic equation (DAE) systems (see [19]) and guarantees efficient simulations. A graphical user interface supports interactive parameter specification. Current drawbacks of Dymola are problems in finding consistent initial conditions, i.e., solving the load flow, and the missing support for sparse matrix computations.

The possibility of utilizing MATLAB/Simulink's capabilities of advanced numerical and symbolical analysis [55], [54] for power system simulation has sparked several research activities.

Hiyama, Fujimoto, and Hayashi [38] and Hiyama and Ueno [40] utilized the advantages of Simulink's environment to perform transient stability studies. The approach taken was to model each device separately (as opposed to PAT's vectorized approach) and models implemented did not cover FACTS devices. In one of the applications reported the real-time capabilities of the MATLAB/Simulink/Real-Time Workshop environment were demonstrated.

Allen et al. [1] report an object-oriented approach within MATLAB/Simulink. Simulink requires causal modeling making it necessary for the user to associate ports with a predetermined input or output functionality. Also, connecting models together creates algebraic loops which are solved iteratively by Simulink's solvers resulting in increased simulation time. These reasons make it impractical for modeling large power systems.

Hiskens and Sokolowski [34] describe a combined symbolical and numerical modeling and simulation approach. The symbolically formulated DAE system is iteratively solved at every time step. Therefore, it shares the advantages of flexibility and modularity with the Dymola 
environment. Due to the missing step of elimination of redundant equations an unnecessarily large DAE system with the drawback of reduced simulation performance results.

MatEMTP [4] is a product developed to analyze electromagnetic phenomena. It is EMTP's (Electromagnetic Transients Program [20]) analogon within MATLAB to perform detailed threephase analysis. Therefore, it is well suited for distribution system studies but not for transient analysis of large-scale electric power systems.

A commercial toolbox for MATLAB/Simulink is the Power System Blockset [43] (PSB). The PSB targets just as MatEMTP detailed three-phase analysis and is, therefore, not appropriate for transient stability studies.

Another commercial third party product for the MATLAB/Simulink environment is the Power System Toolbox (PST ${ }^{1}$ ). The purpose of the PST as developed by Chow in the early 1990s [13] is to provide models of synchronous machines and control systems for performing transient stability simulations of electric power systems and small-signal stability analysis. The PST performs nonlinear simulations of power systems including conventional elements of power generation, transmission, and consumption, e.g., synchronous generators, excitation systems, turbine-governors, power system stabilizers, HVDC links, static VAR compensation, and ZIP-loads. So far the PST does not support modern FACTS devices, e.g., UPFC, STATCOM, SSSC, etc. The numerical solution method for the DAE system is based on a simple predictor-corrector method as ordinarydifferential equation (ODE) solver and Newton's method for interfacing HVDC-converter and static and dynamic load buses. The possibility to set the time-step for the simulation process gives the user control over the accuracy of the simulation results. The incorporation of FACTS devices results in a stiff power system with time constants varying over a far wider range $(1 \mathrm{~ms}$ to $10 \mathrm{~s}$ ) than ever before and ODE solvers have to be able to handle this new situation efficiently. The PST solver lacks this property. Also, a PST user-interface for the nonlinear simulation and linearization process does not exist; data and simulation files are based on the interplay of a large number of m-files only.

The dynamic models are coded as MATLAB-functions [14] and the authors provide a set of demonstration files to enable the user to perform studies. Since the toolbox is based on MATLAB m-files, the possibility to add customized models and applications by following the modeling conventions, structure and data requirements, and the method of interconnecting the models is given.

\footnotetext{
${ }^{1}$ The Power System Toolbox (PST) is maintained by Cherry Tree Scientific Software, Colborne, Ontario, Canada, http: \\www.eagle.ca $\backslash \sim$ cherry.
} 


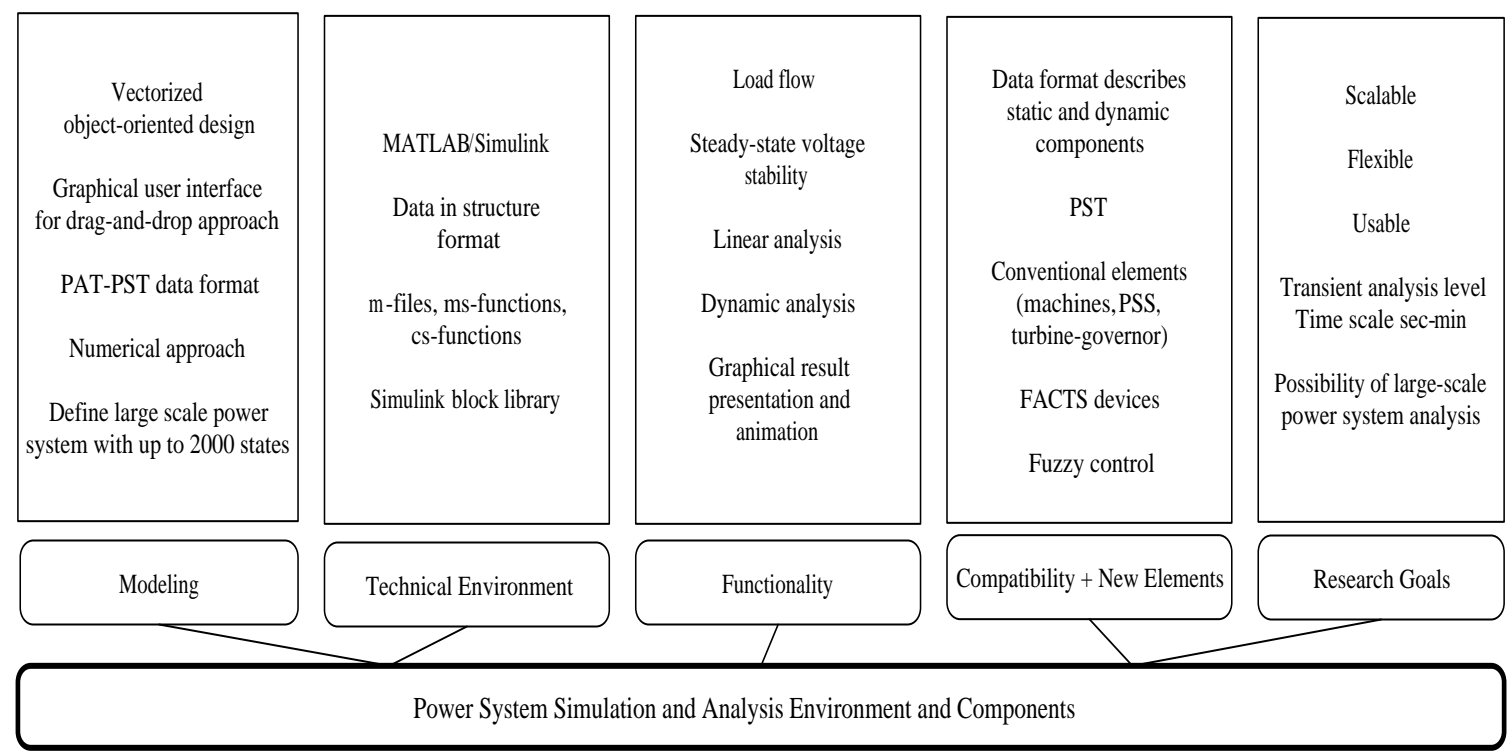

Figure 2.1: Identified environment and components

The advantage of the PST (as compared to many other simulation packages) is the accessibility of all variables used for the computations due to their global visibility in the MATLAB workspace. Also, the extensibility of PST allows the addition of FACTS devices. The drawbacks are the numerical difficulties and low efficiency resulting in long simulation times. The combination of interacting m-files and the global variables creates a rather confusing and hardly extensible simulation environment. Therefore, a different approach is desirable.

The mentioned limitations lead to the idea of "restructuring" the power system in terms of creating a data structure which is easier to understand, simpler to extend, and which makes use of more sophisticated numerical solution techniques. A transient analysis toolbox should build on the PST's advantages of vectorized routines within MATLAB by incorporating FACTS devices and control schemes into the steady-state computations and to develop a Simulink block library for transient stability studies. Both have been targeted and explored in the development of the proposed Power Analysis Toolbox (PAT). A graphical summary of the environment, required components, and desired functionality as identified by the review of available software is shown in Fig. 2.1. 


\subsection{Overview of FACTS devices}

A power system is an interconnection of generating units to load centers through high voltage electric transmission lines. Large disturbances such as loss of transmission lines and/or generating units occur frequently, and will probably occur at a higher frequency due to deregulation. As transmission lines become more and more loaded close to their thermal limits new ways of maintaining stability at all times must be found. The FACTS technology program promotes the use of reliable, high-speed power electronic controllers to increase controllability and optimization of the existing power system. A wide range of FACTS devices is available today. The characteristics of FACTS devices of interest for this research are summarized in the following.

Static VAR Compensator: A SVC is an adjustable susceptance used primarily to maintain a constant voltage at its terminal by adjusting the reactive power exchanged with the power system. The most common topology consists of fixed or switched capacitor-banks in parallel with a thyristor-controlled reactance. The utilization of the SVC to improve damping of power swings has gained increased interest and a number of control schemes have been suggested. Besides the principal idea and modeling in [32], practical application in [47] and robust control schemes improving performance of power systems using fuzzy logic technology [39] have been reported.

Thyristor-Controlled Series Capacitor: The TCSC arrangement resembles the SVC topology but is used as a series device between two power system buses. The overall effective impedance can be varied in a continuous manner. The TCSC compensates the line's reactance by up to $70 \%$. A small inductive operating range has been used in some applications to reduce short-circuit currents and to allow power modulation to damp oscillations [32]. The most common mode of operation is the constant impedance mode combined with an additional transient stability controller to improve the dynamic performance of the power system. Modeling and a basic control scheme have been described in [32], a robust control scheme improving performance of power systems using a model matching approach can be found in [85], and an approach based on the transient energy function in 67.

Static Synchronous Compensator: The basic principle of a STATCOM is the generation of a controllable AC voltage by a voltage-source converter connected to an energy storage unit (DC capacitor) to exchange the necessary amount of reactive power to keep the bus voltage at a specified value [32], [77]. The advantage over the SVC is the improved operating characteristic. The compensation is independent of the actual voltage level at the bus and the time delay between changes in the power system and device response is decreased. Different control schemes ranging 
from simple transfer functions in [11] and [32] to a decoupled approach in [75] and a multivariable approach in 95] have been suggested.

Static Synchronous Series Compensator: The operation principle of the SSSC equals the basic idea of the STATCOM. It also generates a controllable AC voltage through a voltagesource converter connected to an energy storage unit (DC capacitor) but is connected in series to a transmission line. The advantages over the TCSC are an improved overall performance widely independent of the actual operating conditions and the nonexistence of the subsynchronous resonance problem. Modeling and control schemes can be found in [11] and [32].

Unified Power Flow Controller: The UPFC is the most versatile FACTS device to have emerged in the electric power industry so far ${ }^{2}$ It is primarily used for voltage support and control of active and reactive power flows on transmission lines to allow for their secure loading [18], 27]. Secondarily, the UPFC can be used to damp power oscillations [49, 64, and [93. Operation, modeling, interfacing, and UPFC control strategies have been investigated by several authors [42], 62], and [89].

GTO-based Back-to-Back Link: The BTBL is functionally equivalent to the conventional HVDC back-to-back scheme but applying GTO-based voltage-source converter technology results in improved performance characteristics [6]. It can be used to link power system areas with different dynamic characteristics and system frequencies. Notable is the capability of the converters to produce reactive power and therefore add to the voltage-stability support of the power system making additional SVCs (as is the case with traditional HVDC converter technology) at the terminals unnecessary.

An overview of FACTS devices is given in Table 2.1. The various FACTS devices are listed according to their connection characteristics. The table summarizes the operating principle, possible basic control schemes, and local signals as used for supplementary damping control in the literature. Note that $\Delta f_{S}$ and $\Delta V_{S}$ represent synthesized frequencies and voltages, e.g., difference in neighboring bus frequencies [32].

\subsection{Damping control design}

For almost 40 years control devices have been sought to provide damping for low-frequency, electromechanical oscillations. These oscillations are often persistent for long periods of time

\footnotetext{
${ }^{2}$ The only UPFC built so far is at the Inez Station of the American Electric Power (AEP) in Kentucky. Each converter has a rating of $\pm 160 \mathrm{MVA}$ and the UPFC is used for voltage support and power flow control.
} 
Table 2.1: FACTS devices

\begin{tabular}{|c|c|c|c|c|}
\hline Device & Type & $\begin{array}{l}\text { Device } \\
\text { principle }\end{array}$ & $\begin{array}{c}\text { Basic } \\
\text { control }\end{array}$ & $\begin{array}{c}\text { Local } \\
\text { modulation signal }\end{array}$ \\
\hline$\overline{\mathrm{SVC}}$ & shunt & $\begin{array}{c}\text { varying } \\
\text { reactance }\end{array}$ & bus voltage & \multirow{6}{*}{$|P|,|I|, \Delta f_{S}, \Delta V_{S}$} \\
\hline STATCOM & shunt & $\begin{array}{l}\text { reactive } \\
\text { source }\end{array}$ & bus voltage & \\
\hline TCSC & series & $\begin{array}{l}\text { varying } \\
\text { reactance }\end{array}$ & $\begin{array}{c}\text { line } \\
\text { compensation }\end{array}$ & \\
\hline SSSC & series & $\begin{array}{l}\text { reactive } \\
\text { source }\end{array}$ & $\begin{array}{c}\text { line } \\
\text { compensation }\end{array}$ & \\
\hline UPFC & shunt+series & $\begin{array}{c}\text { reactive source+ } \\
\text { series compensation }\end{array}$ & $\begin{array}{c}\text { bus voltages } \\
\text { active power flow } \\
\text { line compensation }\end{array}$ & \\
\hline BTBL & shunt+shunt & $\begin{array}{c}\text { reactive source }+ \\
\text { phase compensation }\end{array}$ & $\begin{array}{c}\text { bus voltages } \\
\text { active power flow }\end{array}$ & \\
\hline
\end{tabular}

thus limiting power transfer capabilities. The Power system stabilizer (PSS) was the first device used to oppose these oscillations via modulation of the generator excitation systems, but static VAR compensators and HVDC links have also been utilized [46]. Much effort was put into research designing appropriate damping controllers. PSSs are located at the generation site and can observe and control local modes. Interarea modes often belong to oscillations which cannot be damped by application of PSSs, and control devices within the transmission system are more effective. A detailed investigation and proof of existence of these so-called fixed modes can be found in [99]. Since the introduction of the FACTS devices, attempts to investigate the probable influence of siting, decision on the best input signal, and the varying capabilities of the different FACTS devices to overcome these restrictions have been reported [25], [57, [91], and [92].

Continuous transfer functions of lead-lag type designed using linear analysis or parameter tuning through simulations have been presented in [42], [90], and [93. They are designed for a specific operating condition and may therefore experience reduced effectiveness when conditions change. In [72] coordination of multiple FACTS stabilizers using optimal eigenvalue placement was presented. Besides linear analysis tools (see [46] for an overview), more advanced and modern approaches including self-tuning control [12], sliding mode control [45], robust techniques [85], [94, and fuzzy logic [15], 41], 49], [58], and [64] have been applied to either PSS, SVC, or UPFC. A self-organizing PSS using a fuzzy auto-regressive moving average model has been presented in [69]. They offer better performance over a wider range of operating conditions than fixedparameter controllers. The transient energy function approach was chosen to design damping controls independent of the power system structure utilizing the UPFC and series compensating 
devices as actuators in [51] and [67].

\subsection{Rule-based control - Fuzzy logic technology}

Fuzzy logic is used to describe systems that are "too complex or too ill-defined to admit precise mathematical analysis [9]." Major features are the use of linguistic terms rather than numerical variables and the characterization of relations between variables by fuzzy conditional statements or rules. For a book on fuzzy logic and control see [96, a report focusing on design of fuzzy controllers is [44, for a summary of fuzzy logic applied to process control see [9], 61] gives an overview of fuzzy set theory and its applications in power systems, and [88] is a recent tutorial on fuzzy logic applications in power systems. Fuzzy logic gives the engineer the possibility to deal with imprecision, a method to model human behavior, and a tool to control systems that cannot be modeled rigorously. The principle difference between conventional techniques and the rule-based approach is that the latter uses qualitative information rather than rigid analytic relations. Nevertheless, the overall process of constructing a fuzzy controller is similar to an analytical controller in the sense that the system must be understood, key parameters identified, and a control methodology developed. However, the two approaches differ in the methods used to calibrate the controller. Whereas numerous analytical tools exist for parameter tuning in conventional control design, the fuzzy logic counterpart lacks a standard technique. Repeated closed-loop trials are necessary to gain enough knowledge to identify crucial parameters, tune parameters, and to formulate the rule-base. In this research the fuzzy logic technology will be used to complement the control of FACTS devices in order to improve transient stability of power systems.

\subsection{Contribution of the dissertation}

The objectives of this work are twofold:

- The impact of FACTS devices on power system operation requires the ability to include new devices into simulation environments with a short implementation time. For this reason PAT has been developed. PAT will serve as a single framework for both steady-state and dynamic stability analysis, i.e., computation of load flow solutions, steady-state voltage stability analysis, transient stability studies, and small-signal analysis. The core of PAT, PAT's data structure, has been designed in a modular way so that the user can access the 
data in a systematic manner as well as expand PAT by new components with a limited amount of additional work. Besides PAT's framework a wide range of FACTS devices and possible control schemes have been implemented. These prototypes can be used to add new devices and control schemes.

- The second part of the work concentrates on the most powerful and complex device of the FACTS series, the UPFC. Besides controlling the power flow, the UPFC can be used to improve the stability of the system. This is investigated using fuzzy techniques. The chosen approach incorporates expert knowledge rather than linear analysis to improve the performance of power systems during low-frequency power oscillations. The performance of the proposed damping controller is demonstrated on test systems. Simulation results show that the UPFC fuzzy damping controller can significantly enhance operation and performance of longitudinal power systems. 


\section{Chapter 3}

\section{Power Analysis Toolbox}

\subsection{Overview}

The objective of PAT is to allow modeling, simulation, and analysis of large-scale electrical power systems at the transmission level in a single environment. As pointed out in previous sections PAT utilizes MATLAB/Simulink's capabilities of vector and matrix computations. Also, the call for advanced numerical ODE techniques and a user-friendlier simulation environment has been addressed by choosing Simulink as an environment for transient stability studies. Simulink is based on block-oriented modeling and allows the extension of its model library by means of system-functions (s-functions) as well as systems formed by already existing library blocks. Sfunctions describe block properties during the different steps of the simulation, e.g., initialization, computation of derivatives and outputs, updates of discrete states, etc. MS-functions are sfunctions written as MATLAB m-files. Therefore, they allow the same flexibility as any MATLAB m-file but with the advantage of the graphical, block-oriented Simulink simulation environment. Simulink itself comes with a choice of advanced ODE solvers improving numerical stability and accelerating the simulation process.

Furthermore, Simulink has been and will be of interest for universities as well as industry as a high-level simulation environment and a platform for add-on products. Already existing products include control toolboxes, neural network and the fuzzy logic toolbox, Stateflow toolbox, and Real-Time Workshop. Simulink and its toolboxes allow a modern and intelligent controller design. Nevertheless, any Simulink model can be linearized at a chosen operating point which guarantees the ability to base the controller design on "classical" methods, e.g., pole placement.

All the "traditional" elements of a power system as well as the FACTS devices mentioned 
previously have been implemented as a new Simulink block library. The PST load flow program has been modified to incorporate FACTS devices and to make use of the advanced data structure. The new data structure presents the power system data in a clear and understandable way. Additionally, functions for retrieving the state space model of a power system and basic modal analysis have been included in PAT. The developed toolbox shows promising results in terms of user friendliness, flexibility in setting up new test systems, flexibility and ease of implementation of new elements, linearization process, and increased simulation speed (up to 20 times faster than the PST) and has been tested with systems of up to 100 synchronous machines and static and dynamic loads of about 1500 states. The following sections describe the conceptual design, the data structure, the main functions provided with PAT, as well as the block library developed.

\subsection{Conceptual design}

The functionality necessary and included in PAT are the basic elements as described earlier in section 2.1.1. These components and their relationships constitute the conceptual design and are shown in Fig. 3.1. The main objective was to create each of these components in a single environment to ensure the possibility of a seamless interplay among modeling, simulation, analysis, and synthesis. A closer look at PAT's functionality is presented in Fig. 3.2. For a specific case study two input files are required. The power system data file, which is an m-file obeying the data format, and secondly the model (MDL) case study file for the time domain analysis. PAT itself is a collection of interacting m-files that perform sub-computations, e.g., setting up the sparse transmission system matrix, with top-level functions as a user interface to PAT's routines. These top-level functions have been written to guarantee a convenient working experience. The most important functions are steady-state computations (load flow and initialization for the various power system devices) and a linearization routine. The following gives details about PAT's implementation.

\subsection{Implementation}

The main functional components included in PAT use an approach similar to object-oriented programming. The functions written operate on the power system data structure, directly facilitating vector and matrix storage and computations of power system data. The next section describes the data structure. 


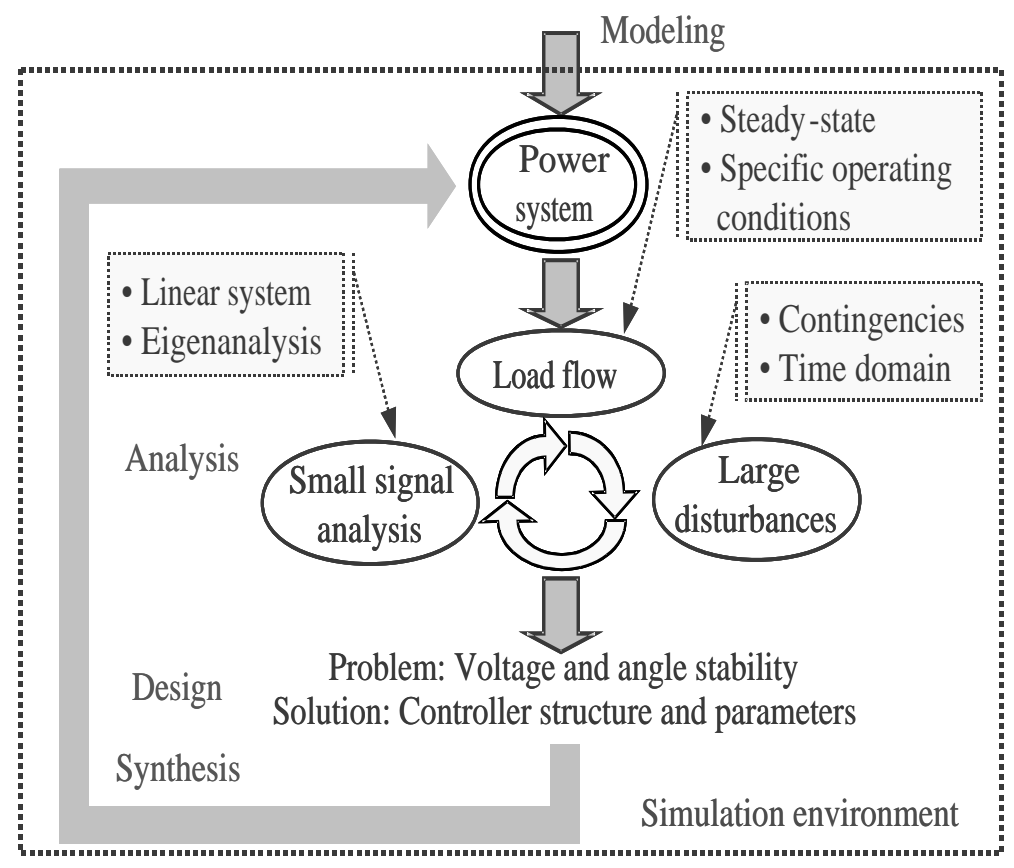

Figure 3.1: PAT's conceptual design

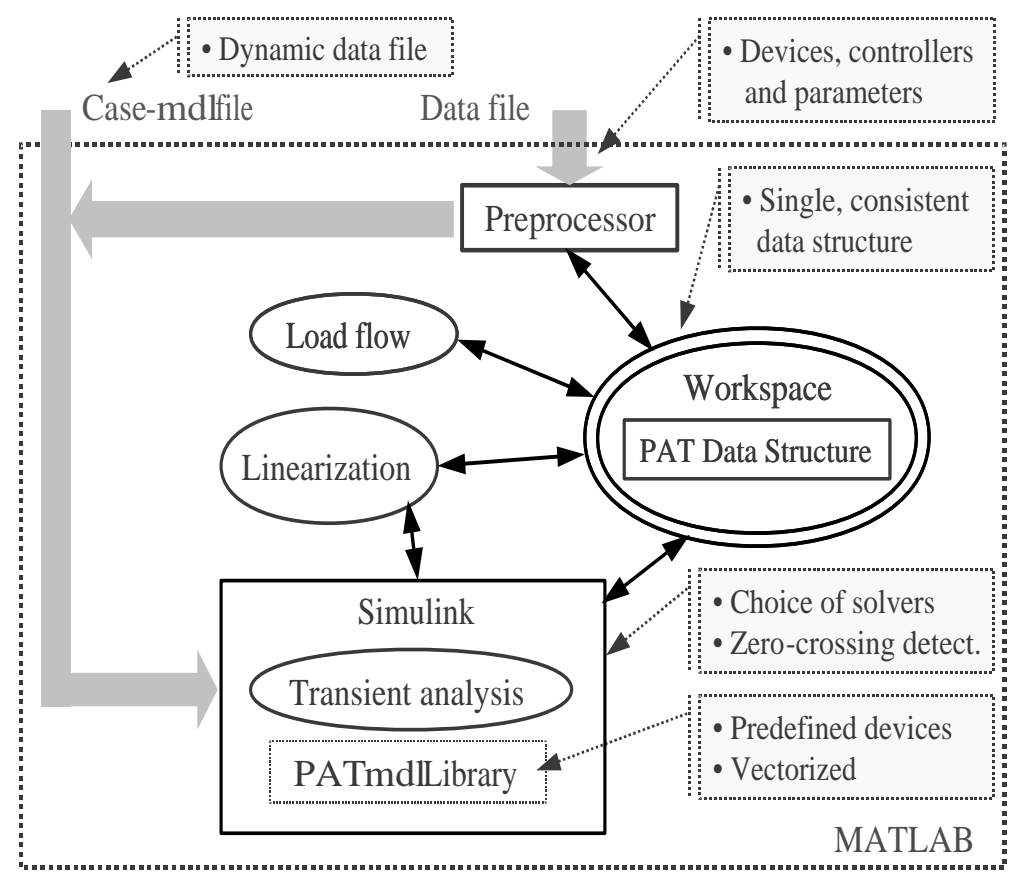

Figure 3.2: PAT's functionality 


\subsubsection{Power system data structure}

The new representation of the power system in MATLAB's workspace makes use of the data structure as defined by MATLAB [55]. Structures are arrays with named "data containers" called fields. The fields of a structure can contain any kind of data. For example, one field might contain a text string representing a device name, another might contain a scalar representing a controller parameter, a third might hold a matrix of transmission line data, and so on.

PAT reads the power system data fil $\oint^{1}$ and sets up the power system data structure in the workspace. A representation of the main elements of the power system structure is shown in Fig. 3.3. It presents part of the relationship between the different elements of a power system and their field names. The root of the structure contains high level descriptions of the power system, e.g., PSS, synchronous machines, FACTS devices, transmission grid information. Each of these stores more details concerning general environment specifications, parameters, control schemes and controller parameters, load flow solution, and state information for each device.

\subsubsection{Preprocessor}

The initial steps in parsing the PAT-data file and creating the power system data structure in the workspace is done by the preprocessor. As of yet only a modified PST-data format is supported. This format supports load flow and dynamic data. Once the structure has been successfully created the load flow can be solved.

\subsubsection{Load flow}

The load flow function takes the data structure as input and returns the data structure with the solved load flow. The algorithm used is an augmented Newton-Raphson iteration scheme allowing the incorporation of the various FACTS devices and their control schemes. After the load flow solution has been found the initial conditions for the dynamic elements are computed and added to the data structure.

Besides the computation of a single load flow case, it is helpful in power system analysis to find the voltage profile and eigenvalues for a range of system loadings. This functionality is also provided.

\footnotetext{
${ }^{1}$ A modified PST-data file format to ensure compatibility with the existing PST but includes the FACTS devices as described in section 3.4 .
} 


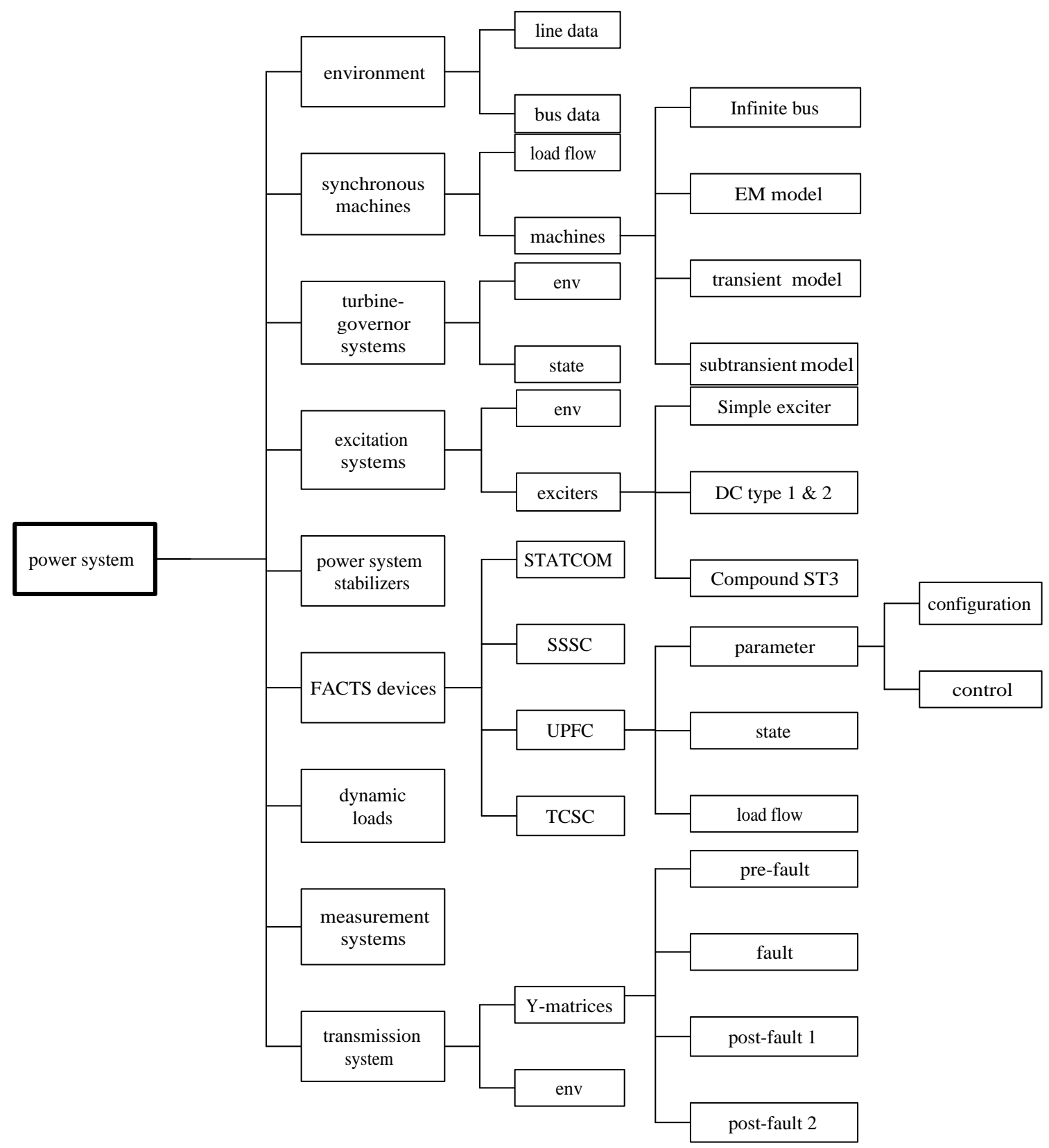

Figure 3.3: Power system data structure 


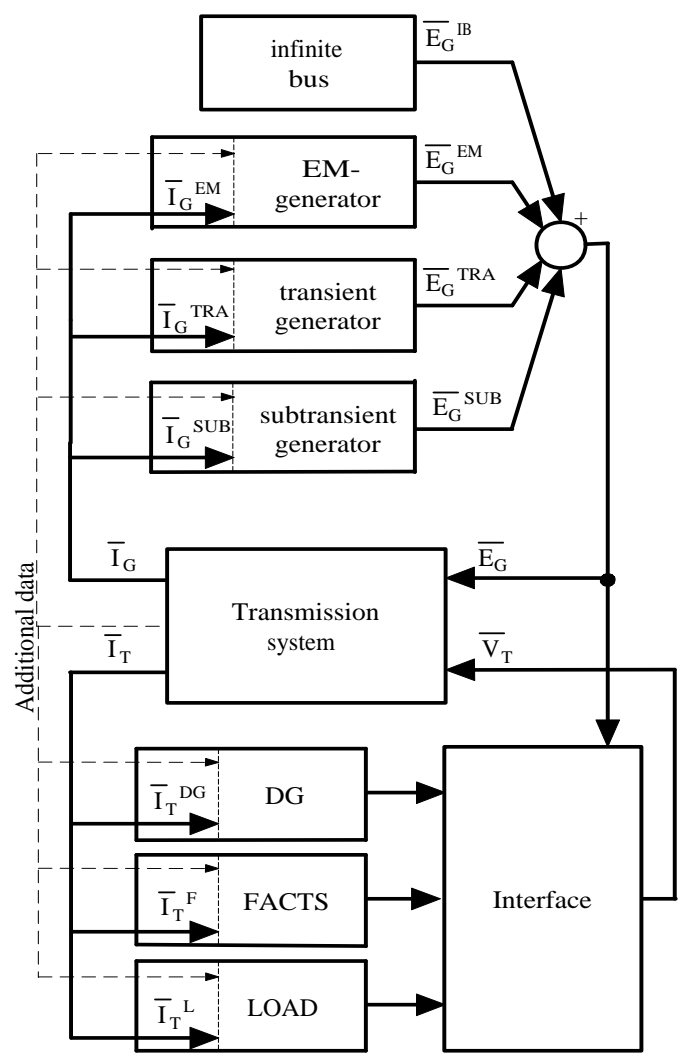

Figure 3.4: PAT's transient modeling concept

\subsubsection{Transient analysis - Simulink block library}

To take advantage of Simulink's environment and its sophisticated numerical techniques to solve ordinary differential equations and algebraic loops a new power system block library has been developed. This library allows the user to drag-and-drop different elements of a power system, e.g., synchronous generators, transmission grid, power system stabilizers, excitation systems, turbine-governor systems, various FACTS devices, and ZIP-load models (static and dynamic) into the model. Through utilization of the power system data structure the Simulink blocks access the necessary information kept in MATLAB's workspace. All blocks make use of the capability to propagate vector signals, therefore allowing the efficient modeling and simulation of large power systems. PAT's transient modeling concept within Simulink is shown in Fig. 3.4 . Each block represents a specific type of device. All devices take the current as input signal from the transmission system but only in the case of the generators are the output voltages explicitly computable. Static and dynamic loads with constant power or current characteristics, FACTS 


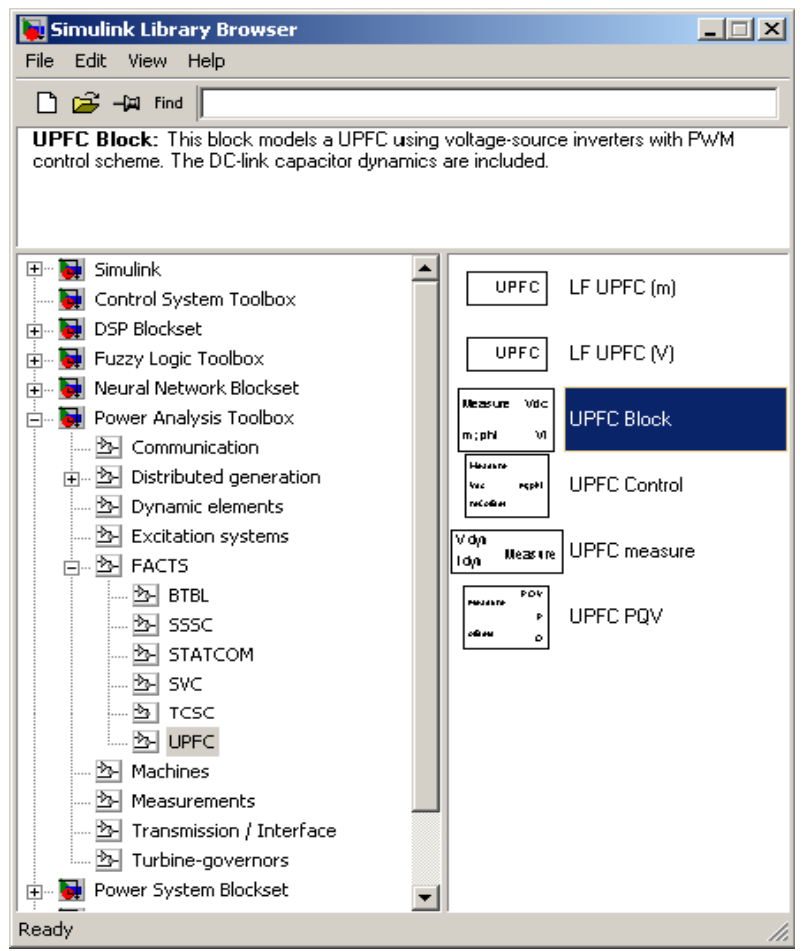

Figure 3.5: PAT's Simulink block library

devices, and distributed generators (DG) which are connected to the power grid using power electronic technology require the terminal voltages to be found iteratively (see section 3.4 for details) using the partitioned-solution approach for the DAE system [52]. Simulink's library has been extended by numerous blocks creating the PAT block library as shown in Fig. 3.5 .

\section{Modeling concept}

The extension of Simulink by additional block libraries can be done in two different ways. Advantages and differences of these approaches can be found in detail in the Simulink s-function manual [53] and the Simulink manual [54]. A brief summary is given next.

System-functions: S-functions [53] provide a mechanism for extending the capabilities of Simulink by adding blocks in MATLAB, C, C++, Fortran, or ADA. By following simple rules, any algorithm can be implemented in an s-function. After writing the s-function and placing its name in an s-function block (available in the Functions \& Tables block library), a customized userinterface can be created by masking the model. Mainly MATLAB-s-functions (ms-functions) will be used for this research. Any s-function uses a special calling syntax that enables it to interact with Simulink's solvers. The form of s-functions is very general and allows the implementation 
of continuous, discrete, and hybrid systems.

Simulink blocks: The combination of already existing Simulink blocks [54] to form new power system elements is another approach. Improved vector- and matrix operation capabilities of blocks and signal lines allow highly optimized computations and simulations of power systems faster than real-time. Additional advantages are the functional correctness of the blocks, improved numerical robustness and interaction with Simulink's solvers, and the ability to compile models for hardware-in-the-loop systems. Nevertheless, s-functions have to be used in order to incorporate models that cannot be realized by Simulink's blocks.

The structure is a necessity for the efficient implementation of the new power system simulation environment within Simulink. Once the load flow is solved the data structure is set up in the workspace and can be accessed by the Simulink model (or better, its blocks) to extract the necessary information (parameters) for the simulation.

\subsubsection{Linear system representation and modal analysis}

PAT utilizes the built-in capability of Simulink to retrieve the state space representation of a MDL-case file. The linearization process is based on the perturbation method as given in the following. Starting with the system in the general form of

$$
\begin{aligned}
& \dot{x}=f(x, u) \\
& y=g(x, u)
\end{aligned}
$$

where $x$ is the state vector, $u$ the input vector, and $y$ the vector of outputs, the linear system at the chosen operating conditions $x_{0}$ and $u_{0}$ and described by

$$
\begin{aligned}
& \Delta \dot{x}=A \Delta x+B \Delta u \\
& \Delta y=C \Delta x+D \Delta u
\end{aligned}
$$

is sought. The symbol $\Delta$ denotes the deviation from the equilibrium point. The matrices are determined by perturbing each state $x_{i}$ and input $u_{i}$ separately by a small amount (of order $10^{-5}$ ) and using

$$
\begin{array}{ll}
A^{i}=\frac{\dot{x}-\dot{x_{0}}}{\Delta x_{i}} & B^{i}=\frac{\dot{x}-\dot{x_{0}}}{\Delta u_{i}} \\
C^{i}=\frac{y-y_{0}}{\Delta x_{i}} & D^{i}=\frac{y-y_{0}}{\Delta u_{i}}
\end{array}
$$

where the matrix index refers to the elements in the $\mathrm{i}^{\text {th }}$ column. 
The toolbox provides a high-level function as convenient interface to the linearization process, finds the reduced power system model by replacing the absolute machine angle states by relative ones, and computes data of interest. The information computed is stored in structure format in MATLAB's workspace. Additionally, the sparsity structure of the system matrix, an eigenvalue plot, and the pole-zero map of the system can be displayed.

An additional high-level function for modal analysis is provided with PAT. It computes controllability, observability, residues, and the frequency and damping of modes and performs a coherency analysis based on speed participation. Results are stored in structure format in the workspace as well as in files.

\subsubsection{Example}

A small example is given here to demonstrate the analysis of a power system using PAT. The power system chosen is the Three machine nine bus system (see Fig. 3.6a), a simplified version of the WSCC system. The system is well documented in the literature, where further details can be found [2]. The main purpose is to present step by step the computations performed and results typically obtained. A graphical presentation of the analysis performed and the interplay of the functions provided are shown in Fig. 3.7.

Step 1 - Load flow: Using the prepared data file as input for the load flow and initialization function the steady-state computations are performed. The data file and the load flow solution are given in appendix $\mathrm{B}$. At this point the necessary information for the time domain analysis has been determined and the next step can follow.

Step 2 - Transient analysis: The second step requires building of the MDL-case file using PAT's block library as shown in Fig. 3.6 b. Results of the transient study of a $83 \mathrm{~ms}$ threephase fault on line 7-5 are shown in Fig. 3.8 and 3.9. The fault excites undamped swings in the synchronous machines that change magnitude, mean, and frequency after reclosing. Whereas the relative angles remain limited, the generator speeds increase indefinitely. From the speed plot it can be seen that generator 2 and 3 form a coherent group swinging against generator 1. The voltage plots underline the system's instability. The plots reveal that Simulink's ODE solver correctly detected the switching times (fault on and clearing time) as shown in Fig. $3.9 \mathrm{~b}$ using its zero-crossing detection algorithms. The simulation of 10 seconds using ODE15s with a maximum time step of $10 \mathrm{~ms}$ requires about $550 \mathrm{~ms}$ (Pentium IV, $512 \mathrm{MB}$ RAM, $1.7 \mathrm{MHz}$, MATLAB/Simulink R12.1, Win2000). 


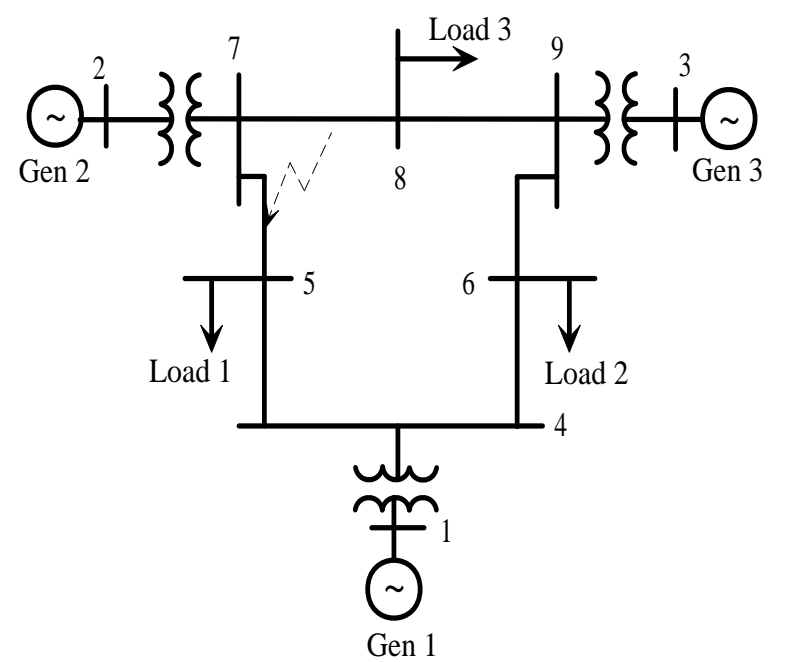

(a) Single-line diagram

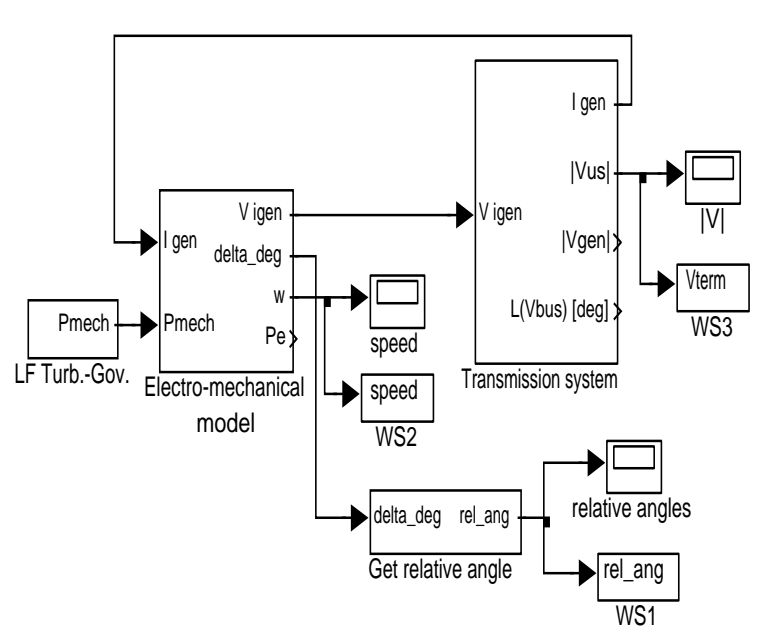

(b) Simulink model

Figure 3.6: Three machine nine bus example

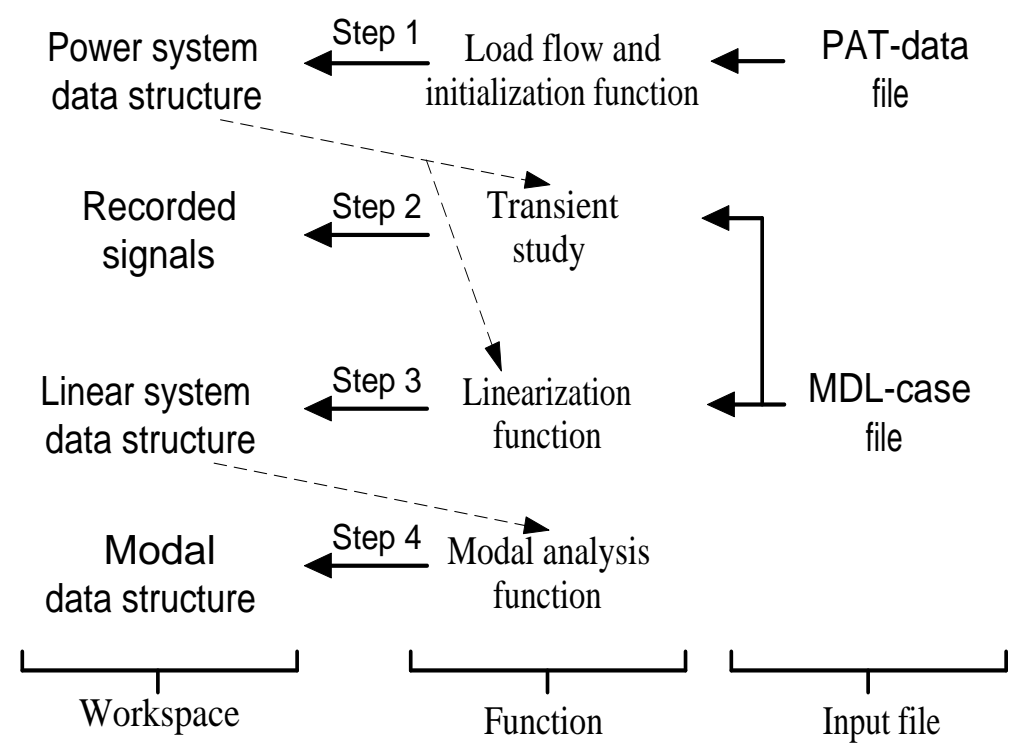

Figure 3.7: Analyzing power systems with PAT 


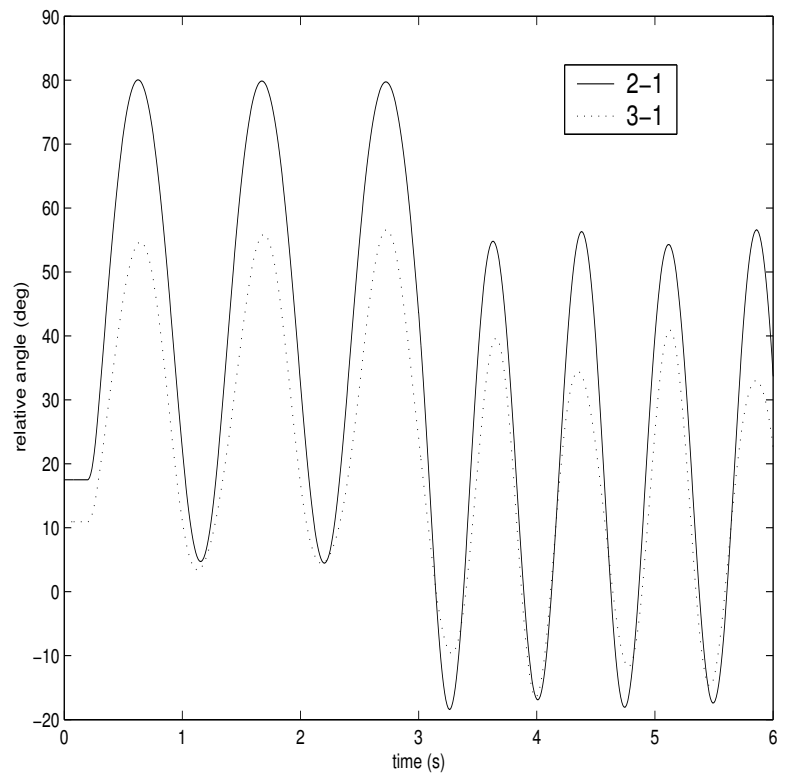

(a) Relative angles

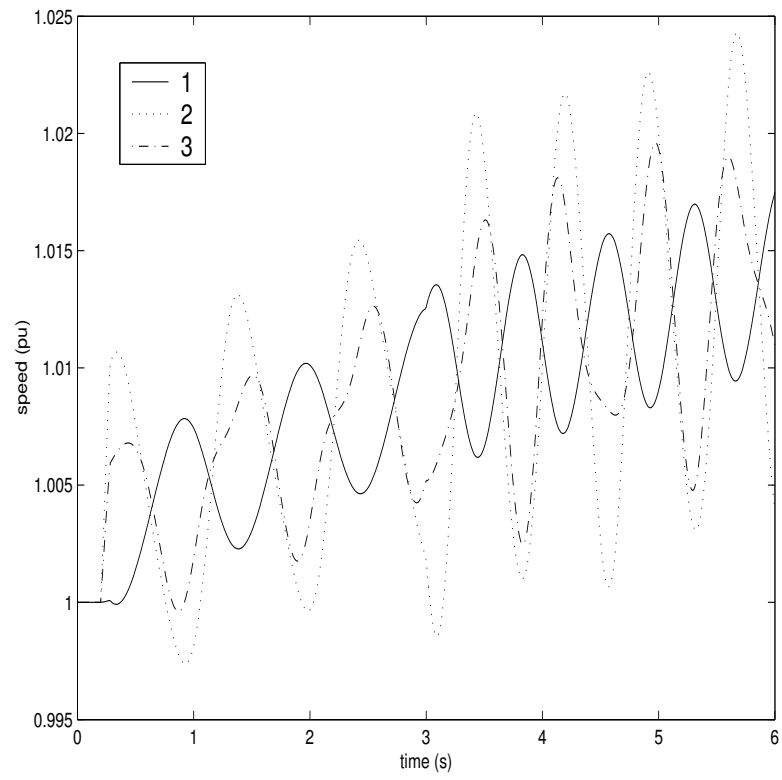

(b) Speed

Figure 3.8: Three machine nine bus example: State response

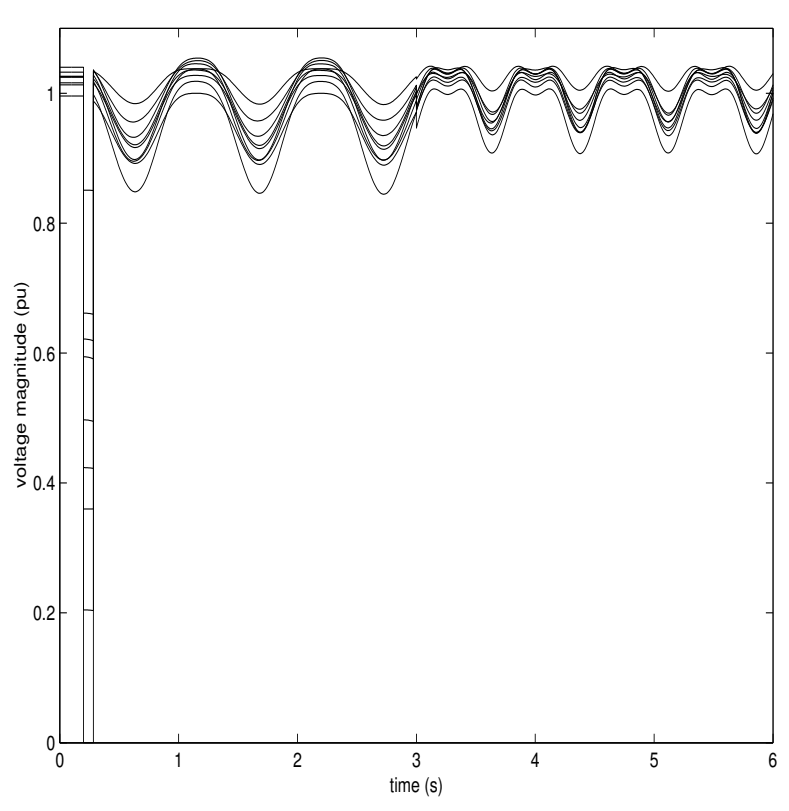

(a) $t=0-6 \mathrm{~s}$

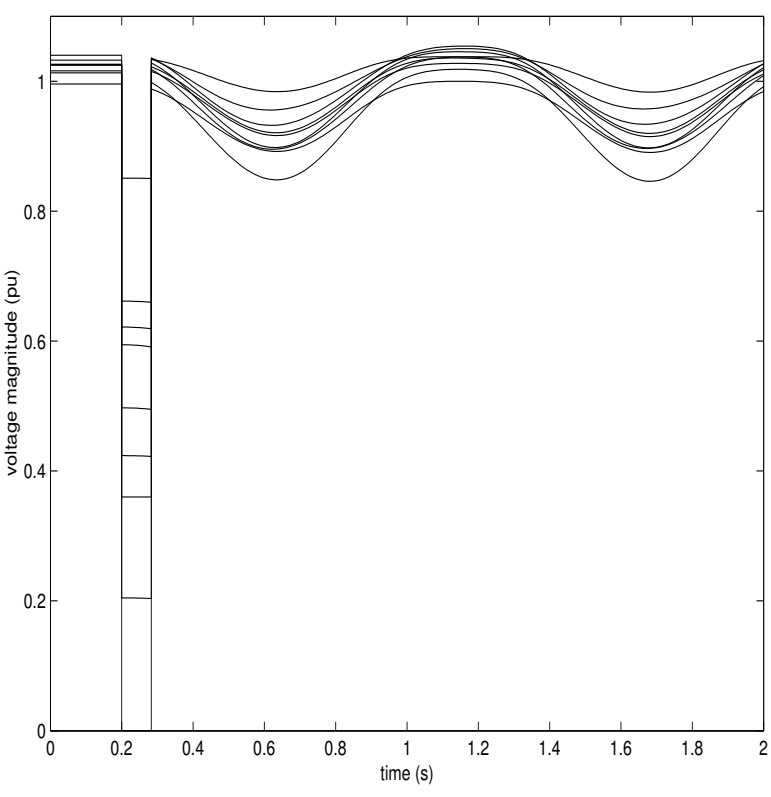

(b) Fault event and first swings

Figure 3.9: Three machine nine bus example: Bus voltages 
Table 3.1: Three machine nine bus example: Modal analysis

(a) Eigenvalues and residues

\begin{tabular}{|c||c|c|c|}
\hline Number & pre/post & faulted & residues \\
\hline \hline 1 & $\mathrm{j} 13.3614$ & $\mathrm{j} 13.4345$ & 0.0001 \\
\hline 2 & $-\mathrm{j} 13.3614$ & $-\mathrm{j} 13.4345$ & 0.0001 \\
\hline 3 & $\mathrm{j} 8.7006$ & $\mathrm{j} 6.7732$ & 0.0032 \\
\hline 4 & $-\mathrm{j} 8.7006$ & $-\mathrm{j} 6.7732$ & 0.0032 \\
\hline 5 & 0 & 0 & 0.0147 \\
\hline
\end{tabular}

(b) States

\begin{tabular}{|c||c|}
\hline Number & States \\
\hline \hline 1 & angle 2-1 \\
\hline 2 & angle 3-1 \\
\hline 3 & speed 1 \\
\hline 4 & speed 2 \\
\hline 5 & speed 3 \\
\hline
\end{tabular}

Table 3.2: System matrix of the WSCC example

$$
\mathbf{A}=\left(\begin{array}{ccccc}
0 & 0 & -376.991 & 376.9911 & 0 \\
0 & 0 & -376.991 & 0 & 376.9911 \\
0.036 & 0.0283 & 0 & 0 & 0 \\
-0.206 & 0.088 & 0 & 0 & 0 \\
0.1957 & -0.4041 & 0 & 0 & 0
\end{array}\right)
$$

Step 3 - Linearization: By invoking the linearization function the state space representation is obtained. Eigenvalues and a list of states are given in Table 3.1. The system matrix is given in Table 3.2. It takes the data structure as one of its input arguments and returns results and additional information in structure format. The eigenvalues have very small real parts due to the neglected damping coefficients. Also, the system has been reduced to the actual number of independent states. Analyzing eigenvalues and time domain signals, it can be seen that the lower frequency mode of about $1 \mathrm{~Hz}$ together with the zero pole dominate in both cases as suggested by the residues. Also, the periods of the swings of the faulted and reclosed line cases agree with the $1.08 \mathrm{~Hz}$ and $1.38 \mathrm{~Hz}$ mode $(6.77 \mathrm{rad} / \mathrm{s}$ and $8.70 \mathrm{rad} / \mathrm{s})$.

Step 4 - Modal analysis: Output produced by the modal analysis function for the $1 \mathrm{~Hz}$ mode is given in Table 3.3. The scaled compass plot for the speed participations is shown in Fig. 3.10. It can be seen that machines 2 and 3 swing against machine 1, which agrees with the result of the time domain analysis. 


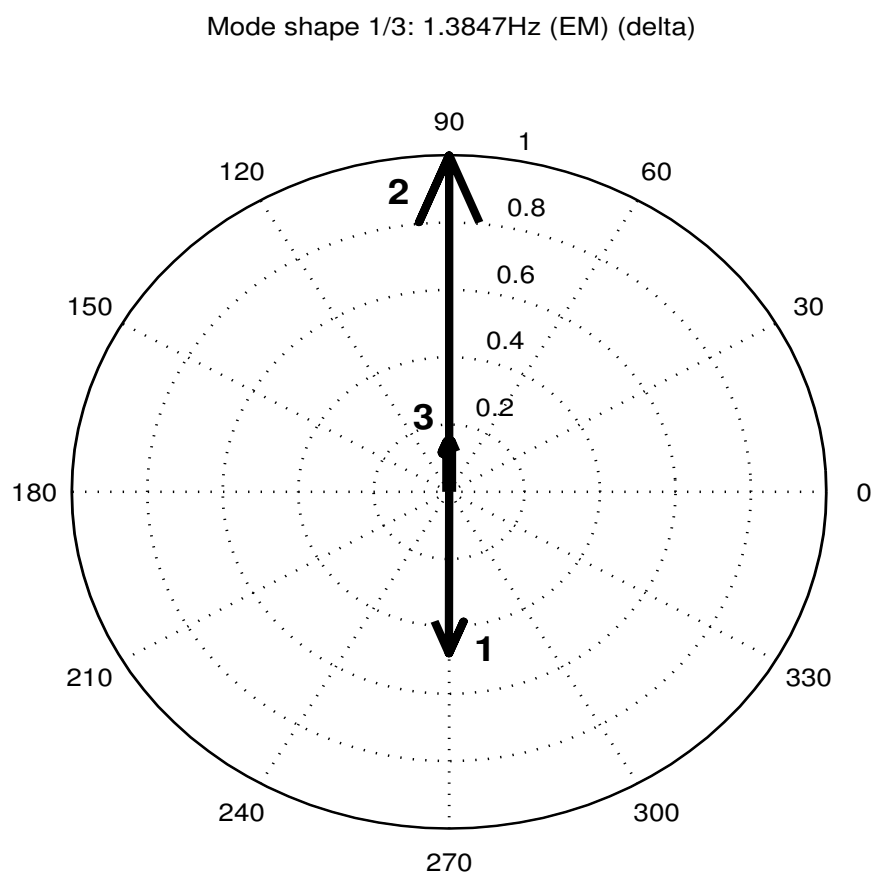

Figure 3.10: Three machine nine bus example: Compass plot of speed participation

Table 3.3: Modal group analysis of the WSCC example System: $\begin{array}{r}\mathrm{A}=[5 \mathrm{x} 5], \mathrm{B}=[5 \times 0] \\ \mathrm{C}=[0 \times 5], \mathrm{D}=[0 \times 5] \\ \text { Found } 3 \text { machines. }\end{array}$

Found 1 low frequency mode(s) in the range of $0.50-2.00 \mathrm{~Hz}$. 1: Mode 3, $1.3847 \mathrm{~Hz} / 8.7006 \mathrm{rad} / \mathrm{d}=-0.00000,(\mathrm{EM})$ (delta)

Analyzing groups ... 1: Mode 3, $1.3847 \mathrm{~Hz} / 8.7006 \mathrm{rad}, \mathrm{d}=-0.00000(\mathrm{EM})$ (delta) Group 1: 1 Group 2: 32 Wrote mode groups into file (ModGroup.txt). 


\subsection{Modeling of FACTS devices}

This chapter presents the various FACTS models implemented for load flow and transient stability studies. The power system and its models are represented by a single-phase equivalent of a 3-phase balanced power system assuming that only the fundamental frequency components of currents and voltages are of importance and, therefore, any harmonics will be ignored. This is common practice for stability studies and simplifies the modeling and computational complexity. However, it still allows to find models that are detailed enough and suitable for transient stability analysis.

\subsubsection{Unified Power Flow Controller (UPFC)}

The UPFC can be used not only to control voltage levels and flow of active and reactive power on transmission lines to allow for their secure loading but also to improve and maintain the stability of electric power systems. Power flow on the line can be affected by either changing the impedance of the line, the voltage magnitudes, or the angles at the terminals of the line. Until recently all of these parameters were controlled separately. However, the UPFC allows simultaneous or sequential control of these parameters with real time transfer from one control scheme to another [3], [5], and [82].

The objective of this chapter is to incorporate the UPFC steady-state and dynamic models and its basic controls in PAT's simulation environment. Later the UPFC will be used to enhance operation and control of electric power systems.

\section{Basic operation}

The UPFC is a device placed between two buses - the sending bus and the receiving bus as shown in Fig. 3.11 27, [89]. The UPFC consists of two voltage-source converters (VSCs) with a common DC link. For the fundamental frequency model the VSCs are replaced by two controlled voltage sources. The voltage source at the sending bus is connected in shunt and will therefore be called the shunt voltage source. The second source, the series voltage source, is placed between the sending and the receiving buses. Both voltage sources are connected to the power system through appropriate transformers. The series converter injects an AC voltage of controllable magnitude ${ }^{2}$ and phase angle in series with the transmission line. The main function of the UPFC shunt converter is to supply or absorb the active power demanded by the series converter at the

\footnotetext{
${ }^{2}$ The term magnitude refers to the root-mean-square value.
} 


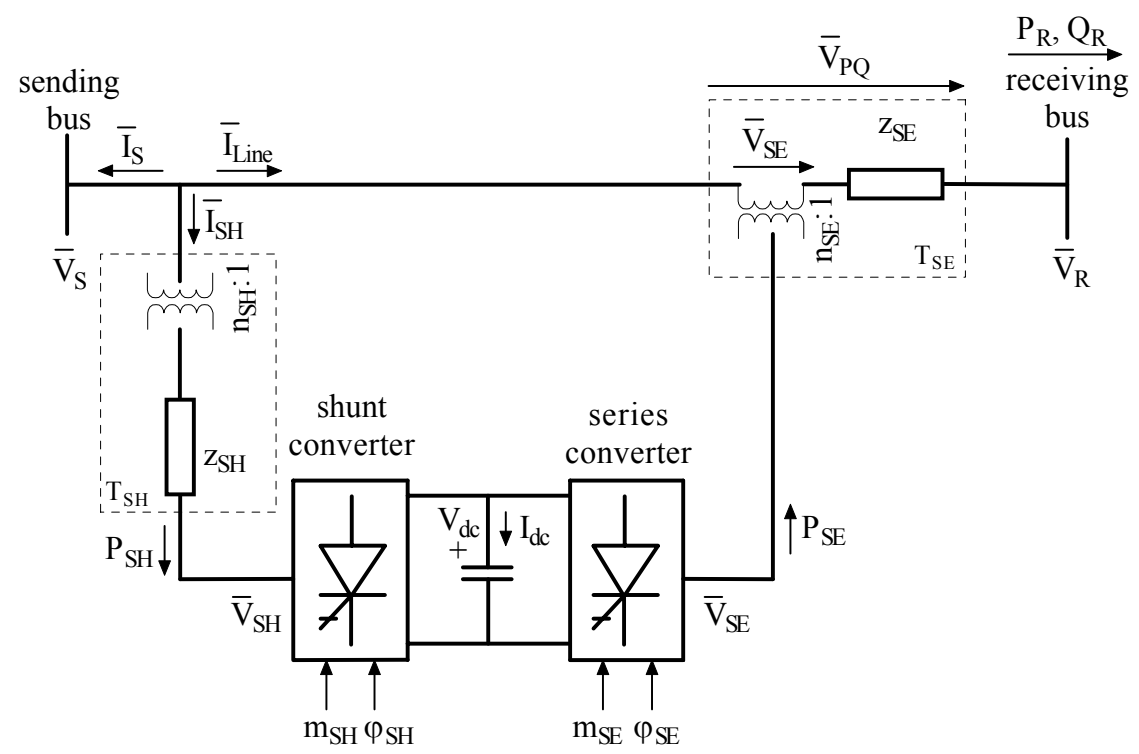

Figure 3.11: UPFC fundamental frequency model

common DC link. This arrangement allows free flow of active power in either direction between the AC terminals. There cannot be reactive power flow through the DC link - the reactive power is exchanged (absorbed or generated) locally by each converter.

\section{Load flow model and algorithm}

The UPFC as part of a power system and its general representation for LF computations is shown in Fig. 3.12, Power injections at the sending and receiving buses combined with an impedance linking the two buses are used as equivalent. This is known as the injection model [62, [66]. The correct values for the power injections and the presence and value of the linking impedance depend on the chosen control scheme. Each of the schemes requires the implementation of a different algorithm as discussed in the following. Common to all is that the steady-state operation of a UPFC is characterized by a constant DC link voltage. In order to keep the capacitor voltage at a specified level a zero net power interaction of the UPFC with the power system has to be ensured. This requirement holds true when the active power supplied by the shunt converter $P_{S H}=$ $\operatorname{Re}\left(\bar{V}_{S H} \bar{I}_{S H}^{*}\right)$ satisfies the active power demanded by the series converter $P_{S E}=\operatorname{Re}\left(\bar{V}_{S E} \bar{I}_{\text {Line }}^{*}\right)$

$$
P_{S H}=P_{S E}
$$

The following discusses the algorithms as implemented in PAT, followed by a summary of computations of UPFC quantities common to all schemes. 

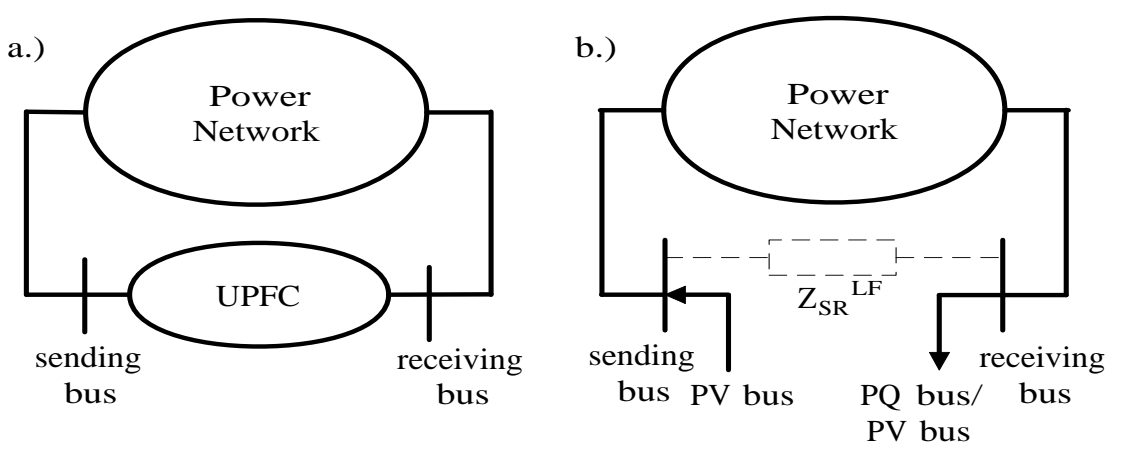

Figure 3.12: UPFC load flow model: (a) Schematic (b) Load flow representation

\section{- Scheme 1: V-PQ control}

This scheme assumes that the UPFC is operated to control the sending bus voltage magnitude and to keep the active and reactive power flow on the transmission line at the receiving bus at specified values. The following choices have been made: No linking impedance, receiving bus modeled as load bus (PQ-type) with the desired PQ-flow as negative load, and the sending bus modeled as generator bus (PV-type). The last choice means that the required reactive generation at the sending bus will be determined as for any generator in the power system. The active part can be directly set to the desired active power flow value in case of a lossless UPFC. Special care has to be taken only in case of considering losse $3^{3}$ by computing the actual occurring losses at the current LF conditions and adding them to the sending bus.

\section{- Scheme 2: V-PV control}

In this scheme the UPFC is operated to control the sending and receiving bus voltage magnitudes and at the same time keeps the active power flow on the transmission line constant. The following has been done to add the scheme to the Newton-Raphson LFprocedure: No linking impedance, receiving bus modeled as generator bus (PV-type) with the desired active power flow modeled as positive generation, and the sending bus modeled as generator bus (PV-type). The required reactive generation at each bus is determined as for any generator in the power system by the usual LF algorithm. The active power injection is determined as in the previous scheme.

\footnotetext{
${ }^{3}$ Losses may include transformer, converter, and DC-link losses. So far, PAT takes only transformer losses into account.
} 


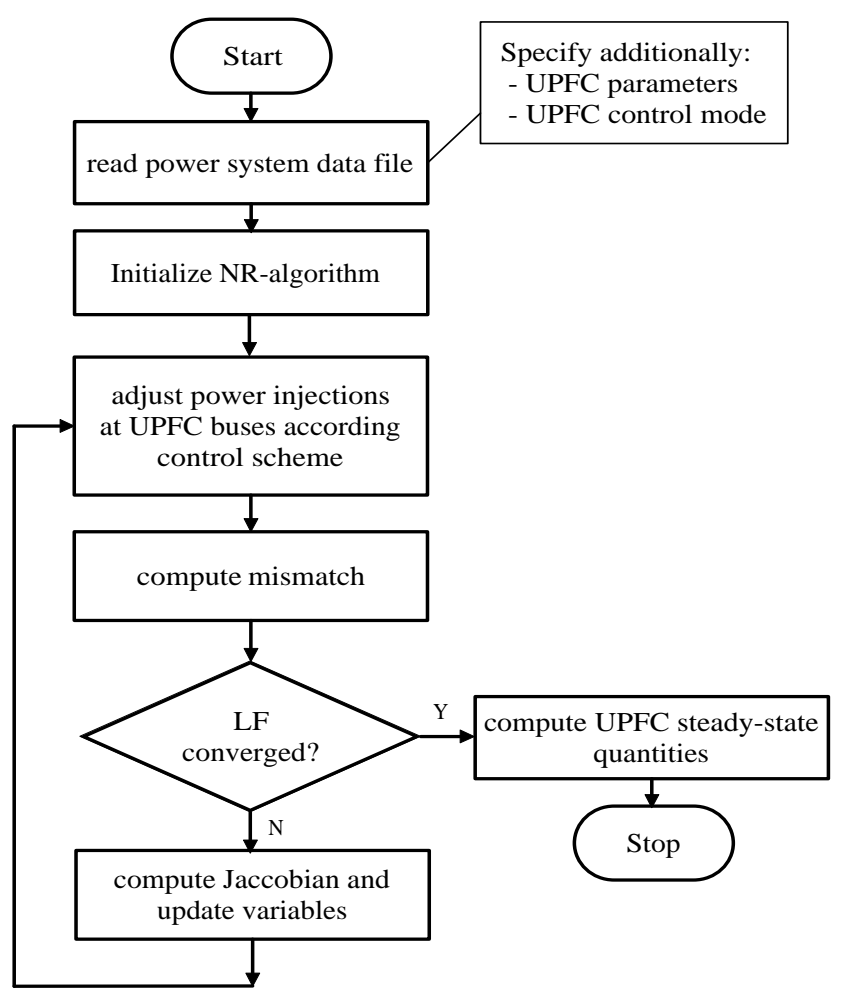

Figure 3.13: UPFC load flow algorithm

\section{- Scheme 3: V-V $\mathrm{V}_{S E}$ control}

In this scheme the UPFC is operated to control the sending bus voltage magnitude and injects a specified (relative) series voltage. This requires the adjustment of active power injection at both buses and the reactive injection at the receiving bus. No linking impedance is used.

\section{- Scheme 4: V-Inactive}

In this scheme the UPFC is operated to control the sending bus voltage magnitude and with inactive series converter. This can be achieved by using a small impedance value linking the buses. No extra computations have to be performed.

The general LF algorithm is given in Fig. 3.13, It shows that the conventional NR-LF steps have to be extended by the required adjustments in injections before computing the actual power mismatch. Also, all of the above control schemes allow set limits for the reactive power injections of the shunt converter including the special case of no voltage control (limit set to zero). 
Common mathematical relationships for the UPFC LF computations are

$$
\begin{aligned}
\bar{I}_{\text {Line }} & =\left(\frac{P_{R}+j Q_{R}}{\bar{V}_{R}}\right)^{*} \\
\bar{V}_{Z_{S E}} & =Z_{S E} \bar{I}_{\text {Line }} \\
\bar{V}_{S E} & =\bar{V}_{R}+\bar{V}_{Z_{S E}}-\bar{V}_{S} \\
\bar{S}_{S E} & =\bar{V}_{S E} \bar{I}_{\text {Line }}^{*} \\
\bar{I}_{S} & =\left(\bar{S}_{S}\right)^{*} \\
\bar{V}_{S} & \\
\bar{I}_{S H} & =-\bar{I}_{S}-\bar{I}_{\text {Line }} \\
\bar{V}_{Z_{S H}} & =Z_{S H} \bar{I}_{S H} \\
\bar{V}_{S H} & =\bar{V}_{S}-\bar{V}_{Z_{S H}} \\
\bar{S}_{S H} & =\bar{V}_{S H} \bar{I}_{S H}^{*}
\end{aligned}
$$

where $P_{R}$ and $Q_{R}$ are the active and reactive line power flow measured at the receiving bus, $\bar{I}_{\text {Line }}$ is the line current, $\bar{V}_{Z_{S E}}$ is the voltage drop due to the series transformer, $\bar{V}_{S E}$ is the injected series voltage, $\bar{S}_{S E}$ is the injected power of the series voltage source, $\bar{S}_{S}$ is the power flow at the sending bus, $\bar{I}_{S}$ is the current at the sending bus, $\bar{I}_{S H}$ is the current into the shunt voltage source, $\bar{V}_{Z_{S H}}$ is the voltage drop due to the shunt transformer, $\bar{V}_{S H}$ is the injected shunt voltage, and $\bar{S}_{S H}$ is the power consumption of the shunt source (see Fig. 3.11 for a graphical representation of the electrical quantities).

\section{Dynamic model}

For transient stability studies the DC link dynamics have to be taken into account and (3.4) can no longer be applied. The DC link capacitor will exchange energy with the system and its voltage will vary. The power frequency dynamic model as given in [62], [89], and [42] has been implemented. The following equation describes this model:

$$
C V_{D C} \frac{d V_{D C}}{d t}=\left(P_{S H}-P_{S E}\right) S_{B}
$$




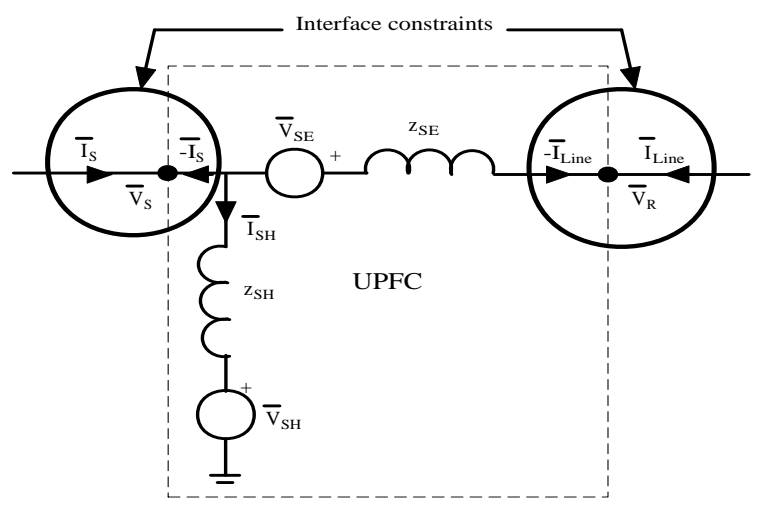

Figure 3.14: UPFC interface model

The relationships between the inverter DC and AC side are obtained by applying the Pulse Width Modulation ${ }^{4}$ (PWM) technique [60] to the two GTO-based VSCs:

$$
\begin{gathered}
\bar{V}_{S H}=V_{S H} \angle \delta_{S H}=m_{S H} \frac{V_{D C}}{2 \sqrt{2} n_{S H} V_{B}} \angle\left(\delta_{S}-\varphi_{S H}\right) \\
\bar{V}_{S E}=V_{S E} \angle \delta_{S E}=m_{S E} \frac{V_{D C}}{2 \sqrt{2} n_{S E} V_{B}} \angle\left(\delta_{S}-\varphi_{S E}\right) .
\end{gathered}
$$

Note that in the above equations the $\mathrm{DC}$ variables are expressed in mksA units while the $\mathrm{AC}$ system variables are expressed as per unit quantities. The system side base values $S_{B}$ and $V_{B}$ are selected as base power and base voltage and all $\mathrm{AC}$ variables are normalized using these base quantities.

\section{Interfacing}

The UPFC model as shown in Fig. 3.14 is used during time domain studies 62], 66]. The network solution has to be found through an iterative approach at every time instant. This is achieved by equating the external and internal ac-network relationships for the UPFC terminal currents $\bar{I}_{B}=\left[\bar{I}_{S} \bar{I}_{\text {Line }}\right]^{T}$. UPFC sending and receiving bus voltages, $\bar{V}_{S}$ and $\bar{V}_{R}$, can then be expressed as a function of generator internal voltages, $\bar{E}_{G}$, and the converter injection voltages, $\bar{V}_{S H}$ and $\bar{V}_{S E}$, by using the relationships for the currents

$$
\begin{aligned}
\bar{I}_{B} & =Y_{B G} \bar{E}_{G}+Y_{B B} \bar{V}_{B} \\
-\bar{I}_{B} & =Y_{B} \bar{V}_{B}+Y_{C} \bar{V}_{C}
\end{aligned}
$$

\footnotetext{
${ }^{4}$ The UPFC at the Inez/AEP substation uses 48 valves in 12 three-level pole converters and appropriate switching logic to avoid switching losses associated with PWM. Also, the high number of valves generates almost sinusoidal voltages making filters unnecessary 32. The control scheme at a higher level can nevertheless be treated similar to the PWM scheme.
} 
resulting in

$$
\bar{V}_{B}=L_{G} \bar{E}_{G}+L_{C} \bar{V}_{C}
$$

where

$$
\begin{aligned}
L_{G} & =\left(Y_{B}-Y_{B B}\right)^{-1} Y_{B G} \\
L_{C} & =-\left(Y_{B}-Y_{B B}\right)^{-1} Y_{C} \\
\bar{V}_{B} & =\left[\begin{array}{l}
\bar{V}_{S} \\
\bar{V}_{R}
\end{array}\right] \quad Y_{B}=\left[\begin{array}{cc}
-\frac{1}{Z_{S H}}-\frac{1}{Z_{S E}} & \frac{1}{Z_{S E}} \\
\frac{1}{Z_{S E}} & -\frac{1}{Z_{S E}}
\end{array}\right] \\
\bar{V}_{C} & =\left[\begin{array}{l}
\bar{V}_{S H} \\
\bar{V}_{S E}
\end{array}\right] \quad Y_{C}=\left[\begin{array}{cc}
\frac{1}{Z_{S H}} & -\frac{1}{Z_{S E}} \\
0 & \frac{1}{Z_{S E}}
\end{array}\right]
\end{aligned}
$$

- $Y_{B B}$ is the admittance matrix connecting currents to the voltages at the buses,

- $Y_{B G}$ is the admittance matrix which gives currents in terms of generator internal voltages,

- $Y_{B}$ is the internal admittance matrix which gives currents in terms of bus voltages, and

- $Y_{C}$ is the internal admittance matrix which gives currents in terms of injected (controlled) voltages.

Control output for modulation indices and firing angles combined with (3.7) determine the UPFC injection voltage magnitudes $V_{S H}$ and $V_{S E}$. However, the phase angles of the injected voltages, $\delta_{S H}$ and $\delta_{S E}$, are unknown since they depend on the phase angle of the sending bus voltage, $\delta_{S}$, which is the result of the network solution. The algorithm chosen to determine the voltages is a fixed-point method and solves (3.8) using functional iterations as long as two consecutive solutions deviate from each other for more than a chosen limit. 5 In each of these steps the absolute angles of the injected voltages are updated and again used in (3.8) to find better approximations of the true terminal voltages. This type of interfacing algorithm has been successfully applied to FACTS devices and has shown good convergence characteristics [42]. But, as for any iterative procedure, convergence can not be guaranteed and the algorithm may fail to find new terminal voltages leading to simulation termination. The algorithm for interfacing the UPFC with the power network is shown in Fig. 3.15. The expression FACTS has been used rather than UPFC to keep the algorithm in a general form. It will serve as an interfacing procedure for other voltage-source converter based FACTS devices.

\footnotetext{
${ }^{5}$ Limit chosen is of order $10^{-9}$.
} 


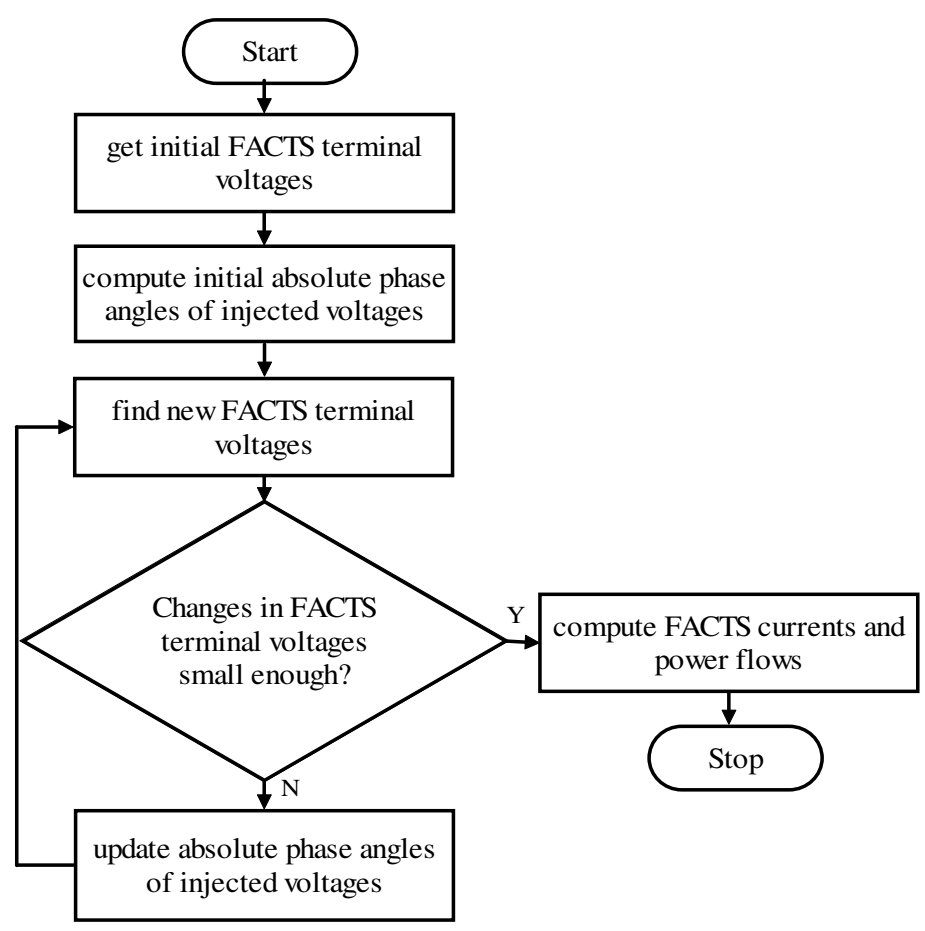

Figure 3.15: Algorithm for interfacing VSC-based FACTS devices with the power network

\section{Basic control design - (almost) decoupled control scheme}

To operate the UPFC in the automatic control modes the UPFC basic control design needs to be performed. This design involves simultaneous regulation of (i) real and reactive power flows on the transmission line or real power flow and receiving bus voltage magnitude, (ii) sending bus voltage magnitude, and (iii) DC voltage. In total it consists of four separate control loops grouped into series and shunt control scheme. Each of the schemes controls two tasks as described next.

Series Control Scheme: This scheme has two control loops, the first for tracking of the real power flow at the receiving bus of the line, and the second for tracking the reactive power flow or the receiving bus voltage magnitude. The objective is to track these quantities following step changes and to eliminate steady-state tracking errors. This is obtained by the appropriate adjustment of the voltage drop between the sending and the receiving bus, which is denoted as $\bar{V}_{P Q}$. The voltage can be decomposed into the following two quantities which affect the tracked power flows:

- $V_{P}=$ voltage component orthogonal to the sending bus voltage (it affects primarily the real power flow on the transmission line), and 


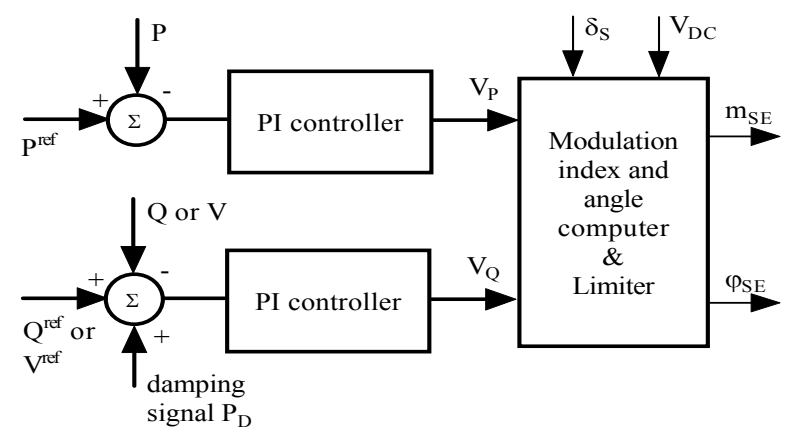

(a) Block diagram

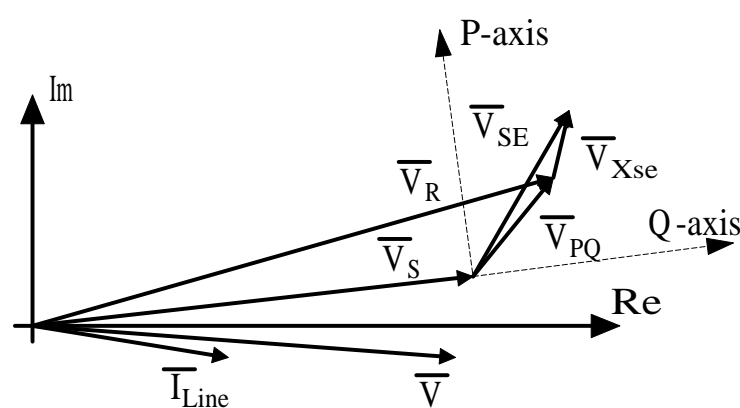

(b) Phasor diagram

Figure 3.16: UPFC series control

- $V_{Q}=$ component in phase with the sending bus voltage (it affects mainly the reactive power flow on the transmission line).

Both voltage components, $V_{P}$ and $V_{Q}$, are obtained by designing PI (proportional-integral) controllers to guarantee error free steady-state control (Fig. 3.16a, [32]). The corresponding phasor diagram is shown in Fig. 3.16 b. Additionally, the two components are limited in order to keep the magnitude of the voltage $\bar{V}_{P Q}$ and line current within ratings. The limited components $V_{P L}$ and $V_{Q L}$ are used to compute the actual injected series voltage:

$$
\begin{aligned}
\bar{V}_{P Q} & =V_{P Q} \angle\left(\phi_{P Q}+\delta_{S}\right) \\
V_{P Q} & =\sqrt{V_{P L}^{2}+V_{Q L}^{2}} \\
\phi_{P Q} & =\tan ^{-1} \frac{V_{P L}}{V_{Q L}} \\
\bar{V}_{S E} & =\bar{V}_{P Q}+\bar{V}_{X_{S E}}
\end{aligned}
$$

where $\delta_{S}$ is the angle of the sending bus voltage, and $\bar{V}_{X_{S E}}$ is the voltage drop across the series transformer reactance.

The influence of changes in one of the control components on the other is small whenever the difference of the sending bus voltage angle $\left(\delta_{S}\right)$ and the remote bus voltage angle of the line connected to the receiving bus $(\delta)$ obeys $\left|\delta_{S}-\delta\right| \ll 90^{\circ}$. Nevertheless, a small disturbance is noticeable because of the interaction with the transmission system. Therefore, the control scheme is only almost decoupled resulting in a short transient period where the change in one control variable will be accompanied by an adjustment in the other.

Shunt control scheme: The second part of the UPFC basic control design deals with the control of the sending bus voltage and the DC link voltage. This is achieved by using two separate 


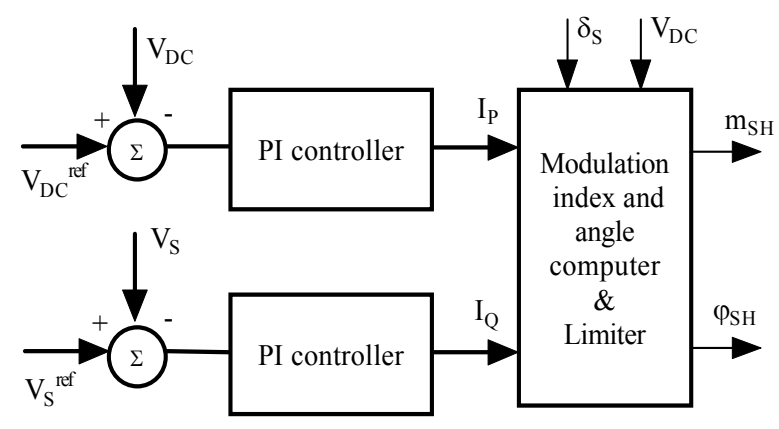

(a) Block diagram

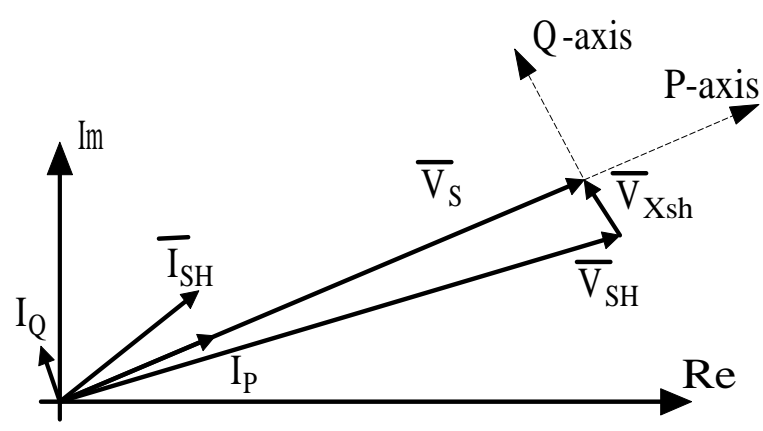

(b) Phasor diagram

Figure 3.17: UPFC shunt control

PI-controllers as shown in Fig. 3.17 [32]. Changing the current component orthogonal to the voltage will affect the reactive power flow in the shunt branch, which in turn will affect the sending bus voltage magnitude (Fig. 3.17b). Adjusting the current component in phase with the voltage will mainly influence the real power flow in the shunt branch. The controller outputs are fed to a limiter in order to keep injected shunt voltage magnitude and converter current within specified limits $\left(V_{S H_{M A X}}\right.$ and $\left.I_{S H_{M A X}}\right)$ [76]. The limited components $I_{P L}$ and $I_{Q L}$ are used to compute the injected shunt voltage

$$
\begin{aligned}
I_{S H} & =\left|I_{P L}+j I_{Q L}\right| \\
\delta_{I_{S H}} & =\delta_{S}+\tan ^{-1}\left(\frac{I_{Q L}}{I_{P L}}\right) \\
\bar{V}_{S H} & =\bar{V}_{S}-\bar{V}_{X_{S H}}
\end{aligned}
$$

where $\bar{V}_{X_{S H}}$ is the voltage drop across the shunt transformer reactance.

\subsubsection{GTO Back-To-Back HVDC link (BTBL)}

A typical arrangement for a BTBL as found in [6] is the following: The system-circuit configuration consists of two high-voltage terminals. Each terminal is based on four self-commutated converters. The windings on the AC-system side of the converter transformers are connected in series. On the DC side, the four converters are connected in parallel and a shunt capacitor is placed between the two terminal DC link. The capacitor joining the two converters smoothes DC-link voltage variations. PWM at a switching frequency of $540 \mathrm{~Hz}$ for a $60 \mathrm{~Hz}$ system (nine times the fundamental frequency) is used for converter firing control. Due to the increased pulse number (nine) the harmonic content is reduced and improved steady-state and dynamic perfor- 


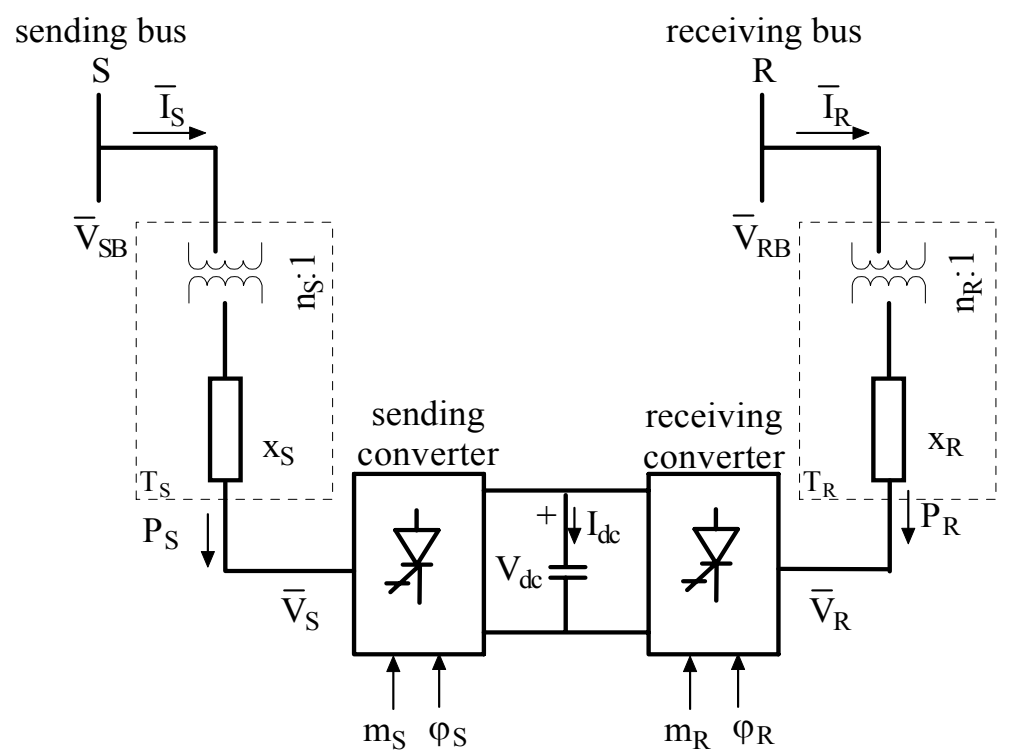

Figure 3.18: BTBL fundamental frequency model

mance of the converters is achieved. At both terminals active and reactive power can be controlled independently of each other.

The BTBL model as implemented here is based on this basic concept. The model will include coupling transformers, HVDC-link capacitor, and utilize a PWM firing scheme. Again, due to the high switching frequency assumed only the fundamental frequency components of currents and voltages are of importance and, therefore, any harmonics will be ignored.

\section{Basic operation}

The BTBL is a device placed between two buses referred to as the BTBL sending bus and the BTBL receiving bus. It consists of two VSCs with a common DC link as shown in Fig. 3.18 For the fundamental frequency model, the VSCs are replaced by two shunt connected controlled voltage sources and transformers.

Applying PWM technique to the two VSCs the following equations for the injected voltage magnitudes for the sending and receiving converters are obtained:

$$
\begin{aligned}
V_{S} & =m_{S} \frac{V_{D C}}{2 \sqrt{2} n_{S} V_{B}} \\
V_{R} & =m_{R} \frac{V_{D C}}{2 \sqrt{2} n_{R} V_{B}}
\end{aligned}
$$

where $m_{S}$ is the amplitude modulation index of the sending VSC, $m_{R}$ the amplitude modulation 
index of the receiving VSC, $n_{S}$ the sending transformer turn ratio, $n_{R}$ the receiving transformer turn ratio, $V_{B}$ the system side base voltage in $\mathrm{kV}$, and $V_{D C}$ the $\mathrm{DC}$ link voltage in $\mathrm{kV}$.

The phase angles of $\bar{V}_{S}$ and $\bar{V}_{R}$ are:

$$
\begin{aligned}
& \delta_{S}=\delta_{S B}-\varphi_{S} \\
& \delta_{R}=\delta_{S B}-\varphi_{R}
\end{aligned}
$$

where:

- $\varphi_{S}$ - firing angle of the sending VSC with respect to the phase angle of the sending bus voltage $\left(\delta_{S B}\right)$

- $\varphi_{R}$ - firing angle of the receiving VSC with respect to the phase angle of the sending bus voltage $\left(\delta_{S B}\right)$

The voltage magnitudes, $V_{S}$ and $V_{R}$, and their firing angles, $\varphi_{S}$ and $\varphi_{R}$, with respect to the sending bus, are controllable in the range of $V_{S, R}^{\min } \leq V_{S, R} \leq V_{S, R}^{\max }$ and $\phi_{\min } \leq \varphi_{S, R} \leq \phi_{\max }$, where the voltage limits are usually set to $\pm 10 \%$ of the nominal voltage level and the angle limits result from converter ratings. The sending converter injects a controllable voltage such that the real component of the current in the sending branch balances the real power demanded by the receiving converter. The real power can flow in either direction between the AC terminals. On the other hand the reactive power cannot flow through the DC link. It is exchanged (absorbed or generated) locally by each converter. The sending converter operated to exchange the reactive power with the AC system provides the possibility of independent shunt compensation for the line. If the injected voltages are regulated to produce reactive current components that will keep the bus voltages at their specified values, then the converters are operated in the Automatic Voltage Control Mode. Another possibility would be to operate the VSCs in the Automatic VAR Mode by controlling reactive currents to meet the desired inductive or capacitive VAR request. The receiving converter will be operated to keep the real power flow at its terminal at a specified value.

\section{Load flow model and algorithm}

The BTBL is assumed to be operated to control the real power flow at the receiving bus and both bus voltage magnitudes. A power system with BTBL as shown in Fig. 3.19a allows the representation by equivalent power injections as given in Fig. 3.19 b. The sending and receiving 

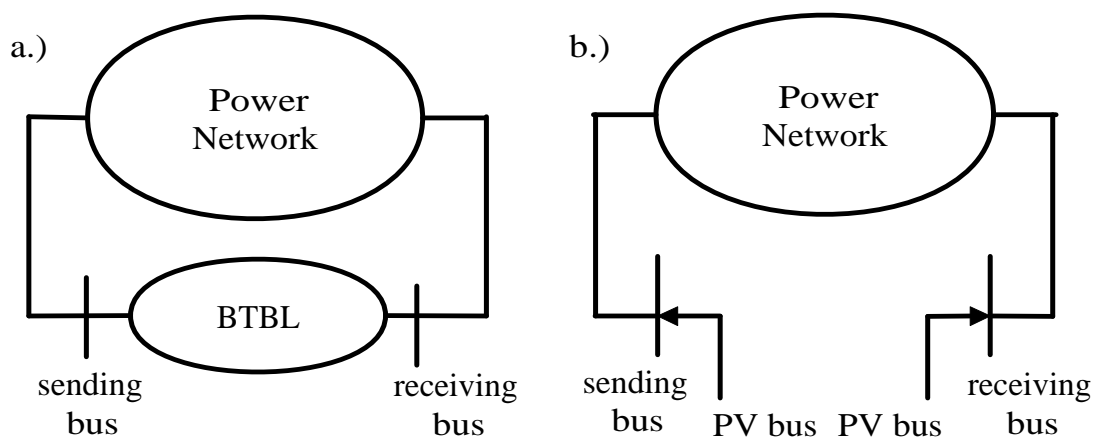

Figure 3.19: BTBL load flow model: (a) Schematic (b) Load flow representation

bus real power injections, $P_{S B}$ and $P_{R B}$, and voltage magnitudes, $V_{S B}$ and $V_{R B}$, can be set as for any other generator bus in the power system. Necessary adjustments when considering losses are required to guarantee zero net real power interaction

$$
P_{S}=-P_{R}
$$

The computations follow the steps as given for the UPFC, and are therefore not repeated here. Steady-state quantities can be computed directly after a LF solution has been found:

$$
\begin{aligned}
\bar{I}_{R} & =-\left(\frac{\bar{S}_{R B}}{\bar{V}_{R B}}\right)^{*} \\
\bar{V}_{X_{R}} & =j X_{R} \bar{I}_{R} \\
\bar{V}_{R} & =\bar{V}_{R B}-\bar{V}_{X_{R}} \\
\bar{S}_{R} & =\bar{V}_{R} \bar{I}_{R}^{*} \\
\bar{I}_{S} & =-\left(\frac{\bar{S}_{S B}}{\bar{V}_{S B}}\right)^{*} \\
\bar{V}_{X_{S}} & =j X_{S} \bar{I}_{S} \\
\bar{V}_{S} & =\bar{V}_{S B}-\bar{V}_{X_{S}} \\
\bar{S}_{S} & =\bar{V}_{S} \bar{I}_{S}^{*}
\end{aligned}
$$

where $\bar{S}_{R B}$ is the power injected into the receiving bus, $\bar{I}_{R}$ is the receiving side current, $\bar{V}_{X_{R}}$ is the voltage drop due to the receiving transformer reactance, $\bar{V}_{R}$ is the injected receiving voltage, $\bar{S}_{R}$ is the consumed power of the receiving voltage source, $\bar{S}_{S B}$ is the power injected into the sending bus, $\bar{I}_{S}$ is the current at the sending bus, $\bar{V}_{X_{S}}$ is the voltage drop due to the sending transformer reactance, $\bar{V}_{S}$ is the injected sending voltage, and $\bar{S}_{S}$ is the power consumption of the sending source. 


\section{Dynamic model}

The dynamic model implemented is the fundamental frequency model of the arrangement as shown in Fig. 3.18. Only the capacitor voltage is considered to be a dynamic state as the BTBL will exchange energy with the system and the DC link voltage will vary during transient periods, e.g., periods caused by changes in system configuration, fault in the power system, etc. The power frequency dynamic model is given by

$$
C V_{D C} \frac{d V_{D C}}{d t}=\left(P_{S}+P_{R}\right) S_{B}
$$

where $P_{S}$ is the real power consumption of the sending VSC, $P_{R}$ the real power consumption of receiving VSC, and $C$ the DC-link capacitor. Note that in the above equation the DC variables are expressed in mksA units while the AC system variables are expressed as per unit quantities. $S_{B}$ is the system base power.

\section{Interfacing}

In order to find the network solution (bus voltages and currents) an iterative approach has to be used. The BTBL sending and receiving bus voltages $\bar{V}_{S B}$ and $\bar{V}_{R B}$ can be expressed as a function of generator internal voltages, $\bar{E}_{G}$, and the BTBL injection voltages, $\bar{V}_{S}$ and $\bar{V}_{R}$ (3.17). Control output and (3.11) determine the BTBL injection voltage magnitudes $V_{S}$ and $V_{R}$. However, the phase angles of the injected voltages, $\delta_{S}$ and $\delta_{R}$, are unknown since they depend on the phase angle of the sending bus voltage, $\delta_{S B}$, which is the result of the network solution. Therefore, the algorithm presented for interfacing FACTS devices in Fig. 3.15 can be used for interfacing the BTBL with the power system.

Equating the external ac-network relationship to compute the BTBL terminal currents with the BTBL internal relationship for its terminal currents results in the equation for the (new) terminal voltages of the BTBL (see the section on interfacing the UPFC for more details, p. 36)

$$
\bar{V}_{B}=L_{G} \bar{E}_{G}+L_{C} \bar{V}_{C}
$$


where

$$
\begin{aligned}
\bar{I}_{B} & =\left[\begin{array}{c}
\bar{I}_{S} \\
\bar{I}_{R}
\end{array}\right] \\
L_{G} & =\left(Y_{B}-Y_{B B}\right)^{-1} Y_{B G} \\
L_{C} & =-\left(Y_{B}-Y_{B B}\right)^{-1} Y_{C} \\
\bar{V}_{B} & =\left[\begin{array}{c}
\bar{V}_{S B} \\
\bar{V}_{R B}
\end{array}\right] \quad Y_{B}=\left[\begin{array}{cc}
-\frac{1}{j X_{S}} & 0 \\
0 & -\frac{1}{j X_{R}}
\end{array}\right] \\
\bar{V}_{C} & =\left[\begin{array}{cc}
\bar{V}_{S} \\
\bar{V}_{R}
\end{array}\right] \quad Y_{C}=\left[\begin{array}{cc}
\frac{1}{j X_{S}} & 0 \\
0 & \frac{1}{j X_{R}}
\end{array}\right]
\end{aligned}
$$

- $Y_{B G}$ is the external admittance matrix that gives currents in terms of generator internal voltages,

- $Y_{B B}$ is the external admittance matrix connecting currents to the voltages at the buses,

- $Y_{B}$ is the internal admittance matrix which gives currents in terms of terminal voltages, and

- $Y_{C}$ is the internal admittance matrix which gives currents in terms of injected (controlled) VSC voltages.

\section{Basic control design - (almost) decoupled control scheme}

The chosen control structure allows the almost decoupled and independent control of the real power flow and the voltage magnitudes at the sending and receiving buses, respectively. The control task is split into two separate schemes for the sending and the receiving bus. Each of these is again based on two controllers and, therefore, the BTBL control is based on four separate controllers in order to keep the device operational as well as to control the desired quantities.

\section{Sending bus VSC control}

The sending bus VSC control deals with the control of the sending bus voltage and the DC link voltage. This is achieved by using two separate PI controllers as shown in Fig. 3.20a. Changing the current component orthogonal to the sending bus voltage $\left(I_{S_{Q}}\right)$ will mainly affect the reactive power flow in the shunt branch, which in turn will affect the sending bus voltage magnitude. 


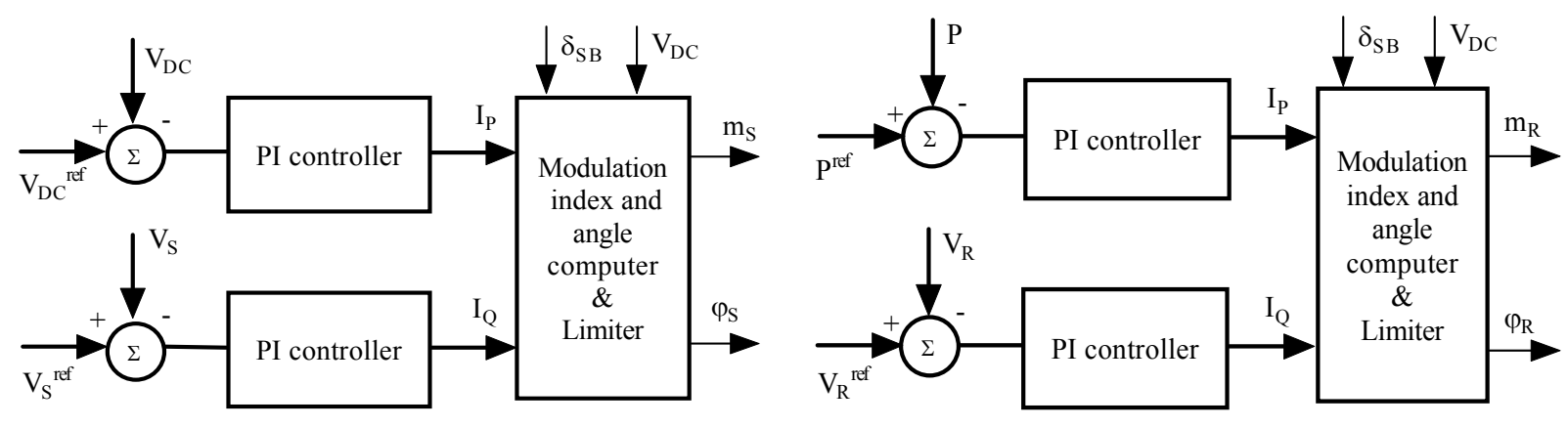

(a) Sending VSC

(b) Receiving VSC

Figure 3.20: BTBL control scheme

Adjusting the current component in phase with the sending bus voltage $\left(I_{S_{P}}\right)$ will mainly influence the real power flow in the shunt branch. The controller outputs are fed to a limiter in order to keep the injected voltage magnitude and converter current within specified ratings. The limited components $I_{S_{P L}}$ and $I_{S_{Q L}}$ and 3.18 are used to compute the injected voltage. Therefore, the phasor diagram as given for the UPFC shunt controller (Fig. 3.17b) applies and is not repeated here.

$$
\begin{aligned}
I_{S} & =\left|I_{S_{P L}}+j I_{S_{Q L}}\right| \\
\delta_{I_{S}} & =\delta_{S B}+\tan ^{-1}\left(\frac{I_{S_{Q L}}}{I_{S_{P L}}}\right) \\
\bar{V}_{S} & =\bar{V}_{S B}-j X_{S} \bar{I}_{S}
\end{aligned}
$$

\section{Receiving bus VSC control}

The second part of the control design deals with the bus voltage and the real power flow into the AC network at the receiving bus terminal. This is again achieved by using two separate PIcontrollers as shown in Fig. $3.20 \mathrm{p}$. Changing the current components, $I_{R_{P}}$ and $I_{R_{Q}}$, within their limits and as explained for the sending bus VSC allows finding the receiving converter voltage

$$
\begin{aligned}
I_{R} & =\left|I_{R_{P L}}+j I_{R_{Q L}}\right| \\
\delta_{I_{R}} & =\delta_{S B}+\tan ^{-1}\left(\frac{I_{R_{Q L}}}{I_{R_{P L}}}\right) \\
\bar{V}_{R} & =\bar{V}_{R B}-j X_{R} \bar{I}_{R}
\end{aligned}
$$




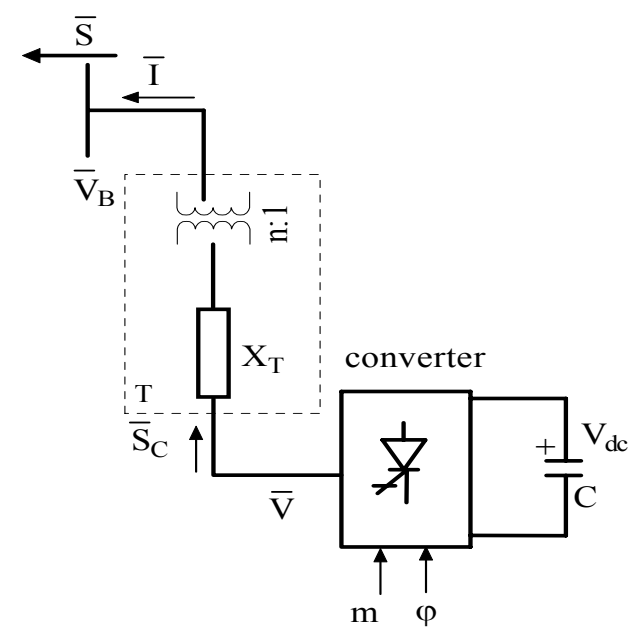

Figure 3.21: STATCOM dynamic model

\subsubsection{Static Synchronous Compensator (STATCOM)}

The STATCOM is a static VAR generator used to control the bus voltage magnitude through a variable synchronous voltage source. The advantage of the VSC scheme over the controlled reactance of the SVC is that the compensation is independent of the actual system voltage.

\section{Basic operation}

The STATCOM is a device placed at a bus in the power system consisting of a VSC with a DC side capacitor as shown in Fig. 3.21. Due to the fact that the STATCOM is placed on high-voltage transmission lines a step-down transformer is required in order to allow the use of power electronics devices. Applying PWM technique to the VSC allows representation of the STATCOM with a voltage at fundamental frequency using the following equation for the injected voltage magnitude:

$$
V=m \frac{V_{D C}}{2 \sqrt{2} n V_{B}}
$$

where $m$ is the amplitude modulation index of the VSC, $n$ the transformer turn ratio, $V_{B}$ the system side base voltage in $\mathrm{kV}$, and $V_{D C}$ the DC link voltage in $\mathrm{kV}$. The phase angle of $\bar{V}$ is

$$
\delta=\delta_{B}-\varphi
$$

where $\varphi$ is the firing angle of the VSC with respect to the phase angle of the bus voltage $\left(\delta_{B}\right)$. The voltage magnitude $V$ is controllable in the rang $\rfloor^{6}$ of $V^{\text {min }} \leq V \leq V^{\text {max }}$, and the firing angle

\footnotetext{
${ }^{6} \mathrm{~A}$ common voltage range for buses in the electric power system is 90 to $110 \%$ of the rated voltage level.
} 
limits have to be adjusted according to the operating conditions to adhere to power and current ratings. The converter injects a controllable voltage such that the real component of the current in the branch keeps the DC voltage at a specified value through exchanging active power with the DC link. The STATCOM's main purpose is to exchange reactive power with the AC system providing the possibility of independent shunt compensation for the line. The injected voltage can be regulated to produce a reactive current component that will either keep the bus voltage at a specified value or produced a desired inductive or capacitive VAR request.

\section{Load flow model and algorithm}

For steady-state operation the DC link voltage remains constant at a given value. In case of a lossless DC link the active power supplied by the converter $P=\operatorname{Re}\left(\bar{V} \bar{I}^{*}\right)$ satisfies

$$
P=0
$$

The load flow model implemented assumes that the STATCOM is operated to keep the bus voltage at a desired level. This allows treatment of the device as an equivalent generator (PV-type bus), setting the active power injection to zero and letting the load flow algorithm find the required reactive power $Q_{B}$. After the load flow solution has been found the steady-state quantities can be computed

$$
\begin{aligned}
\bar{I} & =\left(\frac{j Q_{B}}{\overline{V_{B}}}\right)^{*} \\
\bar{V}_{X} & =j X_{T} \bar{I} \\
\bar{V} & =\bar{V}_{B}+\bar{V}_{X_{T}} \\
\bar{S} & =\bar{V}^{*}
\end{aligned}
$$

where $\bar{I}$ is the current into the bus, $\bar{V}_{X_{T}}$ is the voltage drop due to the transformer reactance, $\bar{V}$ is the injected voltage, and $\bar{S}$ is the injected power due to the voltage source.

\section{Dynamic model}

For transient stability studies the DC voltage dynamics are taken into account as the DC link capacitor will exchange energy with the system and its voltage will vary. The following equation describes the model:

$$
C V_{D C} \frac{d V_{D C}}{d t}=-P S_{B}
$$


The relationship between the inverter DC and AC side is obtained by applying PWM technique to the VSC:

$$
\bar{V}=V \angle \delta=m \frac{V_{D C}}{2 \sqrt{2} n V_{B}} \angle\left(\delta_{B}-\varphi\right)
$$

Note that in the above equations the DC voltage and capacitor are expressed in mksA units while the AC system variables are expressed as per unit quantities. The system side base values $S_{B}$ and $V_{B}$ are selected as base power and base voltage and all $\mathrm{AC}$ variables are normalized using these base quantities.

\section{Interfacing}

The bus voltage $\bar{V}_{B}$ can be expressed as a function of generator internal voltages $\bar{E}_{G}$ and the STATCOM injection voltage $\bar{V}$ 3.24. Using the controller output and 3.20 to determine the injected voltage magnitude $V$ leaves the phase angle $\delta$ of the injected voltage as unknown. It depends on the phase angle of the bus voltage $\delta_{B}$ which is the result of the iterative interfacing procedure. The interface algorithm can be found in Fig. 3.15 where the expression FACTS has to be replaced by STATCOM (see the section on interfacing the UPFC for more details, p. 36).

$$
\bar{V}_{B}=L_{G} \bar{E}_{G}+L_{C} \bar{V}_{C}
$$

where

$$
\begin{aligned}
L_{G} & =\left(Y_{B}-Y_{B B}\right)^{-1} Y_{B G} \\
L_{C} & =-\left(Y_{B}-Y_{B B}\right)^{-1} Y_{C} \\
\bar{V}_{C} & =[\bar{V}] \quad Y_{B}=\left[-\frac{1}{j X_{T}}\right] \quad Y_{C}=\left[\frac{1}{j X_{T}}\right]
\end{aligned}
$$

- $Y_{B B}$ is the admittance matrix connecting the current to the voltage at the bus,

- $Y_{B G}$ is the admittance matrix that gives the current in terms of generator internal voltages,

- $Y_{B}$ is the internal admittance matrix which gives currents in terms of the terminal voltage, and

- $Y_{C}$ is the internal admittance matrix which gives currents in terms of the injected voltage.

\section{Basic control design - (almost) decoupled control scheme}

The control design involves simultaneous regulation of (i) real power flow to the DC link, and

(ii) bus voltage magnitude or VAR demand. This is achieved by two separate control loops using 


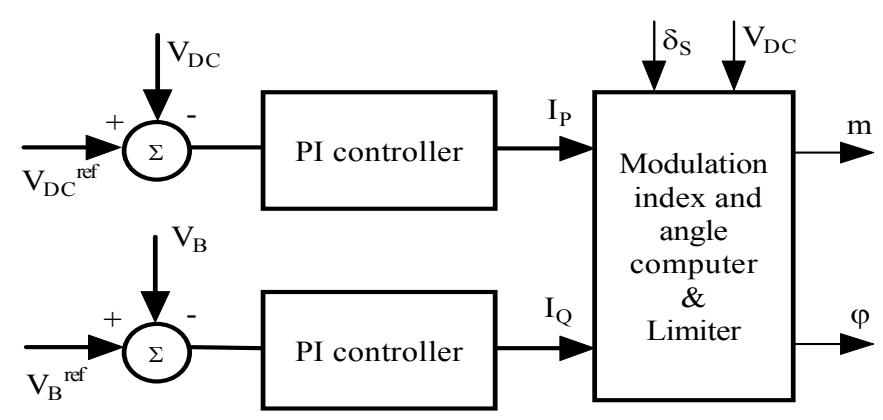

Figure 3.22: STATCOM control scheme

PI-controller as shown in Fig. 3.22 [32]. Changing the current component orthogonal to the bus voltage will mainly affect the reactive power flow in the branch, which in turn will affect the bus voltage magnitude. Adjusting the current component in phase with the sending bus voltage will mainly influence the real power flow in the branch. The controller outputs are fed to a limiter in order to keep the injected voltage magnitude and converter current within specified limits. The limited components $I_{P L}$ and $I_{Q L}$ and $(3.25)$ are used to compute the injected shunt voltage.

$$
\begin{aligned}
I & =\left|I_{P L}+j I_{Q L}\right| \\
\delta_{I} & =\delta_{B}+\tan ^{-1}\left(\frac{I_{Q L}}{I_{P L}}\right) \\
\bar{V} & =\bar{V}_{B}-j X_{T} \bar{I}
\end{aligned}
$$

\subsubsection{Static Synchronous Series Compensator (SSSC)}

The SSSC is a voltage-source converter used for series compensation applications. Affecting the effective angle difference between two power system buses through injecting a variable synchronous voltage allows to increase transfer capabilities and improves transient damping characteristics independent of the actual line current.

\section{Basic operation}

The SSSC is a device placed between two buses in the power system, the sending bus and the receiving bus, consisting of a VSC with a DC side capacitor (Fig. 3.23). Applying PWM technique the fundamental frequency model can be found through replacing the VSC by a controlled voltage source and linking the DC and AC side voltages by 


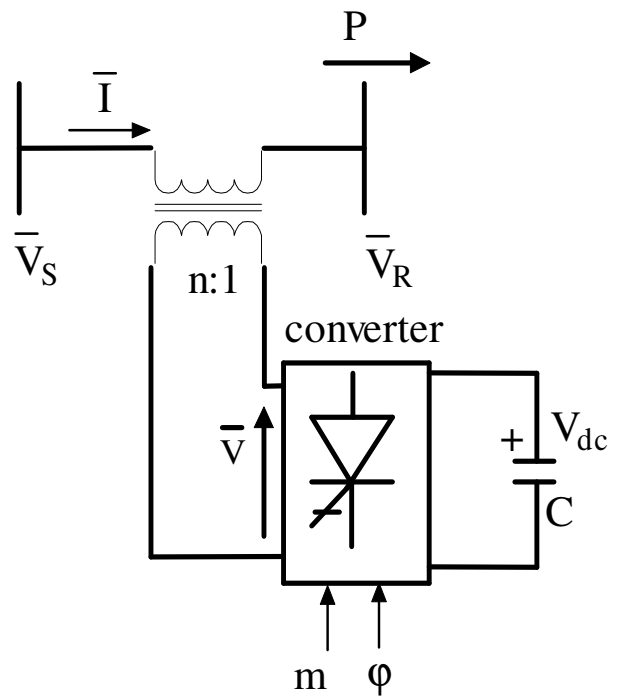

Figure 3.23: SSSC dynamic model

$$
V=m \frac{V_{D C}}{2 \sqrt{2} n V_{B}}
$$

where $m$ is the amplitude modulation index of the VSC, $n$ the transformer turn ratio, $V_{B}$ the system side base voltage in $\mathrm{kV}$, and $V_{D C}$ the DC link voltage in $\mathrm{kV}$. The phase angle of $\bar{V}$ is given by

$$
\delta=\delta_{B}-\varphi
$$

where $\varphi$ is the firing angle of the VSC with respect to the phase angle of the sending bus voltage $\delta_{B}$. The voltage magnitude $V$ and the firing angle $\varphi$ are controllable in the range of $0 \leq V \leq V^{\text {max }}$ and $0 \leq \varphi \leq 360^{\circ}$. The converter injects a controllable voltage such that either the active line power flow or the line current and the DC voltage are kept at specified values. Additionally, a line compensation control mode is possible.

\section{Load flow model and algorithm}

For steady-state operation the DC link voltage remains constant at its given value. In case of a lossless DC link the active power supplied to the converter $P=\operatorname{Re}\left(\bar{V} \bar{I}^{*}\right)$ satisfies

$$
P=0 \text {. }
$$

The load flow model implemented assumes that the SSSC is operated in the active power flow or line reactance compensation mode. The load flow algorithm has been extended to include a 
procedure to force the line power flow to a specified value. The SSSC is replaced by a controlled reactance. The computations in the loop outside the conventional NR-LF procedure adjust the reactance toward a more inductive or capacitive SSSC so that the expected outcome of the next load flow computation tends toward the desired active power flow. The closer the actual power flow to the specified value, the smaller the steps taken in changing the reactance. A graphical representation of the algorithm as used for the SSSC as well as the TCSC is shown in Fig. 3.24. Once the load flow solution has been found characteristic steady-state quantities can be computed:

$$
\begin{aligned}
\bar{V}_{R S} & =\bar{V}_{R}-\bar{V}_{S} \\
\bar{I} & =-\frac{\bar{V}_{R S}}{j X} \\
\bar{V} & =\bar{V}_{R S}+j X_{T} \bar{I} \\
\bar{S} & =\bar{V} \bar{I}^{*}
\end{aligned}
$$

where $\bar{V}_{S}, \bar{V}_{R}$, and $X$ are the bus voltages and reactance as found by the load flow algorithm, respectively. $\bar{I}$ is the current from the sending bus to the receiving bus, $\bar{V}$ is the injected voltage, and $\bar{S}$ is the injected power due to the converter operation.

\section{Dynamic model}

For transient stability studies the DC voltage dynamics have to be taken into account and (3.27) can no longer be applied as the DC link capacitor will exchange energy with the system. The DC link voltage will vary according to

$$
C V_{D C} \frac{d V_{D C}}{d t}=-P S_{B}
$$

The relationship between the inverter DC and AC side is given by

$$
\bar{V}=V \angle \delta=m \frac{V_{D C}}{2 \sqrt{2} n V_{B}} \angle\left(\delta_{S}-\varphi\right)
$$

In the above equations the DC voltage and capacitor are expressed in mksA units while the AC system variables are expressed as per unit quantities. The system side base values $S_{B}$ and $V_{B}$ are selected as base power and base voltage and all $\mathrm{AC}$ variables are normalized using these base quantities. 


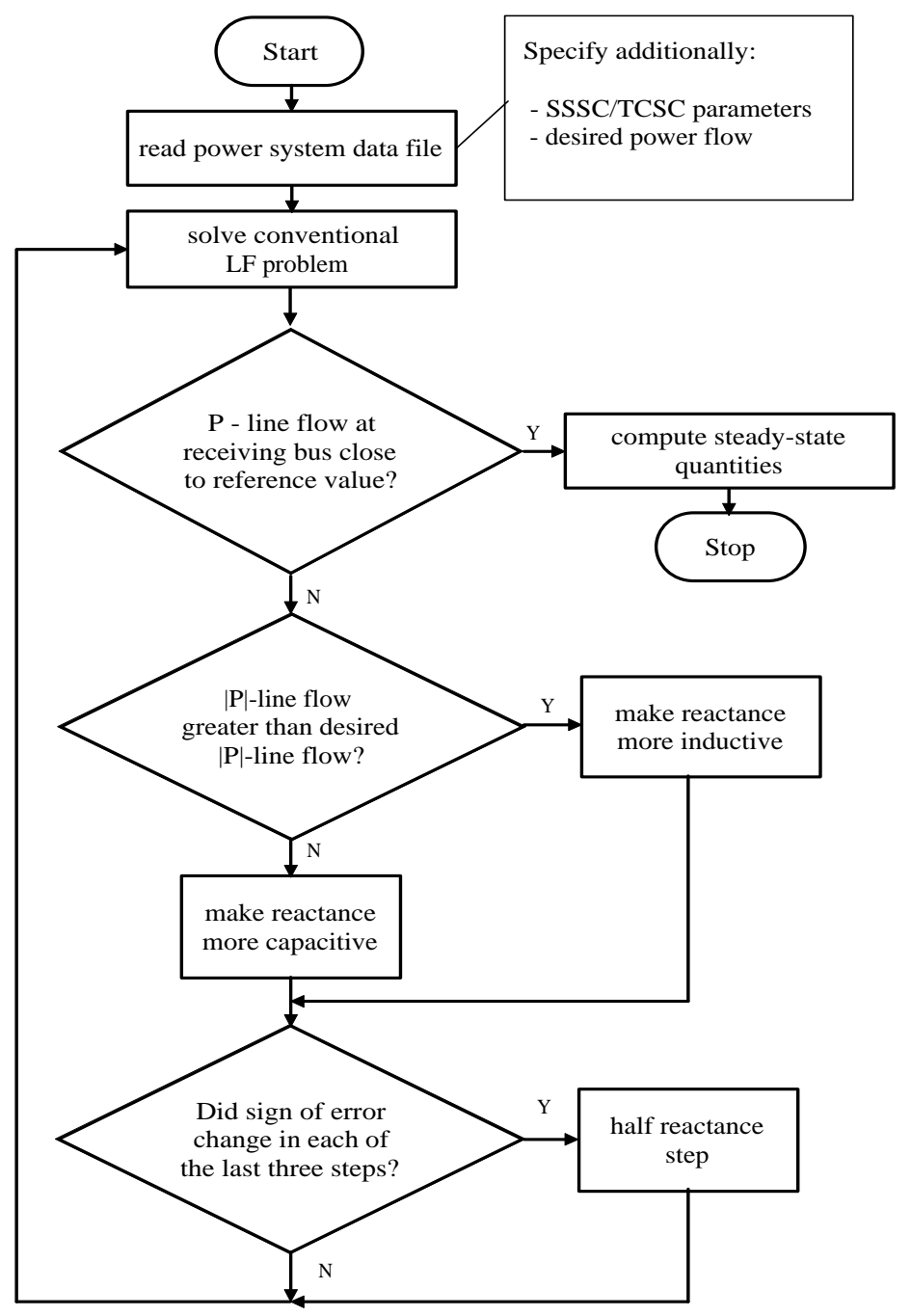

Figure 3.24: Load flow algorithm for line power flow control of SSSC and TCSC 


\section{Interfacing}

In order to find the network solution an iterative approach is applied. The fundamental frequency model of the SSSC is used (Fig. 3.23). Again, the bus voltages can be expressed as a function of generator internal voltages $\bar{E}_{G}$ and the injection voltage $\bar{V}$ (3.31). As for the FACTS devices previously presented, the control output and $(3.26)$ determine the injection voltage magnitude $V$ but the phase angle of the injected voltage, $\delta$, is unknown since it depends on the phase angle of the bus voltage $\delta_{S}$. The algorithm for interfacing can be found in Fig. 3.15 where the expression FACTS has to be replaced by SSSC (see the section on interfacing the UPFC for more details, p. 36.

$$
\bar{V}_{B}=L_{G} \bar{E}_{G}+L_{C} \bar{V}_{C}
$$

where

$$
\begin{aligned}
L_{G} & =\left(Y_{B}-Y_{B B}\right)^{-1} Y_{B G} \\
L_{C} & =-\left(Y_{B}-Y_{B B}\right)^{-1} Y_{C} \\
\bar{V}_{B} & =\left[\begin{array}{c}
\bar{V}_{S} \\
\bar{V}_{R}
\end{array}\right] \quad Y_{B}=\left[\begin{array}{cc}
-\frac{1}{j X_{T}} & \frac{1}{j X_{T}} \\
\frac{1}{j X_{T}} & -\frac{1}{j X_{T}}
\end{array}\right] \\
\bar{V}_{C} & =[\bar{V}] \quad Y_{C}=\left[\begin{array}{c}
-\frac{1}{j X_{T}} \\
\frac{1}{j X_{T}}
\end{array}\right]
\end{aligned}
$$

- $Y_{B G}$ is the external admittance matrix that gives currents in terms of generator internal voltages,

- $Y_{B B}$ is the external admittance matrix connecting currents to the voltages at the buses,

- $Y_{B}$ is the internal admittance matrix which gives currents in terms of terminal voltages, and

- $Y_{C}$ is the internal admittance matrix which gives currents in terms of injected (controlled) VSC voltages.

\section{Basic control design - (almost) decoupled control scheme}

The SSSC operated in the constant active power (current magnitude) control mode requires adjusting two voltage components. The component in phase with the current $\left(V_{P}\right)$ to stabilize 


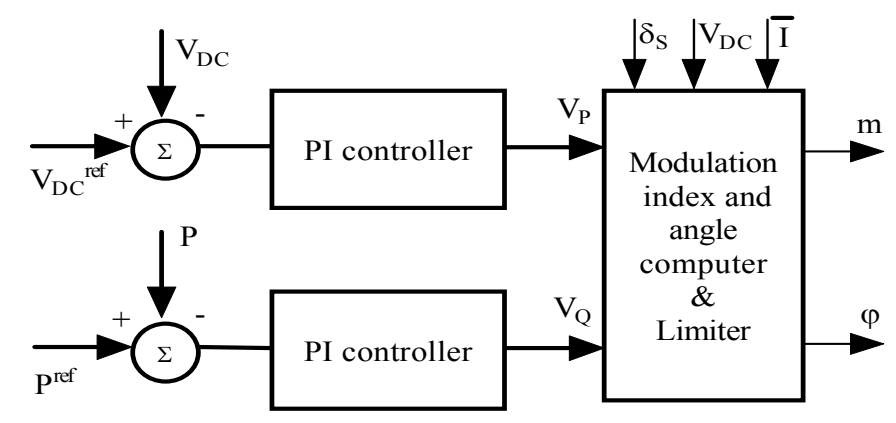

Figure 3.25: SSSC control scheme

the DC link voltage, and the component leading (or lagging) by 90 degrees $\left(V_{Q}\right)$ to control the active power flow (current magnitude). This is achieved through two separate PI-control loops. The control scheme generating the proper modulation index and firing angle using 3.32$)$ is shown in Fig. 3.25. Again, a limiter is applied to protect the VSC and power system from high currents and voltages.

$$
\begin{aligned}
V & =\left|V_{P L}+j V_{Q L}\right| \\
\delta & =\delta_{S}-\delta_{I}-\tan ^{-1}\left(\frac{V_{Q L}}{V_{P L}}\right)
\end{aligned}
$$

The line compensation control mode can be achieved by adjusting the injected $V_{Q}$-component according to the given transmission line reactance value $X_{L}$ and the desired compensation ratio $k$

$$
V_{Q}=k X_{L}|\bar{I}|
$$

\subsubsection{Static VAR Compensator (SVC)}

The SVC is a static VAR generator mainly used to control the bus voltage magnitude through a variable reactive impedance. The following will describe the operational characteristics and modeling of the type of SVC implemented for power system studies.

\section{Basic operation}

Different types of SVCs exist. The chosen SVC structure is the fixed capacitor - thyristor controlled reactor type as shown in Fig. 3.26 . The SVC consists of a capacitor, a thyristor controlled reactor, and a transformer connecting the SVC to the high voltage power system. By modifying the thyristor firing angle $\alpha$ the current flow through the inductor can be adjusted. The firing angle limits of $90^{\circ} \leq \alpha \leq 180^{\circ}$ translate into an inductor current ranging from maximum to 


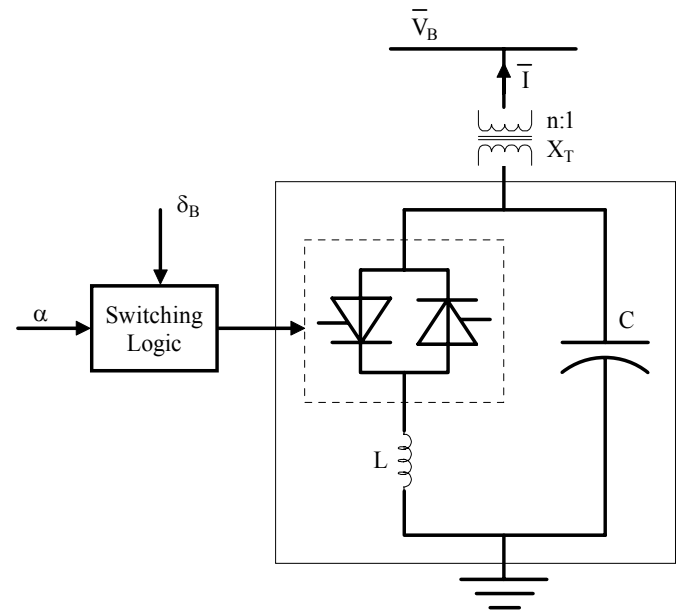

(a) Dynamic model

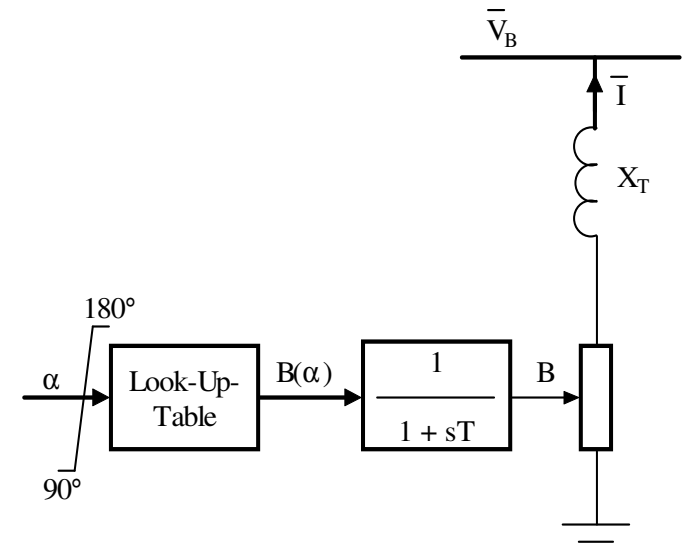

(b) Equivalent model

Figure 3.26: Modeling the SVC

zero yielding an overall SVC reactance varying from inductive to capacitive. Assuming sinusoidal voltages allows finding of the load flow as well as transient stability models as presented next.

\section{Load flow model and algorithm}

For steady-state operation the SVC is assumed to keep the bus voltage at a specified value. Therefore, the SVC can be represented as a generator (generator bus) where the injected active power is set to zero and the required reactive power injection will be found through the conventional load flow algorithm. After the load flow has been solved the steady-state quantities of interest can be computed:

$$
\begin{aligned}
\bar{I} & =\left(\frac{j Q_{B}}{\bar{V}_{B}}\right)^{*} \\
\bar{V} & =\bar{V}_{B}+j X_{T} \bar{I} \\
j B & =-\frac{\bar{I}}{\bar{V}} \\
B(\alpha) & =\frac{2 \alpha-\sin (2 \alpha)-\pi\left(2-\frac{X_{L}}{X_{C}}\right)}{\pi X_{L}}
\end{aligned}
$$

where $Q_{B}$ and $\bar{V}_{B}$ are the injected reactive power and bus voltage as found by the load flow algorithm, $\bar{I}$ is the current into the bus, $\bar{V}$ is the voltage across the SVC, $X_{T}$ is the transformer reactance, and $B$ is the equivalent SVC admittance. The last expression given in (3.34) is the result of a Fourier analysis of the current [46]. The current is a function of the sinusoidal voltage 


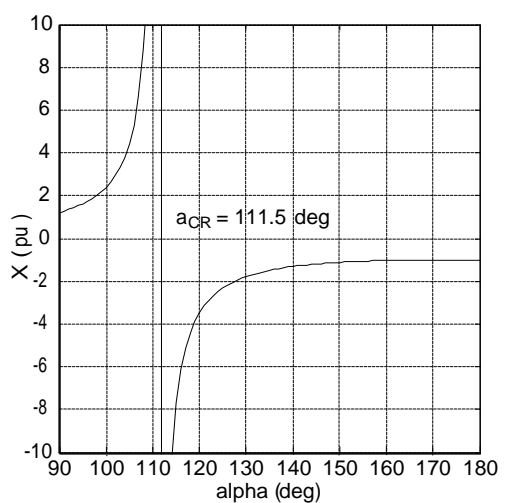

(a) Equivalent reactance

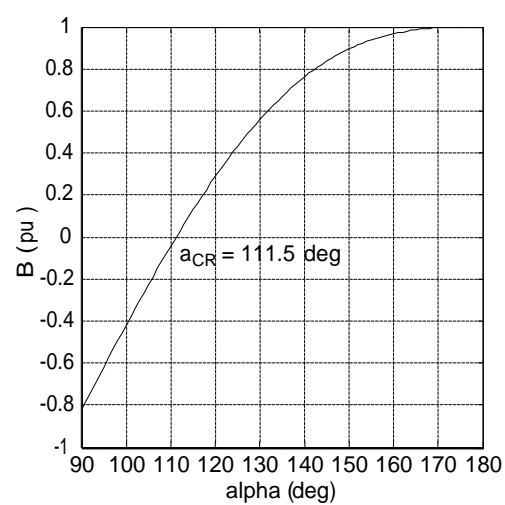

(b) Equivalent admittance

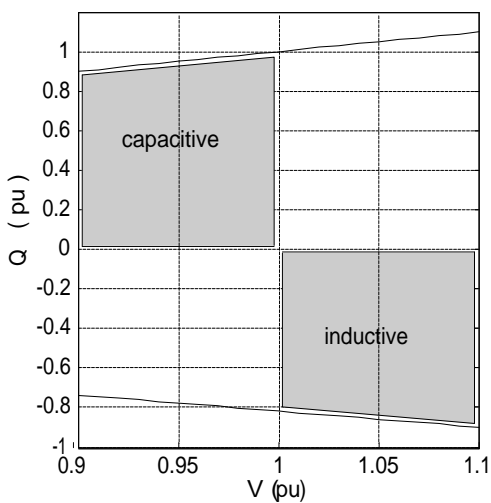

(c) Reactive power range

Figure 3.27: SVC characteristics

and the firing angle. Knowing the admittance the firing angle can be found by solving the nonlinear equation relating the firing angle and fundamental impedance values of reactor $X_{L}$ and capacitor $X_{C}$ to the equivalent admittance. Typical SVC relationships between the firing angle and the resulting reactance and admittance as well as the reactive power injection for a $\pm 10 \%$ voltage range are shown in Fig. $3.27 \mathrm{a}$-c. Chosen SVC data are $X_{C}=1 \mathrm{pu}$ and $X_{L}=0.55 X_{C}$ $\left(X_{T}=0\right)$. The critical firing angle $\alpha_{C R}$ belongs to the resonance point where $B\left(\alpha=\alpha_{C R}\right)=0$. Due to the discontinuity in the reactance the admittance will be chosen as the interfacing variable. The two marked regions in the $Q-V$ plot of Fig. 3.27 represent the typical operating zones of the SVC: capacitive if the bus voltage needs to be supported and inductive in case the actual bus voltage is above the chosen reference value (1 pu in this case).

\section{Dynamic model}

The model used for transient stability analysis is given in Fig. 3.26 [11. The firing angle is the input to the model and the actual admittance used to represent the SVC is found through a linear interpolation in a pre-computed look-up table using $X_{L}, X_{C}$, and $90^{\circ} \leq \alpha \leq 180^{\circ}$. Also, the dynamics of the thyristor firing delay are approximated by a first order delay with a default time constant of $T=3 \mathrm{~ms}$. This resembles the average delay of today's SVCs as presented in [32].

\section{Interfacing}

The network solution is found using the SVC admittance value and transformer reactance as interfacing variables. The expression for the bus voltage depending on the admittance matrix 


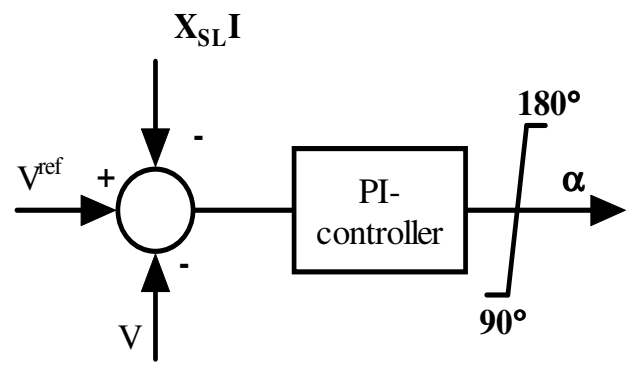

Figure 3.28: SVC control scheme

and internal generator voltages is

$$
\bar{V}_{B}=L_{G} \bar{E}_{G}
$$

where

$$
\begin{aligned}
L_{G} & =\left(Y_{B}-Y_{B B}\right)^{-1} Y_{B G} \\
Y_{B} & =\left[-j\left(\frac{\frac{-B}{X_{T}}}{B-\frac{1}{X_{T}}}\right)\right]
\end{aligned}
$$

- $Y_{B B}$ is the admittance matrix connecting the current to the voltages at the bus,

- $Y_{B G}$ is the admittance matrix which gives the current in terms of generator internal voltages, and

- $Y_{B}$ is the internal admittance matrix which gives currents in terms of terminal voltages.

As for FACTS devices with voltage-source converters an algorithm based on functional iterations is performed by computing new values for the bus voltage as long as two consecutive solutions deviate from each other more than a chosen limit.

\section{Basic control design}

The SVC basic control is based on the automatic voltage mode and this can be achieved by controlling the firing angle within its limits using a PI-controller as shown in Fig. 3.28. The adjustment of the reference voltage by the additional voltage drop due to $X_{S L}$ is necessary to avoid excessive controller reaction caused by small voltage deviations [46], [11].

\subsubsection{Thyristor Controlled Series Capacitor (TCSC)}

The TCSC is a device placed on transmission lines rather than being connected in shunt at a single power system bus, e.g., like the SVC. The series connection scheme allows the power flow 


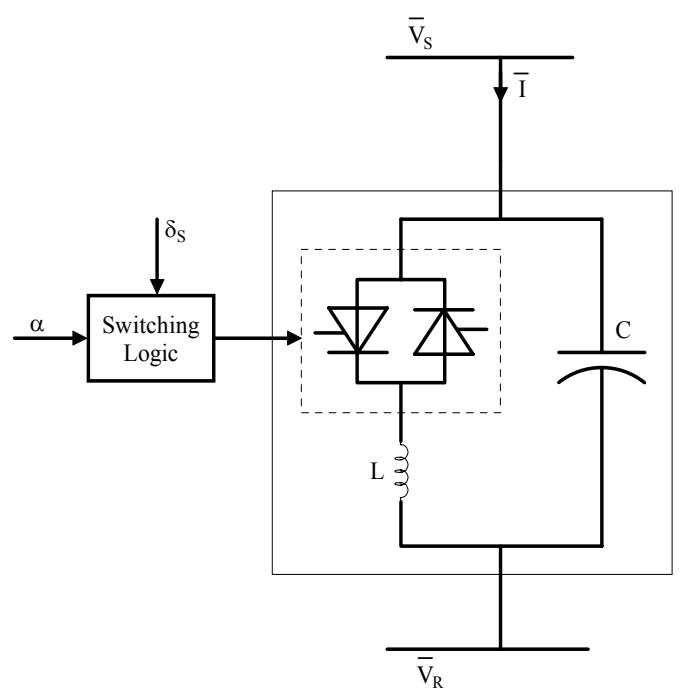

Figure 3.29: TCSC dynamic model

to be influenced through changing the effective admittance linking two buses, and is a method of improving transient stability limits and increasing transfer capabilities.

\section{Basic operation}

The typical structure of a TCSC is the same as the one discussed for the SVC and is shown in Fig. 3.2932 . By varying the firing angle the overall admittance is changed and, due to the series connection with the transmission line, effects the total admittance between the two power system buses. The transmitted power is inversely proportional to the transfer reactance resulting in the possibility to increase transfer limits through compensation. Assuming a 50 to $75 \%$ series compensation the steady-state power flow can be adjusted from twice to four times the original value. Nevertheless, a practical limit of a maximum compensation level of $70 \%$ applies due to uncontrollable variations in power flow caused by otherwise small changes in bus voltages.

Different expressions for the equivalent admittance can be found in the literature [11]. They depend on the choice of voltage (3.36) or current (3.37) as an ideal sine wave. A comparison of both expressions using $X_{C}=1 \mathrm{pu}, X_{L}=0.1 X_{C}$ is shown in Fig. $3.30 \mathrm{a}$ and b. As can be seen, 3.37 is only valid for the capacitive operating range. Both have been used in power system studies applying different limits to the range of operation. The absolute minimum and maximum firing angle of $90^{\circ}$ and $180^{\circ}$ have to be observed and the resonant point of $B=0$ at the critical firing angle $\alpha_{C R}$ has to be avoided. This is done by setting the firing angle range to $90^{\circ} \leq$ 


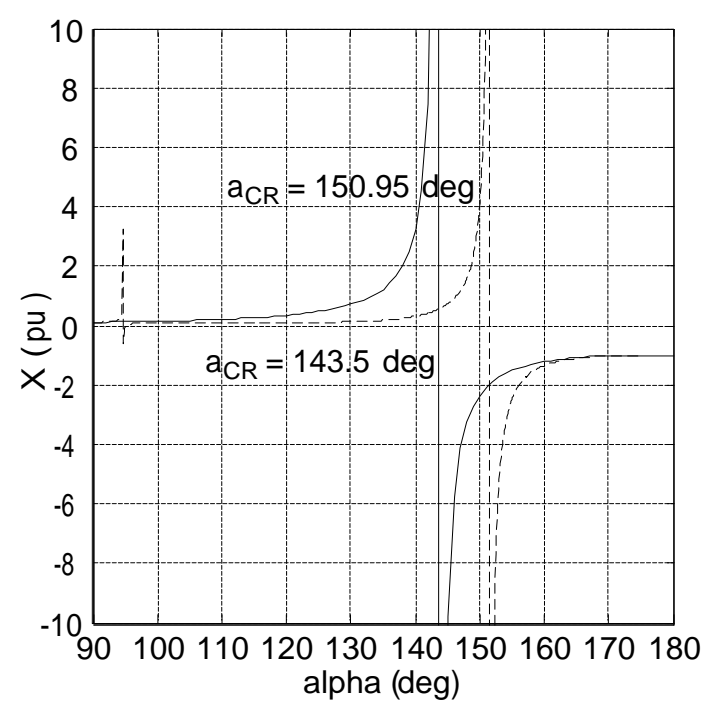

(a) Equivalent reactance

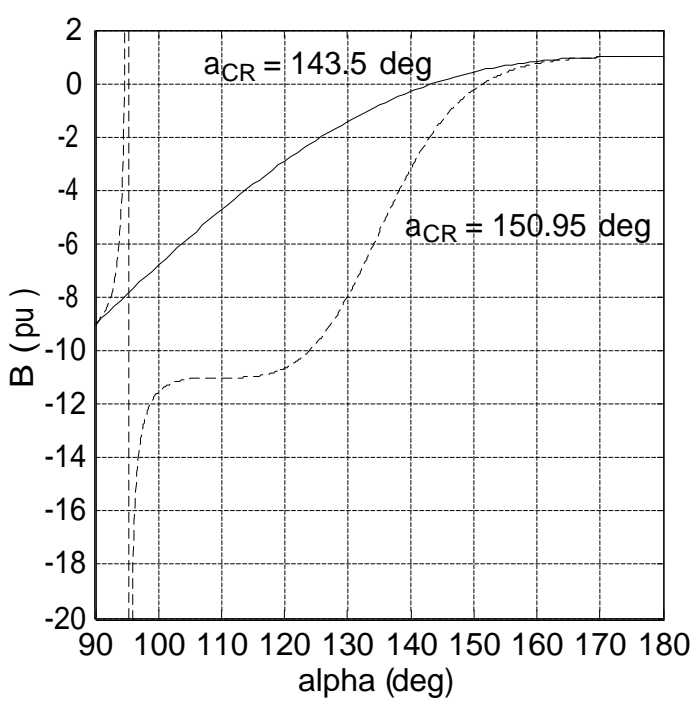

(b) Equivalent admittance

Figure 3.30: TCSC characteristics: solid - sinusoidal voltage, dashed - sinusoidal current

$\alpha \leq \alpha_{C R}-\Delta \alpha$ and $\alpha_{C R}+\Delta \alpha \leq \alpha \leq 180^{\circ}$. For (3.37), which is seen as the more accurate model, only $\alpha_{C R}+\Delta \alpha \leq \alpha \leq 180^{\circ}$ is acceptable.

$$
\begin{aligned}
B(\alpha)= & \frac{2 \alpha-\sin (2 \alpha)-\pi\left(2-\frac{X_{L}}{X_{C}}\right)}{\pi X_{L}} \\
B(\alpha)= & -\frac{1}{X_{C}} \frac{\pi\left(k_{x}^{4}-2 k_{x}^{2}+1\right) \cos k_{x}(\pi-\alpha)}{\pi k_{x}^{4} \cos \left(k_{x}(\pi-\alpha)\right)-\pi \cos \left(k_{x}(\pi-\alpha)\right)-2 k_{x}^{4} \alpha \cos \left(k_{x}(\pi-\alpha)\right)+} \\
& \quad+2 \alpha k_{x}^{2} \cos \left(k_{x}(\pi-\alpha)-k_{x}^{4} \sin (2 \alpha) \cos \left(k_{x}(\pi-\alpha)\right)+k_{x}^{2} \sin (2 \alpha) \cos \left(k_{x}(\pi-\alpha)\right)-\right. \\
k_{x}= & +\sqrt{\frac{X_{C}}{X_{L}}}
\end{aligned}
$$

Also, the inductive operation region results in a high harmonic distortion which is undesirable in power systems. Therefore, this range is only permitted for a short period of time for transient damping applications.

\section{Load flow model and algorithm}

For steady-state operation the TCSC is assumed to either keep the active line power flow constant or compensate the line reactance. The load flow algorithm has been extended by an outer-loop adjusting the effective TCSC reactance (see also section 3.4 .4 for the implementation of the SSSC 


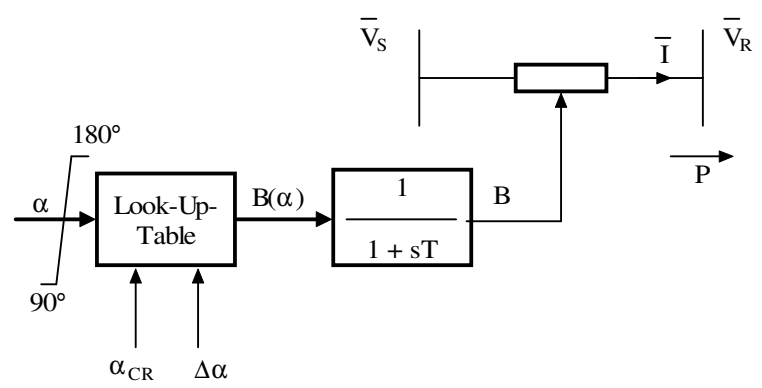

Figure 3.31: TCSC equivalent model

load flow algorithm). The change in the reactance is made toward a more inductive or capacitive TCSC in order to drive the expected outcome of the next load flow computation toward the desired active power flow. The closer the actual power flow to the specified value the smaller the steps taken in changing the reactance. Once the load flow solution has been found characteristic steady-state quantities can be computed:

$$
\begin{aligned}
\bar{V} & =\bar{V}_{S}-\bar{V}_{R} \\
\bar{I} & =\frac{\bar{V}}{j X} \\
B & =-\frac{1}{X}
\end{aligned}
$$

where $\bar{V}_{S}, \bar{V}_{R}$, and $X$ are the bus voltages and reactance as found by the load flow algorithm, respectively.

\section{Dynamic model}

The equivalent model used for transient studies is given in Fig. 3.31. The firing angle is the input signal, a look-up-table is used to find the equivalent admittance value, and, as approximation to the firing delay, a first order time-delay with a default time constant of $T=3 \mathrm{~ms}$ is utilized.

\section{Interfacing}

The network solution for the TCSC using the equivalent admittance as interfacing variable is found by using

$$
\bar{V}_{B}=L_{G} \bar{E}_{G}
$$




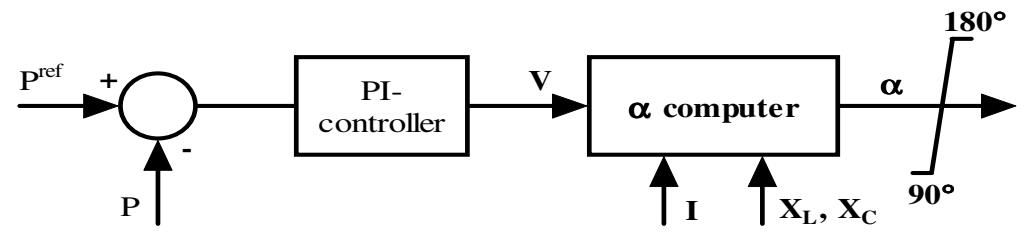

Figure 3.32: TCSC control scheme

where

$$
\begin{aligned}
L_{G} & =\left(Y_{B}-Y_{B B}\right)^{-1} Y_{B G} \\
Y_{B} & =\left[\begin{array}{cc}
-j B & j B \\
j B & -j B
\end{array}\right]
\end{aligned}
$$

- $Y_{B B}$ is the admittance matrix connecting currents to the voltages at the bus,

- $Y_{B G}$ is the admittance matrix that gives currents in terms of generator internal voltages, and

- $Y_{B}$ is the internal admittance matrix which gives currents in terms of terminal voltages.

The algorithm for interfacing is equivalent to the one descript for the SVC.

\section{Basic control design}

The basic control adjusts the compensation voltage across the TCSC to keep the active line power flow or current at its specified value. A PI-controller is used to guarantee steady-state error-free control obeying the previously mentioned limits concerning the firing angle (Fig. 3.32). Additionally, the TCSC can be controlled to partially compensate the transmission line reactance at a fixed ratio. 


\section{Chapter 4}

\section{Transient stability enhancement using FACTS devices}

\subsection{Introduction}

Guaranteeing the stability in case of contingencies has been of interest in the last decades and will be a main issue in a deregulated environment. FACTS devices increase the controllability of power systems but care must nevertheless be taken during the design process. The potential usefulness of any control scheme (see for example [21, p. 2.4-5) requires that the effects it produces upon system dynamics be significant, consistently predictable, and visible to the controller. Therefore, appropriate damping control requires the designer to include concerns about the choice of the FACTS device, the most effective measurement to be utilized as input signal, the damping scheme, the design strategy, and evaluation of the resulting overall system performance. The operation of damping controllers should also be restricted to the minimum time necessary in order to minimize the risk of adverse side effects. Damping control schemes are designed as supplemental control to the fundamental control task (referred to as basic control in this work). This allows the basic control to supervise the damping controller action and to avoid harmful operating conditions, especially during and right after a fault occurred in the system.

A broad range of design techniques is available. Linear analysis has been widely used due to its advantage of a well-established mathematical background [46], [91]- [95]. Nevertheless, it targets specific operating conditions making it prone to changes in its environment. Different approaches toward a robust control design have been suggested to increase the positive damping 


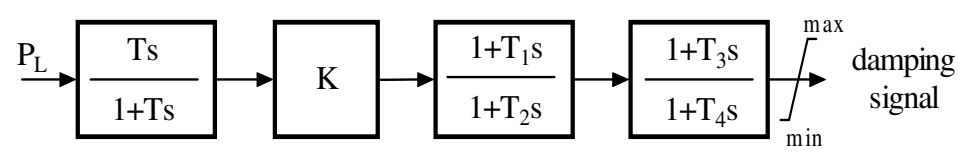

Figure 4.1: Lead-lag controller structure

effect over a broader range of operating conditions [10], [84], [85], and [86]. Nonlinear methods such as a variable structure power system stabilizer [45], [83, a method of coordinated active and reactive power control based on a Lyapunov function [16], and the transient energy function approach in [26] and [51] have been reported. Methods avoiding specific mathematical models and operating conditions include neural networks and fuzzy logic technology. The following will concentrate on analysis and design of damping controllers using the UPFC as an actuator and focusing on fuzzy logic as a design tool for a damping control scheme. Fundamentals concerning its applications to power systems will be presented in the next sections.

\subsection{UPFC as an actuator}

In addition to the previously discussed capability of the UPFC to control key elements in the power system, the UPFC can be used to improve the transient characteristic. Several authors have investigated the effectiveness of the UPFC in damping power system oscillations applying different schemes including modulation of injected voltage magnitudes, relative phase angles, and reference values for power flows. [93] applied a supplementary signal based on generator speed deviation $\Delta \omega$ to augment modulation indices and phase angles of the injected voltages. The UPFC could improve the power oscillation damping of the single-machine infinite bus power system. The damping controller used was of lead-lag type with a transfer function as shown in Fig. 4.1. The fuzzy design in [49] also focused on a single-machine infinite bus power system using machine speed as an input signal but exploring the influence of damping signals applied through a UPFC by means of a fuzzy scheme. The speed signal was used to compute an acceleration signal and both signals were then utilized to damp swings. The fuzzy logic approach in [64 extends this approach by replacing the measurement with the local line power flow. [74] applied fuzzy control to the superconducting magnetic energy storage (SMES) and SSSC. The SMES was controlled through combined active and reactive power injections at the bus to oppose power swings. The SSSC control is based on the Direct Lyapunov Stability method. In [58] TS-fuzzy schemes of PDand PI-type were suggested as basic controllers using deviations in line power flows as inputs. The 
output signals for the two series voltage components were linear combinations of the two input signals and the product of the two. This resulted in a nonlinear control scheme and was judged by the authors to be superior to conventional PI-type controllers. Transient stability of local and interarea modes was examined using linear combinations of generator speed deviations to augment the local power deviation input signal. The parameter tuning process for fuzzy schemes has mainly been done by a trial-and-error approach but could be improved by adaptive methods [96] or learning through interaction with the power system [48]. Techniques like learning automata and reinforcement learning have been applied in small-scale but highly nonlinear systems [7], [97. In [48] an extension to parameter tuning of Hiyama's fuzzy damping scheme as applied to static phase shifters was introduced. Based on small system disturbances (noise) the parameters were continually adjusted until no improvements in a chosen performance criterion could be achieved.

This dissertation proposes a fuzzy logic damping controller based on the fuzzy scheme as originally proposed by Hiyama for the PSS [35] and SVC [39] for the UPFC. The fundamentals of the scheme have also been discussed with respect to robust, near time-optimal control in [65]. The methods differ in either the input signal chosen, controlled device, the determination of the current system state, or the fuzzy method applied. Also, by applying and testing the scheme to more general power systems, a broader range of questions concerning the applicability and possible enhancement in transient stability is investigated.

\subsection{Fundamentals of fuzzy systems - Takagi-Sugeno-Kang fuzzy logic}

Important information for practical systems often comes from two very different resources: The first is a mathematical model that is derived according to physical laws and supported by sensor measurements; the second comes from human experts who describe their knowledge using natural language. Fuzzy logic provides a theory to combine these resources into a single framework. Three different types of fuzzy systems can be found in the literature [96]. In the following only the system known as the Takagi-Sugeno-Kang (TSK) fuzzy system will be explained as it will be the basis for the damping control scheme. In summary, TSK-systems are a collection of IF-THEN rules in the form of

IF Input $X_{1}$ is low and $\cdots$ and Input $X_{n}$ is normal,

THEN the voltage $v^{r}$ applied through the FACTS device is $v^{r}=a_{0}^{r}+a_{1}^{r} X_{1}+\cdots+a_{n}^{r} X_{n}$ 


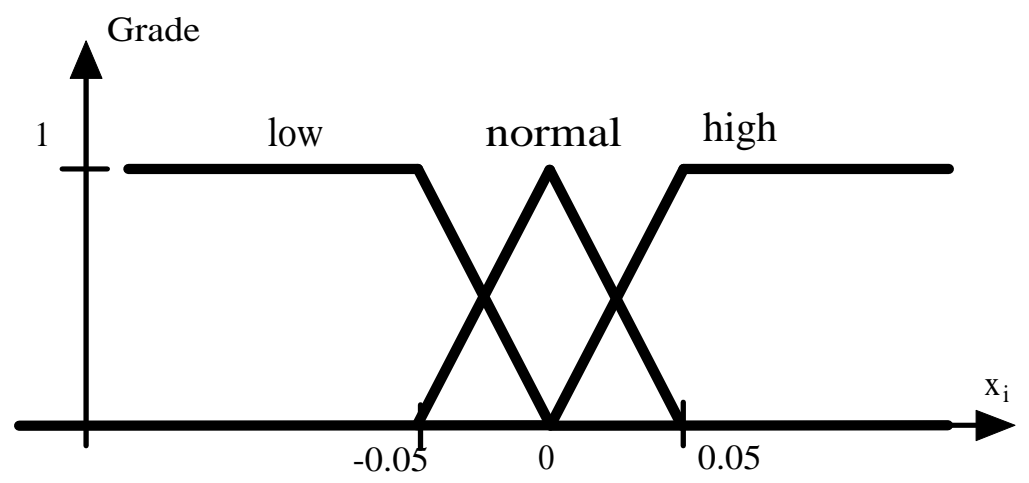

Figure 4.2: Fuzzy membership functions

where the words "low" and "normal" have a specified meaning, $a_{i}$ are constants, and $r$ denotes the rule under consideration. The meaning is expressed through a continuous membership function 1 Examples of such functions are given in Fig. 4.2. The membership functions assign each crisp measurement (horizontal axis) a fuzzy value, the grade or truth content (vertical axis), $m_{X_{i}}^{r}$. Inspecting the fuzzy rule two important properties of TSK-systems can be seen: The IF part describing the input signal or measurement in the antecedent part of the rule takes on a fuzzy value. The THEN part of the rule, the consequence, is a simple mathematical formula, a linear combination of the inputs. The combination of $n_{r}$ rules into a single system is derived through finding the weighted average of the values in the THEN parts

$$
\bar{v}=\frac{\sum_{r=1}^{n_{r}} v^{r} w^{r}}{\sum_{r=1}^{n_{r}} w^{r}}
$$

where the weights $w^{r}$ are computed as

$$
w^{r}=\prod_{i=1}^{n} m_{X_{i}}^{r}
$$

The principle layout of a TSK fuzzy system is shown in Fig. 4.3 .

When compared to other fuzzy system approaches the usage of a mathematical formula rather than words in a natural language in the THEN part results in less freedom in the system description and it may not represent human knowledge in a natural framework. Nevertheless, the existence of a simple mathematical relationship for damping power oscillations will be shown in the next sections. A fact in favor of a simple relationship is that real-world applications using

\footnotetext{
${ }^{1}$ Note: Only a single set of membership functions is implied here for reasons of simplicity. In practical applications it may be useful to define a set of membership functions for each input individually.
} 


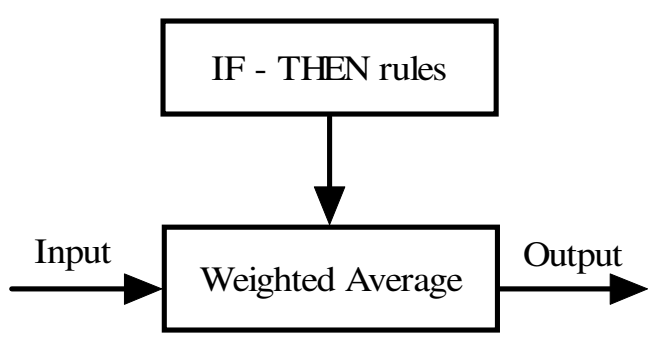

Figure 4.3: Takagi-Sugeno-Kang fuzzy system

signal processors to compute the controller signal rather than sophisticated computers require the restriction to basic mathematical functions as well as a limited number of calculation steps.

\subsection{Control Scheme}

\subsubsection{Damping using excitation systems}

The fuzzy PSS control scheme was originally proposed by Hiyama in [35] and later modified in [36]. The supplementary stabilizing signal was found through a rule-base and applied via a fastacting exciter. The measured generator speed and its computed derivative were used as input signals. These two input signals form a 2-dimensional plane referred to as the phase plane $2^{2}$ The origin of the phase plane represents the steady-state. The actual measurement was used to find the coordinates in the phase plane and was denoted as the state of the generator. Whenever the state of the generator is not in the origin some control action has to be taken to drive it back to the equilibrium point as soon as possible.

The damping signal can take on limited positive and negative values in order to decelerate or accelerate the generator. To find the appropriate signal the phase plane is divided into two sectors and the desired control action for a few chosen sample points examined. Generalization of the results to the entire phase plane yields the fuzzy damping scheme. Three sample points in sector I are shown in Fig. 4.4 and their related control signals $U$ are described in the following ( $U_{\max }$ is the applied limit, $G$ is a gain limited to $0 \leq G \leq 1$, and $S$ represents the sign of the damping signal):

1. Rule: Slight deceleration control - in form of a positive damping signal in order to increase

\footnotetext{
${ }^{2}$ The term phase plane is used throughout the text to designate the input information provided by signal pairs. It shall be explicitly pointed out that it only shares its name with the "Phase plane analysis" method, which is a graphical method for studying second-order systems. The phase plane as used here is not limited by the order of the system under study.
} 


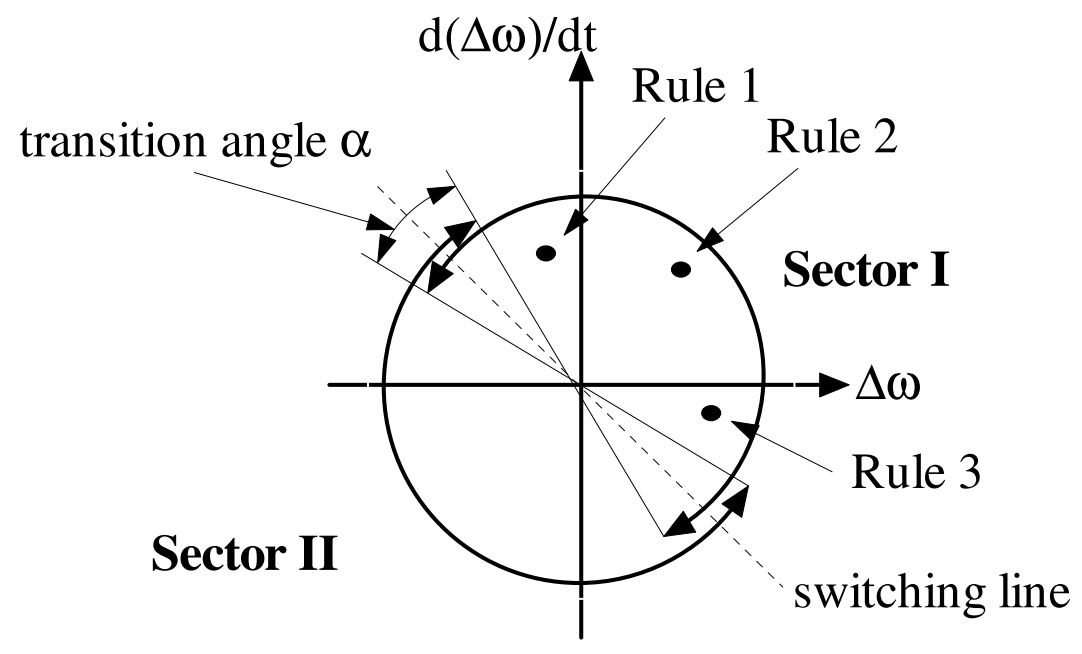

Figure 4.4: Phase plane

the electric output power of the generator - as the speed is almost at steady-state but the acceleration is high, $U=S G U_{\max }, S>0, G$ is low.

2. Rule: Strong deceleration control as the speed deviation and acceleration are high above steady-state, $U=S G U_{\max }, S>0, G$ is high.

3. Rule: Slight deceleration control as the speed is above steady-state but the acceleration is already negative, $U=S G U_{\max }, S>0, G$ is low.

4. Rule: In sector II all of the above described situations require the opposite damping action. Therefore, replacing the control action of deceleration with acceleration yields the appropriate rules: $U=S G U_{\max }, S<0$.

These rules are extended to the entire state plane by membership functions. The membership functions describe the sectors in the state plane leading to the proper deceleration or acceleration control signal.

\subsubsection{Damping through devices within the transmission system}

The direct relationship of speed and its derivative to the damping signal is lost whenever the damping device with its controls is not placed at a generator but within the transmission system. Nevertheless, a closely related control strategy can be applied. To understand the modified idea a simplified two area power system is used as an example. Each of the two areas may represent a 


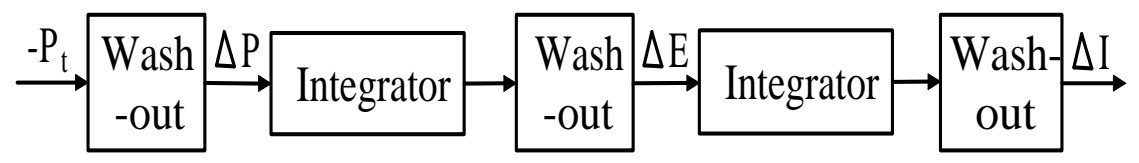

Figure 4.5: Obtaining input signals for fuzzy damping controllers

collection of generating and consuming elements. The two areas are connected by a transmission line. The controlled device is placed at the mid-point of the line and its damping control scheme is used to augment the active power flow on the line. In case of a system disturbance, e.g., short circuit, large load changes, the generators' electric output powers will undergo large changes. These changes depend on the disturbance location and severity. Conventional power system stabilizers such as these described in the previous section are often unable to observe and control swings involving different power system areas and additional measures must therefore be taken.

The concept of damping control using a device on a transmission line is to force an increased or decreased active power flow on the line. The augmented power flow should be such that the resulting transmitted active power opposes the speed deviations in both areas. As a consequence the damping of the transients will be improved and the post-disturbance equilibrium point approached faster. The scheme as described above with an associated damping signal computed by $U=S G U_{\max }$ requires some justification in finding the appropriate sign function $S$. The necessary steps to determine the system state in a state plane and the fuzzy damping controller are described in the next sections.

\subsection{Input signal conditioning}

The process of finding the desired input information requires some signal conditioning. Necessary steps include removing offset components and integration as shown in Fig. 4.5. The input signals to the fuzzy controller are derived from the total active power flow $P_{t}$ (see also the case study of the Two area - Four machine system, Fig. 5.1) at the UPFC sending bus. The damping scheme uses the power flow deviation from its steady-state value, $\Delta P$, to compute the input signals: changes in energy, $\Delta E$, and the changes in its integral, $\Delta I$. Therefore, the fuzzy controller is a two-input-one-output controller. The input signals indicate a required change in transmitted line power flow and have to be driven back to zero for a new steady-state by the damping controller. 


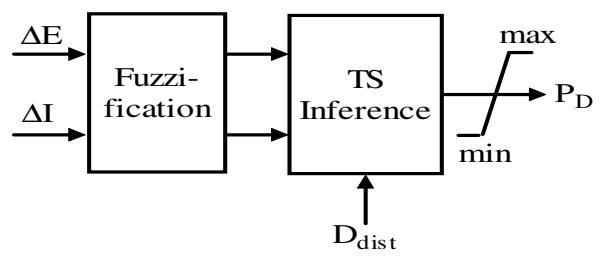

Figure 4.6: TSK-Fuzzy logic control scheme

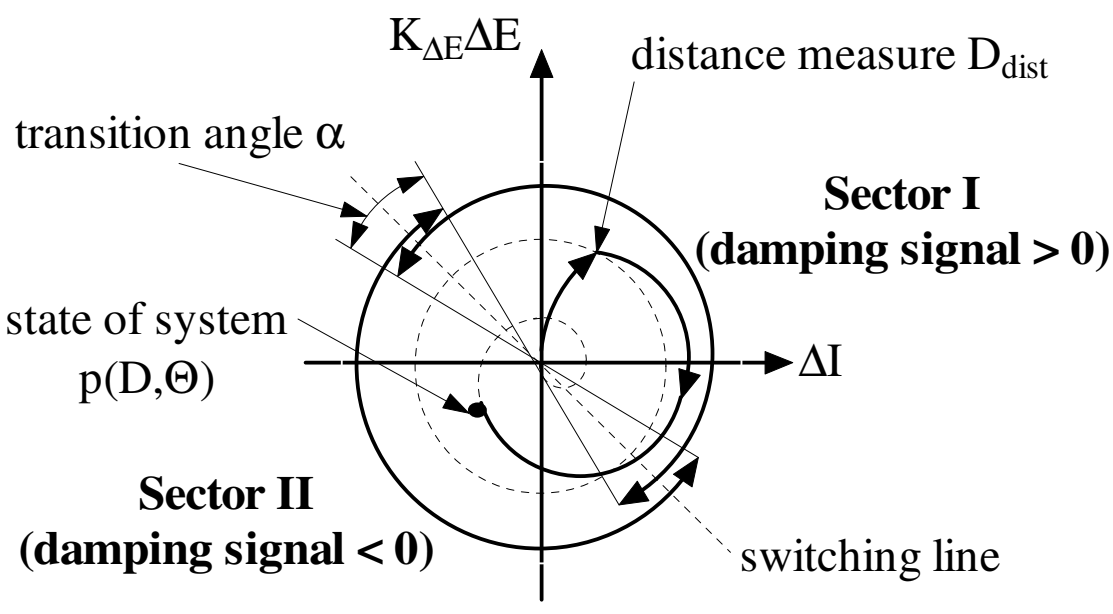

Figure 4.7: TSK-Fuzzy logic control scheme: Phase plane

\subsection{Fuzzy damping control}

Using the TSK-fuzzy system as described earlier allows direct mapping of the sectors to the appropriate damping signal and will be derived in the following. The damping scheme (Fig. 4.6) utilizes the signals for changes in energy flow $\Delta E$ and its integral $\Delta I$ to compute the actual system state. The state is defined as the point $p(D, \Theta)$, in the $\Delta I-K_{\Delta E} \Delta E$ plane (Fig. 4.7). $D$ and $\Theta$ are the polar coordinates of the state $p . K_{\Delta E}$ is a scaling coefficient. The state plane's origin is the desired steady-state operating point. The actual state of the system and two simple fuzzy logic control rules are used to drive the system back to the equilibrium point. The system's state plane is divided into two overlapping sectors, sector I and sector II as shown in Fig. 4.7 . In the first quadrant, part of sector I, the controller output should result in a positive damping signal increasing the line power flow. The damping signal should be negative in the third quadrant decreasing the line power flow. The transitions between these two operating modes take place in the second and fourth quadrant. This transition is done gradually as determined by membership functions, $m_{P}(\Theta)$ and $m_{N}(\Theta)$, which overlap by angle $\alpha$ (Fig. 4.8). Therefore, the two rules 


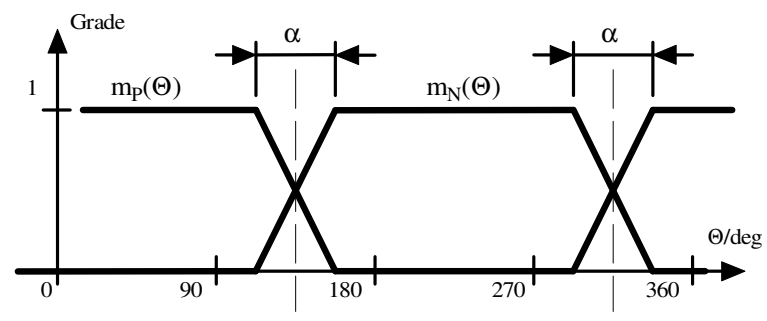

Figure 4.8: Fuzzy membership functions for the phase plane

applied to find the controller signal sign $S$ are

1. IF $\Theta$ is Positive THEN $S^{1}=a_{0}^{1}=1$.

2. IF $\Theta$ is Negative THEN $S^{2}=a_{0}^{2}=-1$.

where both rules are characterized by

$$
a_{1, \cdots}^{1,2}=0
$$

Note, this choice leads to a fuzzification process that is known as singleton fuzzification [96]. Observing that both membership functions as defined sum to one (Fig. 4.8) reduces the computations of the weights 4.2 to

$$
w^{r}=\prod_{i=1}^{1} m_{X_{i}}^{r}=m_{\Theta}^{r}
$$

The output signal using the weighted average method (4.1) yields

$$
S=m_{\Theta}^{1}-m_{\Theta}^{2}=m_{P}(\Theta)-m_{N}(\Theta)=2\left(m_{P}(\Theta)-\frac{1}{2}\right)
$$

The stabilizer's gain may vary according to $0 \leq G \leq 1$ based on the distance from the origin. Hiyama suggested a linear dependency for the gain adjustment

$$
G=\frac{D}{D_{r}}
$$

where $D$ is the actual distance from the origin, and $D_{r}$ is a design parameter. $D_{r}$ was linearly increased over time as soon as the power system was close to a new steady-state to enforce reduced damping signals. The overall damping performance may suffer when the power system operating conditions change. A new gain adjustment based on the system disturbance severity is proposed here by using the following to find the proper gain

$$
G=\left\{\begin{array}{ccc}
\left(\frac{D}{k_{D} D_{\text {dist }}}\right)^{2} & \forall & D \leq k_{D} D_{\text {dist }} \\
1.0 & \forall & D>k_{D} D_{\text {dist }}
\end{array}\right.
$$


The gain factor $G$, determined by $D$ and $k_{D} D_{d i s t}$, varies between 0 and 1 according to the state of the power system. $G$ becomes zero whenever the system is close to a new steady-state. To improve the flexibility of the damping controller the gain adjustment replacing 4.6 is based on a scheme that adjusts to the severity of the disturbance. The distance measure $D_{\text {dist }}$, which can be represented by a circle in the system state plane (see Fig. 4.7), is the distance measured at the time of fault clearance and $k_{D}$ is a design parameter. The signal $S G$ varies between -1 and +1 depending on $\Theta$ and $D$. The actual damping controller signal $P_{D}$, which is of form $U=S G U_{\max }$ as introduced above, is determined between the two specified bounds, the maximum positive line flow offset $P_{M P}>0$ and the maximum negative line flow offset $P_{M N}<0$, by:

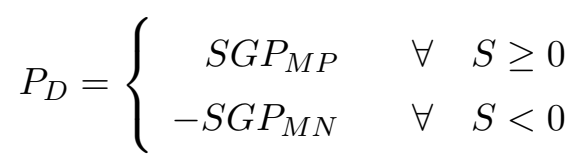

To avoid unwanted control action a trigger event for the damping scheme has to be defined. A list of such events includes sudden changes in voltages, power flows, and currents, e.g., $\Delta P>\Delta P_{L}$. The damping signal is applied to the series converter side through the modulation of the real power reference signal as shown in the UPFC series converter control scheme (Fig. 3.16, p. 39. The calibration of the fuzzy damping scheme will be done through optimization of the chosen performance criteria

$$
C=\sum_{i} \int_{0}^{T}\left|\Delta \omega_{i}\right| d t
$$

where $\Delta \omega_{i}$ is the speed deviation of generator $i$. The cost function $C$ evaluates the transient swings of the synchronous machines in the power system and has to be minimized.

\subsection{Discussion}

Both damping schemes as introduced above are two-input-single-output controllers. The input signal-pairs are utilized to infer the correct damping action. A closer look at these signalpairs reveals that the swings of the resulting power system state about the desired steady-state point have the same frequency but different phase information. The $\Delta E-\Delta I$ information lags the $\Delta P-\Delta E(\Delta \dot{\omega}-\Delta \omega)$ state by roughly one quarter of a cycle. This relationship requires a rotated switching line to yield the same control action and has been verified in simulations (see the Two area-Four machine case study, Damping - dynamic stability, p. 79). In some cases the addition of $\Delta I$ signal to the $\Delta P-\Delta E$ information as third input dimension has been suggested to avoid 
large deviation of the postfault power system from the prefault conditions [37. Therefore, the $\Delta E-\Delta I$ signal-pair has been chosen for the UPFC damping scheme.

The TSK-scheme as described above differs in one point from the fuzzy schemes using the general fuzzy logic concept of fuzzification-inference-defuzzification: The gain in the TSK-scheme is determined by the distance from the origin independent of the phase angle of the power system state whereas the general fuzzy logic scheme uses both the distance and the angle information. The differences in fuzzy consequence and damping controller behavior can also be found in the Two area-four machine system case study. The fuzzy controller is denoted as CM-fuzzy scheme due the center-average-method used in the defuzzification step.

The choice of active power as input signal has been made due to its direct relationship to the power imbalance during transients. Other measurements at the UPFC site contain similar information and have been used for the design of damping controls. For example, in [16] the bus frequency has been utilized and applied to superconducting magnetic energy storage (SMES) devices as actuators.

Extending the bus frequency measurement to both UPFC buses reveals the close relationship to another damping scheme found in the literature. The line power flow measurement can be replaced by the fictitious power flow between the sending and receiving UPFC buses due to the series transformer reactance as it is part of the injection model used to interface the UPFC: $P_{S R}=\frac{V_{S} V_{R}}{X_{S E}} \sin \left(\delta_{S}-\delta_{R}\right)$. The deviations in power flow are related to changes in bus frequencies by $\dot{P}_{S R} \simeq \frac{V_{S} V_{R}}{X_{S E}} \cos \left(\delta_{S}-\delta_{R}\right) \frac{d\left(\delta_{S}-\delta_{R}\right)}{d t}$. Therefore both signals, the change in power flow and frequency difference, contain information about transients and can be used to infer the required damping signal. The significance of the difference in bus frequencies has been found in both [67 and [50] by using the transient energy function approach (TEF). The TEF control law is given by

$$
\begin{array}{llll}
\text { IF } & \frac{d\left(\delta_{S}-\delta_{R}\right)}{d t}<0 & \text { THEN } & \varphi_{S E}=-\frac{\pi}{2}-\delta_{S R} \\
\text { IF } & \frac{d\left(\delta_{S}-\delta_{R}\right)}{d t} \geq 0 & \text { THEN } & \varphi_{S E}=+\frac{\pi}{2}-\delta_{S R}
\end{array}
$$

and determines the injected series voltage for damping control. The damping law has been summarized by [67] as "The active power injection by the controllable components must oppose the growth of the active power through the transmission line." The switching law can be implemented using relational operators or by the TSK-scheme with its input-signal conditioning unit and fuzzy switching logic applied to the $\Delta P-\Delta E$ signal pair. A study comparing both damping controllers can be found in the New England - New York power system case study, section 5.3.4, p. 96 . 


\section{Chapter 5}

\section{Power system case studies}

\subsection{Stability of the Two Area - Four Machine power system}

The proposed damping control scheme has been applied to the Two area - Four machine power system (Fig. 5.1) that is prone to instability after fault occurrence. This benchmark system has been intensively used to examine oscillations between two weakly linked areas (see for example [46], data is given in appendix C). The $230 \mathrm{~km}$ interconnecting tie-lines carry $400 \mathrm{MW}$ from area 1 into area 2 during nominal operating conditions. After a $100 \mathrm{~ms} 3$-phase fault in area 1 at bus 3, the line power flow starts oscillating. The UPFC is placed at bus 101 on one of the transmission lines to bus 13 in order to support the voltage at the bus and to control the active and reactive line power flows. The power system model using PAT's block library is shown in Fig. 5.2 .

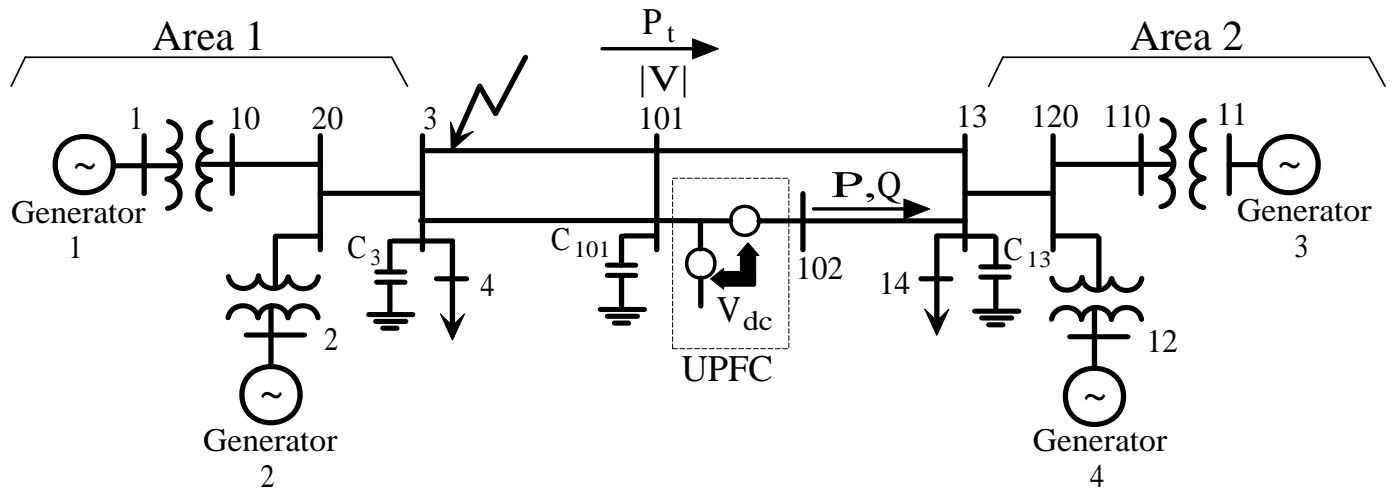

Figure 5.1: Two area - Four machine power system 


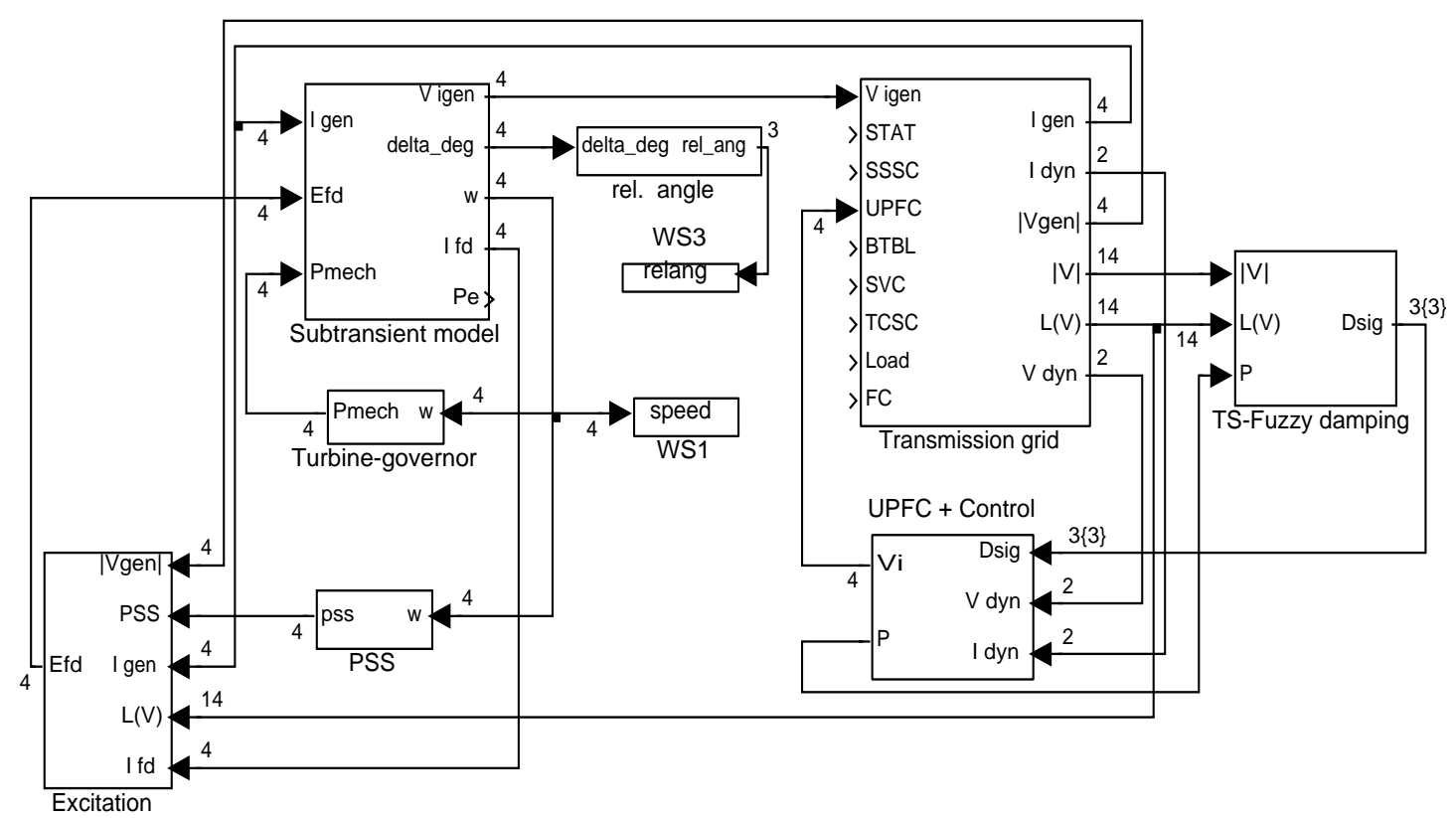

Figure 5.2: Simulink model of the Two area - Four machine system including UPFC

The placement of the UPFC is based on two considerations. First, for its basic operation, the possible steady-state stability improvement is of interest, and secondly, the optimal placement for disturbance measurement and damping. In the next section a brief discussion of the load flow related studies including steady-state voltage stability will be given followed by transient stability studies evaluating the effect of the fuzzy damping scheme.

\subsubsection{Load flow and voltage stability}

The shunt compensation possibility can improve the overall voltage stability of the power system within its specified power rating. The voltages of the power system both with and without the UPFC as a function of the load power ratio are shown in Fig. 5.3. The necessary shunt VAR compensation in case of the applied UPFC is given in Fig. 5.4 a. Whenever the chosen limit of 320 MVA is violated the reference voltage for the sending bus is reduced by a small amount $(0.5 \%)$ until a solution within the rating is found. Note that the power ratio of 1 pu refers to the condition as given as case (a) in Table 5.2. The sudden steps in some of the bus voltages are caused by the tap changers at the load buses. Also, the buses with constant voltage belong to 


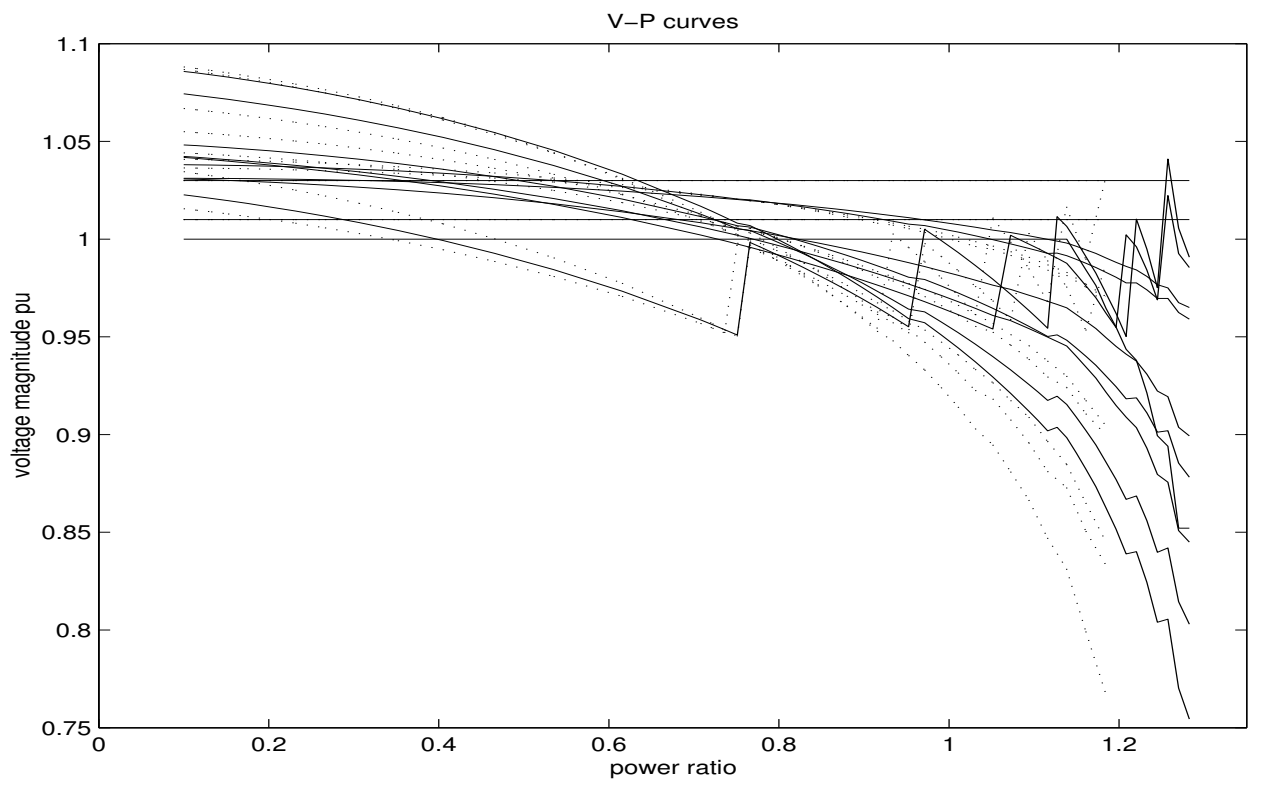

Figure 5.3: Two area system: Voltage stability (dotted - w/o UPFC, solid - with UPFC)

Table 5.1: Two area system: Injected series voltages

\begin{tabular}{|c|c||c|c|c|c|c|c|}
\hline$V_{S E}$ & $\mathrm{pu}$ & 0.005 & 0.010 & 0.025 & 0.050 & 0.100 & 0.150 \\
\hline$\varphi_{S E}$ & $\mathrm{deg}$ & 0 & 10 & $\cdots$ & $\cdots$ & 350 & 360 \\
\hline
\end{tabular}

the generators $\left(\left.1.01 \mathrm{pu}\right|^{1}\right.$ and $1.03 \mathrm{pu}$, respectively). The UPFC sending bus voltage is set to $1 \mathrm{pu}$ in the beginning. When the power rating is violated the voltage rapidly drops until the load flow fails to converge. The overall loading could be improved from $1.18 \mathrm{pu}$ to $1.26 \mathrm{pu}$ resulting in an increase of $6.8 \%$. During the dynamic stability study part of the necessary shunt compensation for a voltage of $1 \mathrm{pu}$ will be supplied from a switched capacitor bank of $160 \mathrm{MVA}$, leaving the UPFC to compensate for mostly post-disturbance VAR demands. Besides increasing steady-state stability, the installation at the mid-point of the long distance transmission line is favorable due to the possibility of improved system damping widely independent of operating conditions [46].

Additional investigations regarding the load flow characteristics of the system including the UPFC are concerned with the range of receiving voltage magnitude, converter ratings, and active and reactive line flows as function of the injected series voltage. Load flow computations using the combinations of injected magnitude and relative angle as given in Table 5.1 were performed.

Fig. $5.4 \mathrm{~b}$ shows that the sending bus can be stabilized at the desired value, but only at the cost of extreme voltage deviations on the receiving side. Such negative and limiting effects should be considered when designing a control scheme for the UPFC.

\footnotetext{
${ }^{1}$ System base power $S_{B}=100 M V A$
} 


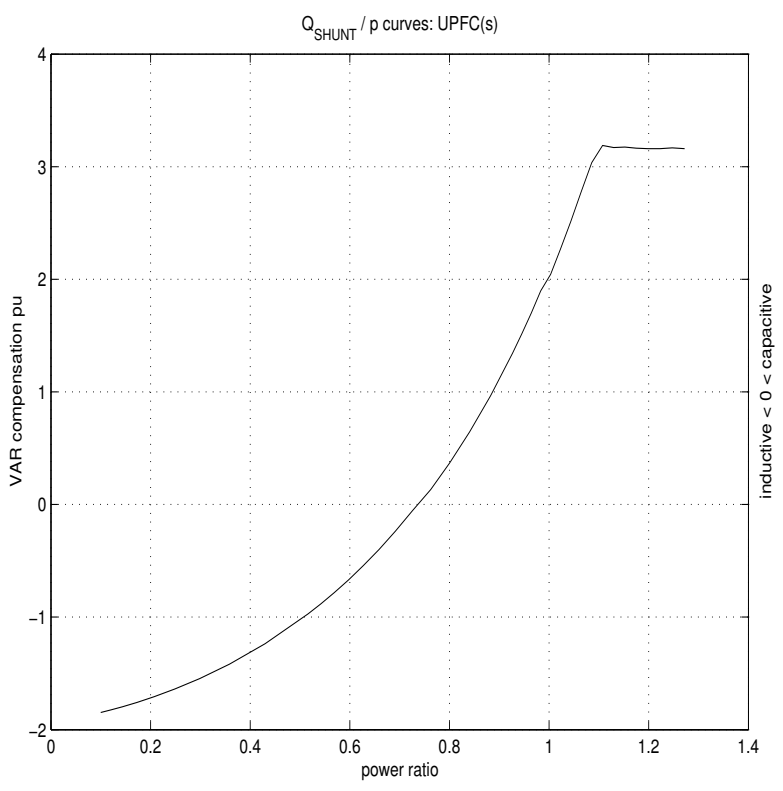

(a) Compensation at sending bus

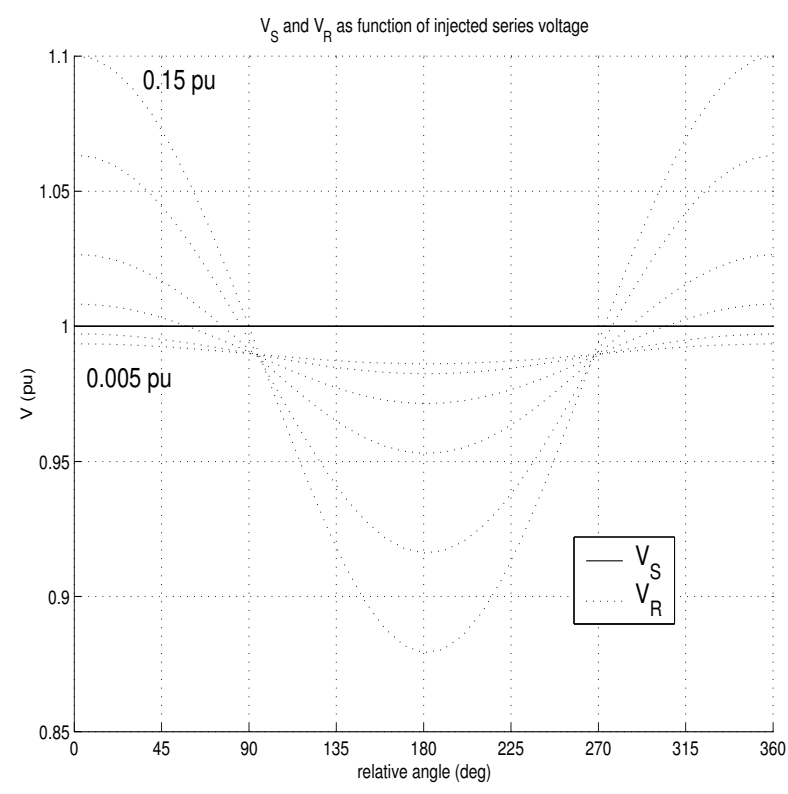

(b) Sending and receiving voltages

Figure 5.4: Two area system: UPFC load flow characteristics

Furthermore, the shunt and series converter worst case interactions with the power system have been recorded (Fig. 5.5) for analysis of possible converter ratings using a capacitor bank at the sending bus of 160 MVA. A rating of 160 MVA for both converters (allowing the series converter as a backup shunt compensator) seems satisfactory for all expected operating conditions. More details of the interactions as a function of the two parameters, voltage magnitude and relative angle, are given in Fig. 5.6. It is worthwhile to note that the reactive compensation as a major factor concerning the shunt rating can clearly be seen. The maximum series converter interaction is also determined by the reactive part but varies muss less due to an increased active power influence.

The active and reactive power flows for the chosen voltages are depicted in Fig. 5.7a. Additionally, the same study was performed in the time domain using the Simulink MDL-case file. For every magnitude the angle was uniformly ramped over the $360^{\circ}$ range. The total process was set to complete in 170 seconds. As can been seen, the results are in agreement with each other. The differences are caused by system dynamics. Though existent, the dynamic process of increasing the injected voltage magnitude to the next level at an injected relative angle of $0^{\circ}$ cannot be seen at this scale. In the case of the two area system the transients are too small in magnitude and decay too fast to be observed. Fig. 5.7b presents the resulting line power flow differently from 


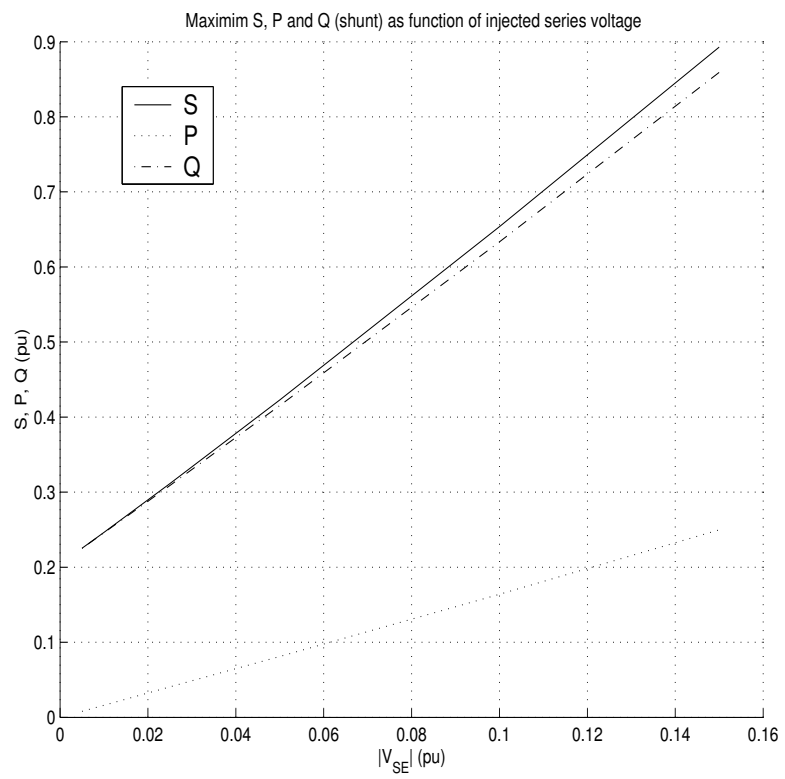

(a) Shunt

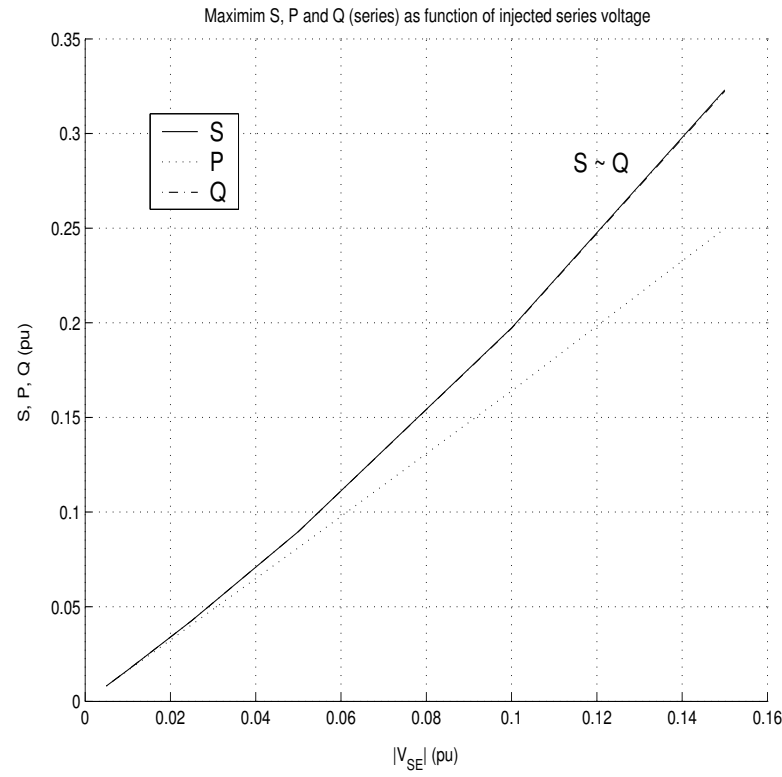

(b) Series

Figure 5.5: Two area system: Maximum UPFC converter interactions

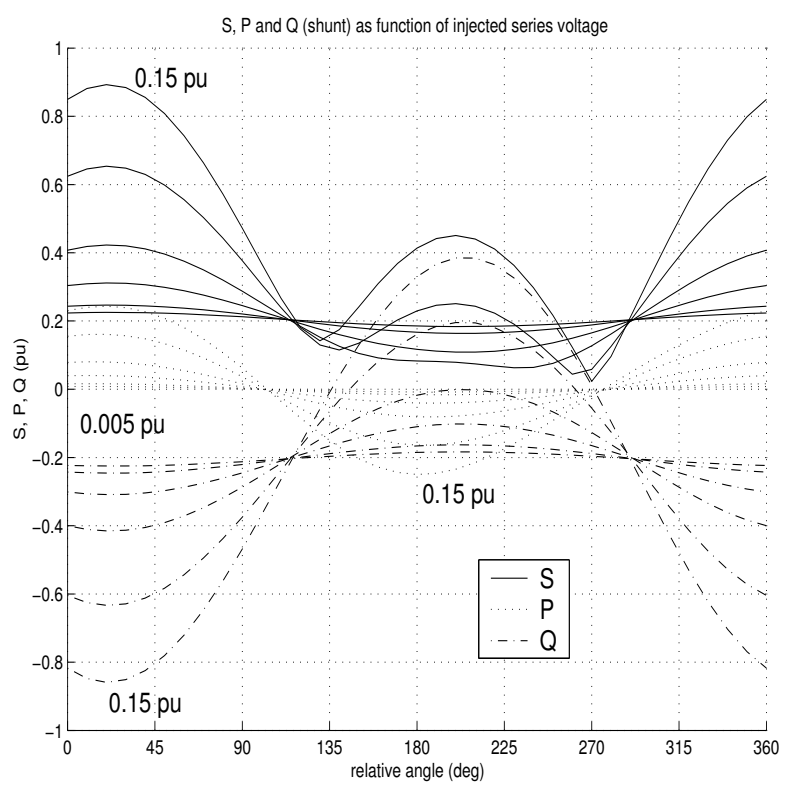

(a) Shunt

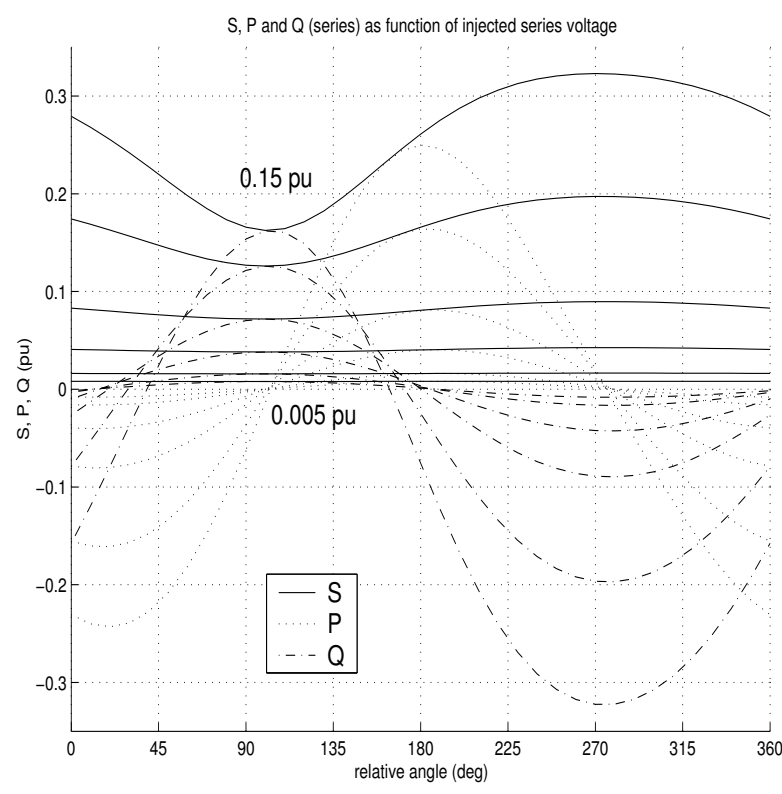

(b) Series

Figure 5.6: Two area system: Converter interactions 


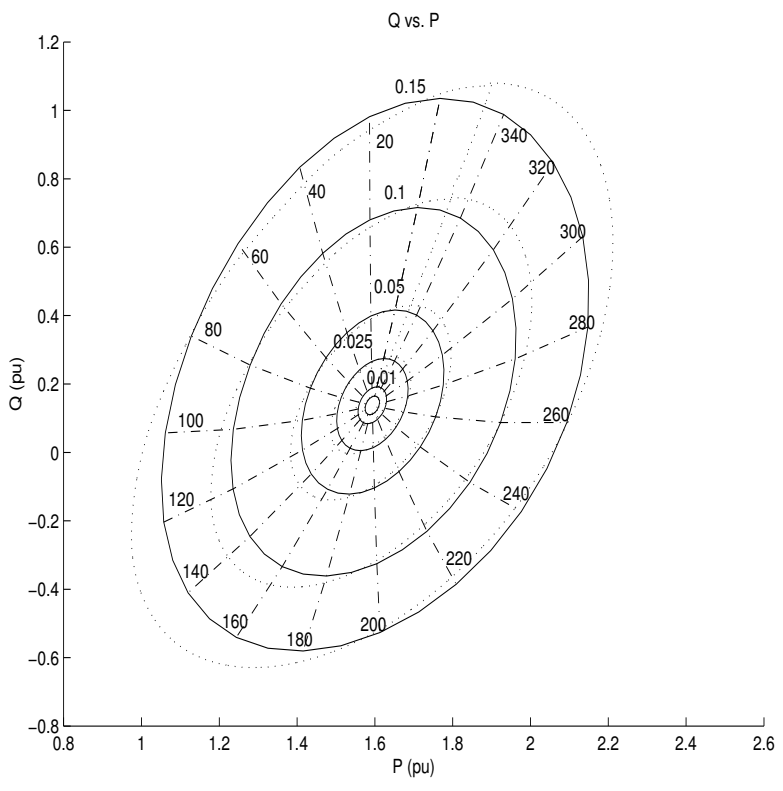

(a) Reactive vs. active flow (solid - LF, dotted - time domain)

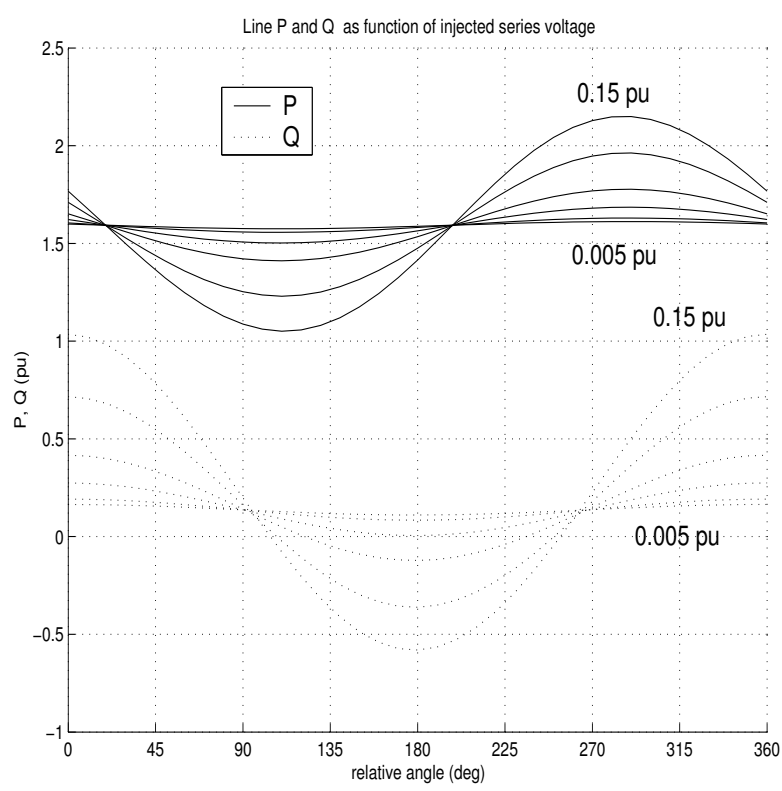

(b) Power flows vs. relative angle

Figure 5.7: Two area system: Active and reactive line flows

Fig. 5.7 to highlight the almost $90^{\circ}$ phase rotation between active and reactive power flow.

The basic series control scheme makes use of the property of almost decoupled active and reactive line power flow control via the voltage components $V_{P}$ and $V_{Q}$. The influence of changing one of the two components at a time has been studied and the result is depicted in Fig. 5.8. The arrows denote the changes in line power flows by increasing either $V_{P}$ (ranging from -0.15 pu to $0.15 \mathrm{pu}$ ) or $V_{Q}$ (ranging from $-0.05 \mathrm{pu}$ to $0.05 \mathrm{pu}$ ).

\subsubsection{Damping - dynamic stability}

In order to show the usefulness and robustness of the proposed control scheme, various operating conditions were simulated. Also, the scheme proposed here has been compared to the fuzzy scheme presented in [80] (referred to as CM-fuzzy method). Both the active power that each interconnecting tie-line carries from area 1 to area 2 during pre-fault operation as well as the MVA rating of the capacitor bank at bus 101 are shown in Table 5.2. The capacitor bank is used to maintain the sending bus steady-state voltage magnitude of $1 \mathrm{pu}$ which allows the UPFC shunt rating to be fully utilized for transient control. The fuzzy controllers are applied to the series converter side. Both fuzzy damping controllers were designed for operating condition (a). 


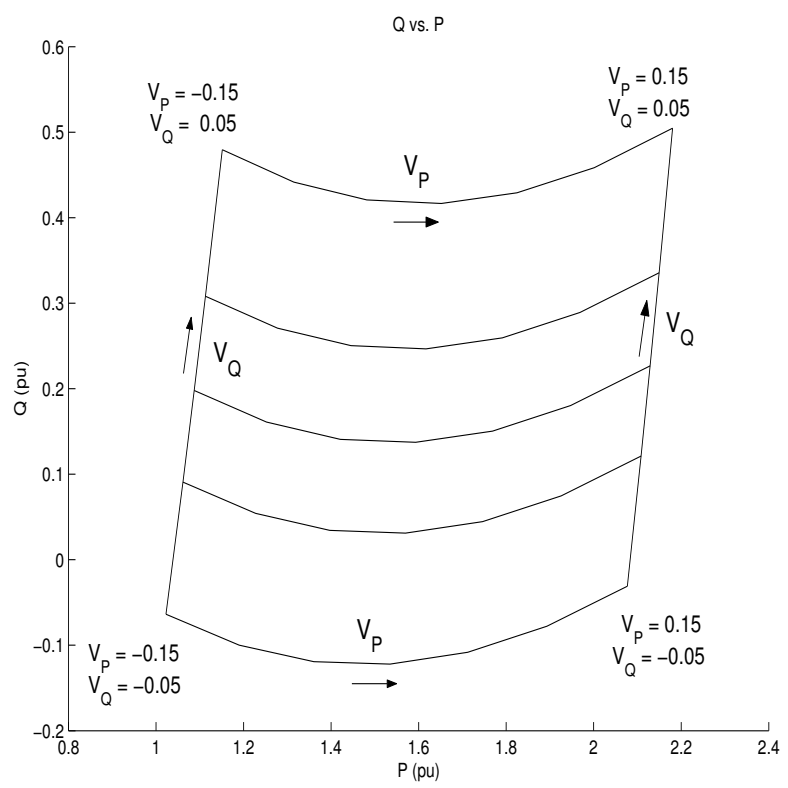

Figure 5.8: Two area system: Line flows as controlled by series VSC control scheme

The simulation results for the relative machine angle between machine 1 and $3\left(\delta_{1-3}\right)$ in Fig. 5.9 a show that the damping of the swings could be increased. The same improvement was observed for the other two operating conditions. Both input-signal pairs, $\Delta P-\Delta E$ (CM-scheme) and $\Delta E$ $\Delta I$ (TSK-scheme), have been used in the case study to demonstrate their abilities in damping transients.

A closer look at the first seconds of case (a) is depicted in Fig. 5.9b by comparing the swings for the six cases ranging from no PSS to PSS+UPFC+fuzzy-damping control. It is interesting to note that the UPFC without damping control decreases stability during this initial phase before its damping becomes eventually better than without the UPFC installed. An observation that has been found by several researchers, e.g., [91. The supplementary control signal for case (a) is shown in Fig. 5.10 and has also been added to the fuzzy consequence surfaces in Fig. 5.11. The scheme and its tuned parameters result in a primarily bang-bang control behavior during the initial transient period. Also, the proposed gain adjustment method works satisfactorily. It reduces the control effort accordingly for a smooth transition from transient stability control to a small-signal control until it turns of the damping control completely. The advantage of the TSK scheme over the CM-scheme is that the same good damping can be achieved with both reduced amount and less complex computations. The TSK scheme was also compared to the linear gain scheduling scheme and proved to reduce the control effort after the initial transient period with 
Table 5.2: Two area system: Operating conditions (values in MW and MVA)

\begin{tabular}{|c||c|c|c|c|c|}
\hline case & $\begin{array}{c}\text { line } \\
\text { 101-13 }\end{array}$ & $\begin{array}{c}\text { line } \\
\mathbf{1 0 2 - 1 3}\end{array}$ & $\begin{array}{c}\text { load } \\
\text { bus 4 }\end{array}$ & $\begin{array}{c}\text { load } \\
\text { bus 14 }\end{array}$ & $\begin{array}{c}\text { capacitor } \\
\text { bank 101 }\end{array}$ \\
\hline \hline a.) & 232 & 160 & 976 & 1767 & 160 \\
b.) & 24 & 160 & 1176 & 1567 & 80 \\
c.) & -232 & -160 & 1767 & 976 & 160 \\
\hline
\end{tabular}

Table 5.3: Two area system: Interarea mode for different system configurations

\begin{tabular}{|c||c|c|c|}
\hline $\begin{array}{c}\text { system } \\
\text { configuration }\end{array}$ & $\begin{array}{c}\text { interarea } \\
\text { mode }\end{array}$ & $\begin{array}{c}\text { damping } \\
\mathbf{\%}\end{array}$ & $\begin{array}{c}\text { expected settling } \\
\text { time } t_{2 \%}(\mathbf{s})\end{array}$ \\
\hline \hline No PSS & $0.160 \pm \mathrm{j} 3.398$ & -4.8 & - \\
\hline PSS pre-fault & $-0.282 \pm \mathrm{j} 3.360$ & 8.4 & 14 \\
\hline PSS post & $-0.085 \pm \mathrm{j} 2.719$ & 3.1 & 46 \\
\hline UPFC pre-fault & $-0.568 \pm \mathrm{j} 3.539$ & 15.8 & 7.5 \\
\hline UPFC post & $-0.297 \pm \mathrm{j} 2.745$ & 10.7 & 13 \\
\hline TSK pre-fault & $-0.579 \pm \mathrm{j} 3.546$ & 16.1 & 6.5 \\
\hline TSK post & $-0.295 \pm \mathrm{j} 2.748$ & 10.7 & 13 \\
\hline
\end{tabular}

either better or similar overall damping of the angle swings. The maximum values for the injected voltage components in phase and perpendicular to the sending bus voltage were set to $0.3 \mathrm{pu}$ and $0.15 \mathrm{pu}$, respectively. Those values allow to force the desired line power flow without excessive stress on the system due to the short transient period. Of major concern during the first few seconds is the converter current. The short time overload capacity for case (a) requires shunt currents of up to $2.5 \mathrm{pu}$ (nominal is $1.6 \mathrm{pu}$ ) whereas the series converter rating is satisfactory.

Linear analysis has been used to evaluate the small signal characteristics of system configurations at operating condition (a). The dominant interarea modes for various system configurations are given in Table 5.3. The unstable eigenvalue pair (pre-fault case - before the line is removed) is shifted by the PSSs as applied to the two fast exciters (one in each area) to a damping of $3 \%$ (post-fault case - one line between bus 3 and 101 removed). The UPFC further improves the damping to $10 \%$. These eigenvalues match the transient response in expected damping and frequency very well, only the damping value for the UPFC with TSK-fuzzy damping scheme seems to be underestimated. The fuzzy control was replaced by a second-order function to approximate the small-signal behavior, a combination of a washout, gain, and first-order filter. Though the resulting damping coefficient does not give a close match for the large disturbance it resembles the system behavior in the small at the end of the swings. 


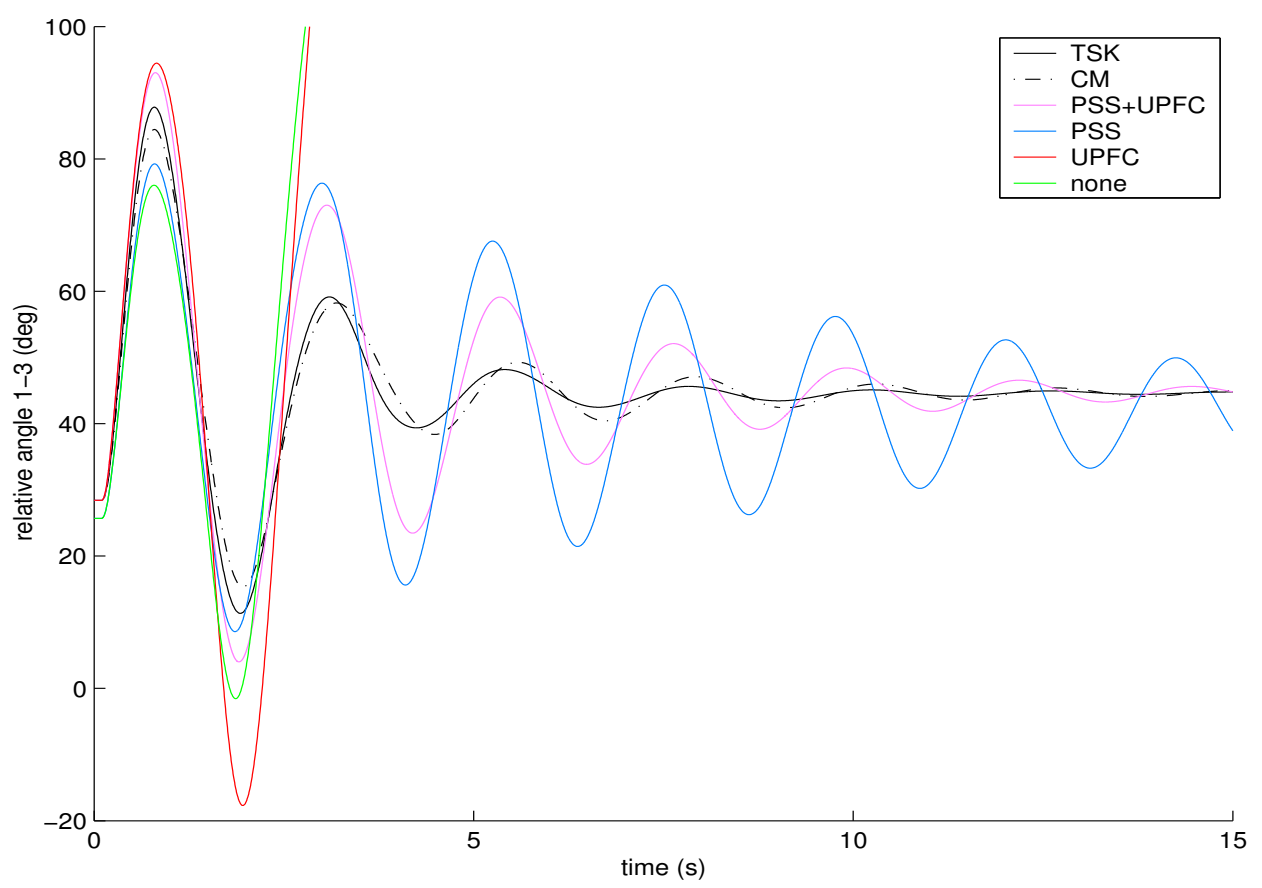

(a) Transient period

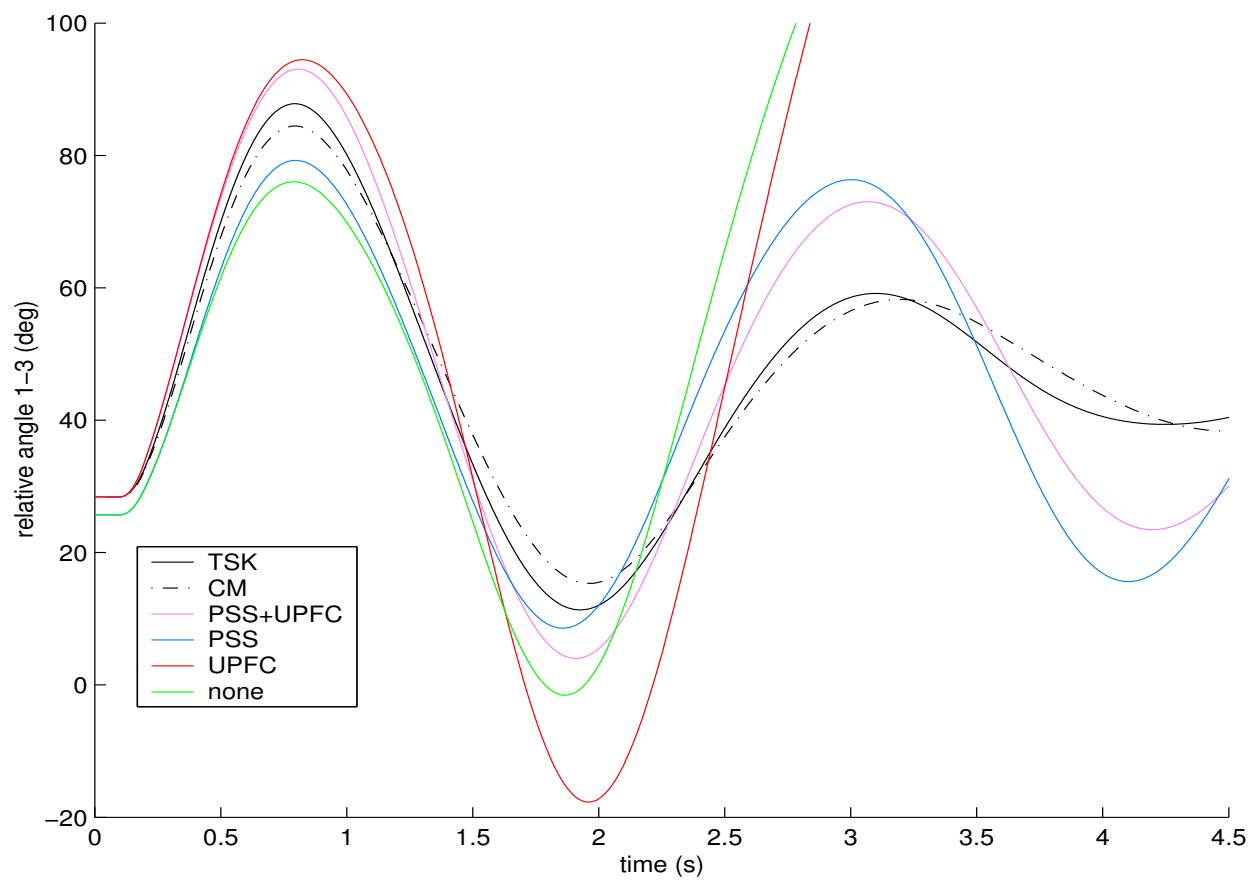

(b) First swing comparison

Figure 5.9: Relative machine angles $\delta_{1-3}$ for case (a) 


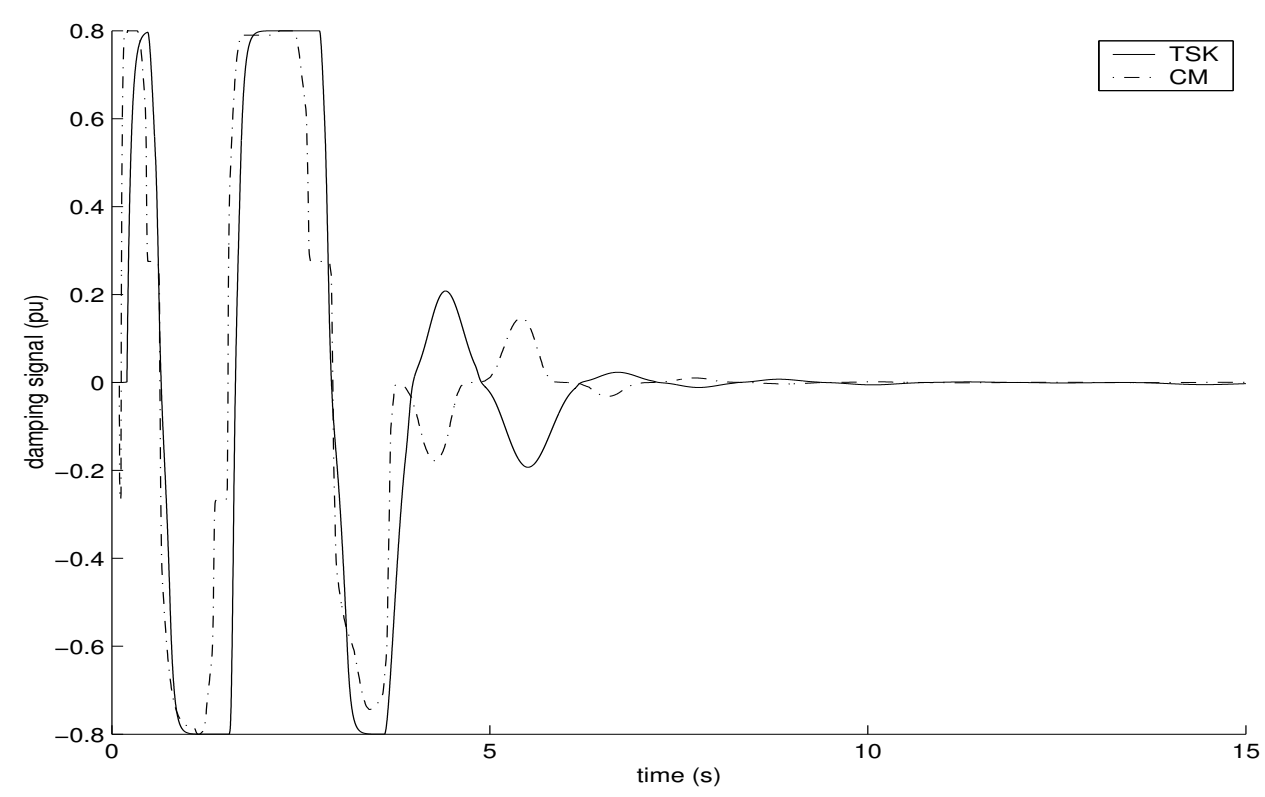

Figure 5.10: Damping signals of CM- and TSK-fuzzy schemes for case (a)

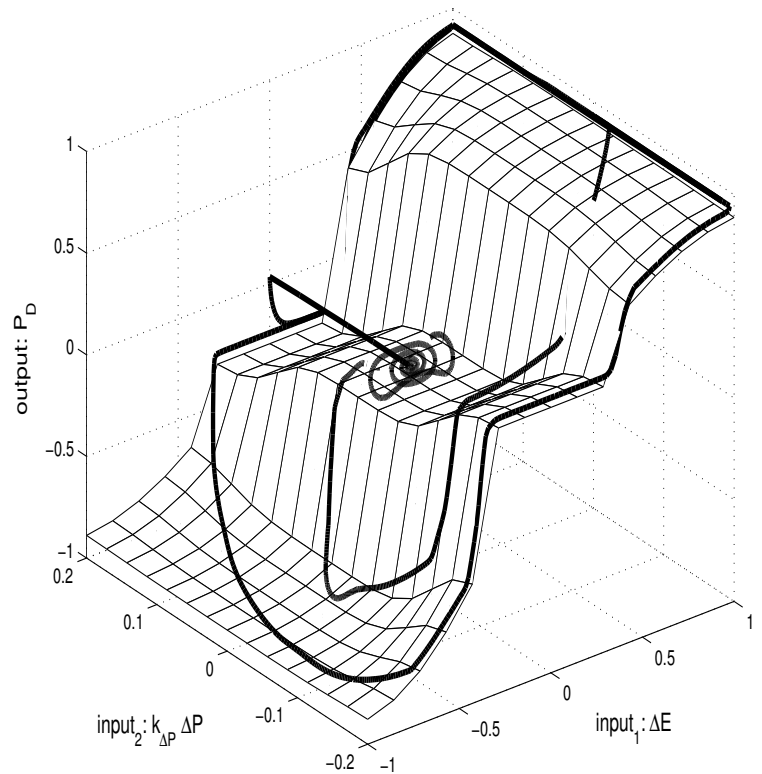

(a) CM-scheme

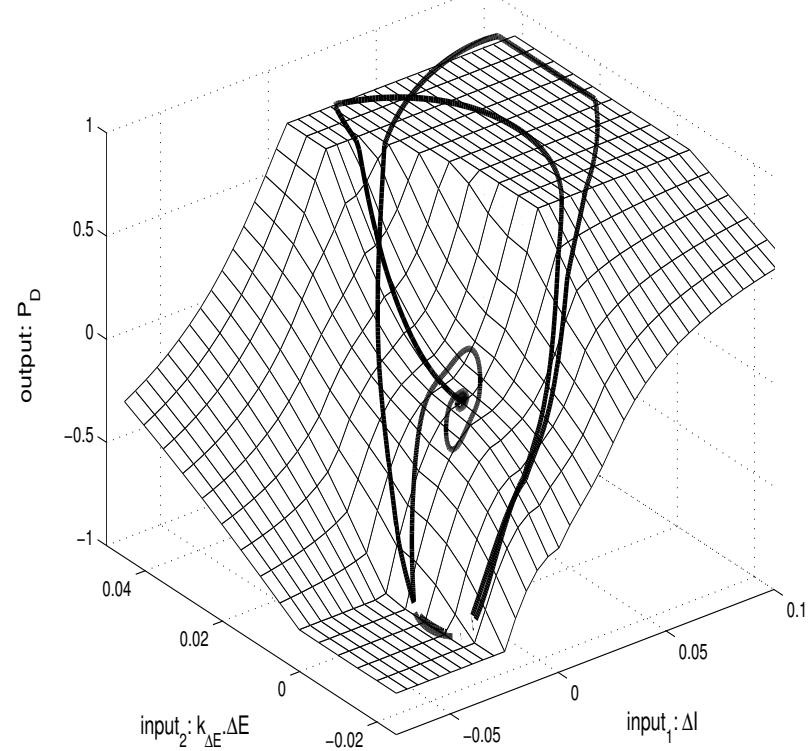

(b) TSK-scheme

Figure 5.11: Two area system: Consequence surfaces of fuzzy schemes 


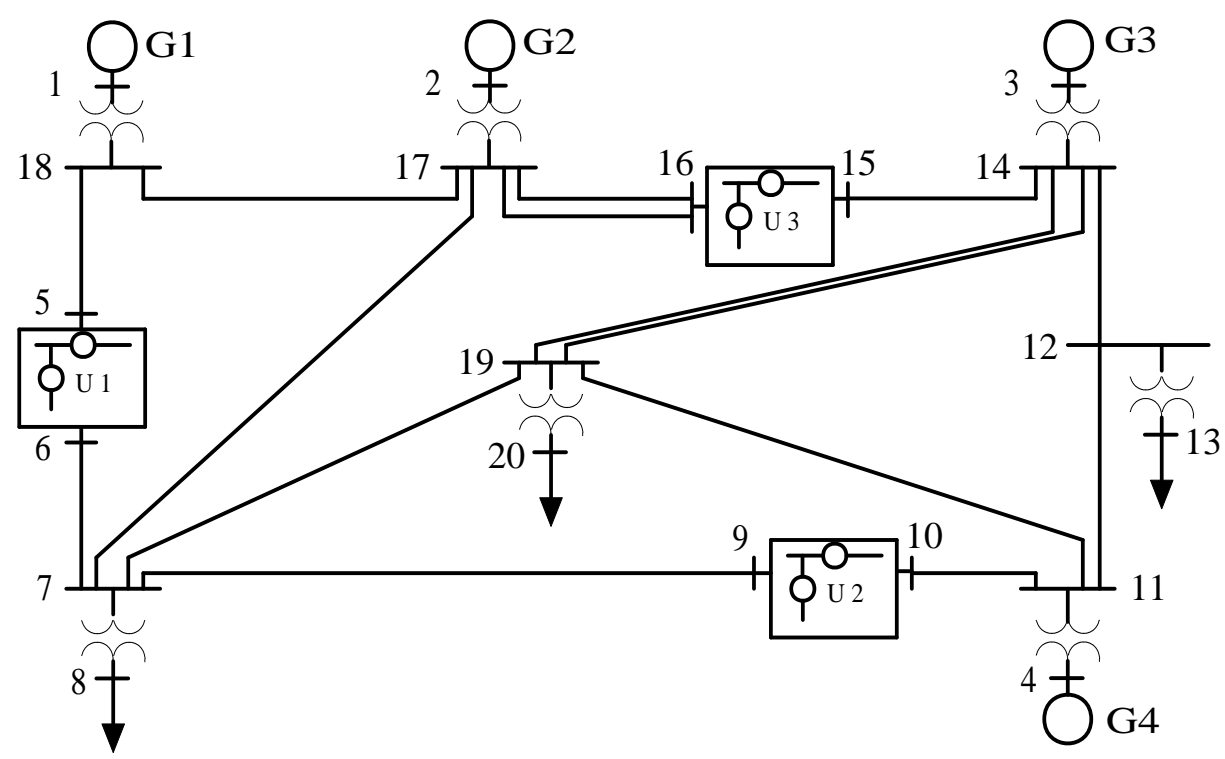

Figure 5.12: Meshed power system

\subsection{Meshed power system}

\subsubsection{Investigating the influence of the UPFCs using local signals}

The second case study involves a much more interconnected power system. The system has been taken from [8], [31] and is shown in Fig. 5.12. It consists of 4 generators, 3 loads, 20 buses, and 3 UPFCs. The system has some interesting characteristics due to its relatively high degree of interconnections and will therefore be referred to as the Meshed power system ${ }^{2}$ (MPS) in the following. The focus will be on the dynamics of the system after a large disturbance has occurred.

Three UPFCs have been placed throughout the system to allow a high degree of flexibility in power flow control and to study the coordination of these in order to ensure a broad range of goals. Some of these are: (a) keep MVA flows on the lines within limits, (b) in case of overloads use the most effective UPFC, and (c) automatically reconfigure control parameters after outages. The control schemes used include the basic ability of the UPFCs to control sending bus voltage magnitude, real and reactive power flow at the receiving bus, and a multi-input-multi-output (MIMO) stabilizer for each UPFC using local inputs. The MIMO stabilizer was designed using the state space representation of the full power system to ensure overall stability. The signal

\footnotetext{
${ }^{2}$ The system has been modeled within PAT to result in a dynamic response as close as possible to the cited one. No attempt was made to improve the transient characteristic by either redesigning basic controls or changing device ratings.
} 
Table 5.4: MPS: UPFCs' influence on active line flows (in \%)

\begin{tabular}{|c|c|c||c|c|c||}
\cline { 2 - 6 } \multicolumn{2}{c|}{ Bus } & UPFC 1 & UPFC 2 & UPFC 3 \\
& From & To & $(\mathbf{5}-\mathbf{6})$ & $(\mathbf{9}-\mathbf{1 0})$ & $(\mathbf{1 5}-\mathbf{1 6})$ \\
\hline \hline 1 & $\mathbf{6}$ & $\mathbf{7}$ & 100 & - & - \\
\hline 2 & $\mathbf{7}$ & $\mathbf{9}$ & - & 100 & - \\
\hline 3 & $\mathbf{7}$ & $\mathbf{1 9}$ & - & -100 & 100 \\
\hline 4 & $\mathbf{1 0}$ & $\mathbf{1 1}$ & - & 100 & - \\
\hline 5 & $\mathbf{1 1}$ & $\mathbf{1 2}$ & - & 34.21 & 26.32 \\
\hline 6 & $\mathbf{1 4}$ & $\mathbf{1 2}$ & - & -34.21 & -26.32 \\
\hline 7 & $\mathbf{1 4}$ & $\mathbf{1 5}$ & - & - & 100 \\
\hline 8 & $\mathbf{1 4}$ & $\mathbf{1 9}$ & - & 17.11 & -36.84 \\
\hline 9 & $\mathbf{1 4}$ & $\mathbf{1 9}$ & - & 17.11 & -36.84 \\
\hline 10 & $\mathbf{1 7}$ & $\mathbf{7}$ & -100 & - & 100 \\
\hline 11 & $\mathbf{1 6}$ & $\mathbf{1 7}$ & - & - & 50 \\
\hline 12 & $\mathbf{1 6}$ & $\mathbf{1 7}$ & - & - & 50 \\
\hline 13 & $\mathbf{1 8}$ & $\mathbf{5}$ & 100 & - & - \\
\hline 14 & $\mathbf{1 8}$ & $\mathbf{1 7}$ & -100 & - & - \\
\hline 15 & $\mathbf{1 1}$ & $\mathbf{1 9}$ & - & 65.79 & -26.32 \\
\hline \hline
\end{tabular}

generated by the transient damping controllers are applied at the output of the basic controllers and fed to the converter control to generate appropriate firing signals (Note that the TSK-scheme applies its signal at the input of the basic control to allow device limitations to be ensured.)

The UPFCs' influence on active power flows using the modified generation shift factors as defined in [8] are given in Table 5.4. The entries in the table give the change in active line flows due to a change in UPFCs' controlled active line powers and have been scaled to the changes in the reference commands.

Two interesting conclusions have been drawn by analyzing a $100 \mathrm{~ms} 3$-phase short circuit at the midpoint of line 19-11 (reclosing followed $220 \mathrm{~ms}$ after the fault had been cleared). Firstly, due to the high degree of interconnectivity and its inherent good damping characteristic the addition of damping controllers does not improve the damping of transients. Secondly, rather than designing (costly) damping controls it is in the favor of the system to deactivate the fast basic controls of the UPFCs to decrease the first swing peaks. These results are depicted by the injected active generator power (Fig. 5.13) as well as the injected reactive shunt current part and applied active power flow control voltage component of UPFC 2 (Fig. 5.14). The nearby generator 4 is influenced most and has its output power flow reduced to $25 \%$ during the short-circuit time period. The basic UPFC control (focusing on nearby UPFC 2 in the following) responds quickly to the fault and reaches the limit for power flow control. This yields a large peak in generator 
output at the time of fault clearing and line reclosing. While the deactivation of the basic contro $3^{3}$ results in reduced initial transients and it maintains the same damping characteristics.

The proposed TSK-damping scheme has been applied to study the impact on the system. The resulting transients have been added to the figures. The results support the conclusion that the damping can be hardly improved if at all for this (type of) power system. Basic controls have been disabled for the fault duration and then reactivated to allow the sending bus voltage control as well as the TSK-damping scheme to augment the active line power flow. The damping control helps to improve the first swing characteristic and then turns itself off.

This result is in sharp contrast to the Two area - Four generator system response where the first swing was almost fully determined by the fault and system inertia and the subsequent damping could be improved by the TSK-scheme. The reason for this shift is caused in the transmission system. Augmenting the controlled line flow in the longitudinal two area system results in explicit changes in generators' electrical output power. Also, the transients were locally predictable as they were mostly in phase in each area and out-of-phase between the areas. The meshed power system such as that studied here seems to be a good representative of limitations as observed by the power system industry. As $[87]^{4}$ notes: Large-scale real-world systems as opposed to single machine-infinite bus systems and somewhat more complex three or four machine systems show hardly any performance improvement using FACTS devices. Properly tuned conventional PSSs seem to be the best answer considering both technical and financial resources. FACTS devices may even degrade the overall performance through adverse interactions between controls.

\subsubsection{Investigating the influence of the UPFCs using wide-area measurements}

The inability of the local damping scheme sparked interest in the question of whether UPFCs can improve the overall transient stability of the system in the event that more details about the actual power system state are available. Today's possibility of wide-area measurements (see for example [87]) allow the communication of remote measurements to distant places. Therefore, an alternative damping scheme based on remote measurements will be introduced and its influence on system behavior examined. The following assumptions are made: (a) The accelerating power $\left(P_{a c c}\right)$ of each generator is measurable, $(b)$ the measured power can be transmitted to each UPFC,

\footnotetext{
${ }^{3}[8$ used an autonomous coordination scheme that derived rules for a fuzzy gain scheduling. The gain as inferred is used to turn the basic control off (allowing the damping controller to fully operate the UPFC) as soon as a major disturbance has been detected. After swings are almost damped the basic control is reactivated. A simple time controlled deactivation scheme has been used here to reproduce the overall system behavior.

${ }^{4}$ Appendix J: A new look at damping control, p. J-1.
} 


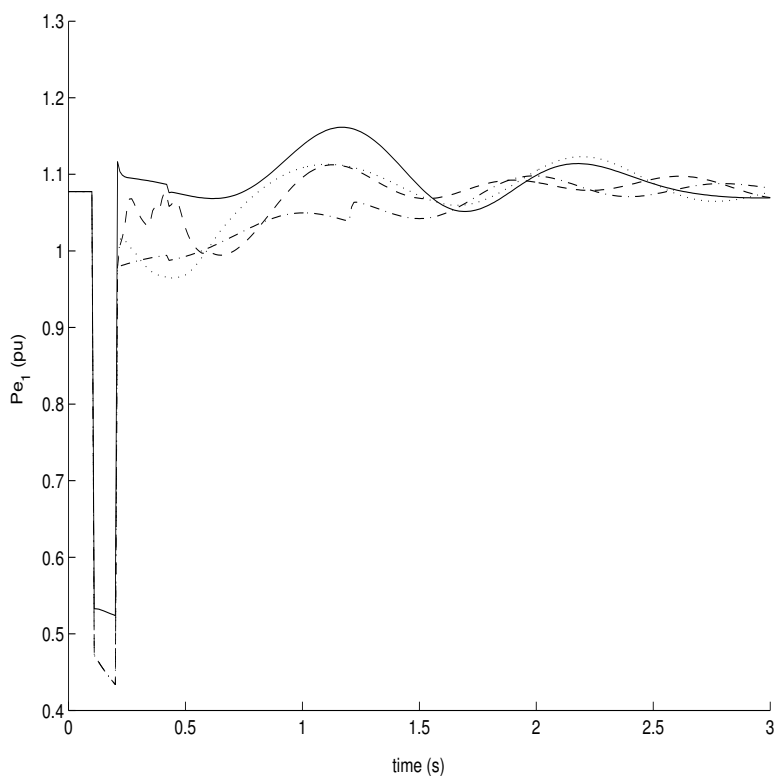

(a) Generator 1

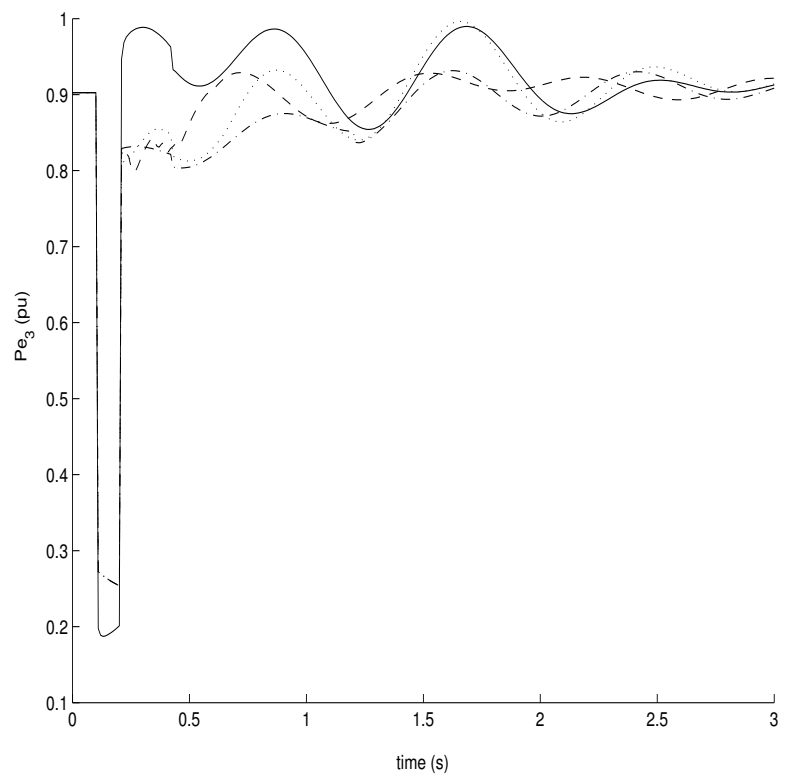

(c) Generator 3

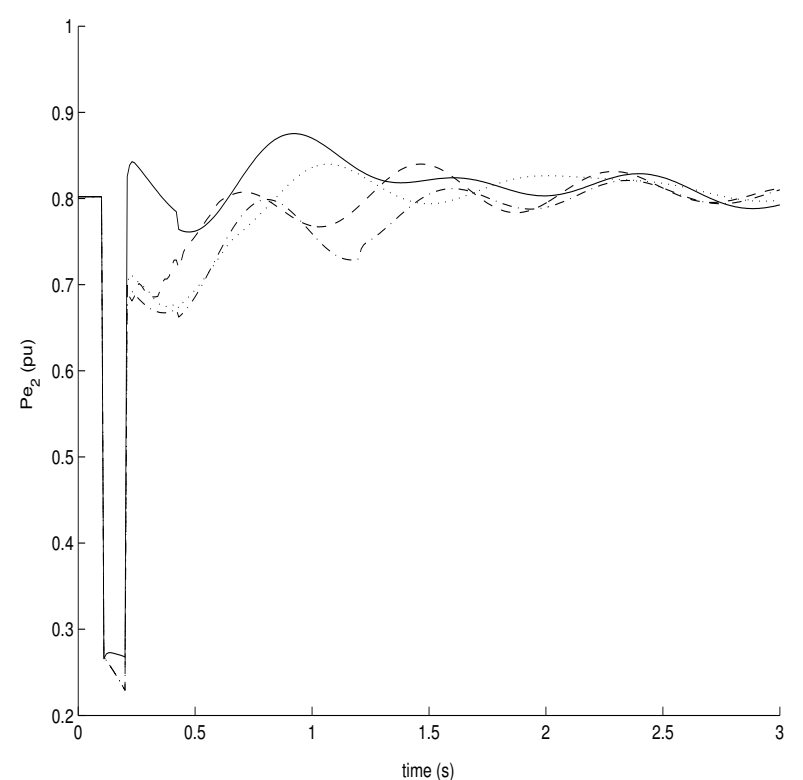

(b) Generator 2

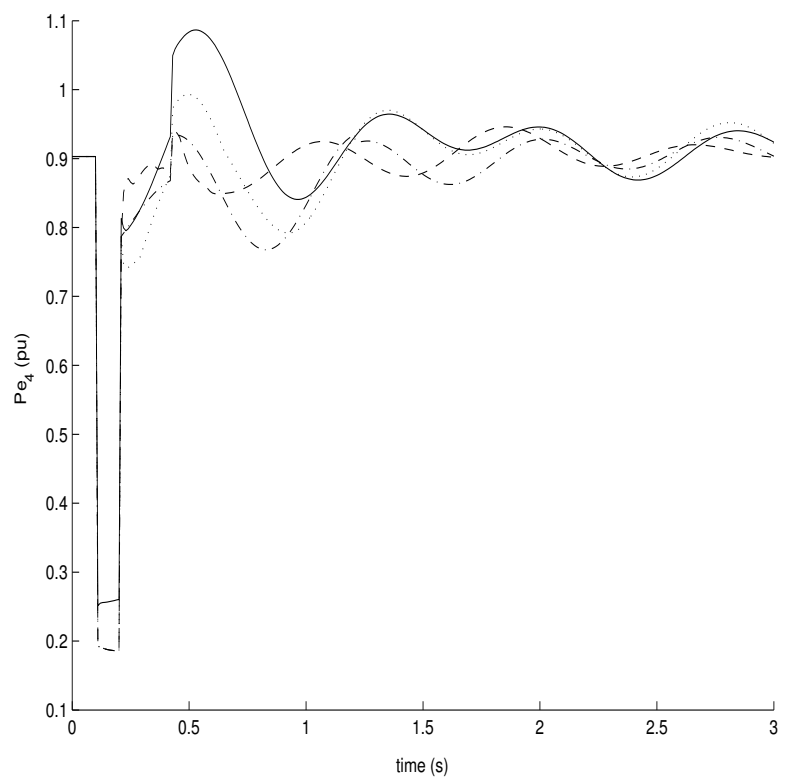

(d) Generator 4

Figure 5.13: Active power injected by generators 1-4 (solid - active, dash-dotted - inactive, dotted - TSK, dashed - voting) 


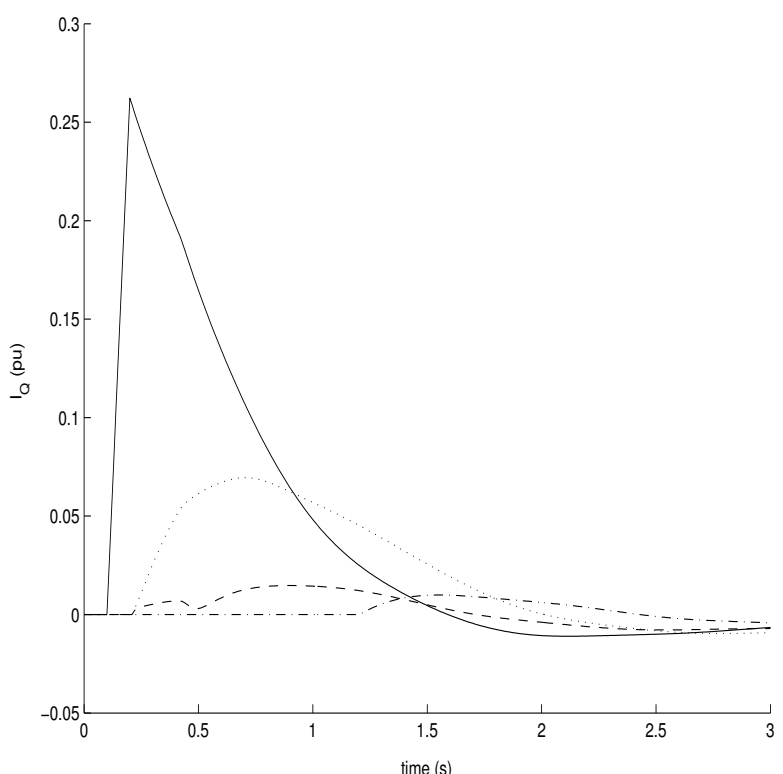

(a) Reactive current component

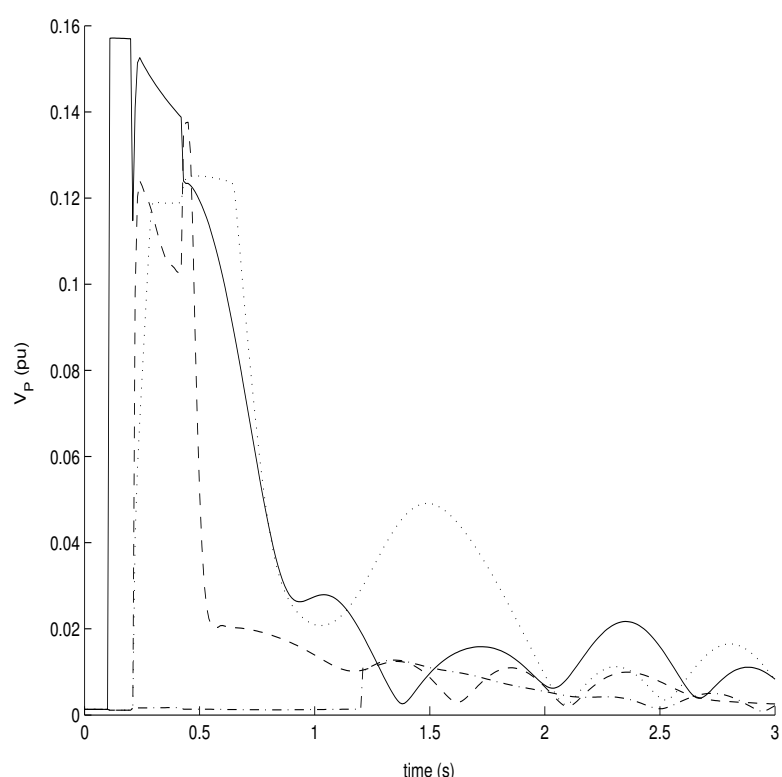

(b) Voltage component controlling active power

Figure 5.14: Controlled components of UPFC 2 (solid - active, dash-dotted - inactive, dotted TSK, dashed - voting)

(c) a table relating a change in active line power flow at each UPFC to a change in accelerating power of each generator is available, and (d) by using the table and a voting process the correct damping signals can be inferred.

Comments on these assumptions: The communication requirements of twelve channels (4 generators * 3 UPFCs) with a reasonable limit on delays should be realizable with respect to both technical and economical aspects. The table can be created using the linearized system or simply by evaluating the response to a forced line power flow augmentation. The only practical problem is the determination of the accelerating power due to the involved mechanical component $\left(P_{a c c}=\right.$ $P_{\text {mech }}-P_{e}$ ), which needs to be estimated/computed from the actual speed (or frequency) of the generator, e.g., through use of a common washout elements and filters. Using the accelerating power and speed deviation as input signals, the TSK-scheme is used to determine each generator's state.

Using the telemetered state signals at the local UPFC sites the table is used to determine the currently best control action; Increasing or decreasing the line flow? Due to its underlying principle, to infer the correct action by allowing each generator to submit its suggestion and to find the winning action by determining which action has been chosen most often, the scheme 


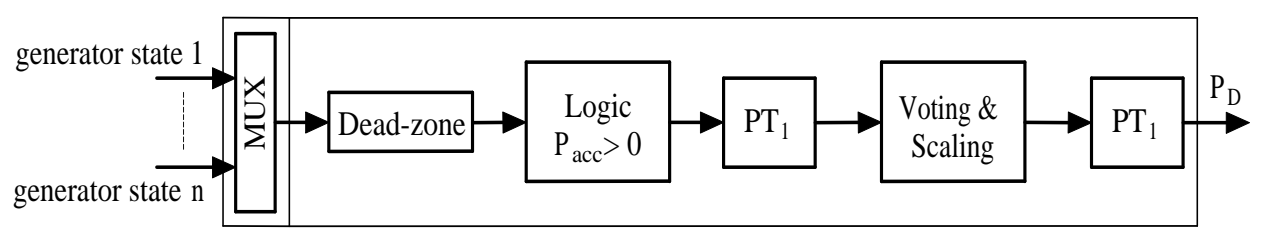

Figure 5.15: Voting damping controller

will be referred to as the voting damping controller in the following. The UPFCs' influence as evaluated through using a small sinusoidal excitation signal is given in Table 5.5. The phase shifts in swings in accelerating power have been translated into the linguistic terms accelerating and decelerating. These two terms link the local UPFC action to the change in generators' electrical power outputs causing acceleration or deceleration. Once the decision on the correct damping action has been made the table is used to find the appropriate UPFC control command. The entry for UPFC 2 - generator 2 shows a phase shift somewhere between both, and is therefore an indicator that no reliable action can be inferred and will thus be ignored by the voting process. The damping controller scheme is shown in Fig. 5.15. It includes $\mathrm{PT}_{1}$ elements at the in- and outports to model delays as well as a dead-zone to restrict damping actions to larger deviations from the steady-state only $5^{5}$

The control scheme was tested under the same conditions as stated above and the results have been added to the previously mentioned figures. The damping signals inferred by voting are shown in Fig. 5.16. The simulation results depict that this system has the best first swing behavior. Also, the damping scheme correctly turns itself off shortly after line reclosing, leaving the system to its inherent damping. Whereas the local scheme suffered from control interactions, the global scheme uses input signals that represent the state of the system (observability) well and the UPFCs are able to remotely augment the generators' electric power outputs correctly using the voting process resulting in limited and coordinated damping actions (controllability).

\footnotetext{
${ }^{5}$ The scheme proposed here is only meant to be a reference for a possible coordinated control of multiple FACTS devices. Besides the influence of time delays on signal transmission and the voting process no other investigations into technical difficulties and parameter tuning have been performed. It was found that delays of up to $100 \mathrm{~ms}$ result in improved performance.
} 
Table 5.5: MPS: UPFCs' influence on generators

\begin{tabular}{|c|c|c|c|c|c|c|c|c|c|}
\hline & \multicolumn{3}{|c|}{ UPFC 1} & \multicolumn{3}{|c|}{ UPFC 2} & \multicolumn{3}{|c|}{ UPFC 3} \\
\hline & Mag & Phase & Linguis- & Mag & Phase & Linguis- & Mag & Phase & Linguis- \\
\hline & $\%$ & deg & tic & $\%$ & $\operatorname{deg}$ & tic & $\%$ & $\operatorname{deg}$ & tic \\
\hline$\overline{\text { Gen }_{1}}$ & $\overline{70}$ & 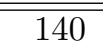 & $\overline{\mathrm{dec}}$ & $\overline{56}$ & $\bar{~} 166$ & " dec & 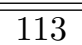 & $\overline{c-15}$ & 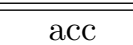 \\
\hline $\mathrm{Gen}_{2}$ & 80 & -180 & dec & 18 & 115 & - & 37 & -50 & acc \\
\hline $\mathrm{Gen}_{3}$ & 65 & -22 & acc & 67 & -7 & acc & 72 & 151 & dec \\
\hline $\mathrm{Gen}_{4}$ & 65 & -22 & acc & 46 & -36 & acc & 92 & 166 & dec \\
\hline
\end{tabular}

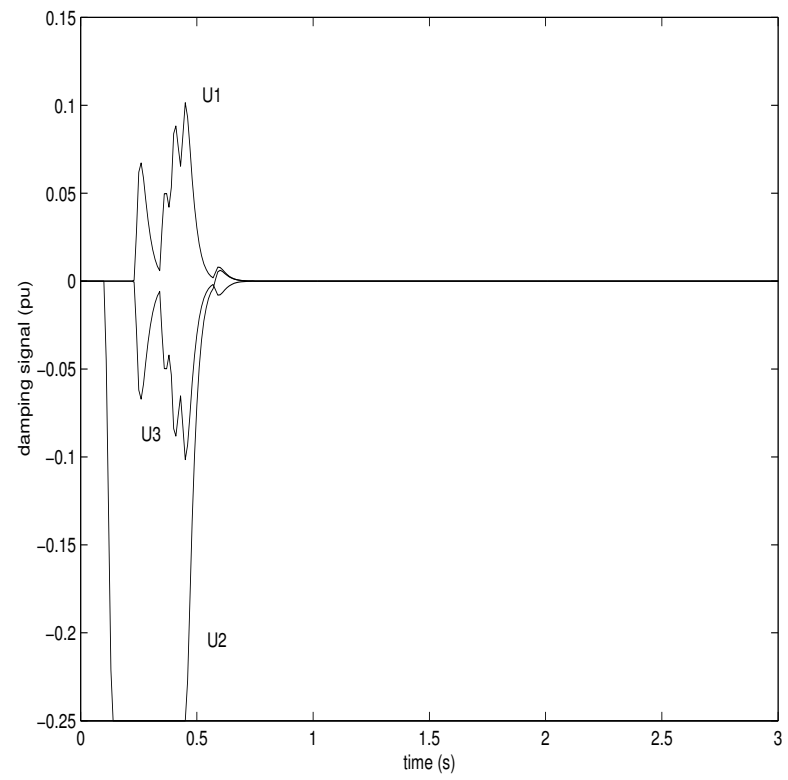

Figure 5.16: Damping signals inferred by voting process 


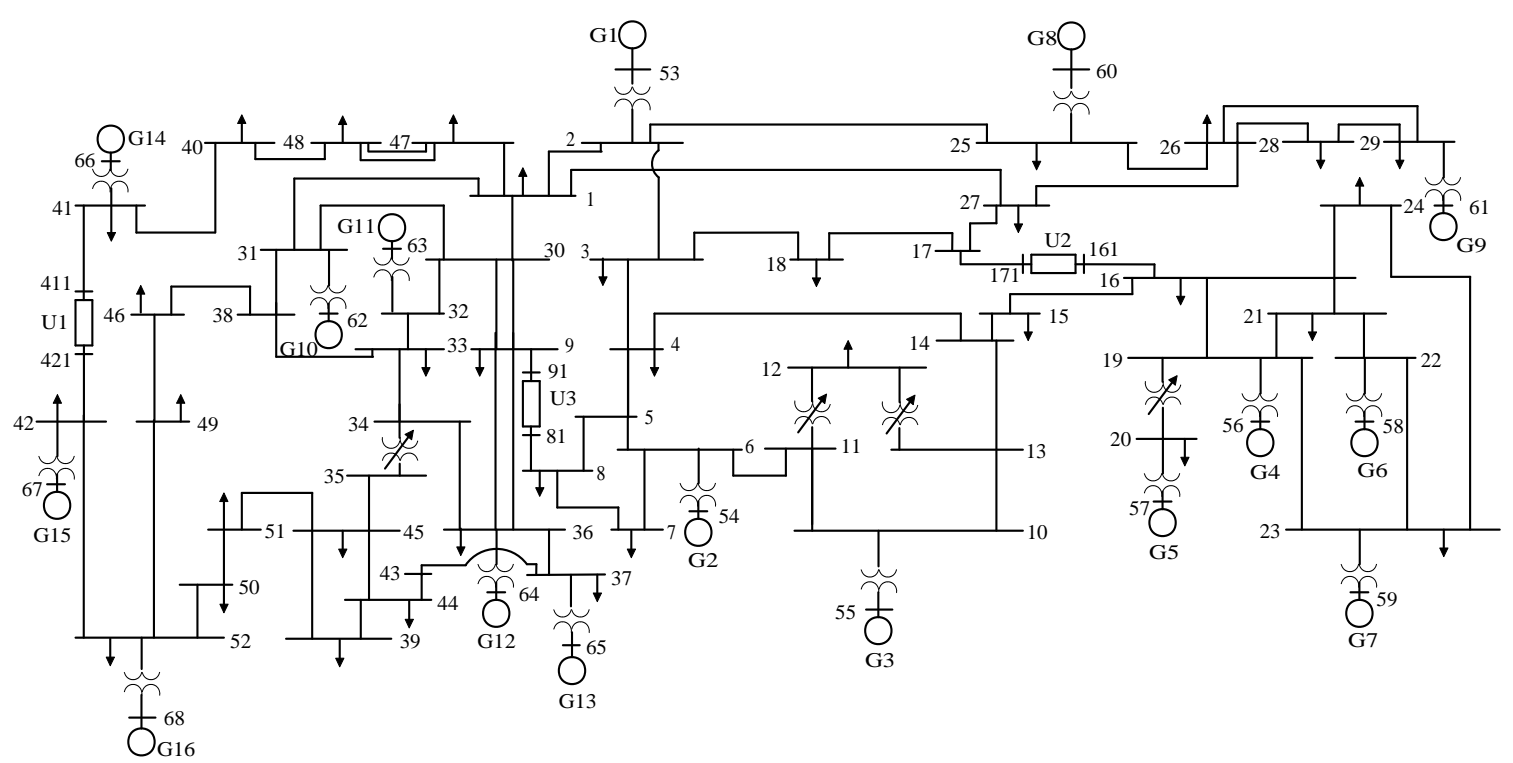

Figure 5.17: New England - New York system

\subsection{New England - New York power system}

The third case study involves a reduced order model of the New England - New York power system [14], [73]. The system consists of 16 generators, 68 buses (35 of them are load buses), and 89 interconnecting lines. Each generator is modeled in detail, has a static exciter and PSS, and includes thermal turbine-governors. The system is shown in Fig. 5.17. Dynamics within the power system after a large disturbance may include five areas of coherently swinging buses [73] and therefore create an interesting stability problem. The following presents a brief discussion of UPFC siting followed by simulation results that are representative for the system behavior in three different cases: A contingency involving a line that is in some distance from the UPFCs, a contingency on a line in close proximity to one of the UPFCs, and a case study examining the influence of a UPFC on its region of influence.

\subsubsection{Load flow analysis and UPFC siting}

Load flow analysis showed that shunt compensation is only of importance at loading levels of about $120 \%$. Therefore, the UPFC sites were chosen to be at the mid-points of tie-lines that typically separate coherently swinging groups of generators and buses after large disturbances. Three of these weak links, the lines 41-42, 16-17, and 8-9 (as identified in [73]) have been chosen as candidates for UPFC installation. The number of UPFCs has been kept low to differ from 
the previous case study where the number of UPFCs has been determined to guarantee a strong controllability of power flows with a high degree of possible interactions between UPFCs.

\subsubsection{Contingency 1 - Far case}

The first contingency examines the system response due to a $100 \mathrm{~ms}$ fault on line 29-28. The line is not reclosed after fault clearance. This contingency has been identified as critical in previous studies ([29], [73]) and used as validation for successful PSS design. The result for the relative angle of generators 9 (reference is generator 1 ) that is close to the fault location, is shown in Fig. 5.18. The plot compares the system with PSS designed using the phase compensation method to shift modes of interest to the left [73], PSS tuned using genetic algorithms (GA) [29], system with GA tuned PSS and inactive UPFCs, and GA tuned PSS with active UPFC and TSK-damping scheme. The loads have been replaced with a constant impedance-type model. The swings for the system with UPFCs but without fuzzy damping control are not shown because of only minor differences. The presence of the UPFCs and their efforts in stabilizing the local swings seems to be the best solution. Further tests with different TSK-parameters lead to an interesting result. When the parameters for the TSK-scheme were chosen to result in high initial controller effort of UPFC 2, which is the closest UPFC to the fault location and generator 9, the damping of machine 9 could be improved as is shown in Fig. 5.19, The positive effect comes with the disadvantage of a persistent local mode as can be seen in the figure. At about 4-5 seconds the generator swings are successfully damped but the swings local to UPFC 2 excite them again causing continuous swings and a successive degradation of system performance. The generator and UPFCs are close and remote to the fault location, respectively. Nevertheless, negative impact on the first swing stability just as in the two area and meshed power systems can be observed. The damping has not been improved.

Different load models have been used to gain further insight due to changed loading conditions: (a) Constant impedance load, (b) Static ZIP-loads (20\%, 30\%, and 50\%, respectively), and (c) Dynamic IP-loads with a first-order time delay of $200 \mathrm{~ms}$ plus constant impedance load $(30 \%, 50 \%$, and $20 \%$, respectively) have been investigated. Very different post-disturbance behavior resulting from these three loading conditions have been observed (Fig. 5.20). The plots show results for both machine 1 and 9, which are distant and close to the fault location, and compare the postdisturbance transients depending on the UPFCs' control modes. The modes examined are: (a) constant injected series voltages as found during load flow computations (LF), (b) basic control 


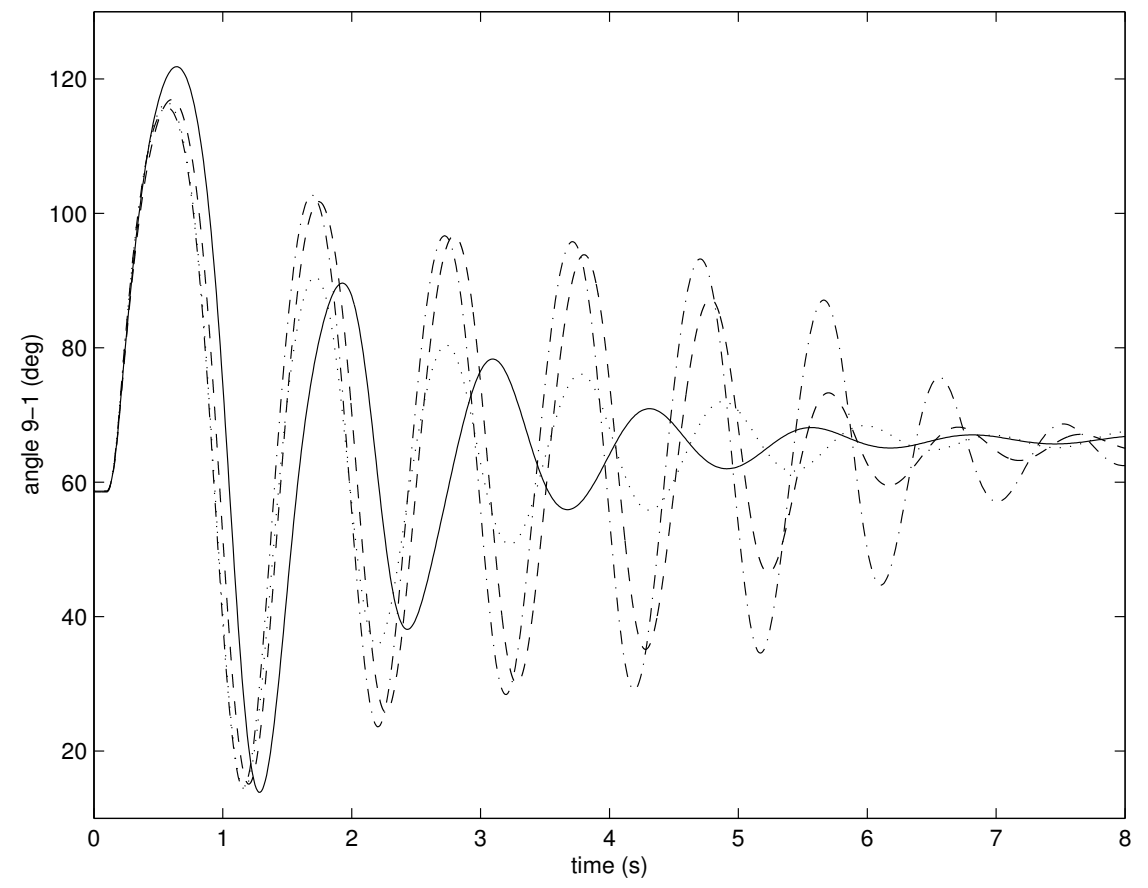

Figure 5.18: NE-NY contingency 1: Influence on machine 9 (dash-dotted - PSS, dotted - GA PSS, dashed - inactive UPFC, solid - UPFC+TSK)

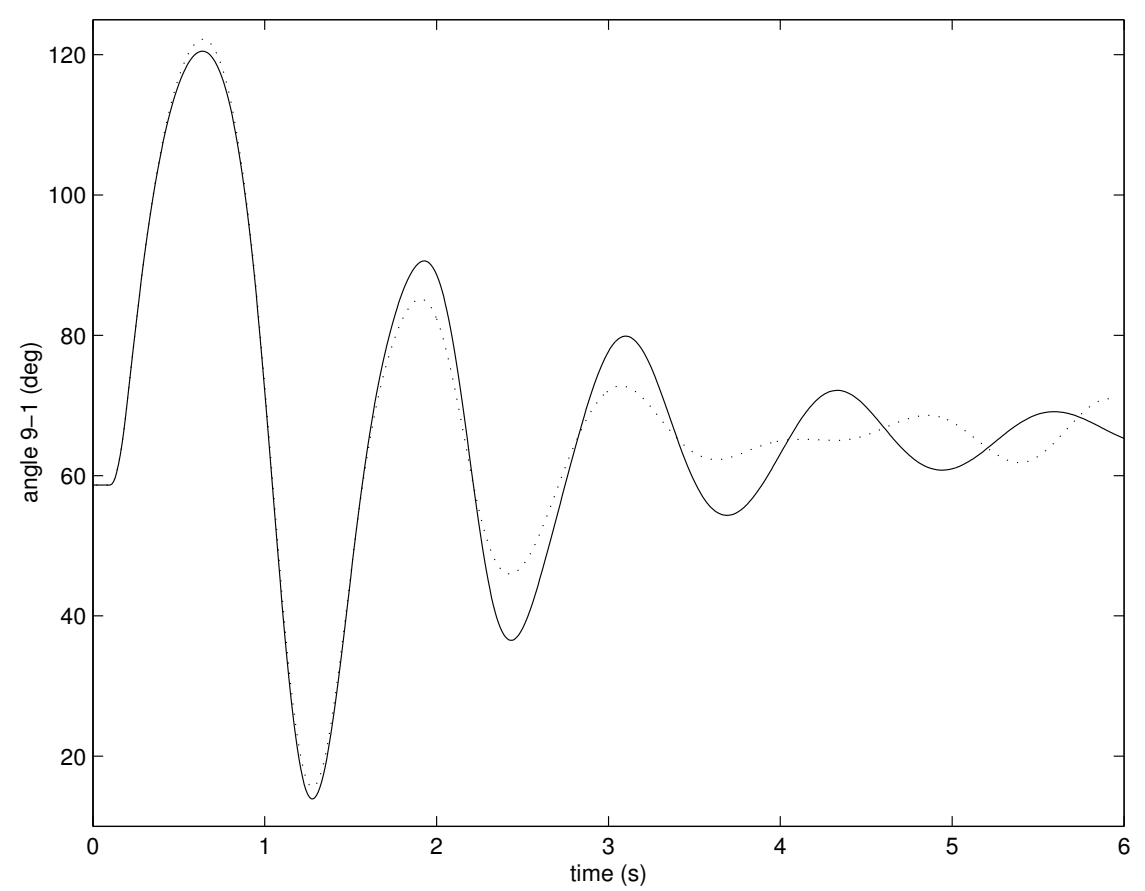

Figure 5.19: NE-NY contingency 1: Fuzzy damping control influence on machine 9 (solid - TSK, dotted - High gain TSK) 

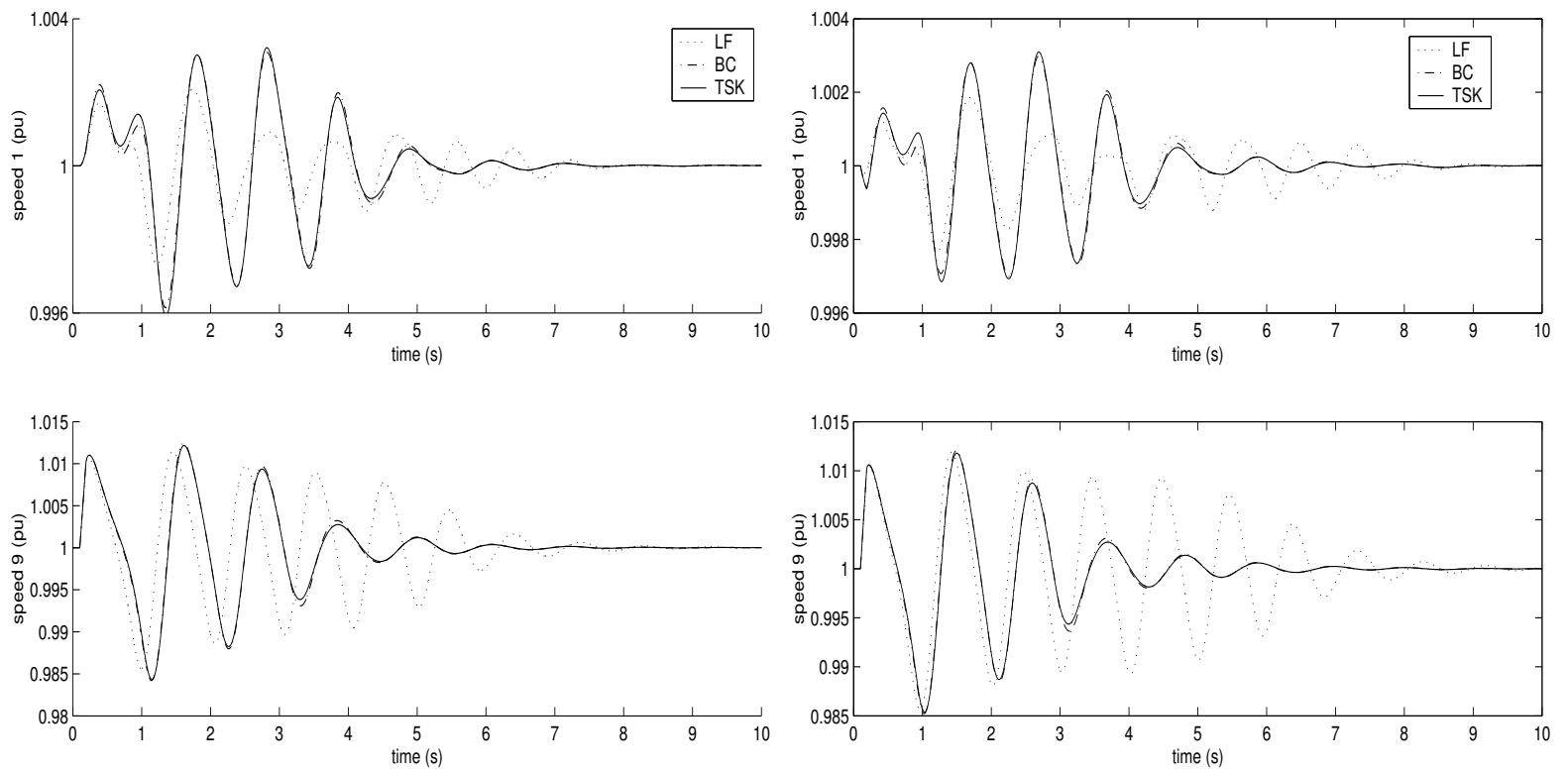

(a) Static $Y$

(b) Static P-I-Y
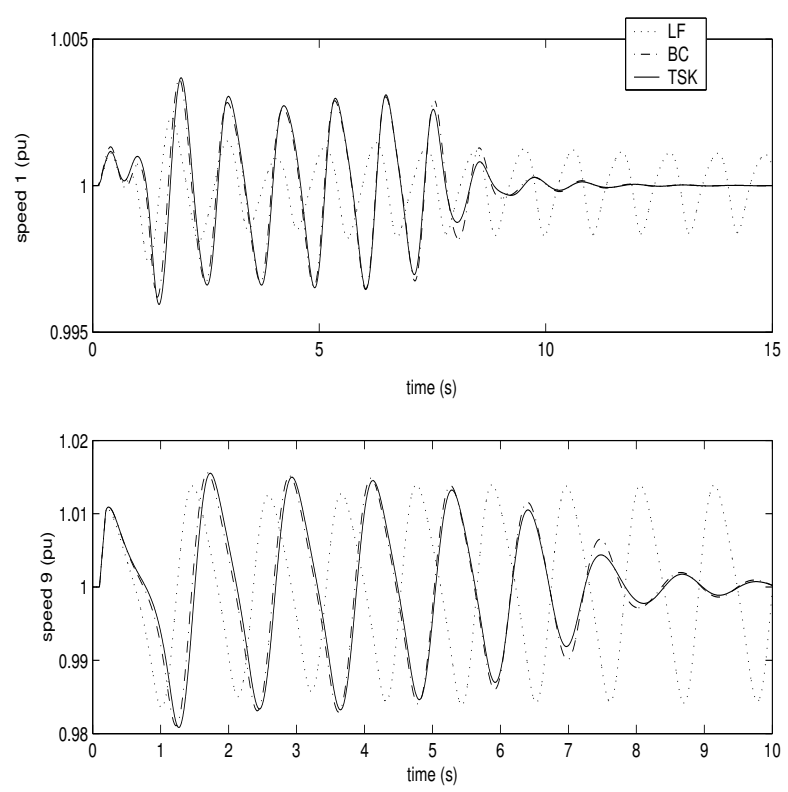

(c) Dynamic P-I and static $Y$

Figure 5.20: NE-NY contingency 1: Machine speed response for different types of loads 

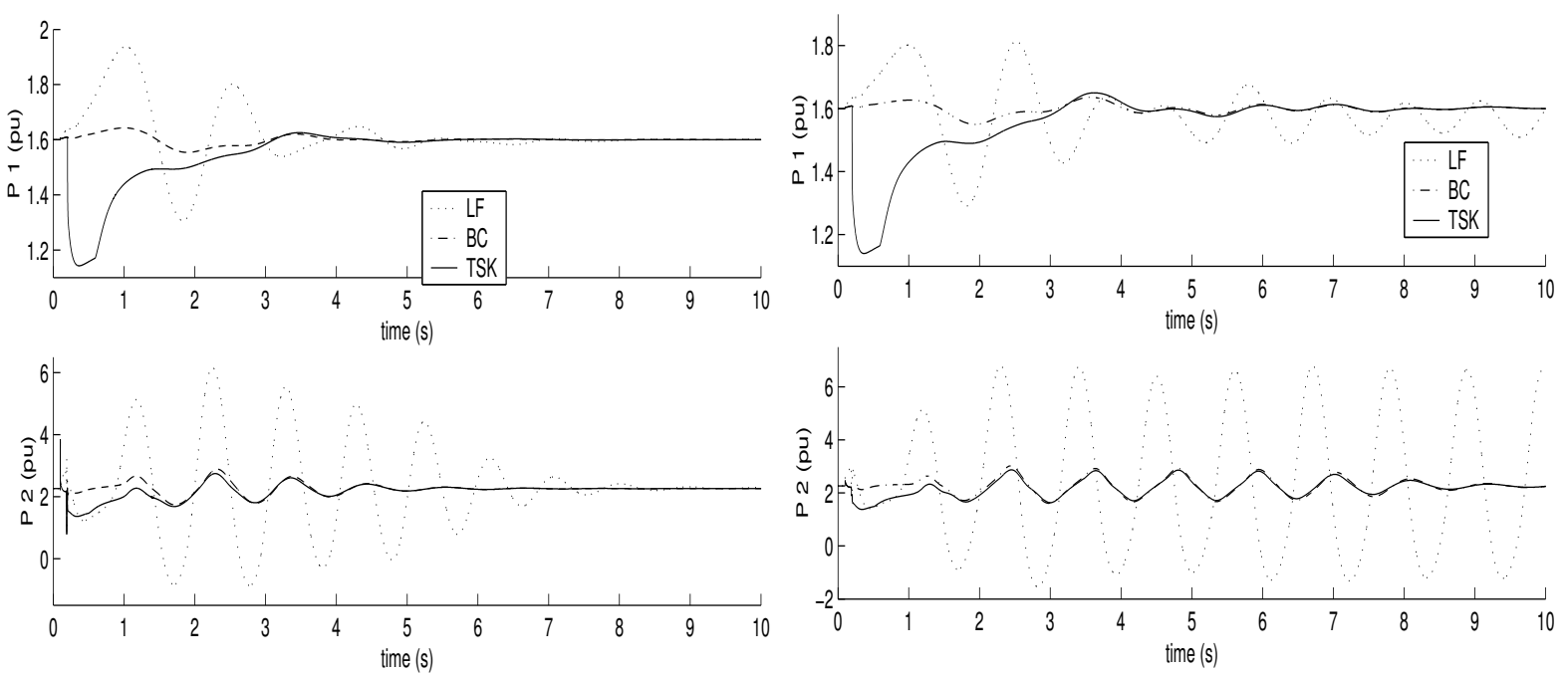

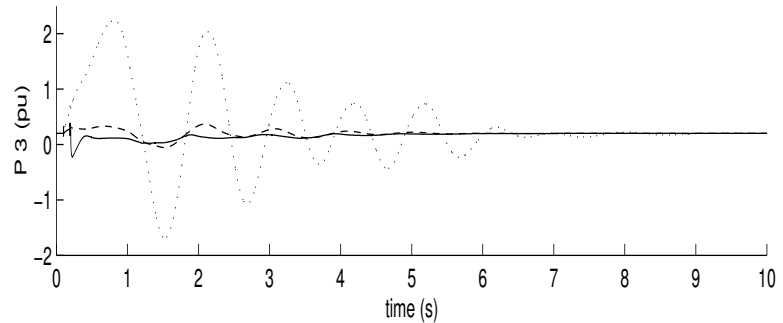

(a) Constant impedance

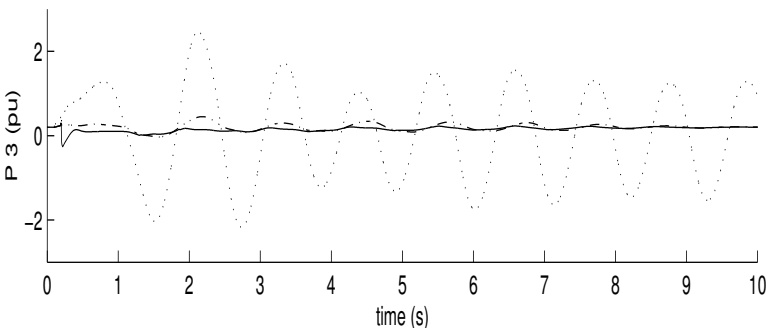

(b) Dynamic power

Figure 5.21: NE-NY contingency 1: Active line power flows at UPFC sites

of bus voltage and power flows (BC), and (c) active TSK-damping control (TSK). In all cases the TSK-damping with restrictions on maximum controller effort, e.g., maximum series injected voltage magnitude of $0.3 \mathrm{pu}$, cannot improve the system damping characteristics. Depending on the load characteristics different peaks and settling times have been observed. The UPFCs with active controls increase damping in the case of constant impedance loads and static ZIP-loads to some extend and improved it greatly in the case of dynamic IP-loads. The different characteristics in system behavior can also be seen in the active line power flows at the UPFCs' sites (Fig. 5.21).

\subsubsection{Contingency 2 - Near case}

The second contingency examines the system response due to a $100 \mathrm{~ms}$ fault on line $18-17$. The line is reclosed after an additional 200 ms elapsed. The results for the generators 1, 9, and 15 are shown in Fig. 5.22, This case differs from the first one in that the fault location is in close 
proximity to one of the UPFCs (UPFC 2). The speed responses show that a compromise has to be made during the tuning process. While local swings including transients of machine 9 can be improved in case of active controls, distant generators do not necessarily underline the advanced system characteristics. Fig. $5.22 \mathrm{a}$ gives the speed response of machine 1 that has a slightly improved first swing stability. Nevertheless, machine 15 (Fig. 5.22 ) experiences an increase in speed offsets.

This case study clearly shows that the improvements in damping by application of FACTS devices that are placed throughout the transmission system requires a careful control design and parameter tuning process. Otherwise, the fast reacting FACTS devices have the capability to force swings in even distant parts of the power system by interfering with excitation and stabilizer controls suggesting that inactivated UPFC controls may be the better choice.

\subsubsection{Contingency 3 - Region of influence}

The third contingency is used to discuss the possible influence of a UPFC and its damping scheme on its region of influence as well as possible adjustments to the damping scheme by using different local information and remote measurements. Rather then requesting information from all generators as for the meshed power system case study a scheme with limited communication is tested. The following concentrates on UPFC 1 that is placed on line 41-42.

The assumption made for UPFC 1 is that it should be utilized as damping controller for its region of influence. Examining the UPFC's location it can be seen that a change in active power flow will have immediate impact on the two branches from bus 41 to 1 (including buses 40, 48, 47, and 66) and 41 - 52 (including buses 42 and 67). Therefore, the three generators 14, 15, and 16 are in the region of the UPFC's influence.

Simulation of fault occurrences in the region of influence, e.g., between buses 41-1, lead to the conclusion that the local fuzzy damping scheme using the line power flow as input is not able to determine the representative state of the power system. It was observed that, first, the UPFC only stabilized its local power flow swings, and second, infers incorrect damping signals. The second observation is explained as follows: Faults reduce the electric power output of generator 14 but also result in a shift of power flow to the line where UPFC 1 is located. Therefore, any scheme based on the total power flow measurement will infer that the generator is forced to provide excess electrical power and its speed is reducing rather than increasing.

The first choice in improving damping is to find an input signal that allows better observation 


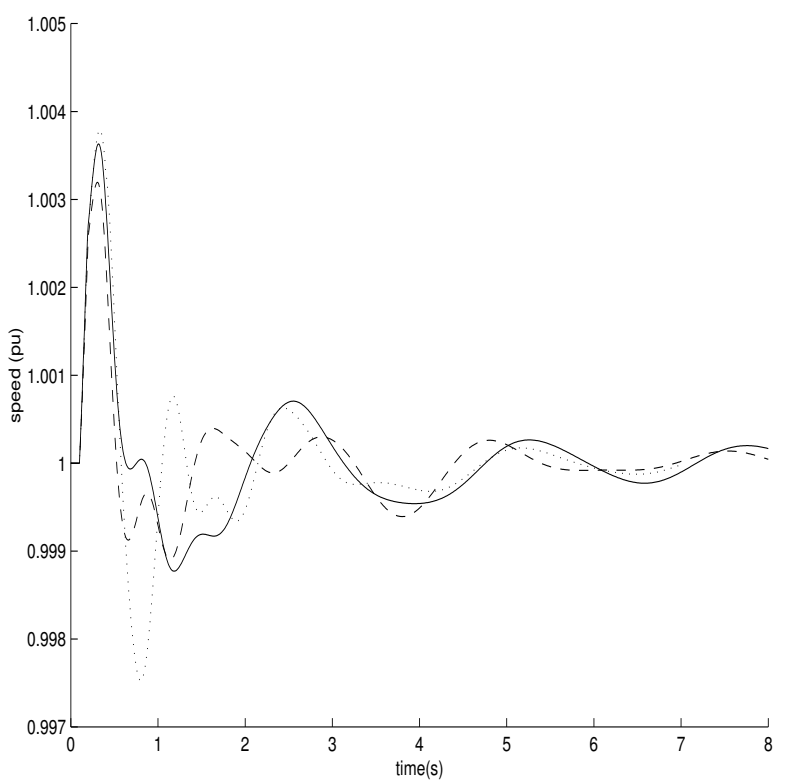

(a) Machine 1

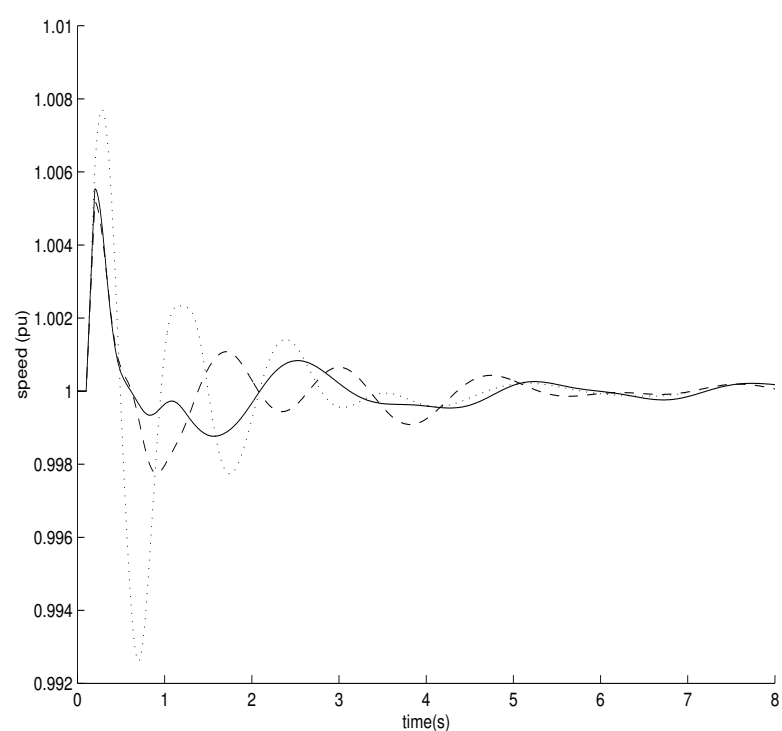

(b) Machine 9

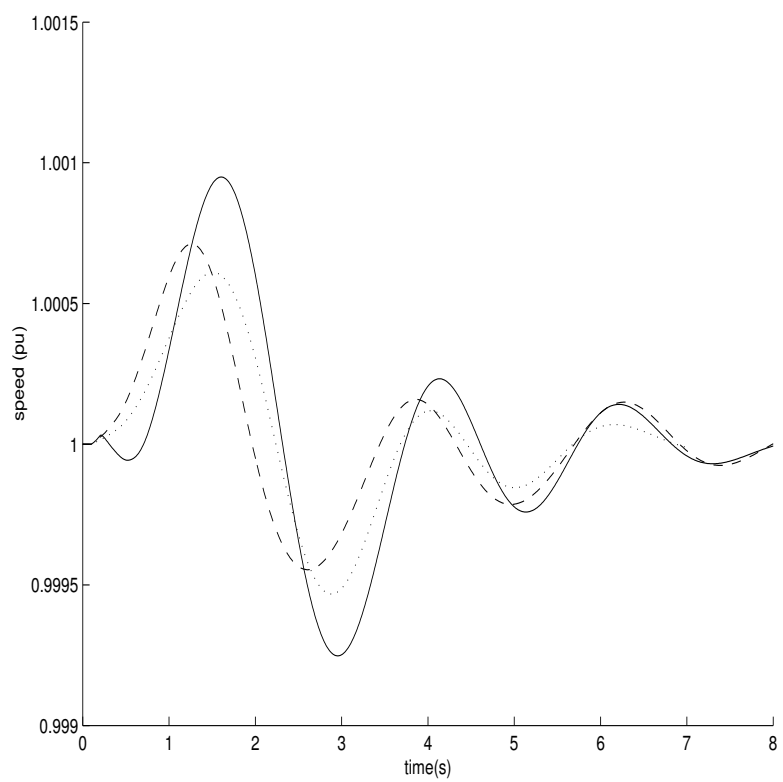

(c) Machine 15

Figure 5.22: NE-NY contingency 2: Speed responses (dashed - inactive UPFC, dotted - UPFC, solid - UPFCs with TSK-damping) 
and control of transients. In [16 the frequency deviation has been suggested as measurement for the active and reactive power control of energy storage units that are installed at any bus within the network. Simulations performed using this choice revealed that only faults between buses 41 and 1 can be successfully damped but faults between 42 and 52 result in undesirable system transients. The extension of the frequency measurement to both UPFC buses to use the derivative of the angle difference between them is not only a reasonable choice but also results in a damping scheme based on the transient energy function (TEF) approach as discussed above (see 4.7. p. 72. The TEF control law and the TSK equivalent have been tested and the simulation results are given in Fig. 5.23 (250 ms 3-phase fault cleared by opening line 41-40, reclosing after additional $250 \mathrm{~ms}$ elapsed) and Fig. 5.24 (100 ms 3-phase fault cleared by opening line 52-42, reclosing after additional $100 \mathrm{~ms}$ elapsed). Additionally, the results for inactive controls (meaning that the voltages as found by the load flow are injected) as well as active basic controls have been added to the figures to allow further comparisons. Both schemes can only improve the system performance in case the basic UPFC controls were activated at the time of fault occurrence. Also, after the initial transients have been reduced unnecessary control action causing increased settling times is observed. Whereas the TSK-TEF scheme swings at the prefault operating point the TEF-method causes a shift in the operating point due to the missing integrator signal as utilized in the TSK's input signal conditioning unit.

The problem of unsatisfactory transient behavior can only be solved by using the generator's output power (or an equivalent signal such as speed) as input to the damping scheme. The remote measurement allows to infer the best UPFC control action to help stabilize the generators. The generator swings have been added to Fig. $5.23 \mathrm{a}$. As expected this will have a negative impact on nearby generators such as generator 15 and is shown in Fig. 5.23 b. The benefits of this damping scheme in stabilizing the machine that is mostly disturbed require a trade-off during the design process to ensure stability of swings in other machines. The responses using the local frequency deviation have not been added to the line 41-40 contingency but the damping of the transients is comparable to the remote case scenario apart from the observation that the negative effect on machine 15 increased.

A generalization of this scheme can be achieved by monitoring the active power outputs of all three generators. This allows secure operation of the branches controllable by the UPFC. The signals guarantee correct fault detection, the decision which of the three generators requires damping, and the appropriate damping signal. The simulation results for a fault on line 52-42 
are shown to demonstrate the correctness for a different fault scenario within the UPFC's region of influence. The improved transient performance of the generator mainly involved can be seen in Fig. $5.24 \mathrm{~b}$.

The conclusion is that the local damping schemes can not improve over the results as found in the case of inactivated basic controls. Simulation results for loads represented as a mix of static and dynamic ZIP-models have shown small stabilizing effects and are not presented here. 


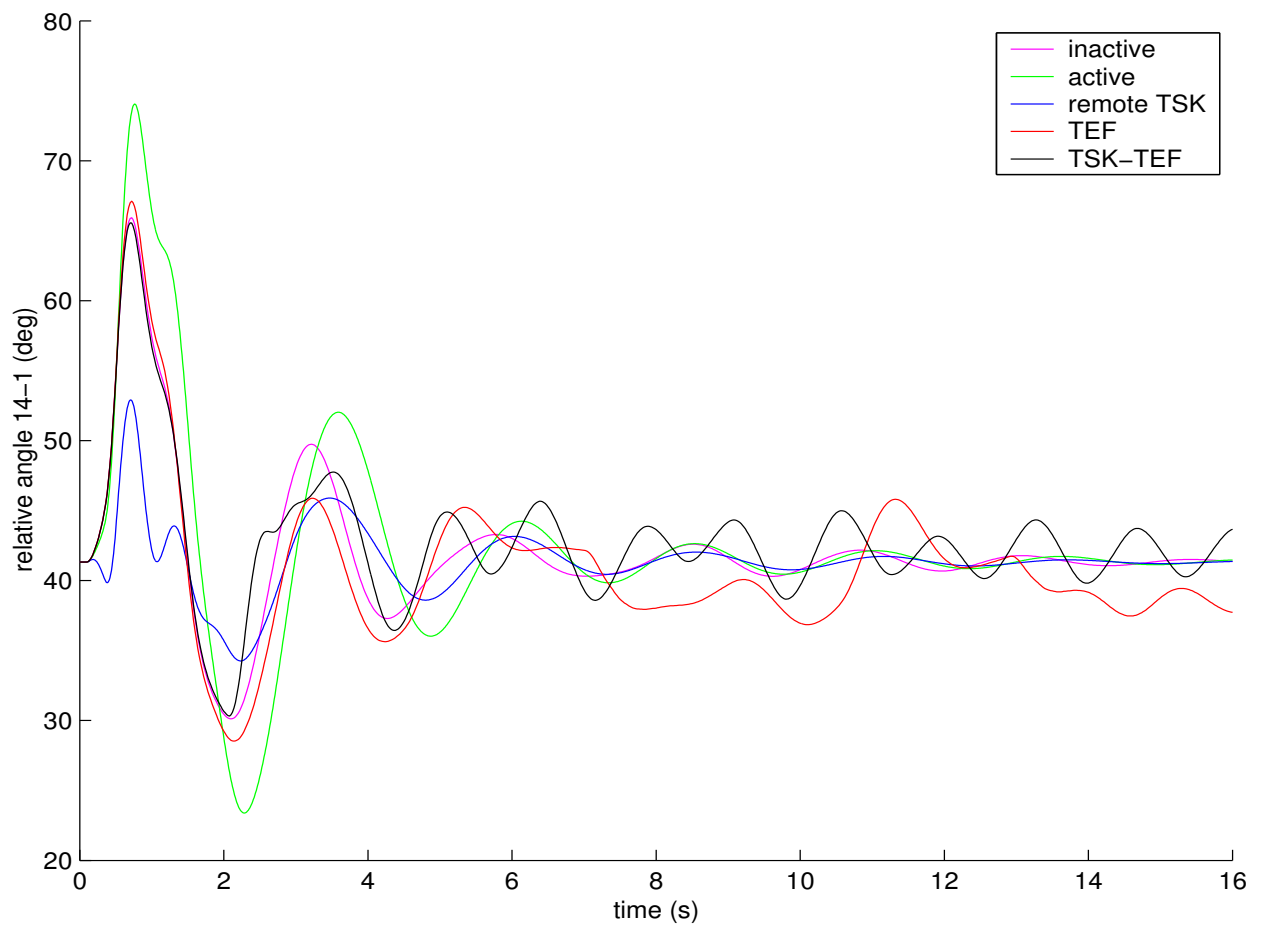

(a) Machine 14

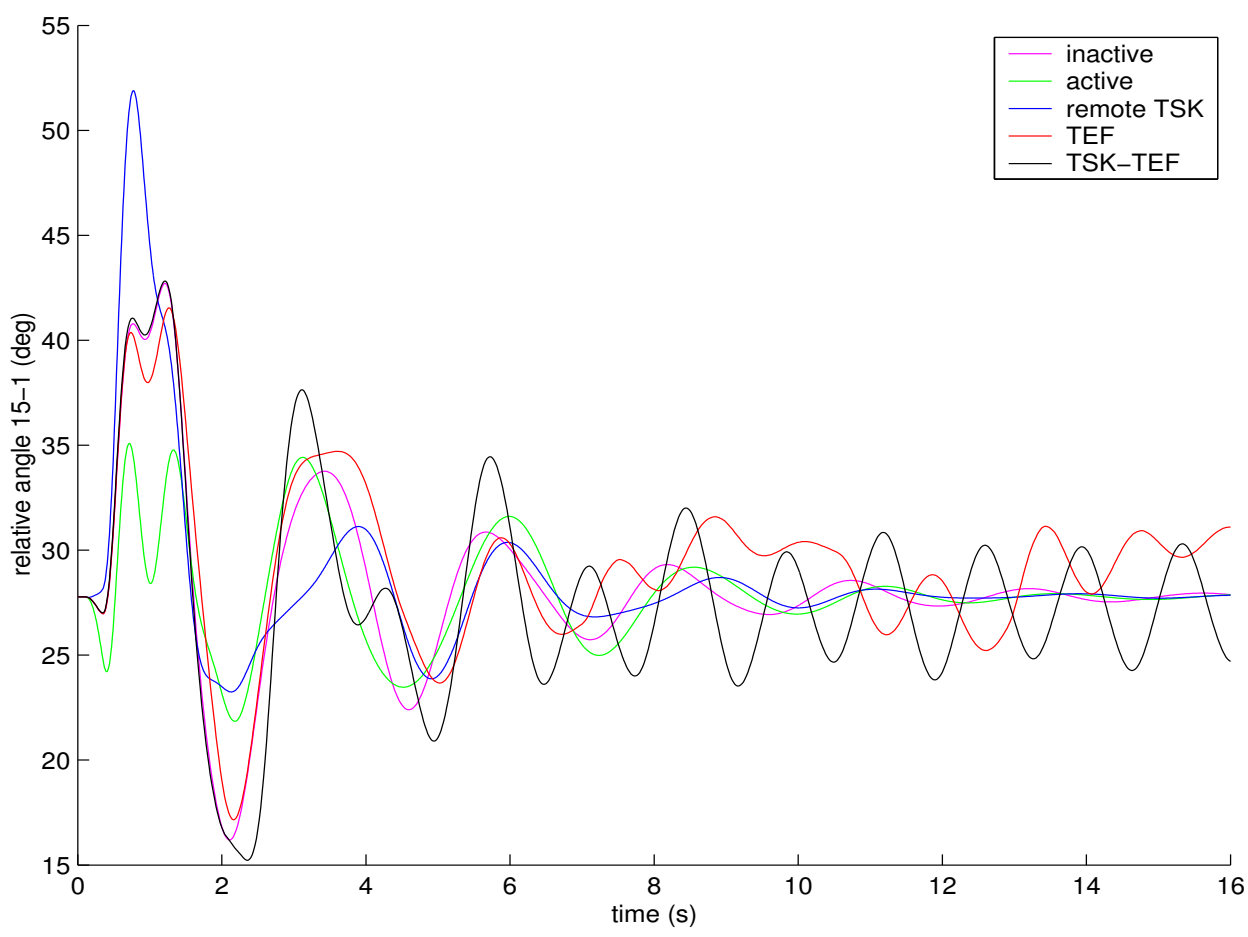

(b) Machine 15

Figure 5.23: NE-NY contingency 3: Speed responses fault 41-40 


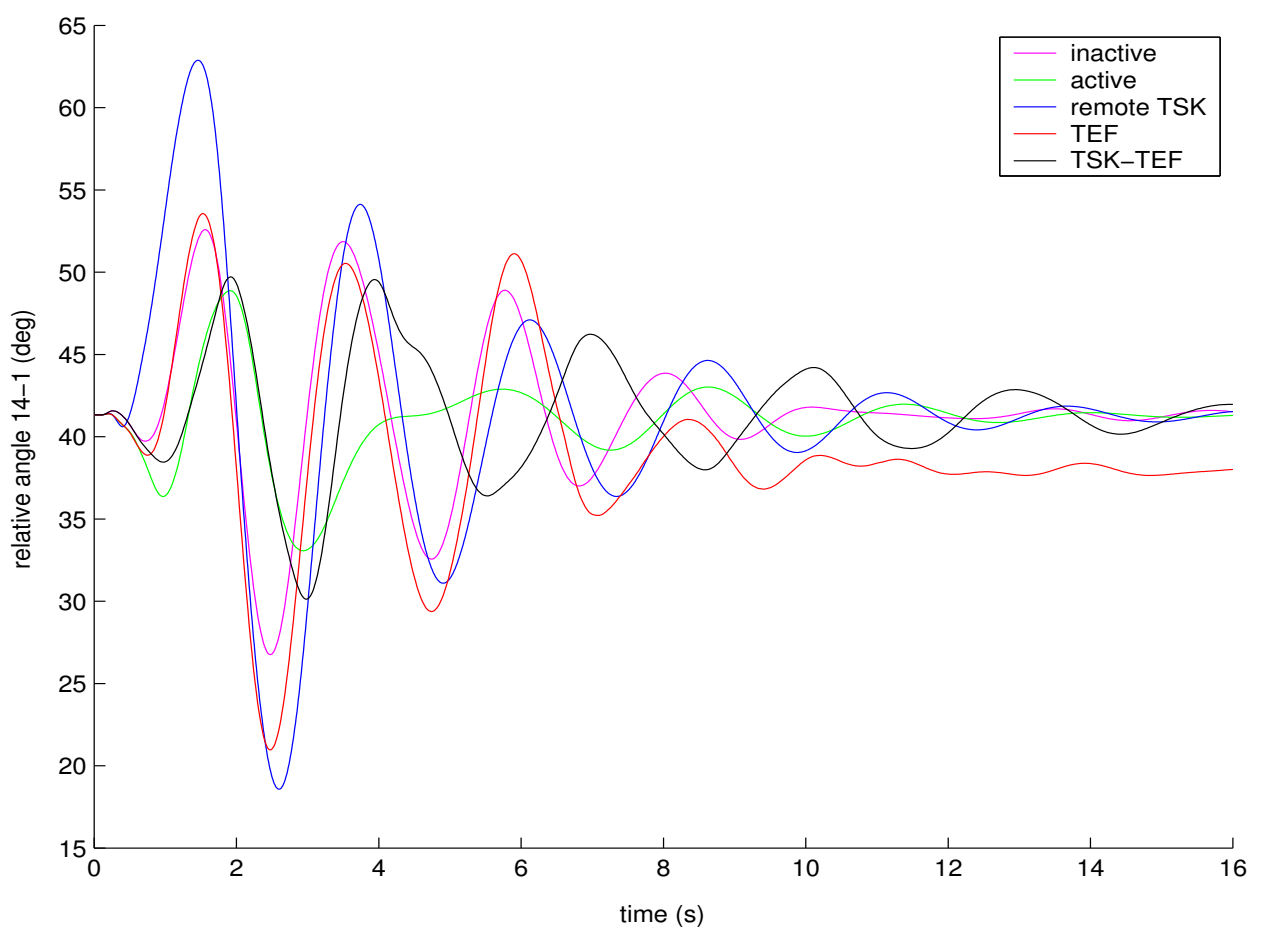

(a) Machine 14

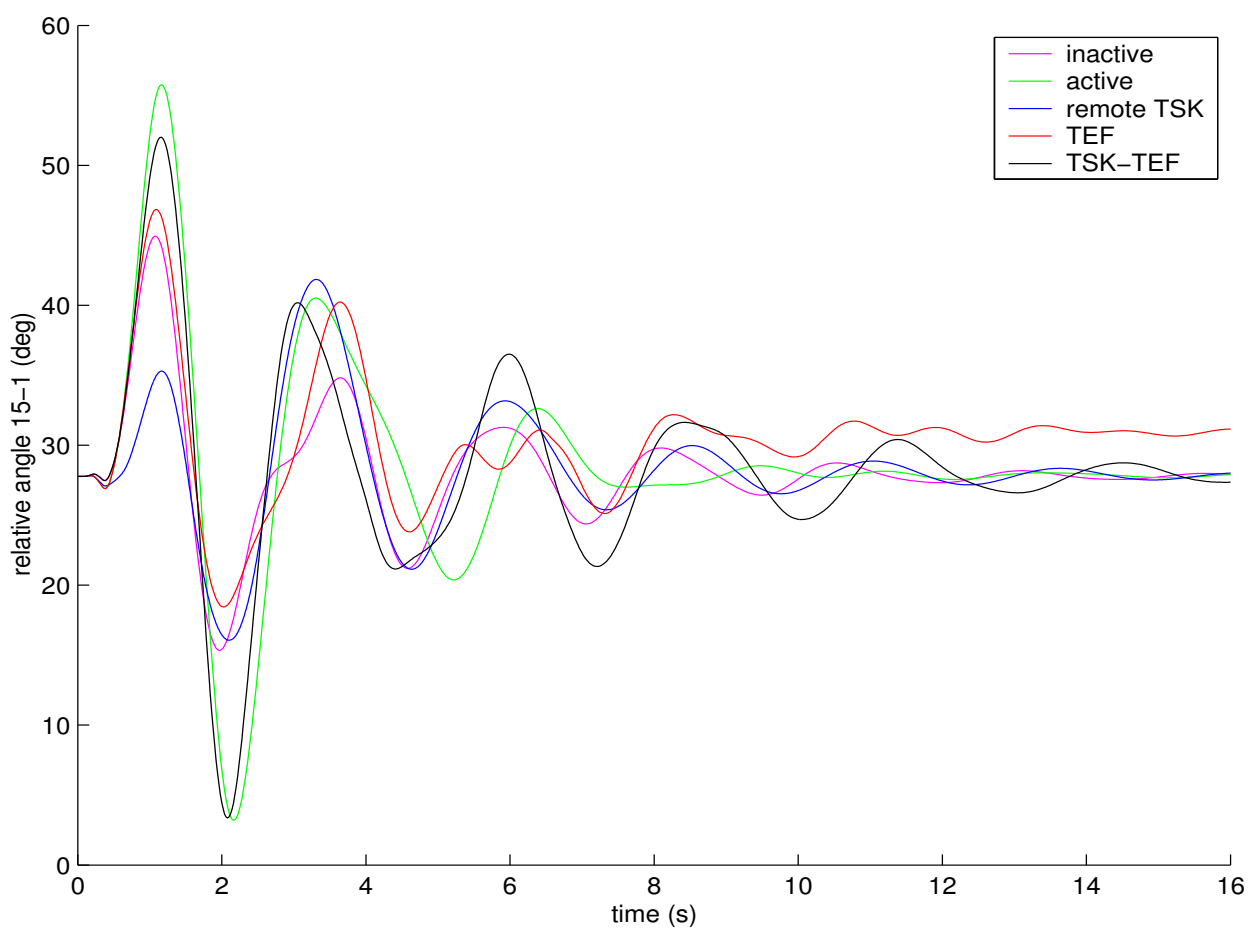

(b) Machine 15

Figure 5.24: NE-NY contingency 3: Speed responses fault 52-42 


\section{Chapter 6}

\section{Summary and conclusions}

Improvements in simulation environment with the incorporation of FACTS devices, and the flexibility in designing and adding control schemes within MATLAB/Simulink have been presented. The new Power Analysis Toolbox that was developed provides a general platform for power system stability studies. PAT has proved its usability in the case studies presented in terms of setting-up power system examples, load flow computations, and transient simulation studies. The results using a fuzzy damping scheme applied to the UPFC have shown improved damping for a variety of operating conditions. Due to the decentralized design utilizing a locally available measurement, practical feasibility is guaranteed.

In case of the Two area - Four machine system a great impact of the fuzzy damping scheme was observed. This is not surprising considering the objectives of the power system model itself. The swings between the two areas are easily tracked by the signal conditioning unit and can be translated into the appropriate damping signal by the fuzzy scheme. The adjustable gain makes it possible to deal with different loading conditions and disturbance levels yielding positive damping contributions to the various case scenarios. Also, the fault event itself is relatively easy to detect by observing unusually large steps in local measurements. Therefore, any power system that can be represented by this structure, i.e., Single machine infinite bus systems and two areas swinging against each other, will benefit from the fuzzy damping scheme.

Much more complex control effects have been discovered in the meshed power system case studies. The possibility of adverse influences through the fast acting FACTS devices makes a detailed transient analysis of these systems a challenging task. In case of the meshed system two conclusions can be drawn: First, inactivation of basic controls is favorable for post-disturbance 
transients, and second, only minor improvements can be achieved using local measurements. The TSK-scheme could improve the first swing stability but not the system damping. This observation leads to the idea of a damping scheme using global information and decision schemes. The generators' accelerating power and tables relating each UPFC to a change in such were used to infer the correct damping signal by a simple voting process. The validity of the scheme and the improvements in system performance were ensured via simulations.

Case studies involving the New England - New York system have been performed to investigate a large multi-machine system with a limited number of FACTS devices. The test system leads to different conclusions for the various scenarios presented. The interesting observation is that, though the number of FACTS devices is low, severe negative effects have been observed in the case of static and dynamic power and current loads when basic controls had been deactivated for the UPFCs. This result differs from the meshed power system case study. Active basic controls, especially power flow control, improves stability in parts of the system. This observation depends on the actual load siting and transmission system configuration. For UPFCs with a higher influence on line flows and nearby generators the inactivation of basic controls may improve system stability. Increased interactions caused by the local damping schemes limit their applicability in the highly interconnected power system and suggest that remote measurements may be a necessity.

\subsection{Work based on this dissertation}

The developed PAT has already been used in the research of [23] and [30]. Both utilized PAT as a simulation environment and basis for the design and evaluation of suggested control schemes. Linear analysis and design techniques were used and [30] combined PAT with a toolbox for genetic algorithms, a third-party product. In the latter, the possibility to find the state space representation using PAT and batch-processing capabilities of MATLAB to generate and test a large number of controller designs proved to be very useful. It solved the problem of finding a solution in a large, highly nonlinear parameter space. Also, work on load frequency control, distributed generation, system identification, and model reduction currently in progress make use of PAT's modeling capabilities bundled with MATLAB's toolboxes. 


\subsection{Suggestions for future work}

Modeling of FACTS devices within the PST resulted in an undesirably inflexible tool without the possibility to automatically generate the state space representation as well as low simulation performance. The complexity of variables and their interdependencies were seen as strong disadvantage. PAT has been developed to overcome these drawbacks. The data and modeling structure introduced targeted the minimization of implementation time required for new components. A logical next step in developing PAT should be to add an advanced object-oriented top-layer modeling scheme. The object-oriented approach is considered as the most promising way to cope with the diversity and number of different devices. The representation of the physical power system by meaningful objects would greatly simplify the modeling and add additional advantages, such as the possibility to incorporate symbolic modeling and computations. This would allow preprocessing of the resulting DAE system and thus minimize the time required for solving the remaining set of nonlinear equations. Furthermore, general conclusions in analyzing power systems, e.g., sensitivity computations and functional optimization, could be realized with little extra cost. Improvements in the speed of transient stability studies should also be sought. This could be done by replacing part of the network (or transmission system) interface with Csystem functions. System functions written in C allow improved communication with Simulink's ODE solvers, which in turn allow handling of switching events in an advanced manner. Part of generating these functions could be implemented through automatic code generation as provided by the symbolic toolbox. Also, while the power system sparsity is used to reduce the amount of memory required for the load flow computations and sparse eigenanalysis functions are provided with MATLAB, the Simulink ODE solvers do not make use of sparsity structures. Finding a solution to overcome this drawback would lead to a power analysis package very well suited for analysis of real-world systems where the number of states may be up to $14,000-25,000$. The main disadvantage of PAT is the necessity of an extra block for interfacing FACTS devices. By generating a consistent set of DAEs need for an extra interface scheme could be overcome and the solution at the current time step could be solved with a single iterative procedure.

The toolbox was utilized to analyze the proposed fuzzy damping scheme for UPFCs. Though a satisfactory damping with a scheme of limited computational requirements could be achieved further research could expand the efforts made. The possible range of yet unresolved issues includes the extension to systems with a high degree of interconnections, utilization of wide area measurements by proper selection of signals and measurement schemes, online-algorithms 
for dynamic system security assessment, and the control schemes applied at FACTS devices translating these advanced techniques into appropriate control actions.

The work in this dissertation concentrated on decentralized control, a topic that has dominated the power system industry for decades. The inherent disadvantages of controls relying on the availability and response characteristics of communication links are still a major burden. Nevertheless, new technologies allow obtaining of accurate measurements, fast signal processing, and communication using a variety of different types of carriers with improved security features. These will make it possible to perform real-time control of fast power system dynamics. New control algorithms will be required to ensure the most advantageous overall system response. A fairly simple scheme has been introduced in this dissertation but more of these, especially in the form of the currently evolving view of controllers as intelligent agents, will be of use in modern electric power systems. Controls with limited communication have already drawn research interest and will be of the utmost importance in the deregulated environment. This is not only due to the demonstrated possibility of negative technical effects of FACTS devices and their controls but also due to the exchange of information that will be a natural part of generating, transmitting, and distributing electrical energy in the new power system market. 


\section{Appendix A}

\section{Publications}

The work done so far has been presented at several conferences and published in the corresponding proceedings. Two journal articles and a book chapter have been accepted for publication. Each publication is given with its abstract and reference:

- Load-Flow and Dynamic Model of the Unified Power Flow Controller (UPFC) within the Power System Toolbox (PST):

Abstract: To assess the UPFC's capabilities through simulation, a software tool is needed. The Power System Toolbox (PST) has several power device models but not the UPFC. This paper develops a UPFC module that is integrated within the PST. It consists of three components: a steady-state model or load-flow model, a dynamic model, and an interface algorithm. All of these three components are described in this paper following the section on the UPFC's basic operation. A Two-Area-Four-Generator power system with a UPFC is used to demonstrate the proposed tools.

Reference: Schoder, K., Hasanović, A., Feliachi, A., "Load-Flow and Dynamic Model of the Unified Power Flow Controller (UPFC) within the Power System Toolbox (PST)," Proc. of Midwest Symposium on Circuits and Systems, Lansing, Michigan, Vol. 2, pp. 634-637, August 2000.

- Enhancing Transient Stability using a Fuzzy Control Scheme for the Unified Power Flow Controller (UPFC):

Abstract: This paper proposes a power system oscillation damping scheme through a supplementary signal applied to a Unified Power Flow Controller (UPFC). The supplementary signal is based on the active power flow along the transmission line. The controller designed 
is based on fuzzy logic. The UPFC model and its controls are implemented in the Power System Toolbox (PST). To demonstrate the effectiveness of the controller under dynamic conditions a two area power system is used. When a large disturbance is applied, simulation results show that the UPFC can significantly enhance power system operation and performance.

Reference: Schoder, K., Hasanović, A., Feliachi, A., "Enhancing Transient Stability using a Fuzzy Control Scheme for the Unified Power Flow Controller (UPFC)," Proc. of Midwest Symposium on Circuits and Systems, Lansing, Michigan, Vol. 3, pp. 1382-1385, August 2000 .

\section{- Fuzzy Damping Controller for the Unified Power Flow Controller (UPFC):}

Abstract: The Unified Power Flow Controller (UPFC) is one of the latest Flexible AC Transmission Systems (FACTS) devices which is capable of maintaining and improving power system transient stability. This paper focuses on UPFC damping controller design based on fuzzy logic. The effectiveness of the controller is illustrated through nonlinear simulation of a two-area-four-machine power system using Power System Toolbox (PST).

Reference: Schoder, K., Hasanović, A., Feliachi, A., "Fuzzy Damping Controller for the Unified Power Flow Controller (UPFC)," Proc. of the North American Power Symposium (NAPS), Waterloo, Canada, Vol. 2, pp. 5-21 - 5-27, October 2000.

\section{- Power System Damping Using Fuzzy Controlled Unified Power Flow Controller:}

Abstract: The paper presents a design of a UPFC damping controller using two fuzzy logic schemes one based on Mamdani inference engine using the center of gravity method to find the controller output, and the second based on Takagi-Sugeno engine computing the controller output as linear combination of the inputs. Fuzzy control design is attractive for nonlinear systems application because it does not require a mathematical model, and it can cover a wide range of operating conditions. The advantages of the proposed controllers are their feasibility guaranteed by the use of a local measurement, which in this case is the tie line power flow, and their simplicity. The effectiveness of the controllers under dynamic conditions is illustrated thru nonlinear simulations of a two-area-four-machine power system. Simulations are carried out using the Power System Toolbox (PST).

Reference: Schoder, K., Hasanović, A., Feliachi, A., "Power System Damping Using Fuzzy Controlled Unified Power Flow Controller," Proc. of the IEEE Power Engineering Society Winter Meeting, Columbus, Ohio, January 29 - February 1, Vol. 2, pp. 617-622, 2001. 
- Selection and Design of a TCSC Control Signal in Damping Power System Inter-Area Oscillations for Multiple Operating Conditions

Abstract: A method is proposed to identify an effective local signal that can be used by a Thyristor Controlled Series Compensation (TCSC) device as a supplementary controller to dampen interarea oscillations for multiple power system operating conditions. Two residuebased indices are developed for this purpose. The first index is to identify the most effective signal to feedback for different operating conditions, and the second index is to assess the interaction of the controller with other oscillation modes than the critical mode, i.e. the mode that is to be controlled. Two designs are presented to illustrate the proposed methodologies, a conventional lead-lag controller, and a controller using a multi-step control design approach. The proposed techniques are applied to a four-generator two-area power system. Nonlinear simulation is used to demonstrate the effectiveness of the designed controller.

Reference: Fan, L., Feliachi, A., Schoder, K., "Selection and Design of a TCSC Control Signal in Damping Power System Inter-Area Oscillations for Multiple Operating Conditions," Electric Power Systems Research, 2002.

\section{- PAT: A Power Analysis Toolbox for MATLAB/Simulink}

Abstract: A power system simulation environment in MATLAB/Simulink is presented in this paper. The developed Power Analysis Toolbox (PAT) is a very flexible and modular tool for load flow, transient and small signal analysis of electric power systems. Standard power system component models and a wide range of FACTS devices are included. Its data structure and block library have been tested to confirm its applicability to small to medium sized power systems. Its advantages over an existing commercial package is given.

Reference: Schoder, K., Hasanović, Amer, Feliachi, A., Hasanović, Azra, "PAT: A Power Analysis Toolbox for MATLAB/Simulink," submitted to IEEE Transactions on Power Systems.

- Feliachi, A., Hasanović, A., Schoder, K., The power electronics handbook, chapter 20: "Unified Power Flow Controllers," Skvarenina, T. L. (editor), CRC Press LLC, 2002. 


\section{Appendix B}

\section{Three machine-Nine bus system data}

\begin{tabular}{|c|c|c|c|c|c|c|c|}
\hline \multirow{3}{*}{$\begin{array}{c}\text { bus } \\
\text { bumber }\end{array}$} & \multirow[b]{2}{*}{ V } & \multirow{2}{*}{$\begin{array}{c}\text { Angle } \\
\text { (deg) }\end{array}$} & \multicolumn{2}{|c|}{ Generation } & \multicolumn{2}{|c|}{ Load } & \multirow{2}{*}{$\begin{array}{l}\text { Bus } \\
\text { type }\end{array}$} \\
\hline & & & Pg & Qg & $\mathbf{P}$ & Q & \\
\hline & 1 & 2 & 3 & 4 & 5 & 6 & 7 \\
\hline 1 & 1.0400 & 0.00 & 0.7164 & 0.2710 & - & - & Slack \\
\hline 2 & 1.0250 & 9.32 & 1.6300 & 0.0659 & - & - & PV \\
\hline 3 & 1.0250 & 4.70 & 0.8500 & -0.1092 & - & - & PV \\
\hline 4 & 1.0260 & -2.18 & - & - & - & - & $\mathrm{PQ}$ \\
\hline 5 & 0.9958 & -3.95 & - & - & 1.25 & 0.50 & $\mathrm{PQ}$ \\
\hline 6 & 1.0128 & -3.65 & - & - & 0.90 & 0.30 & $\mathrm{PQ}$ \\
\hline 7 & 1.0258 & -3.76 & - & - & - & - & PQ \\
\hline 8 & 1.0159 & 0.76 & - & - & 1.00 & 0.35 & $\mathrm{PQ}$ \\
\hline 9 & 1.0324 & 2.00 & - & - & - & - & $\mathrm{PQ}$ \\
\hline
\end{tabular}

Bus data case (a) (system base: 100 MVA)

\begin{tabular}{||c||c|c|c||}
\hline \hline \multirow{2}{*}{$\begin{array}{c}\text { bus } \\
\text { number }\end{array}$} & $\begin{array}{c}\text { base } \\
\text { MVA }\end{array}$ & $\begin{array}{c}x_{d}^{\prime} \\
(\mathbf{p u})\end{array}$ & $\begin{array}{c}\mathbf{H} \\
\text { (sec.) }\end{array}$ \\
\cline { 2 - 4 } & $\mathbf{1}$ & $\mathbf{2}$ & $\mathbf{3}$ \\
\hline \hline 1 & 100 & 0.0608 & 23.64 \\
\hline 2 & 100 & 0.1198 & 6.40 \\
\hline 3 & 100 & 0.1813 & 3.01 \\
\hline \hline
\end{tabular}

Generator data

\begin{tabular}{||c||c|c|c|c|c||}
\hline \hline \multirow{2}{*}{$\begin{array}{c}\text { line } \\
\text { number }\end{array}$} & $\begin{array}{c}\text { from } \\
\text { bus }\end{array}$ & $\begin{array}{c}\text { to } \\
\text { bus }\end{array}$ & $\begin{array}{c}\text { resistance } \\
(\mathbf{p u})\end{array}$ & $\begin{array}{c}\text { reactance } \\
(\mathbf{p u})\end{array}$ & $\begin{array}{c}\text { line charging } \\
(\mathbf{p u})\end{array}$ \\
\cline { 2 - 7 } & $\mathbf{1}$ & $\mathbf{2}$ & $\mathbf{3}$ & $\mathbf{4}$ & $\mathbf{5}$ \\
\hline \hline $\mathbf{1}$ & 1 & 4 & - & 0.0567 & - \\
\hline $\mathbf{2}$ & 2 & 7 & - & 0.0625 & - \\
\hline $\mathbf{3}$ & 3 & 9 & - & 0.0586 & - \\
\hline $\mathbf{4}$ & 4 & 5 & 0.0100 & 0.0850 & $0.0880^{*} 2$ \\
\hline $\mathbf{5}$ & 4 & 6 & 0.0170 & 0.0920 & $0.0790^{*} 2$ \\
\hline $\mathbf{6}$ & 5 & 7 & 0.0320 & 0.1610 & $0.1530^{*} 2$ \\
\hline $\mathbf{7}$ & 6 & 9 & 0.0390 & 0.1700 & $0.1790^{*} 2$ \\
\hline $\mathbf{8}$ & 7 & 8 & 0.0085 & 0.0720 & $0.0745^{*} 2$ \\
\hline $\mathbf{9}$ & 8 & 9 & 0.0119 & 0.1008 & $0.1045^{*} 2$ \\
\hline \hline
\end{tabular}

Line data 


\section{Appendix C}

\section{Two Area-Four Machine system data}

\begin{tabular}{|c|c|c|c|c|c|c|c|}
\hline \multirow{3}{*}{$\begin{array}{c}\text { bus } \\
\text { bumber }\end{array}$} & \multirow[b]{2}{*}{ V } & \multirow{2}{*}{$\begin{array}{l}\text { Angle } \\
\text { (deg) }\end{array}$} & \multicolumn{2}{|c|}{ Generation } & \multicolumn{2}{|c|}{ Load } & \multirow{2}{*}{$\begin{array}{l}\text { Bus } \\
\text { type }\end{array}$} \\
\hline & & & $\mathbf{P g}$ & Qg & $\mathbf{P}$ & $\mathbf{Q}$ & \\
\hline & 1 & 2 & 3 & 4 & 5 & 6 & 7 \\
\hline 1 & 1.0300 & 0.00 & 7.10 & 1.76 & - & - & Slack \\
\hline 2 & 1.0100 & -9.97 & 7.00 & 2.06 & - & - & PV \\
\hline 3 & 0.9697 & -25.12 & - & 2.00 & - & - & $\mathrm{PQ}$ \\
\hline 4 & 0.9632 & -28.11 & - & & 9.76 & 1.00 & $\mathrm{PQ}$ \\
\hline 10 & 1.0081 & -6.56 & - & & - & - & PQ \\
\hline 11 & 1.0300 & -27.88 & 7.19 & 1.99 & - & - & PV \\
\hline 12 & 1.0100 & -38.13 & 7.00 & 2.57 & - & - & PV \\
\hline 13 & 0.9551 & -53.55 & - & 3.50 & - & - & $\mathrm{PQ}$ \\
\hline 14 & 0.9965 & -58.61 & - & - & 17.67 & 1.00 & $\mathrm{PQ}$ \\
\hline 20 & 0.9827 & -16.74 & - & - & - & - & $\mathrm{PQ}$ \\
\hline 101 & 1.0000 & -38.42 & -3.20 & 0.0038 & - & - & $\mathrm{PV}$ \\
\hline 102 & 0.9480 & -42.30 & - & - & - & - & PQ \\
\hline 110 & 1.0045 & -34.54 & - & - & 1.00 & 0.35 & $\mathrm{PQ}$ \\
\hline 120 & 0.9744 & -44.96 & - & - & - & - & $\mathrm{PQ}$ \\
\hline
\end{tabular}

Bus data (system base: 100 MVA)

\begin{tabular}{||c||c|c|c|c||}
\hline \hline \multirow{2}{*}{$\begin{array}{c}\text { bus } \\
\text { bumber }\end{array}$} & & \multicolumn{2}{c|}{ Load } & Shunt \\
\cline { 2 - 5 } & case & $\mathbf{1}$ & $\mathbf{2}$ & $\mathbf{3}$ \\
\hline \hline $\mathbf{4}$ & (b) & 11.76 & 1.00 & - \\
\hline $\mathbf{1 4}$ & (b) & 15.67 & 1.00 & - \\
\hline $\mathbf{1 0 1}$ & (b) & - & - & 0.8 \\
\hline \hline $\mathbf{4}$ & (c) & 17.76 & 1.00 & - \\
\hline $\mathbf{1 4}$ & (c) & 9.76 & 1.00 & - \\
\hline $\mathbf{1 0 1}$ & (c) & - & - & 1.6 \\
\hline \hline \multicolumn{5}{|c|}{ case (b) and (c) data }
\end{tabular}




\begin{tabular}{|c|c|c|c|c|c|c|c|c|}
\hline \multirow{2}{*}{$\begin{array}{c}\text { line } \\
\text { number }\end{array}$} & $\begin{array}{c}\text { from } \\
\text { bus }\end{array}$ & $\begin{array}{l}\text { to } \\
\text { bus }\end{array}$ & $\begin{array}{l}\text { resistance } \\
\text { (pu) }\end{array}$ & $\begin{array}{l}\text { reactance } \\
(\mathrm{pu})\end{array}$ & $\begin{array}{c}\text { line charging } \\
\text { (pu) }\end{array}$ & \multicolumn{3}{|c|}{ ULTC } \\
\hline & 1 & 2 & 3 & 4 & 5 & 6 & 7 & 8 \\
\hline 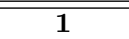 & 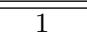 & $\overline{10}$ & - & 0.0167 & - & - & - & - \\
\hline 2 & 2 & 20 & - & 0.0167 & - & - & - & - \\
\hline 3 & 10 & 20 & 0.0025 & 0.0250 & 0.0437 & - & - & - \\
\hline 4 & 20 & 3 & 0.0010 & 0.0100 & 0.0175 & - & - & - \\
\hline 5 & 3 & 4 & - & 0.0050 & - & 1.2 & 0.8 & 0.05 \\
\hline 6 & 3 & 101 & 0.0110 & 0.1100 & 0.1925 & - & - & - \\
\hline 7 & 3 & 101 & 0.0110 & 0.1100 & 0.1925 & - & - & - \\
\hline 8 & 101 & 13 & 0.0110 & 0.1100 & 0.1925 & - & - & - \\
\hline 9 & 102 & 13 & 0.0110 & 0.1100 & 0.1925 & - & - & - \\
\hline 10 & 13 & 14 & - & 0.0050 & - & 1.2 & 0.8 & 0.05 \\
\hline 11 & 13 & 120 & 0.0010 & 0.0100 & 0.0175 & - & - & - \\
\hline 12 & 120 & 110 & 0.0025 & 0.0250 & 0.0437 & - & - & - \\
\hline 13 & 11 & 110 & - & 0.0167 & - & - & - & - \\
\hline 14 & 12 & 120 & - & 0.0167 & - & - & & - \\
\hline
\end{tabular}

\begin{tabular}{|c|c|c|c|c|c|c|c|c|}
\hline \multirow{2}{*}{$\begin{array}{l}\text { machine } \\
\text { number }\end{array}$} & \multirow{2}{*}{$\begin{array}{c}\text { bus } \\
\text { number }\end{array}$} & $\begin{array}{l}\text { base } \\
\text { MVA }\end{array}$ & $\begin{array}{c}x_{l} \\
(\mathbf{p u})\end{array}$ & $\begin{array}{c}\text { resis- } \\
\text { tance } \\
(\mathrm{pu})\end{array}$ & $\begin{array}{c}x_{d} \\
\text { (pu) }\end{array}$ & $\begin{array}{c}x_{d}^{\prime} \\
(\mathbf{p u})\end{array}$ & $\begin{array}{c}x_{d}^{\prime \prime} \\
(\mathbf{p u})\end{array}$ & $\begin{array}{c}T_{d o}^{\prime} \\
(\text { sec) }\end{array}$ \\
\hline & & 1 & 2 & 3 & 4 & 5 & 6 & 7 \\
\hline 1,2 & 1,2 & 900 & 0.2 & 0.0025 & 1.8 & 0.30 & 0.25 & 8 \\
\hline 3,4 & 11,12 & 900 & 0.2 & 0.0025 & 1.8 & 0.30 & 0.25 & 8 \\
\hline & & $\begin{array}{c}T_{d o}^{\prime} \\
(\mathbf{p u}) \\
8\end{array}$ & $\begin{array}{c}x_{q} \\
(\mathbf{p u}) \\
\mathbf{9}\end{array}$ & $\begin{array}{c}x_{q}^{\prime} \\
(\mathrm{pu}) \\
10\end{array}$ & $\begin{array}{c}x_{q}^{\prime \prime} \\
(\mathrm{pu}) \\
\mathbf{1 1}\end{array}$ & $\begin{array}{c}T_{q o}^{\prime} \\
(\mathbf{p u}) \\
\mathbf{1 2}\end{array}$ & $\begin{array}{c}T_{q o}^{\prime \prime} \\
(\mathrm{pu}) \\
\mathbf{1 3}\end{array}$ & $\begin{array}{c}\text { H } \\
\text { (sec.) } \\
14\end{array}$ \\
\hline & & 0.03 & 1.7 & 0.55 & 0.25 & 0.4 & 0.05 & 6.500 \\
\hline & & 0.03 & 1.7 & 0.55 & 0.25 & 0.4 & 0.05 & 6.175 \\
\hline
\end{tabular}

\begin{tabular}{|c|c|c|c|c|c|c|}
\hline $\begin{array}{l}\text { turbine- } \\
\text { governor }\end{array}$ & $\begin{array}{c}\text { steady-state } \\
\text { gain } \\
1 / \mathbf{R} \\
(\mathrm{pu}) \\
\end{array}$ & $\begin{array}{c}\text { maximum } \\
\text { power } \\
\text { (on mac. base) } \\
(\mathrm{pu})\end{array}$ & $\begin{array}{c}\text { servo } \\
\text { time } \\
\text { constant } \\
(\text { sec }) \\
\end{array}$ & $\begin{array}{l}\text { governor } \\
\text { time } \\
\text { constant } \\
(\text { sec }) \\
\end{array}$ & $\begin{array}{c}\text { HP section } \\
\text { time } \\
\text { constant } \\
(\text { sec }) \\
\end{array}$ & $\begin{array}{l}\text { Reheater } \\
\text { time } \\
\text { constant } \\
(\text { sec }) \\
\end{array}$ \\
\hline number & 1 & 2 & 3 & 4 & 5 & 6 \\
\hline $1,2,3,4$ & 25.00 & 1.00 & 0.10 & 0.50 & 1.25 & 5.00 \\
\hline
\end{tabular}

\begin{tabular}{|c|c|c|c|c|c|c|c|}
\hline exciter & $\begin{array}{c}\text { machine } \\
\text { number }\end{array}$ & $\begin{array}{l}\text { exciter } \\
\text { type }\end{array}$ & $\begin{array}{c}\text { input filter } \\
T_{R} \\
(\mathrm{sec}) \\
\end{array}$ & $\begin{array}{c}\text { gain } \\
K_{A} \\
(\mathrm{pu})\end{array}$ & $\begin{array}{c}\text { time const. } \\
T_{A} \\
(\mathrm{sec}) \\
\end{array}$ & $\begin{array}{c}\max \\
V_{R} \\
(\mathbf{p u}) \\
\end{array}$ & $\begin{array}{c}\min \\
V_{R} \\
(\mathbf{p u})\end{array}$ \\
\hline number & 1 & 2 & 3 & 4 & 5 & 6 & 7 \\
\hline 1 & 1 & IEEE DC 1 & 0.01 & 46.0 & 0.06 & 1.00 & $\overline{-0.9}$ \\
\hline 2 & 4 & IEEE DC 2 & 0.01 & 300.0 & 0.01 & 4.95 & -4.9 \\
\hline $\begin{array}{c}\text { exc. const. } \\
K_{E}\end{array}$ & $\begin{array}{c}\text { exc. time const. } \\
T_{E} \\
(\mathrm{sec}) \\
\end{array}$ & $E_{1}$ & $S_{E}\left(E_{1}\right)$ & $E_{2}$ & $\begin{array}{l}S_{E}\left(E_{2}\right) \\
\text { angle } \\
\text { (deg) }\end{array}$ & $\begin{array}{c}\text { stabilizer } \\
\text { gain } k_{F}\end{array}$ & $\begin{array}{c}\text { stabilizer } \\
\text { time } T_{F} \\
\text { (sec) }\end{array}$ \\
\hline 8 & 9 & 10 & 11 & 12 & 13 & 14 & 15 \\
\hline- & 0.46 & 3.1 & 0.33 & 2.3 & 0.1 & 0.1 & 1.0 \\
\hline 1.0 & 1.33 & 3.05 & 0.279 & 2.29 & 0.117 & 0.1 & 0.675 \\
\hline
\end{tabular}

\begin{tabular}{||c||c|c|c|c|c|c|c|}
\hline \hline \multirow{2}{*}{$\begin{array}{c}\text { exciter } \\
\text { number }\end{array}$} & $\begin{array}{c}\text { machine } \\
\text { number }\end{array}$ & $\begin{array}{c}\text { exciter } \\
\text { type }\end{array}$ & $\begin{array}{c}\text { input filter } \\
T_{R} \\
(\mathbf{s e c})\end{array}$ & $\begin{array}{c}\text { gain } \\
K_{A} \\
(\mathbf{p u})\end{array}$ & $\begin{array}{c}\text { time const. } \\
T_{A} \\
(\mathbf{s e c})\end{array}$ & $\begin{array}{c}\text { max } \\
V_{R} \\
(\mathbf{p u})\end{array}$ & $\begin{array}{c}\text { min } \\
V_{R} \\
(\mathbf{p u})\end{array}$ \\
\hline \hline 3 & $\mathbf{1}$ & $\mathbf{2}$ & $\mathbf{3}$ & $\mathbf{4}$ & $\mathbf{5}$ & $\mathbf{6}$ & $\mathbf{7}$ \\
\hline \hline
\end{tabular}




\begin{tabular}{|c|c|c|c|c|c|c|}
\hline exciter & $\begin{array}{c}\text { machine } \\
\text { number }\end{array}$ & $\begin{array}{c}\text { exciter } \\
\text { type }\end{array}$ & $\begin{array}{c}\text { input filter } \\
T_{R} \\
(\mathrm{sec})\end{array}$ & $\begin{array}{c}\text { gain } \\
K_{A} \\
(\mathbf{p u})\end{array}$ & $\begin{array}{c}T_{A} \\
(\mathbf{s e c})\end{array}$ & $\begin{array}{c}\max \\
V_{R} \\
(\mathbf{p u})\end{array}$ \\
\hline number & 1 & 2 & $\mathbf{3}$ & 4 & 5 & 6 \\
\hline 4 & 2 & IEEE ST3 & 0.01 & 7.04 & 1.0 & 10.0 \\
\hline $\begin{array}{c}\min \\
V_{R} \\
(\mathbf{p u}) \\
\end{array}$ & $\begin{array}{c}T_{B} \\
\text { (sec) }\end{array}$ & $\begin{array}{c}T_{C} \\
\text { (sec) }\end{array}$ & $\begin{array}{l}\text { max int. } \\
\text { sig. } V_{I \max }\end{array}$ & $\begin{array}{c}\text { min int. } \\
\text { sig. } V_{I \max }\end{array}$ & $\begin{array}{c}\text { regulator } \\
\text { gain } k_{J}\end{array}$ & $\begin{array}{c}\text { pot. circ. } \\
\text { gain } k_{P}\end{array}$ \\
\hline 7 & 8 & 9 & 10 & 11 & 12 & 13 \\
\hline-10.0 & 6.67 & 1.0 & 0.2 & -0.2 & 200 & 4.37 \\
\hline $\begin{array}{c}\text { pot. circ. } \\
\text { phase angle } q_{P} \\
\text { (deg) }\end{array}$ & $\begin{array}{c}\text { pot. circ. } \\
\text { gain } k_{I}\end{array}$ & $\begin{array}{l}\text { pot. source } \\
\text { reactance } \\
(\mathrm{pu})\end{array}$ & $\begin{array}{c}\text { rectifier } \\
\text { loading } \\
\text { factor } k_{C}\end{array}$ & $\begin{array}{l}\text { max. field } \\
\text { voltage } \\
\text { (pu) }\end{array}$ & $\begin{array}{c}\text { inner loop } \\
\text { fdb. } k_{G}\end{array}$ & $\begin{array}{c}\text { max. inner } \\
\text { loop } \mathbf{F B} V_{G \max } \\
(\mathbf{p u})\end{array}$ \\
\hline 14 & 15 & 12 & 13 & 14 & 15 & 15 \\
\hline 20 & 4.83 & 0.09 & 1.1 & 8.63 & 1.0 & 6.53 \\
\hline
\end{tabular}

\begin{tabular}{|c|c|c|c|c|c|c|c|c|c|}
\hline \multirow{2}{*}{$\begin{array}{c}\text { PSS } \\
\text { number }\end{array}$} & \multirow{2}{*}{$\begin{array}{c}\text { machine } \\
\text { number }\end{array}$} & $\begin{array}{l}\text { gain } \\
\text { (pu) }\end{array}$ & $\begin{array}{c}\text { washout } \\
(\mathrm{sec})\end{array}$ & $\begin{array}{l}\text { lead } T_{11} \\
(\mathrm{sec})\end{array}$ & $\begin{array}{c}\text { lag } T_{12} \\
\text { (sec) }\end{array}$ & $\begin{array}{l}\text { lead } T_{21} \\
\quad(\mathrm{sec})\end{array}$ & $\begin{array}{c}\text { lag } T_{22} \\
\text { (sec) }\end{array}$ & $\begin{array}{l}\max \\
(p u)\end{array}$ & $\begin{array}{l}\text { min } \\
(\mathrm{pu})\end{array}$ \\
\hline & & 1 & 2 & 3 & 4 & 5 & 6 & 7 & 8 \\
\hline 1 & 2 & 300 & 20 & 0.10 & 0.02 & 0.10 & 0.02 & 0.20 & -0.05 \\
\hline 2 & 3 & 300 & 20 & 0.06 & 0.04 & 0.08 & 0.04 & 0.20 & -0.05 \\
\hline
\end{tabular}

\begin{tabular}{|c|c|c|c|c|c|c|c|}
\hline $\begin{array}{l}\text { device } \\
\text { UPFC }\end{array}$ & $\begin{array}{l}\text { sending } \\
\text { bus }\end{array}$ & $\begin{array}{c}\text { receiving } \\
\text { bus }\end{array}$ & $\begin{array}{c}\text { shunt } \\
\text { reactance } \\
(\mathrm{pu})\end{array}$ & $\begin{array}{c}\text { series } \\
\text { reactance } \\
(\mathrm{pu})\end{array}$ & $\begin{array}{c}\text { shunt } \\
\text { turn ratio }\end{array}$ & $\begin{array}{c}\text { series } \\
\text { turn ratio }\end{array}$ & $\begin{array}{c}\text { DC link } \\
\text { voltage } \\
(\mathrm{kV})\end{array}$ \\
\hline number & 1 & 2 & 3 & 4 & 5 & 6 & 7 \\
\hline 1 & 101 & 102 & 0.0575 & 0.05 & 0.0295 & 0.048 & 22 \\
\hline & $\begin{array}{l}\text { DC link } \\
\text { capacitor } \\
(\mathrm{pu})\end{array}$ & $\begin{array}{c}\text { AC base } \\
\text { voltage } \\
(\mathrm{kV})\end{array}$ & $\begin{array}{l}\text { Shunt conv. } \\
\text { rating } \\
(\mathrm{pu})\end{array}$ & $\begin{array}{l}\text { Series conv. } \\
\text { rating } \\
(\mathrm{pu})\end{array}$ & $\begin{array}{c}\max V_{P} \\
(\mathbf{p u})\end{array}$ & \multicolumn{2}{|c|}{$\begin{array}{c}\max V_{Q} \\
(\mathbf{p u})\end{array}$} \\
\hline & 8 & 9 & 10 & 11 & 12 & \multicolumn{2}{|c|}{13} \\
\hline & 0.055 & 220 & 1.60 & 1.60 & 0.30 & \multicolumn{2}{|c|}{0.15} \\
\hline
\end{tabular}

\begin{tabular}{|c||c|c||c|c||c|c||c|c||}
\hline \hline \multirow{2}{*}{ control } & \multicolumn{2}{c||}{ DC voltage } & \multicolumn{2}{c||}{ AC voltage } & \multicolumn{2}{c||}{ Active power } & \multicolumn{2}{c||}{ Reactive power } \\
& $k_{P}$ & $T_{I}$ & $k_{P}$ & $T_{I}$ & $k_{P}$ & $T_{I}$ & $k_{P}$ & $T_{I}$ \\
UPFC & $(\mathbf{p u})$ & $(\mathbf{m s})$ & $(\mathbf{p u})$ & $(\mathbf{m s})$ & $(\mathbf{p u})$ & $(\mathbf{s e c})$ & $(\mathbf{p u})$ & $(\mathbf{s e c})$ \\
\cline { 2 - 9 } number & $\mathbf{1}$ & $\mathbf{2}$ & $\mathbf{1}$ & $\mathbf{2}$ & $\mathbf{1}$ & $\mathbf{2}$ & $\mathbf{1}$ & $\mathbf{2}$ \\
\hline \hline 1 & 10 & 10 & 30 & 80 & 0.01 & 1.1 & 0.01 & 1.1 \\
\hline \hline
\end{tabular}

\begin{tabular}{|c|c|c|c|c|c|c|}
\hline \multirow{3}{*}{$\begin{array}{c}\text { phase- } \\
\text { plane } \\
\text { measure- } \\
\text { ment }\end{array}$} & \multicolumn{2}{|c|}{ Power } & \multicolumn{2}{|c|}{ Energy } & \multicolumn{2}{|c|}{ Energy Integral } \\
\hline & $\begin{array}{c}\text { washout } \\
\text { (sec) }\end{array}$ & scaling & $\begin{array}{c}\text { washout } \\
\text { (sec) }\end{array}$ & scaling & $\begin{array}{c}\text { washout } \\
\text { (sec) }\end{array}$ & scaling \\
\hline & 1 & 2 & 3 & 4 & 5 & 6 \\
\hline 1 & 0.8 & 1 & 0.5 & 0.1 & 0.3 & 1 \\
\hline
\end{tabular}

\begin{tabular}{|c|c|c|c|c|c|c|c|}
\hline \multirow{3}{*}{$\begin{array}{c}\text { TSK } \\
\text { number }\end{array}$} & \multicolumn{3}{|c|}{ fault trigger level } & \multirow{2}{*}{$\begin{array}{c}\text { maximum } \\
\text { output } \\
\text { (pu) }\end{array}$} & \multirow{2}{*}{$\begin{array}{c}\text { minimum } \\
\text { output } \\
\text { (pu) }\end{array}$} & \multirow{2}{*}{$\begin{array}{c}\text { transition } \\
\text { angle } \\
\text { (deg) }\end{array}$} & \multirow{2}{*}{$\begin{array}{c}\text { turn-off } \\
k_{D}\end{array}$} \\
\hline & $\begin{array}{c}\Delta P \\
(\mathbf{p u})\end{array}$ & $\begin{array}{c}\Delta \dot{P} \\
(\mathrm{pu} / \mathrm{ms})\end{array}$ & $\begin{array}{c}\Delta V \\
(\mathbf{p u})\end{array}$ & & & & \\
\hline & 1 & 2 & 3 & 4 & 5 & 6 & 7 \\
\hline 1 & 0.15 & 1 & 0.10 & 0.80 & -0.80 & 25 & 0.90 \\
\hline
\end{tabular}




\section{Appendix D}

\section{Meshed Power System data}

\begin{tabular}{|c|c|c|c|c|c|c|c|}
\hline \multirow{3}{*}{$\begin{array}{c}\text { bus } \\
\text { bumber }\end{array}$} & \multirow[b]{2}{*}{ V } & \multirow{2}{*}{$\begin{array}{c}\text { Angle } \\
\text { (deg) }\end{array}$} & \multicolumn{2}{|c|}{ Generation } & \multicolumn{2}{|c|}{ Load } & \multirow{2}{*}{$\begin{array}{l}\text { Bus } \\
\text { type }\end{array}$} \\
\hline & & & $\mathrm{Pg}$ & Qg & $\mathbf{P}$ & Q & \\
\hline & 1 & 2 & 3 & 4 & 5 & 6 & 7 \\
\hline 1 & 1.00 & 0.00 & 1.07 & 0.23 & - & - & Slack \\
\hline 2 & 1.00 & -3.79 & 0.80 & 0.17 & - & - & PV \\
\hline 3 & 1.00 & -5.68 & 0.90 & 0.19 & - & - & PV \\
\hline 4 & 1.00 & -8.10 & 0.90 & 0.37 & - & - & PV \\
\hline 5 & 0.98 & -3.70 & - & - & - & - & $\overline{P Q}$ \\
\hline 6 & 0.98 & -3.70 & - & - & - & - & PQ \\
\hline 7 & 0.92 & -17.03 & - & - & - & - & $\mathrm{PQ}$ \\
\hline 8 & 0.90 & -23.60 & - & - & 2.20 & 0.30 & $\mathrm{PQ}$ \\
\hline 9 & 0.98 & -10.41 & - & - & - & - & $\mathrm{PQ}$ \\
\hline 10 & 0.98 & -10.36 & - & - & - & - & $\mathrm{PQ}$ \\
\hline 11 & 0.98 & -12.58 & - & - & - & - & PQ \\
\hline 12 & 0.96 & -14.77 & - & - & - & - & $\mathrm{PQ}$ \\
\hline 13 & 0.94 & -7.92 & - & - & 0.80 & 0.30 & $\mathrm{PQ}$ \\
\hline 14 & 0.99 & -7.87 & - & - & - & - & $\mathrm{PQ}$ \\
\hline 15 & 0.99 & -5.78 & - & - & - & - & PQ \\
\hline 16 & 0.99 & -2.68 & - & - & - & - & $\mathrm{PQ}$ \\
\hline 17 & 0.99 & -14.60 & - & - & - & - & $\mathrm{PQ}$ \\
\hline 18 & 0.99 & -16.12 & - & - & - & - & $\mathrm{PQ}$ \\
\hline 19 & 0.95 & -12.42 & - & - & - & - & $\mathrm{PQ}$ \\
\hline 20 & 0.95 & -11.46 & - & - & 0.60 & 0.10 & PQ \\
\hline
\end{tabular}




\begin{tabular}{|c|c|c|c|c|}
\hline \multirow{2}{*}{$\begin{array}{c}\text { line } \\
\text { number }\end{array}$} & $\begin{array}{c}\text { from } \\
\text { bus }\end{array}$ & $\begin{array}{l}\text { to } \\
\text { bus }\end{array}$ & $\begin{array}{c}\text { length } \\
\text { (km) }\end{array}$ & $\begin{array}{c}\text { reactance } \\
(\mathrm{pu})\end{array}$ \\
\hline & 1 & 2 & 3 & 4 \\
\hline 1 & 6 & 7 & 120 & - \\
\hline 2 & 7 & 9 & 140 & - \\
\hline 3 & 7 & 19 & 100 & - \\
\hline 4 & 10 & 11 & 80 & - \\
\hline 5 & 11 & 12 & 70 & - \\
\hline 6 & 14 & 12 & 2 & - \\
\hline 7 & 14 & 15 & 200 & - \\
\hline 8 & 14 & 19 & 200 & - \\
\hline 9 & 14 & 19 & 120 & - \\
\hline 10 & 17 & 7 & 160 & - \\
\hline 11 & 16 & 17 & 160 & - \\
\hline 12 & 16 & 17 & 10 & - \\
\hline 13 & 18 & 5 & 140 & - \\
\hline 14 & 18 & 17 & 130 & - \\
\hline 15 & 11 & 19 & 80 & - \\
\hline 16 & 1 & 18 & - & 0.0431 \\
\hline 17 & 2 & 17 & - & 0.0431 \\
\hline 18 & 3 & 14 & - & 0.0431 \\
\hline 19 & 4 & 11 & - & 0.0431 \\
\hline 20 & 7 & 8 & - & 0.0431 \\
\hline 21 & 12 & 13 & - & 0.0431 \\
\hline 22 & 19 & 20 & - & 0.0431 \\
\hline
\end{tabular}

\begin{tabular}{||c|c|c|c|c|c|c|c||}
\hline \hline \multirow{2}{*}{$\begin{array}{c}\text { machine } \\
\text { number }\end{array}$} & $\begin{array}{c}\text { bus } \\
\text { number }\end{array}$ & \begin{tabular}{c} 
bVA \\
\cline { 3 - 8 }
\end{tabular} & $\begin{array}{c}x_{l} \\
(\mathbf{p u})\end{array}$ & $\begin{array}{c}\text { resistance } \\
(\mathbf{p u})\end{array}$ & $\begin{array}{c}x_{d} \\
(\mathbf{p u})\end{array}$ & $\begin{array}{c}x_{d}^{\prime} \\
(\mathbf{p u})\end{array}$ & $\begin{array}{c}x_{d}^{\prime \prime} \\
(\mathbf{p u})\end{array}$ \\
\hline \hline $1,2,3,4$ & $1,2,3,4$ & 1250 & 0.25 & 0.003 & 2.38 & 0.34 & - \\
\hline \hline$T_{d o}^{\prime}$ & $T_{d o}^{\prime}$ & $x_{q}$ & $x_{q}^{\prime}$ & $x_{q}^{\prime \prime}$ & $T_{q o}^{\prime}$ & damping \\
$(\mathbf{p u})$ & $(\mathbf{p u})$ & $\begin{array}{c}\mathbf{H} \\
(\mathbf{p u})\end{array}$ & $(\mathbf{p e c})$ \\
\hline $\mathbf{7}$ & $\mathbf{8}$ & $\mathbf{9}$ & $\mathbf{1 0}$ & $\mathbf{1 1}$ & $\mathbf{1 2}$ & $\mathbf{1 3}$ & $\mathbf{1 4}$ \\
\hline \hline 5.88 & - & 2.27 & 0.91 & - & 2.27 & 2 & 6.5 \\
\hline \hline
\end{tabular}

\begin{tabular}{|c|c|c|c|c|c|c|}
\hline $\begin{array}{l}\text { turbine- } \\
\text { governor }\end{array}$ & $\begin{array}{c}\text { steady-state } \\
\text { gain } \\
1 / R \\
\text { (pu) }\end{array}$ & $\begin{array}{c}\text { maximum } \\
\text { power } \\
\text { (on mac. base) } \\
(\text { pu })\end{array}$ & $\begin{array}{c}\text { servo } \\
\text { time } \\
\text { constant } \\
(\text { sec })\end{array}$ & $\begin{array}{l}\text { governor } \\
\text { time } \\
\text { constant } \\
(\text { sec })\end{array}$ & $\begin{array}{c}\text { HP section } \\
\text { time } \\
\text { constant } \\
(\text { sec })\end{array}$ & $\begin{array}{c}\text { Reheater } \\
\text { time } \\
\text { constant } \\
(\text { sec })\end{array}$ \\
\hline number & 1 & 2 & 3 & 4 & 5 & 6 \\
\hline $1,2,3,4$ & 20 & 1.1 & 0.04 & 0.2 & 1.5 & 2 \\
\hline
\end{tabular}

\begin{tabular}{|c|c|c|c|c|c|c|c|}
\hline exciter & $\begin{array}{c}\text { machine } \\
\text { number }\end{array}$ & $\begin{array}{l}\text { exciter } \\
\text { type }\end{array}$ & $\begin{array}{c}\text { input filter } \\
T_{R} \\
(\mathrm{sec})\end{array}$ & $\begin{array}{c}\text { gain } \\
K_{A} \\
(\mathbf{p u})\end{array}$ & $\begin{array}{c}\text { time const. } \\
T_{A} \\
(\mathrm{sec})\end{array}$ & $\begin{array}{c}\max \\
V_{R} \\
(\mathbf{p u})\end{array}$ & $\begin{array}{c}\min \\
V_{R} \\
(\mathbf{p u})\end{array}$ \\
\hline number & 1 & 2 & $\mathbf{3}$ & 4 & 5 & 6 & 7 \\
\hline $1,2,3,4$ & $1,2,3,4$ & IEEE DC 1 & 0.5 & 5 & 0.01 & 5.75 & -8.47 \\
\hline $\begin{array}{c}\text { exc. const. } \\
K_{E}\end{array}$ & $\begin{array}{c}\text { exc. time const. } \\
T_{E} \\
(\mathrm{sec})\end{array}$ & $E_{1}$ & $S_{E}\left(E_{1}\right)$ & $E_{2}$ & $\begin{array}{c}S_{E}\left(E_{2}\right) \\
\text { angle } \\
\text { (deg) }\end{array}$ & $\begin{array}{c}\text { stabilizer } \\
\text { gain } k_{F}\end{array}$ & $\begin{array}{c}\text { stabilizer } \\
\text { time } T_{F} \\
\quad(\text { sec) }\end{array}$ \\
\hline 8 & 9 & 10 & 11 & 12 & 13 & 14 & 15 \\
\hline 1 & 0.65 & 3.1 & 0.33 & 2.3 & 0.1 & 0.04 & 1.65 \\
\hline
\end{tabular}




\begin{tabular}{||c|c||c|c|c|c|c|c|c|c||}
\hline \hline \multirow{2}{*}{$\begin{array}{c}\text { PSS } \\
\text { number }\end{array}$} & \multirow{2}{*}{$\begin{array}{c}\text { machine } \\
\text { number }\end{array}$} & $\begin{array}{c}\text { gain } \\
(\mathbf{p u})\end{array}$ & $\begin{array}{c}\text { washout } \\
(\mathbf{s e c})\end{array}$ & $\begin{array}{c}\text { lead } T_{11} \\
(\mathbf{s e c})\end{array}$ & $\begin{array}{c}\text { lag } T_{12} \\
(\mathbf{s e c})\end{array}$ & $\begin{array}{c}\text { lead } T_{21} \\
(\mathbf{s e c})\end{array}$ & $\begin{array}{c}\text { lag } T_{22} \\
(\mathbf{s e c})\end{array}$ & $\begin{array}{c}\text { max } \\
(\mathbf{p u})\end{array}$ & $\begin{array}{c}\text { min } \\
(\mathbf{p u})\end{array}$ \\
\hline \hline 1 & 1 & $\mathbf{2}$ & $\mathbf{3}$ & $\mathbf{4}$ & $\mathbf{5}$ & $\mathbf{6}$ & $\mathbf{7}$ & $\mathbf{8}$ \\
\hline 2 & 2 & 10 & 10 & 0.08 & 0.01 & 0.08 & 0.01 & 0.20 & -0.05 \\
\hline 3 & 3 & 10 & 10 & 0.08 & 0.01 & 0.08 & 0.01 & 0.20 & -0.05 \\
\hline 4 & 4 & 10 & 10 & 0.04 & 0.02 & 0.10 & 0.01 & 0.20 & -0.05 \\
\hline \hline
\end{tabular}

\begin{tabular}{|c|c|c|c|c|c|c|c|}
\hline $\begin{array}{l}\text { device } \\
\text { UPFC }\end{array}$ & $\begin{array}{l}\text { sending } \\
\text { bus }\end{array}$ & $\begin{array}{c}\text { receiving } \\
\text { bus }\end{array}$ & $\begin{array}{c}\text { shunt } \\
\text { reactance } \\
\text { (pu) }\end{array}$ & $\begin{array}{l}\text { series } \\
\text { reactance } \\
\text { (pu) }\end{array}$ & $\begin{array}{c}\text { shunt } \\
\text { turn ratio }\end{array}$ & $\begin{array}{c}\text { series } \\
\text { turn ratio }\end{array}$ & $\begin{array}{c}\text { DC link } \\
\text { voltage } \\
(\mathrm{kV})\end{array}$ \\
\hline number & 1 & 2 & 3 & 4 & 5 & 6 & 7 \\
\hline $1,2,3$ & $5,9,15$ & $6,10,16$ & 0.2413 & 0.0031 & 0.0295 & 0.038 & 22 \\
\hline & $\begin{array}{l}\text { DC link } \\
\text { capacitor } \\
\text { (pu) }\end{array}$ & $\begin{array}{c}\text { AC base } \\
\text { voltage } \\
(\mathrm{kV})\end{array}$ & $\begin{array}{l}\text { Shunt conv. } \\
\text { rating } \\
\text { (pu) }\end{array}$ & $\begin{array}{l}\text { Series conv. } \\
\text { rating } \\
\text { (pu) }\end{array}$ & $\begin{array}{c}\max V_{P} \\
(\mathrm{pu})\end{array}$ & \multicolumn{2}{|c|}{$\overline{\quad} \quad \max V_{Q}$} \\
\hline & 8 & 9 & 10 & 11 & 12 & \multicolumn{2}{|c|}{13} \\
\hline & 0.055 & 220 & 1.60 & 1.60 & 0.155 & \multicolumn{2}{|c|}{0.1} \\
\hline
\end{tabular}

\begin{tabular}{|c|c|c|c|c|c|c|c|c|}
\hline \multirow{3}{*}{$\begin{array}{c}\text { control } \\
\text { UPFC } \\
\text { number }\end{array}$} & \multicolumn{2}{|c|}{ DC voltage } & \multicolumn{2}{|c|}{ Reactive current } & \multicolumn{2}{|c|}{ Active power } & \multicolumn{2}{|c|}{ Reactive power } \\
\hline & $\begin{array}{c}k_{P} \\
(\mathbf{p u})\end{array}$ & $\begin{array}{c}T_{I} \\
(\mathrm{~ms})\end{array}$ & $\begin{array}{c}k_{P} \\
(\mathbf{p u})\end{array}$ & $\begin{array}{c}T_{I} \\
(\mathbf{m s})\end{array}$ & $\begin{array}{c}k_{P} \\
(\mathbf{p u})\end{array}$ & $\begin{array}{c}T_{I} \\
(\mathrm{sec})\end{array}$ & $\begin{array}{c}k_{P} \\
(\mathbf{p u})\end{array}$ & $\begin{array}{c}T_{I} \\
(\mathbf{s e c})\end{array}$ \\
\hline & 1 & 2 & 3 & 4 & 5 & 6 & 7 & 8 \\
\hline$\overline{c 1}$ & 10 & 20 & $\overline{0} 0$ & 200 & 0.1 & (20.01 & 0.1 & .01 \\
\hline
\end{tabular}

\begin{tabular}{|c|c|c|c|c|c|c|c|}
\hline \multirow{3}{*}{$\begin{array}{c}\text { TSK } \\
\text { number }\end{array}$} & \multicolumn{3}{|c|}{ fault trigger level } & \multirow{2}{*}{$\begin{array}{c}\text { maximum } \\
\text { output } \\
(\mathrm{pu})\end{array}$} & \multirow{2}{*}{$\begin{array}{c}\text { minimum } \\
\text { output } \\
\text { (pu) }\end{array}$} & \multirow{2}{*}{$\begin{array}{c}\text { transition } \\
\text { angle } \\
\text { (deg) }\end{array}$} & \multirow{2}{*}{$\begin{array}{c}\text { turn-off } \\
k_{D}\end{array}$} \\
\hline & $\begin{array}{c}\Delta P \\
(\mathbf{p u})\end{array}$ & $\begin{array}{c}\Delta \dot{P} \\
(\mathbf{p u} / \mathbf{m s})\end{array}$ & $\begin{array}{c}\Delta V \\
(\mathbf{p u})\end{array}$ & & & & \\
\hline & 1 & 2 & 3 & 4 & 5 & 6 & 7 \\
\hline $1,2,3$ & 0.15 & 1 & 0.1 & 0.25 & -0.25 & 25 & 0.90 \\
\hline
\end{tabular}

\begin{tabular}{|c|c|c|c|c|c|c|}
\hline \multirow{3}{*}{$\begin{array}{c}\text { phase- } \\
\text { plane } \\
\text { measure- } \\
\text { ment }\end{array}$} & \multicolumn{2}{|c|}{ Power } & \multicolumn{2}{|c|}{ Energy } & \multicolumn{2}{|c|}{ Energy Integral } \\
\hline & $\begin{array}{c}\text { washout } \\
\text { (sec) }\end{array}$ & scaling & $\begin{array}{c}\text { washout } \\
\text { (sec) }\end{array}$ & scaling & $\begin{array}{c}\text { washout } \\
\text { (sec) }\end{array}$ & scaling \\
\hline & 1 & 2 & 3 & 4 & 5 & 6 \\
\hline $1,2,3$ & 0.8 & 1 & 0.5 & 0.1 & 0.3 & 1 \\
\hline
\end{tabular}




\section{Appendix E}

\section{New England-New York system data}

\begin{tabular}{|c|c|c|c|c|c|c|c|}
\hline \multirow{3}{*}{$\begin{array}{c}\text { bus } \\
\text { bumber }\end{array}$} & \multirow[b]{2}{*}{ V } & \multirow{2}{*}{$\begin{array}{c}\text { Angle } \\
\text { (deg) }\end{array}$} & \multicolumn{2}{|c|}{ Generation } & \multicolumn{2}{|c|}{ Load } & \multirow{2}{*}{$\begin{array}{l}\text { Bus } \\
\text { type }\end{array}$} \\
\hline & & & $\mathbf{P g}$ & Qg & $\mathbf{P}$ & $\mathbf{Q}$ & \\
\hline & 1 & 2 & 3 & 4 & 5 & 6 & 7 \\
\hline 1 & 1.06 & 6.61 & - & - & 2.53 & 1.19 & PQ \\
\hline 2 & 1.05 & 8.43 & - & - & - & - & PQ \\
\hline 3 & 1.03 & 5.42 & - & - & 3.22 & 0.02 & PQ \\
\hline 4 & 1.00 & 4.30 & - & - & 5.00 & 1.84 & PQ \\
\hline 5 & 1.00 & 5.26 & - & - & - & - & $\mathrm{PQ}$ \\
\hline 6 & 1.00 & 5.95 & - & - & - & - & $\mathrm{PQ}$ \\
\hline 7 & 0.99 & 3.65 & - & - & 2.34 & 0.84 & PQ \\
\hline 8 & 0.99 & 3.10 & - & - & 5.22 & 1.77 & PQ \\
\hline 9 & 1.04 & 2.58 & - & - & 1.04 & 1.25 & PQ \\
\hline 10 & 1.01 & 8.48 & - & - & - & - & $\mathrm{PQ}$ \\
\hline 11 & 1.01 & 7.62 & - & - & - & - & $\mathrm{PQ}$ \\
\hline 12 & 1.05 & 7.64 & - & - & 0.09 & 0.88 & PQ \\
\hline 13 & 1.01 & 7.81 & - & - & - & - & PQ \\
\hline 14 & 1.01 & 6.24 & - & - & - & - & PQ \\
\hline 15 & 1.01 & 6.14 & - & - & 3.20 & 1.53 & PQ \\
\hline 16 & 1.03 & 7.67 & - & - & 3.29 & 0.32 & $\mathrm{PQ}$ \\
\hline 17 & 1.03 & 6.58 & - & - & - & - & PQ \\
\hline 18 & 1.03 & 5.71 & - & - & 1.58 & 0.30 & PQ \\
\hline 19 & 1.05 & 12.27 & - & - & - & - & PQ \\
\hline 20 & 0.99 & 10.84 & - & - & 6.80 & 1.03 & $\mathrm{PQ}$ \\
\hline 21 & 1.03 & 10.31 & - & - & 2.74 & 1.15 & $\mathrm{PQ}$ \\
\hline 22 & 1.05 & 15.00 & - & - & - & - & PQ \\
\hline 23 & 1.04 & 14.71 & - & - & 2.48 & 0.85 & PQ \\
\hline 24 & 1.04 & 7.85 & - & - & 3.09 & - & PQ \\
\hline 25 & 1.06 & 9.69 & - & - & 2.24 & 0.47 & $\mathrm{PQ}$ \\
\hline 26 & 1.06 & 8.19 & - & - & 1.39 & 0.17 & PQ \\
\hline 27 & 1.04 & 6.30 & - & - & 2.81 & 0.76 & PQ \\
\hline 28 & 1.05 & 11.33 & - & - & 2.06 & 0.28 & PQ \\
\hline 29 & 1.05 & 13.96 & - & - & 2.84 & 0.27 & PQ \\
\hline 30 & 1.05 & 6.07 & - & - & - & - & PQ \\
\hline 31 & 1.06 & 8.63 & - & - & - & - & PQ \\
\hline 32 & 1.05 & 10.96 & - & - & - & - & PQ \\
\hline 33 & 1.06 & 7.47 & - & - & 1.12 & - & PQ \\
\hline 34 & 1.07 & 2.54 & - & - & - & - & PQ \\
\hline 35 & 1.01 & 2.53 & - & - & - & - & $\mathrm{PQ}$ \\
\hline 36 & 1.04 & -0.85 & - & - & 1.02 & - & $\mathrm{PQ}$ \\
\hline
\end{tabular}


continued from previous page

\begin{tabular}{|c|c|c|c|c|c|c|c|}
\hline \multirow{3}{*}{$\begin{array}{c}\text { bus } \\
\text { bumber }\end{array}$} & \multirow[b]{2}{*}{ V } & \multirow{2}{*}{$\begin{array}{c}\text { Angle } \\
\text { (deg) }\end{array}$} & \multicolumn{2}{|c|}{ Generation } & \multicolumn{2}{|c|}{ Load } & \multirow{2}{*}{$\begin{array}{l}\text { Bus } \\
\text { type }\end{array}$} \\
\hline & & & $\mathrm{Pg}$ & $\mathrm{Qg}$ & $\mathbf{P}$ & Q & \\
\hline & 1 & 2 & 3 & 4 & 5 & 6 & 7 \\
\hline 37 & 1.03 & -6.81 & - & - & 60.00 & 3.00 & $\mathrm{PQ}$ \\
\hline 38 & 1.06 & 8.68 & - & - & - & - & $\mathrm{PQ}$ \\
\hline 39 & 1.01 & -8.44 & - & - & 2.67 & 0.13 & $\mathrm{PQ}$ \\
\hline 40 & 1.07 & 15.20 & - & - & 0.66 & 0.24 & $\mathrm{PQ}$ \\
\hline 41 & 1.00 & 44.45 & - & - & 10.00 & 2.50 & $\mathrm{PQ}$ \\
\hline 42 & 1.00 & 38.96 & - & - & 11.50 & 2.50 & $\mathrm{PQ}$ \\
\hline 43 & 1.01 & -7.61 & - & - & - & - & $\mathrm{PQ}$ \\
\hline 44 & 1.01 & -7.64 & - & - & 2.68 & 0.05 & $\mathrm{PQ}$ \\
\hline 45 & 1.02 & 2.53 & - & - & 2.08 & 0.21 & $\mathrm{PQ}$ \\
\hline 46 & 1.03 & 9.65 & - & - & 1.51 & 0.29 & $\mathrm{PQ}$ \\
\hline 47 & 1.07 & 7.36 & - & - & 2.03 & 0.33 & PQ \\
\hline 48 & 1.08 & 9.27 & - & - & 2.41 & 0.02 & PQ \\
\hline 49 & 1.01 & 12.89 & - & - & 1.64 & 0.29 & $\mathrm{PQ}$ \\
\hline 50 & 1.01 & 19.35 & - & - & 1.00 & - & $\mathrm{PQ}$ \\
\hline 51 & 1.02 & 6.53 & - & - & 3.37 & - & $\mathrm{PQ}$ \\
\hline 52 & 0.99 & 38.61 & - & - & 24.70 & 1.23 & $\mathrm{PQ}$ \\
\hline 53 & 1.05 & 10.85 & 2.50 & 1.21 & - & - & $\mathrm{PV}$ \\
\hline 54 & 0.98 & 14.48 & 5.45 & 2.09 & - & - & PV \\
\hline 55 & 0.98 & 16.50 & 6.50 & 2.19 & - & - & PV \\
\hline 56 & 1.00 & 17.49 & 6.32 & 1.11 & - & - & PV \\
\hline 57 & 1.01 & 16.01 & 5.05 & 1.64 & - & - & PV \\
\hline 58 & 1.05 & 20.34 & 7.00 & 2.24 & $\begin{array}{ll}- \\
-\end{array}$ & - & PV \\
\hline 59 & 1.06 & 22.57 & 5.60 & 1.01 & - & - & PV \\
\hline 60 & 1.03 & 16.45 & 5.40 & 0.04 & - & - & PV \\
\hline 61 & 1.03 & 20.78 & 8.00 & 0.07 & $\begin{array}{ll}- \\
-\end{array}$ & - & PV \\
\hline 62 & 1.01 & 15.91 & 5.00 & 0.07 & - & - & PV \\
\hline 63 & 1.00 & 18.35 & 10.00 & -0.16 & - & - & PV \\
\hline 64 & 1.02 & 4.86 & 13.50 & 2.51 & - & - & PV \\
\hline 65 & 1.01 & 0.00 & 35.92 & 8.77 & - & - & Slack \\
\hline 66 & 1.00 & 45.99 & 17.85 & 0.61 & - & - & PV \\
\hline 67 & 1.00 & 39.82 & 10.00 & 0.66 & - & - & PV \\
\hline 68 & 1.00 & 45.55 & 40.00 & 4.61 & - & - & PV \\
\hline 411 & 1.02 & 41.64 & - & - & - & - & PQ \\
\hline 421 & 1.02 & 41.64 & - & - & - & - & PQ \\
\hline 161 & 1.03 & 7.12 & - & - & - & - & PQ \\
\hline 171 & 1.03 & 7.12 & - & - & - & - & PQ \\
\hline 81 & 1.00 & 2.85 & -0.20 & 0.56 & - & - & PV \\
\hline 91 & 1.02 & 2.84 & - & -1.16 & -0.20 & - & PQ \\
\hline
\end{tabular}

system base: 100 MVA 


\begin{tabular}{|c|c|c|c|c|c|c|}
\hline line & $\begin{array}{c}\text { from } \\
\text { bus }\end{array}$ & $\begin{array}{c}\text { to } \\
\text { bus }\end{array}$ & $\begin{array}{c}\text { resistance } \\
\text { (pu) }\end{array}$ & $\begin{array}{c}\text { reactance } \\
(\mathrm{pu})\end{array}$ & $\begin{array}{c}\text { line charging } \\
(\mathrm{pu})\end{array}$ & tap \\
\hline number & 1 & 2 & 3 & 4 & $\mathbf{5}$ & 6 \\
\hline 1 & 1 & 2 & 0.0035 & 0.0411 & 0.6987 & - \\
\hline 2 & 1 & 30 & 0.0008 & 0.0074 & 0.4800 & - \\
\hline 3 & 2 & 3 & 0.0013 & 0.0151 & 0.2572 & - \\
\hline 4 & 2 & 25 & 0.0070 & 0.0086 & 0.1460 & - \\
\hline 5 & 2 & 53 & - & 0.0181 & - & 1.0250 \\
\hline 6 & 3 & 4 & 0.0013 & 0.0213 & 0.2214 & - \\
\hline 7 & 3 & 18 & 0.0011 & 0.0133 & 0.2138 & - \\
\hline 8 & 4 & 5 & 0.0008 & 0.0128 & 0.1342 & - \\
\hline 9 & 4 & 14 & 0.0008 & 0.0129 & 0.1382 & - \\
\hline 10 & 5 & 6 & 0.0002 & 0.0026 & 0.0434 & - \\
\hline 11 & 5 & 8 & 0.0008 & 0.0112 & 0.1476 & - \\
\hline 12 & 6 & 7 & 0.0006 & 0.0092 & 0.1130 & - \\
\hline 13 & 6 & 11 & 0.0007 & 0.0082 & 0.1389 & - \\
\hline 14 & 6 & 54 & - & 0.0250 & - & 1.0700 \\
\hline 15 & 7 & 8 & 0.0004 & 0.0046 & 0.0780 & - \\
\hline 16 & 8 & 81 & 0.0012 & 0.0182 & 0.1902 & - \\
\hline 17 & 91 & 9 & 0.0012 & 0.0182 & 0.1902 & - \\
\hline 18 & 9 & 30 & 0.0019 & 0.0183 & 0.2900 & - \\
\hline 19 & 10 & 11 & 0.0004 & 0.0043 & 0.0729 & - \\
\hline 20 & 10 & 13 & 0.0004 & 0.0043 & 0.0729 & - \\
\hline 21 & 10 & 55 & - & 0.0200 & - & 1.0700 \\
\hline 22 & 12 & 11 & 0.0016 & 0.0435 & - & 1.0600 \\
\hline 23 & 12 & 13 & 0.0016 & 0.0435 & - & 1.0600 \\
\hline 24 & 13 & 14 & 0.0009 & 0.0101 & 0.1723 & - \\
\hline 25 & 14 & 15 & 0.0018 & 0.0217 & 0.3660 & - \\
\hline 26 & 15 & 16 & 0.0009 & 0.0094 & 0.1710 & - \\
\hline 27 & 16 & 161 & 0.0004 & 0.0045 & 0.0671 & - \\
\hline 28 & 171 & 17 & 0.0004 & 0.0045 & 0.0671 & - \\
\hline 29 & 16 & 19 & 0.0016 & 0.0195 & 0.3040 & - \\
\hline 30 & 16 & 21 & 0.0008 & 0.0135 & 0.2548 & - \\
\hline 31 & 16 & 24 & 0.0003 & 0.0059 & 0.0680 & - \\
\hline 32 & 17 & 18 & 0.0007 & 0.0082 & 0.1319 & - \\
\hline 33 & 17 & 27 & 0.0013 & 0.0173 & 0.3216 & - \\
\hline 34 & 19 & 20 & 0.0007 & 0.0138 & - & 1.0600 \\
\hline 35 & 19 & 56 & 0.0007 & 0.0142 & - & 1.0700 \\
\hline 36 & 20 & 57 & 0.0009 & 0.0180 & - & 1.0090 \\
\hline 37 & 21 & 22 & 0.0008 & 0.0140 & 0.2565 & - \\
\hline 38 & 22 & 23 & 0.0006 & 0.0096 & 0.1846 & - \\
\hline 39 & 22 & 58 & - & 0.0143 & - & 1.0250 \\
\hline 40 & 23 & 24 & 0.0022 & 0.0350 & 0.3610 & - \\
\hline 41 & 23 & 59 & 0.0005 & 0.0272 & - & - \\
\hline 42 & 25 & 26 & 0.0032 & 0.0323 & 0.5310 & - \\
\hline 43 & 25 & 60 & 0.0006 & 0.0232 & - & 1.0250 \\
\hline 44 & 26 & 27 & 0.0014 & 0.0147 & 0.2396 & - \\
\hline 45 & 26 & 28 & 0.0043 & 0.0474 & 0.7802 & - \\
\hline 46 & 26 & 29 & 0.0057 & 0.0625 & 1.0290 & - \\
\hline 47 & 28 & 29 & 0.0014 & 0.0151 & 0.2490 & - \\
\hline 48 & 29 & 61 & 0.0008 & 0.0156 & - & 1.0250 \\
\hline 49 & 9 & 30 & 0.0019 & 0.0183 & 0.2900 & - \\
\hline 50 & 9 & 36 & 0.0022 & 0.0196 & 0.3400 & - \\
\hline 51 & 9 & 36 & 0.0022 & 0.0196 & 0.3400 & - \\
\hline 52 & 36 & 37 & 0.0005 & 0.0045 & 0.3200 & - \\
\hline 53 & 34 & 36 & 0.0033 & 0.0111 & 1.4500 & - \\
\hline 54 & 35 & 34 & 0.0001 & 0.0074 & - & 0.9460 \\
\hline 55 & 33 & 34 & 0.0011 & 0.0157 & 0.2020 & - \\
\hline
\end{tabular}

continued on next page 
continued from previous page

\begin{tabular}{|c|c|c|c|c|c|c|}
\hline line & $\begin{array}{c}\text { from } \\
\text { bus }\end{array}$ & $\begin{array}{l}\text { to } \\
\text { bus }\end{array}$ & $\begin{array}{c}\text { resistance } \\
(\mathrm{pu})\end{array}$ & $\begin{array}{c}\text { reactance } \\
(\mathrm{pu})\end{array}$ & $\begin{array}{c}\text { line charging } \\
(\mathrm{pu})\end{array}$ & tap \\
\hline number & 1 & 2 & 3 & 4 & 5 & 6 \\
\hline 56 & 32 & 33 & 0.0008 & 0.0099 & 0.1680 & - \\
\hline 57 & 30 & 31 & 0.0013 & 0.0187 & 0.3330 & - \\
\hline 58 & 30 & 32 & 0.0024 & 0.0288 & 0.4880 & - \\
\hline 59 & 1 & 31 & 0.0016 & 0.0163 & 0.2500 & - \\
\hline 60 & 31 & 38 & 0.0011 & 0.0147 & 0.2470 & - \\
\hline 61 & 33 & 38 & 0.0036 & 0.0444 & 0.6930 & - \\
\hline 62 & 38 & 46 & 0.0022 & 0.0284 & 0.4300 & - \\
\hline 63 & 46 & 49 & 0.0018 & 0.0274 & 0.2700 & - \\
\hline 64 & 1 & 47 & 0.0013 & 0.0188 & 1.3100 & - \\
\hline 65 & 47 & 48 & 0.0025 & 0.0268 & 0.4000 & - \\
\hline 66 & 47 & 48 & 0.0025 & 0.0268 & 0.4000 & - \\
\hline 67 & 48 & 40 & 0.0020 & 0.0220 & 1.2800 & - \\
\hline 68 & 35 & 45 & 0.0007 & 0.0175 & 1.3900 & - \\
\hline 69 & 37 & 43 & 0.0005 & 0.0276 & - & - \\
\hline 70 & 43 & 44 & 0.0001 & 0.0011 & - & - \\
\hline 71 & 44 & 45 & 0.0025 & 0.0730 & - & - \\
\hline 72 & 39 & 44 & - & 0.0411 & - & - \\
\hline 73 & 39 & 45 & - & 0.0839 & - & - \\
\hline 74 & 45 & 51 & 0.0004 & 0.0105 & 0.7200 & - \\
\hline 75 & 50 & 52 & 0.0012 & 0.0288 & 2.0600 & - \\
\hline 76 & 50 & 51 & 0.0009 & 0.0221 & 1.6200 & - \\
\hline 77 & 49 & 52 & 0.0076 & 0.1141 & 1.1600 & - \\
\hline 78 & 52 & 42 & 0.0040 & 0.0600 & 2.2500 & - \\
\hline 79 & 411 & 41 & 0.0020 & 0.0300 & 1.1250 & - \\
\hline 80 & 421 & 42 & 0.0020 & 0.0300 & 1.1250 & - \\
\hline 81 & 41 & 40 & 0.0060 & 0.0840 & 3.1500 & - \\
\hline 82 & 31 & 62 & - & 0.0260 & - & 1.0400 \\
\hline 83 & 32 & 63 & - & 0.0130 & - & 1.0400 \\
\hline 84 & 36 & 64 & - & 0.0075 & - & 1.0400 \\
\hline 85 & 37 & 65 & - & 0.0033 & - & 1.0400 \\
\hline 86 & 66 & 41 & - & 0.0015 & - & 1.0000 \\
\hline 87 & 42 & 67 & - & 0.0015 & - & 1.0000 \\
\hline 88 & 52 & 68 & - & 0.0030 & - & 1.0000 \\
\hline 89 & 1 & 27 & 0.0320 & 0.3200 & 0.4100 & 1.0000 \\
\hline
\end{tabular}

\begin{tabular}{|c|c|c|c|c|c|c|c|c|c|c|c|c|c|}
\hline $\begin{array}{c}\text { mac./ } \\
\text { bus }\end{array}$ & $\begin{array}{l}\text { base } \\
\text { MVA }\end{array}$ & $\begin{array}{c}x_{l} \\
(\mathbf{p u})\end{array}$ & $\begin{array}{c}x_{d} \\
(\mathrm{pu})\end{array}$ & $\begin{array}{c}x_{d}^{\prime} \\
(\mathrm{pu})\end{array}$ & $\begin{array}{c}x_{d}^{\prime \prime} \\
(\mathrm{pu})\end{array}$ & $\begin{array}{c}T_{d o}^{\prime} \\
\text { (sec) }\end{array}$ & $\begin{array}{l}T_{d o}^{\prime} \\
(\mathbf{p u})\end{array}$ & $\begin{array}{c}x_{q} \\
(\mathbf{p u})\end{array}$ & $\begin{array}{c}x_{q}^{\prime} \\
(\mathrm{pu})\end{array}$ & $\begin{array}{c}x_{q}^{\prime \prime} \\
(\mathrm{pu})\end{array}$ & $\begin{array}{l}T_{q o}^{\prime} \\
(\mathbf{p u})\end{array}$ & $\begin{array}{l}T_{q o}^{\prime \prime} \\
(\mathbf{p u})\end{array}$ & $\begin{array}{c}\mathbf{H} \\
(\mathrm{sec})\end{array}$ \\
\hline no. & 1 & 2 & 3 & 4 & 5 & 6 & 7 & 8 & 9 & 10 & 11 & 12 & 13 \\
\hline $1 / 53$ & 1800 & .013 & 1.8 & .558 & .450 & 10.20 & $\overline{0.05}$ & $\begin{array}{l}1.242 \\
\end{array}$ & .504 & .450 & 1.50 & $\bar{~} .035$ & 2.333 \\
\hline $2 / 54$ & 610 & .035 & 1.8 & .425 & .305 & 6.56 & 0.05 & 1.721 & .366 & .305 & 1.50 & .035 & 4.949 \\
\hline $3 / 55$ & 721 & .030 & 1.8 & .383 & .325 & 5.70 & 0.05 & 1.710 & .361 & .325 & 1.50 & .035 & 4.962 \\
\hline $4 / 56$ & 687 & .030 & 1.8 & .300 & .240 & 5.69 & 0.05 & 1.773 & .275 & .240 & 1.50 & .035 & 4.163 \\
\hline $5 / 57$ & 545 & .027 & 1.8 & .360 & .273 & 5.40 & 0.05 & 1.691 & .327 & .273 & 0.44 & .035 & 4.767 \\
\hline $6 / 58$ & 709 & .022 & 1.8 & .354 & .283 & 7.30 & 0.05 & 1.708 & .319 & .283 & 0.40 & .035 & 4.911 \\
\hline $7 / 59$ & 610 & .032 & 1.8 & .299 & .244 & 5.66 & 0.05 & 1.782 & .275 & .244 & 1.50 & .035 & 4.327 \\
\hline $8 / 60$ & 621 & .028 & 1.8 & .354 & .279 & 6.70 & 0.05 & 1.738 & .310 & .279 & 0.41 & .035 & 3.915 \\
\hline $9 / 61$ & 855 & .030 & 1.8 & 487 & .385 & 4.79 & 0.05 & 1.752 & .427 & .385 & 1.96 & .035 & 4.037 \\
\hline $10 / 62$ & 1065 & .020 & 1.8 & .487 & .426 & 9.37 & 0.05 & 1.225 & .479 & .426 & 1.50 & .035 & 2.911 \\
\hline $11 / 63$ & 1406 & .010 & 1.8 & .253 & .169 & 4.10 & 0.05 & 1.730 & .211 & .169 & 1.50 & .035 & 2.005 \\
\hline $12 / 64$ & 1782 & .022 & 1.8 & .552 & .446 & 7.40 & 0.05 & 1.693 & .499 & .446 & 1.50 & .035 & 5.179 \\
\hline $13 / 65$ & 12162 & .003 & 1.8 & .334 & .243 & 5.90 & 0.05 & 1.739 & .304 & .243 & 1.50 & .035 & 4.078 \\
\hline $14 / 66$ & 10000 & .002 & 1.8 & .285 & .230 & 4.10 & 0.05 & 1.730 & .250 & .230 & 1.50 & .035 & 3.000 \\
\hline $15 / 67$ & 10000 & .002 & 1.8 & .285 & .230 & 4.10 & 0.05 & 1.730 & .250 & .230 & 1.50 & .035 & 3.000 \\
\hline $16 / 68$ & 10112 & .004 & 1.8 & .359 & .278 & 7.80 & 0.05 & 1.689 & .303 & .278 & 1.50 & .035 & 4.450 \\
\hline
\end{tabular}




\begin{tabular}{||c||c|c|c|c|c|c||}
\hline \hline $\begin{array}{c}\text { turbine- } \\
\begin{array}{c}\text { guveady-state } \\
\text { gain } \\
\text { number }\end{array}\end{array}$ & $\begin{array}{c}\text { maximum } \\
\mathbf{1} / \mathbf{R} \\
(\mathbf{p u})\end{array}$ & $\begin{array}{c}\text { power } \\
(\text { on mac. base) } \\
(\mathbf{p u})\end{array}$ & $\begin{array}{c}\text { servo } \\
\text { time } \\
\text { constant } \\
(\mathbf{s e c})\end{array}$ & $\begin{array}{c}\text { governor } \\
\text { time } \\
\text { constant } \\
(\mathbf{s e c})\end{array}$ & $\begin{array}{c}\text { HP section } \\
\text { time } \\
\text { constant } \\
(\mathbf{s e c})\end{array}$ & $\begin{array}{c}\text { Reheater } \\
\text { time } \\
\text { constant } \\
(\mathbf{s e c})\end{array}$ \\
\cline { 2 - 7 }
\end{tabular}

\begin{tabular}{||c||c|c|c|c|c|c|c||}
\hline \hline \multirow{2}{*}{$\begin{array}{c}\text { exciter } \\
\text { number }\end{array}$} & $\begin{array}{c}\text { machine } \\
\text { number }\end{array}$ & $\begin{array}{c}\text { exciter } \\
\text { type }\end{array}$ & $\begin{array}{c}\text { input filter } \\
T_{R} \\
(\mathbf{s e c})\end{array}$ & $\begin{array}{c}\text { gain } \\
K_{A} \\
(\mathbf{p u})\end{array}$ & $\begin{array}{c}\text { time const. } \\
T_{A} \\
(\mathbf{s e c})\end{array}$ & $\begin{array}{c}\text { max } \\
V_{R} \\
(\mathbf{p u})\end{array}$ & $\begin{array}{c}\text { min } \\
V_{R} \\
(\mathbf{p u})\end{array}$ \\
\cline { 2 - 8 } & $\mathbf{1}$ & $\mathbf{2}$ & $\mathbf{3}$ & $\mathbf{4}$ & $\mathbf{5}$ & $\mathbf{6}$ & $\mathbf{7}$ \\
\hline \hline $1-16$ & $1-16$ & Simple & - & 200.0 & 0.05 & 5.00 & -5.00 \\
\hline \hline
\end{tabular}

\begin{tabular}{|c|c|c|c|c|c|c|c|c|c|}
\hline \multirow{2}{*}{$\begin{array}{c}\text { PSS } \\
\text { number }\end{array}$} & \multirow{2}{*}{$\begin{array}{l}\text { machine } \\
\text { number }\end{array}$} & $\begin{array}{l}\text { gain } \\
\text { (pu) }\end{array}$ & $\begin{array}{c}\text { washout } \\
(\mathrm{sec})\end{array}$ & $\begin{array}{l}\text { lead } T_{11} \\
(\mathrm{sec})\end{array}$ & $\begin{array}{c}\operatorname{lag} T_{12} \\
(\mathrm{sec})\end{array}$ & $\begin{array}{c}\text { lead } T_{21} \\
(\text { sec) }\end{array}$ & $\begin{array}{c}\operatorname{lag} T_{22} \\
(\mathrm{sec})\end{array}$ & $\begin{array}{l}\max \\
(\mathrm{pu})\end{array}$ & $\begin{array}{l}\min \\
(\mathrm{pu})\end{array}$ \\
\hline & & 1 & 2 & 3 & 4 & 5 & 6 & 7 & 8 \\
\hline 1 & 1 & 100 & 10 & 0.08 & 0.01 & 0.08 & 0.01 & 0.20 & -0.05 \\
\hline 2 & 2 & 100 & 10 & 0.08 & 0.01 & 0.08 & 0.01 & 0.20 & -0.05 \\
\hline 3 & 3 & 100 & 10 & 0.04 & 0.02 & 0.10 & 0.01 & 0.20 & -0.05 \\
\hline 4 & 4 & 50 & 10 & 0.08 & 0.02 & 0.08 & 0.02 & 0.20 & -0.05 \\
\hline 5 & 5 & 50 & 10 & 0.05 & 0.01 & 0.08 & 0.02 & 0.20 & -0.05 \\
\hline 6 & 6 & 80 & 10 & 0.05 & 0.01 & 0.08 & 0.02 & 0.20 & -0.05 \\
\hline 7 & 7 & 80 & 10 & 0.05 & 0.01 & 0.08 & 0.02 & 0.20 & -0.05 \\
\hline 8 & 8 & 30 & 10 & 0.08 & 0.01 & 0.08 & 0.02 & 0.20 & -0.05 \\
\hline 9 & 9 & 100 & 10 & 0.05 & 0.01 & 0.05 & 0.02 & 0.20 & -0.05 \\
\hline 10 & 10 & 100 & 10 & 0.08 & 0.01 & 0.08 & 0.02 & 0.20 & -0.05 \\
\hline 11 & 11 & 30 & 10 & 0.08 & 0.03 & 0.05 & 0.01 & 0.20 & -0.05 \\
\hline 12 & 12 & 100 & 10 & 0.08 & 0.01 & 0.08 & 0.01 & 0.20 & -0.05 \\
\hline 13 & 13 & 200 & 10 & 0.04 & 0.01 & 0.05 & 0.01 & 0.20 & -0.05 \\
\hline 14 & 14 & 200 & 10 & 0.04 & 0.01 & 0.05 & 0.01 & 0.20 & -0.05 \\
\hline 15 & 15 & 200 & 10 & 0.04 & 0.01 & 0.05 & 0.01 & 0.20 & -0.05 \\
\hline 16 & 16 & 200 & 10 & 0.03 & 0.02 & 0.05 & 0.01 & 0.20 & -0.05 \\
\hline
\end{tabular}

\begin{tabular}{|c|c|c|c|c|c|c|c|}
\hline $\begin{array}{l}\text { device } \\
\text { UPFC }\end{array}$ & $\begin{array}{l}\text { sending } \\
\text { bus }\end{array}$ & $\begin{array}{c}\text { receiving } \\
\text { bus }\end{array}$ & $\begin{array}{c}\text { shunt } \\
\text { reactance } \\
(\mathbf{p u})\end{array}$ & $\begin{array}{c}\text { series } \\
\text { reactance } \\
(\mathbf{p u})\end{array}$ & $\begin{array}{c}\text { shunt } \\
\text { turn ratio }\end{array}$ & $\begin{array}{c}\text { series } \\
\text { turn ratio }\end{array}$ & $\begin{array}{c}\text { DC link } \\
\text { voltage } \\
(\mathrm{kV})\end{array}$ \\
\hline number & 1 & 2 & 3 & 4 & 5 & 6 & 7 \\
\hline $1,2,3$ & $5,9,15$ & $6,10,16$ & 0.2413 & 0.0031 & 0.0295 & 0.038 & 22 \\
\hline & $\begin{array}{l}\text { DC link } \\
\text { capacitor } \\
\text { (pu) }\end{array}$ & $\begin{array}{c}\text { AC base } \\
\text { voltage } \\
(\mathrm{kV})\end{array}$ & $\begin{array}{l}\text { Shunt conv. } \\
\text { rating } \\
(\mathrm{pu})\end{array}$ & $\begin{array}{l}\text { Series conv. } \\
\text { rating } \\
(\mathrm{pu})\end{array}$ & $\begin{array}{c}\max V_{P} \\
(\mathbf{p u})\end{array}$ & \multicolumn{2}{|c|}{$\max V_{Q}$} \\
\hline & 8 & 9 & 10 & 11 & 12 & \multicolumn{2}{|c|}{13} \\
\hline & 0.055 & 220 & 1.60 & 1.60 & 0.155 & \multicolumn{2}{|c|}{0.1} \\
\hline
\end{tabular}

\begin{tabular}{||c||c|c||c|c||c|c||c|c||}
\hline \hline \multirow{2}{*}{ control } & \multicolumn{2}{c||}{ DC voltage } & \multicolumn{2}{c||}{ AC voltage } & \multicolumn{2}{c||}{ Active power } & \multicolumn{2}{c||}{ Receiving voltage } \\
& $k_{P}$ & $T_{I}$ & $k_{P}$ & $T_{I}$ & $k_{P}$ & $T_{I}$ & $k_{P}$ & $T_{I}$ \\
UPFC & $(\mathbf{p u})$ & $(\mathbf{m s})$ & $(\mathbf{p u})$ & $(\mathbf{m s})$ & $(\mathbf{p u})$ & $(\mathbf{s e c})$ & $(\mathbf{p u})$ & $(\mathbf{s e c})$ \\
\cline { 2 - 9 } number & $\mathbf{1}$ & $\mathbf{2}$ & $\mathbf{1}$ & $\mathbf{2}$ & $\mathbf{1}$ & $\mathbf{2}$ & $\mathbf{1}$ & $\mathbf{2}$ \\
\hline \hline $1,2,3$ & 100 & 10 & 40 & 20 & 0.1 & .4 & 0.01 & 1.1 \\
\hline \hline
\end{tabular}

\begin{tabular}{|c|c|c|c|c|c|c|}
\hline \multirow{3}{*}{$\begin{array}{c}\text { phase- } \\
\text { plane } \\
\text { measure- } \\
\text { ment }\end{array}$} & \multicolumn{2}{|c|}{ Power } & \multicolumn{2}{|c|}{ Energy } & \multirow{2}{*}{$\begin{array}{c}\text { Energy } \\
\text { washout } \\
(\mathrm{sec})\end{array}$} & \multirow{2}{*}{$\begin{array}{l}\text { Integral } \\
\begin{array}{|l}\text { scaling }\end{array}\end{array}$} \\
\hline & $\begin{array}{c}\text { washout } \\
\text { (sec) }\end{array}$ & scaling & $\begin{array}{c}\text { washout } \\
\text { (sec) }\end{array}$ & scaling & & \\
\hline & 1 & 2 & 3 & 4 & 5 & 6 \\
\hline $1,2,3$ & 0.8 & 1 & 0.5 & 0.1 & 0.3 & 1 \\
\hline
\end{tabular}




\begin{tabular}{||c||c|c|c|c|c|c|c||}
\hline \hline \multicolumn{1}{||c||c|c|c|}{$\begin{array}{c}\text { fault trigger level } \\
\text { TSK } \\
\text { number }\end{array}$} & $\begin{array}{c}\Delta P \\
(\mathbf{p u})\end{array}$ & $\begin{array}{c}\Delta \dot{P} \\
(\mathbf{p u} / \mathbf{m s})\end{array}$ & $\begin{array}{c}\Delta V \\
(\mathbf{p u})\end{array}$ & $\begin{array}{c}\text { maximum } \\
\text { output } \\
(\mathbf{p u})\end{array}$ & $\begin{array}{c}\text { minimum } \\
\text { output } \\
(\mathbf{p u})\end{array}$ & $\begin{array}{c}\text { transition } \\
\text { angle } \\
(\mathbf{d e g})\end{array}$ & $\begin{array}{c}\text { turn-off } \\
k_{D}\end{array}$ \\
\hline \hline $1,2,3$ & $\mathbf{1}$ & $\mathbf{2}$ & $\mathbf{3}$ & $\mathbf{4}$ & $\mathbf{5}$ & $\mathbf{6}$ & $\mathbf{7}$ \\
\hline \hline
\end{tabular}

\begin{tabular}{|c|c|c|c|c|c|c|c|c|c|}
\hline $\begin{array}{l}\text { GA tuned } \\
\text { PSS } \\
\text { number }\end{array}$ & $\begin{array}{c}\text { machine } \\
\text { number }\end{array}$ & $\begin{array}{l}\text { gain } \\
\text { (pu) } \\
1\end{array}$ & $\begin{array}{c}\text { washout } \\
\text { (sec) } \\
2\end{array}$ & $\begin{array}{c}\text { lead } T_{11} \\
\text { (sec) } \\
\mathbf{3}\end{array}$ & $\begin{array}{c}\operatorname{lag} T_{12} \\
(\mathrm{sec}) \\
4\end{array}$ & $\begin{array}{c}\text { lead } T_{21} \\
(\mathrm{sec}) \\
\mathbf{5}\end{array}$ & $\begin{array}{c}\operatorname{lag} T_{22} \\
(\mathrm{sec}) \\
6\end{array}$ & $\begin{array}{c}\max \\
(\mathrm{pu}) \\
7\end{array}$ & $\begin{array}{c}\min \\
(\mathrm{pu}) \\
8\end{array}$ \\
\hline $\begin{array}{ll} & 1\end{array}$ & $\begin{array}{ll}1 \\
\end{array}$ & $\begin{array}{l}194 \\
\end{array}$ & 20 & 0.21 & 0.10 & 0.21 & 0.10 & 0.20 & $\begin{array}{c}-0.05 \\
\end{array}$ \\
\hline 2 & 2 & 75 & 20 & 0.22 & 0.05 & 0.22 & 0.05 & 0.20 & -0.05 \\
\hline 3 & 3 & 46 & 20 & 0.45 & 0.07 & 0.45 & 0.07 & 0.20 & -0.05 \\
\hline 4 & 4 & 169 & 20 & 0.17 & 0.06 & 0.17 & 0.06 & 0.20 & -0.05 \\
\hline 5 & 5 & 130 & 20 & 0.16 & 0.08 & 0.16 & 0.08 & 0.20 & -0.05 \\
\hline 6 & 6 & 78 & 20 & 0.35 & 0.10 & 0.35 & 0.10 & 0.20 & -0.05 \\
\hline 7 & 7 & 39 & 20 & 0.39 & 0.07 & 0.39 & 0.07 & 0.20 & -0.05 \\
\hline 8 & 8 & 65 & 20 & 0.32 & 0.06 & 0.32 & 0.06 & 0.20 & -0.05 \\
\hline 9 & 9 & 54 & 20 & 0.42 & 0.14 & 0.42 & 0.14 & 0.20 & -0.05 \\
\hline 10 & 10 & 107 & 20 & 0.40 & 0.06 & 0.40 & 0.06 & 0.20 & -0.05 \\
\hline 11 & 11 & 77 & 20 & 0.16 & 0.05 & 0.16 & 0.05 & 0.20 & -0.05 \\
\hline 12 & 12 & 25 & 20 & 0.98 & 0.21 & 0.98 & 0.21 & 0.20 & -0.05 \\
\hline 13 & 13 & 108 & 20 & 0.16 & 0.10 & 0.16 & 0.10 & 0.20 & -0.05 \\
\hline 14 & 14 & 101 & 20 & 0.52 & 0.19 & 0.52 & 0.19 & 0.20 & -0.05 \\
\hline 15 & 15 & 160 & 20 & 0.18 & 0.04 & 0.18 & 0.04 & 0.20 & -0.05 \\
\hline 16 & 16 & 195 & 20 & 0.31 & 0.09 & 0.31 & 0.09 & 0.20 & -0.05 \\
\hline
\end{tabular}




\section{References}

[1] Allen, E., LaWhite, N., Yong, Y., Chapman, J., Ilic, M., "Interactive Object-Oriented Simulation of Interconnected Power Systems using Simulink," IEEE Transactions on Education, Vol. 44, No. 1, pp. 87-95, 2001.

[2] Anderson, Fouad, Power System Control and Stability, IEEE Press, 1994.

[3] Arabi, S., Kundur, P., "A Versatile FACTS Device Model for Power Flow and Stability Simulations," IEEE Transactions of Power Systems, Vol. 11, No. 4, pp. 1944-1950, November 1996.

[4] Mahseredjian, J., Alvarado, F., "Creating an Electromagnetic Transient Program in MATLAB: MatEMTP," IEEE Transactions on Power Delivery, Vol. 12, No. 1, pp. 380-388, 1997.

[5] Arabi, S., Kundur, P., Adapa, R., "Innovative Techniques in Modeling UPFC for Power System Analysis," IEEE Transactions of Power Systems, Vol. 15, No. 1, pp. 336-341, February 2000 .

[6] Arrillaga, J., High Voltage Direct Current Transmission, 2nd edition, IEE Power Engineering Series 29, 1998.

[7] Sutton, R., Barto, A. G., Reinforcement Learning, Adaptive Computation and Machine Learning Series, MIT Press, 1998.

[8] Becker, Ch., Autonome Systeme zur koordinierenden Regelung von FACTS-Geräten, dissertation, University of Dortmund, 2001.

[9] Bernard, J. A., "Use of a Rule-based System for Process Control," IEEE Control Systems Magazine, Vol. 8, No. 5, pp. 3-13, October 1988.

[10] Boukarim, G. E., Wang, S., Chow, J. H., Taranto, G. N., Martins, N., "A Comparison of Classical, Robust, and Decentralized Control Designs for Multiple Power System Stabilizers," IEEE Transactions on Power Systems, Vol. 15, No. 4, pp. 1287-1292, November 2000 .

[11] Cañizares, C. A., "Power Flow and Transient Stability Models of FACTS Controllers for Voltage and Angle Stability Studies," Proceedings IEEE Power Engineering Winter Meeting, Vol. 2, pp. 1447-1454, 2000. 
[12] Cheng, S., Malik, O. P., Hope, G. S., Self Tuning Stabilizers for a Multimachine Power System," IEE Proceedings, Part C, No. 4, pp. 176-185, 1986.

[13] Chow, J. H., Cheung, K. W., "A Toolbox for Power System Dynamics and Control Engineering Education and Research," IEEE Transactions on Power Systems, Vol. 7, No. 4, pp. 1559-1564, November 1992.

[14] Chow, J. H., Power System Toolbox Version 2.0 Dynamic Tutorial and Functions, Cherry Tree Scientific Software, Colborne, Ontario, Canada, http: \\www.eagle.ca/ cherry, 1997.

[15] Dash, P. K., Mishra, S., Panda, G., "Damping Multimodal Power System Oscillation Using a Hybrid Fuzzy Controller for Series Connected FACTS Devices," IEEE Transactions on Power Systems, Vol. 15, No. 4, pp. 1360-1366, November 2000.

[16] Dilger, R., Nelles, D., "Improvement of Network Damping and Transient Stability by Active and Reactive Power Control," IEE Proceedings Generation Transmission Distribution, Vol. 144, No. 2, pp. 125-128, March 1997.

[17] Dynasim AB, Dynamic Modeling Laboratory, Lund, Sweden, http: \\www.dymola.com, 2002.

[18] Edris, A. Mehraban, A. S., Rahman, M., Gyugyi, L., Arabi, S., Rietman, T., "Controlling the Flow of Real and Reactive Power," IEEE Computer Application in Power, pp. 20-25, January 1998.

[19] Elmqvist, H., Otter, M., Cellier, F. E., "Inline Integration: A new mixed symbolic/numeric approach for solving differential-algebraic equation systems," Proceedings of European Simulation MultiConference, Prague, Czech Republic, pp. 23-34, 1995.

[20] DCG/EPRI, EMTP, http:\\www.emtp96.com.

[21] EPRI, Proceedings: FACTS Conference I - The Future in High-Voltage Transmission, Editor: Maratukulam, D., Electric Power Research Institute, Inc., Palo Alto, California, 1992.

[22] EUROSTAG, Software for Simulation of Power System Dynamics, Tractebel Energy Engineering, Brussels, Belgium, http:\\www.eurostag.be, 2001.

[23] Fan, L., Robust decentralized control of power systems through excitation systems and thyristor controlled series capacitor, disseration, Lane Dep. of CSEE, College of Engineering and Mineral Resources, West Virginia University, Morgantown, 2001.

[24] Fuerte-Esquivel, R., Acha, E., Tan, S. G., Rico J. J., "Efficient Object Oriented Power Systems Software for the Analysis of Large-Scale Networks containing FACTS-controlled Branches," IEEE Transactions on Power Systems, Vol. 13, No. 2, pp. 464-470, February 1998.

[25] Gibbard, M. J., Vowels, D. J., Pourbeik, P., "Interactions between, and Effectiveness of, Power System Stabilizers and FACTS Device Stabilizers in Multimachine Systems," IEEE Transactions on Power Systems, Vol. 15, No. 2, pp. 748-755, November 2000. 
[26] Gronquist, J. F., Sethares, W. A., Alvarado, F. L., Lasseter, R.J., D. J., Pourbeik, P., "Power Oscillation Damping Control Strategies for FACTS Devices using Locally Available Quantities," IEEE Transactions on Power Systems, Vol. 10, No. 3, pp. 1598-1605, August 1995.

[27] Gyugyi, L., "A Unified Power Flow Control Concept for Flexible AC Transmission Systems," IEE Proceedings-C, Vol. 139, No. 4, pp. 323-331, July 1992.

[28] Gyugyi, L., Schauder, C.D., Williams, S.L., Rietman, T.R., Torgerson, D.R., Edris, A., "The Unified Power Flow Controller: A New Approach to Power Transmission Control," IEEE Transactions on Power Delivery, Vol. 10, No. 2, pp. 1085-1093, April 1995.

[29] Hasanović, Amer, A Simulation and Analysis Toolbox for Power Systems and Genetic Algorithm Based Damping Controller Design, M.S. thesis, Lane Dep. of CSEE, College of Engineering and Mineral Resources, West Virginia University, Morgantown, 2001.

[30] Hasanović, Azra, Unified Power Flow Controller, M.S. thesis, Lane Dep. of CSEE, College of Engineering and Mineral Resources, West Virginia University, Morgantown, 2000.

[31] Handschin, E., Becker, C., Rehtanz, C., Park, J.-K., Moon, S.-I, Brosda, J., "Automatic Fuzzy Rule Generation for Coordination of FACTS-Devices," Journal of Electrical Engineering and Information Science, Vol. 4, No. 6, pp. 747-753, 1999.

[32] Hingorani, N. G., Gyugyi, L., Understanding FACTS Concepts and Technology of Flexible AC Transmission Systems, IEEE Press, 2000.

[33] Hingorani, N. G., "Flexible AC Transmission," IEEE Spectrum, pp. 40-44, April 1993.

[34] Hiskens, I. A., Sokolowski, P., "Systematic Modeling and Symbolically assisted Simulation of Power Systems," IEEE Transactions on Power Systems, Vol. 16, No. 2, pp. 229-234, 2001.

[35] Hiyama, T., "Application of Rule-based Stabilizing Controller to Electrical Power System," IEE Proceedings, Part C, Vol. 136, No. 3, pp. 175-181, May 1989.

[36] Hiyama, T., "Real Time Control of Mirco-machine System using Mirco-computer based Fuzzy Logic Power System Stabilizer," IEEE Transactions on Power Systems, Vol. 9, No. 4, pp. 724-730, February 1994.

[37] Hiyama, T., Oniki, S., Nagashima, H., "Evaluation of Advanced Fuzzy Logic PSS on Analog Network Simulator and Actual Installation on Hydro Generators," IEEE Transactions on Energy Conversion, Vol. 11, No. 1, pp. 125-131, March 1996.

[38] Hiyama, T., Fujimoto, Y., Hayashi, J., "MATLAB/Simulink Based Transient Stability Simulation of Electric Power Systems," IEEE PES Winter Meeting, pp. 249-253, January 1998.

[39] Hiyama, T., Hubbi, W., Ortmeyer, Th., "Fuzzy Logic Control Scheme with Variable Gain for Static Var Compensator to Enhance Power System Stability," IEEE Transactions on Power Systems, Vol. 14, No. 1, pp. 186-191 February 1999. 
[40] Hiyama, T., Ueno, A., "Development of Real Time Power System Simulator in MATLAB/Simulink Environment," IEEE Proceedings of the PES Summer Meeting, Seattle, WA, 16-20 July, 2000.

[41] Hoang, P., Tomsovic, K., "Design and Analysis of an Adaptive Fuzzy Power System Stabilizers," IEEE Transactions on Energy Conversion, Vol. 11, No. 2, pp. 455-461, June 1996.

[42] Huang, Z., Ni, Y., Shen, C. M., Wu, F. F., Chen, S., Zhang, B., "Application of Unified Power Flow Controller in Interconnected Power Systems - Modeling, Interface, Control Strategy and Case Study," Proceedings of the IEEE Power Engineering Society Summer Meeting, 1999.

[43] Hydro-Quebec, TEQSIM International, Power System Blockset for Use with Simulink, The Mathworks Inc., 2001.

[44] Jantzen, J., Design of Fuzzy Controllers, Techn. Report No. 98-E 864 (design), Technical University of Denmark, Department of Automation, August 1998.

[45] Kothari, M. L., Nanda, J., Bhattacharya, K., "Design of variable structure Power System Stabilizers with Desired Eigenvalues in the Sliding Mode," IEE Proceedings, Part C, Vol. 140, No. 4, July 1993.

[46] Kundur, P., Power System Control and Stability, McGraw-Hill Inc., 1994.

[47] Lee, R. L., Beshir, M. J., Finley, A. T., Hayes, D. R., Hsu, J. C., Peterson, H. R., DeShazo, G. L., Gerlach, D. W., "Application of Static VAR Compensators for the Dynamic Performance of the Mead-Adelanto and Mead-Phoenix Transmission Projects," IEEE Transactions on Power Systems, Vol. 10, No. 1, pp. 459-466, January 1995.

[48] Li, B. H., Wu, Q. H., Wang, P. Y., Zhou, X. X., "Learning-coordinated fuzzy logic control of dynamic quadrature boosters in multi-machine power systems," IEE Proceedings Generation Transmission Distribution, Vol. 146, No. 6, pp. 577-585, November 1999.

[49] Limyingcharoen, S., Annakkage, U. D., Pahalawaththa, N. C., "Fuzzy Logic based Unified Power Flow Controllers for Transient Stability Improvement," IEE Proceedings Generation Transmission Distribution, Vol. 145, No. 3, pp. 225-232, May 1998.

[50] Lo, K. L., Ma, T. T., "UPFC Damping Control Strategy based on Transient Energy Function," Electric Power Systems Research, No. 56, pp. 195-203, 2000.

[51] Ma, T. T., Lo, K. L., "Nonlinear Power System Damping Control Strategies for the Unified Power Flow Controller (UPFC)," Proceedings of the International Conference on Power System Technology (PowerCon), Vol. 2, pp. 673-678, Perth, Australia, 4-7. December 2000.

[52] Machowski, J., Bialek, J. W., Bumby, J. R., Power System Dynamics and Stability, John Wiley \& Sons, Chicester, 1997.

[53] The Mathworks, Simulink Dynamic System Simulation for MATLAB - Writing S-functions, Version 4, The Mathworks, Inc., 2000. 
[54] The Mathworks, Simulink Dynamic System Simulation for MATLAB, Version 4, The Mathworks, Inc., 2000.

[55] The Mathworks, MATLAB - The Language of Technical Computing, Version 6, The Mathworks, Inc., 2000.

[56] Manzoni, A., e Silva, A. S., Decker, I. C., "Power Systems Dynamics Simulation using Object-Oriented Programming," IEEE Transactions on Power Systems, Vol. 14, No. 1, pp. 249-255, 1998.

[57] Mihalic, R., Zunko, P., Povh, D., "Improvement of Transient Stability using Unified Power Flow Controller," IEEE Transactions on Power Delivery, Vol. 11, No. 1, pp. 485-491, January 1996.

[58] Mishra, S., Dash, P. K., Panda, G., "TS-fuzzy Controller for UPFC in a multimachine power system," IEE Proceedings on Generation, Transmission, Distribution, Vol. 147, No. 1, pp. 15-22, January 2000.

[59] Modelica, Modelica - A Unified Object-Oriented Language for Physical Systems Modeling, http: \\www.modelica.org, version 1.4, Modelica Association, December 2000.

[60] Mohan, N., Undeland, T. M., Robbins, W. P., Power Electronics Converters, Applications, and Design, 2nd edition, John Wiley \& Sons, Inc., 1995.

[61] Momoh, J. A., Ma, X. W., Tomsovic, K., "Overview and Literature Survey of Fuzzy Set Theory in Power Systems," IEEE Transactions on Power Systems, Vol. 10, No. 3, pp. 1676-1690, August 1995. \& Sons, Inc., 1995.

[62] Nabavi-Niaki, A., Iravani, M. R., "Steady-state and Dynamic Models of Unified Power Flow Controller (UPFC) for Power System Studies," IEEE Transactions of Power Systems, Vol. 11, No. 4, pp. 1937-1943, November 1996.

[63] Navarro, I. R., Larsson, M., Olsson G., "Object-Oriented Modeling and Simulation of Power Systems using Modelica," Proceedings of the IEEE Winter Meeting, Singapore, January, 2000 .

[64] Ni, Y., Mak, L. O., Huang, Z., Chen, S., Zhang, B., "Fuzzy Logic Damping Controller for FACTS Devices in Interconnected Power Systems," IEEE Proceedings of the International Symposium on Circuits and Systems, Vol. 5, pp. 591-594, 1999.

[65] Noroozian, M., Andersson, G., Tomsovic, K., "Robust, Near Time-Optimal Control of Power System Oscillations with Fuzzy Logic," IEEE Transactions on Power Delivery, Vol. 11, No. 1, pp. 393-400, January 1996.

[66] Noroozian, M., Angquist, L., Ghandhari, M., Andersson, G., "Use of UPFC for Optimal Power Flow Control," IEEE Transactions on Power Delivery, Vol. 12, No. 4, pp. 1629-1634, October 1997. 
[67] Noroozian, M., Angquist, L., Ghandhari, M., Andersson, G., "Improving Power System Dynamics by Series-Connected FACTS Devices," IEEE Transactions on Power Delivery, Vol. 12, No. 4, pp. 1635-1641, October 1997.

[68] ObjectStab, A Modelica Library for Power System Stability Studies, Lund University, Sweden, http: \\www.iea.lth.se/ ielmats/ObjectStab, 2002.

[69] Park, Y.-M., Lee, K.Y., "A Self-Organizing Power System Stabilizer using Fuzzy AutoRegressive Moving Average (FARMA) Model," IEEE Transactions on Energy Conversion, Vol. 11, No. 2, pp. 442-448, June 1996.

[70] PSAPAC, The Power System Analysis Package, Powertech Labs Inc., Surrey, B.C., Canada, http: \\powertech.bc.ca, 2002.

[71] PSS/E, Power System Simulator for Engineering, Power Technologies Inc., Schenectady, http: \\www.pti-us.com, New York, 2001.

[72] Ramirez, J. M., Davalos, R. J., Valenzuela V., A, "Coordination of FACTS-Based Stabilizers for Damping Oscillations," IEEE Power Engineering Review, Vol. 20, No. 12, pp. 46-49, December 2000.

[73] Rogers, G., Power System Oscillations, Kluwer Academic Publishers, 2000.

[74] Sadeghzadeh, S. M., Ehsan, M., Said, N. H., Feuillet, R., "Improvement of Transient Stability Limit in Power System Transmission Lines using Fuzzy Control of FACTS Devices," IEEE Transactions on Power Systems, Vol. 13, No. 3, pp. 917-922, August 1998.

[75] Schauder, C., Metha, H., "Vector Analysis and Control of Advanced Static VAR Compensators," IEE Proceedings-C, Vol. 140, No. 4, pp. 299-306, July 1993.

[76] Schauder, C. D.,Gyugyi, L., Lund, M. R., Hamai, D. M., Rietman, T.R., Torgerson, D.R., Edris, A., "Operation of Unified Power Flow Controller (UPFC) under Practical Constraints," IEEE Transactions on Power Delivery, Vol. 13, No. 2, pp. 630-639, April 1998.

[77] Schauder, C. D., Stacey, E. J., Lund, M. R., Gyugyi, L, Kovalsky, L., Keri, A., Mehraban, A., Edris, A., "AEP UPFC Project: Installation, Commissioning and Operation of the \pm 160 MVA STATCOM (Phase I)," IEEE Transactions on Power Delivery, Vol. 13, No. 4, pp. 1530-1535, October 1998.

[78] Schoder, K., Hasanovic, A., Feliachi, A., "Load-Flow and Dynamic Model of the Unified Power Flow Controller (UPFC) within the Power System Toolbox (PST)," Proceedings of Midwest Symposium on Circuits and Systems, Lansing, Michigan, Vol. 2, pp. 634-737, August 2000.

[79] Schoder, K., Hasanovic, A., Feliachi, A., "Enhancing Transient Stability using a Fuzzy Control Scheme for the Unified Power Flow Controller (UPFC)," Proceedings of Midwest Symposium on Circuits and Systems, Lansing, Michigan, Vol. 3, pp. 1382-1385, August 2000 . 
[80] Schoder, K., Hasanovic, A., Feliachi, A., "Fuzzy Damping Controller for the Unified Power Flow Controller (UPFC)," Proceedings of the North American Power Symposium (NAPS), Waterloo, Canada, Vol. 2, pp. 5-21 - 5-27, October 2000.

[81] Schoder, K., Hasanovic, A., Feliachi, A., "Power System Damping Using Fuzzy Controlled Unified Power Flow Controller," Proceedings of the IEEE Power Engineering Society Winter Meeting, Columbus, Ohio, January 29 - February 1, Vol. 2, pp. 617-622, 2001.

[82] Sen, K. K., Stacey, E. J., "UPFC - Unified Power Flow Controller: Theory, Modeling, and Applications," IEEE Transactions on Power Delivery, Vol. 13, No. 4, pp. 1453-1460, October 1998.

[83] Senjyu, T., Yamane, S., Uezato, K., "Enhancement of Power System Stability with FACTS Using Adaptive Fuzzy Controller," IEEE International Conference Proceedings on Systems, Man, and Cybernetics, Vol. 6, pp. 533-538, 1999.

[84] Shiau, J-K., Taranto, G. N., Chow, J. H, Boukarim, G., "Power Swing Damping Controller Design Using an Iterative Linear Matrix Inequality Algorithm," IEEE Transactions on Control System Technology, Vol. 7, No. 3, pp. 371-381, May 1999.

[85] Taranto, G. N., Robust Control Design for Power System Damping Controllers with Application to FACTS Devices, dissertation, Rensselear Polytechnic Institute, 1994.

[86] Taranto, G. N., Shiau, J.-K., Chow, J. H., Othman, H. A., "Robust Decentralised Design for Multiple FACTS Damping Controllers," IEE Proceedings Generation Transmission Distribution, Vol. 144, No. 1, pp. 61-67, January 1997.

[87] Taylor, C. (convenor), Advanced Angle Stability Controls, CIGRE Technical Brochure, TF 38.02.17, December 1999.

[88] Tomsovic, K. and Chow, M. Y. (editors), Tutorial on Fuzzy Logic Applications in Power Systems, IEEE PES, January 2000.

[89] Uzunovic, E., Cañizares, C. A., Reeve, J., "Fundamental Frequency Model of Unified Power Flow Controller," North American Power Symposium (NAPS), Cleveland, Ohio, October 1998.

[90] Uzunovic, E., Cañizares, C. A., Reeve, J., "EMTP Studies of UPFC power oscillation damping," Proceedings North American Power Symposium (NAPS), Obispo, CA, pp. 405410, October 1999.

[91] Wang, H. F., Swift, F. J., "A Unified Model for the Analysis of FATCS Devices in Damping Power System Oscillations Part I: Single-machine Infinite Bus Power Systems," IEEE Transactions on Power Delivery, Vol. 12, No. 2, pp. 941-946, April 1997.

[92] Wang, H. F., Swift, F. J., Li, M., "A Unified Model for the Analysis of FATCS Devices in Damping Power System Oscillations Part II: Multi-machine Power Systems," IEEE Transactions on Power Delivery, Vol. 13, No. 4, pp. 1355-1362, October 1998. 
[93] Wang, H. F., "Damping Function of Unified Power Flow Controller," IEE Proceedings Generation Transmission Distribution, Vol. 146, No. 1, pp. 81-87, January 1999.

[94] Wang, H. F., "Selection of Robust Installing Locations and Feedback Signals of FACTS based Stabilizers in Multi-machine Power Systems," IEEE Transactions on Power Systems, Vol. 14, No. 2, pp. 569-574, May 1999.

[95] Wang, H. F., Li, F., "Multivariable sampled regulators for the co-ordinated control of STATCOM AC and DC voltage," IEE Proceedings on Generation, Transmission, Distribution, Vol. 147, No. 2, pp. 93-98, March 2000.

[96] Wang, Li-Xin, A Course in Fuzzy Systems and Control, Prentice-Hall, Inc., 1997.

[97] Wu Q. H, Pugh, A. C., "Reinforcement Learning Control of Unknown Dynamic Systems," IEE Proc.-D, Vol. 140, No. 5, pp. 313-322, September 1993.

[98] Yang, X., Feliachi, A., "Stabilization of inter-area oscillation modes through excitation systems," IEEE Transactions on Power Systems, Vol. 9, No. 1, pp. 494-502, February 1994.

[99] Yang, X., Feliachi, A., Adapa, R., "Damping Enhancement in the Western Power System," IEEE Transactions on Power System, Vol. 10, No. 3, pp. 1271-1278, August 1995.

[100] Zadeh, L. A., "Outline of a New Approach to the Analysis of Complex Systems and Decision Processes," IEEE Transactions on Systems, Man, and Cybernetics, Vol. SMC-3, No. 1, pp. 28-44, 1973. 